Cochrane Database of Systematic Reviews

\title{
School-based physical activity programs for promoting physical activity and fitness in children and adolescents aged 6 to 18
} (Review)

Dobbins M, Husson H, DeCorby K, LaRocca RL

Dobbins M, Husson H, DeCorby K, LaRocca RL.

School-based physical activity programs for promoting physical activity and fitness in children and adolescents aged 6 to 18 .

Cochrane Database of Systematic Reviews 2013, Issue 2. Art. No.: CD007651.

DOI: 10.1002/14651858.CD007651.pub2.

www.cochranelibrary.com

School-based physical activity programs for promoting physical activity and fitness in children and adolescents 
TABLE OF CONTENTS

HEADER 1

ABSTRACT

PLAIN LANGUAGE SUMMARY

SUMMARY OF FINDINGS

BACKGROUND

OBJECTIVES

METHODS

Figure 1.

RESULTS

Figure 2.

Figure 3.

DISCUSSION

AUTHORS' CONCLUSIONS

ACKNOWLEDGEMENTS

REFERENCES

CHARACTERISTICS OF STUDIES

ADDITIONAL TABLES

APPENDICES

WHAT'S NEW

HISTORY

CONTRIBUTIONS OF AUTHORS

DECLARATIONS OF INTEREST

SOURCES OF SUPPORT

DIFFERENCES BETWEEN PROTOCOL AND REVIEW

INDEX TERMS

1

2

3

4

7 
[Intervention Review]

\section{School-based physical activity programs for promoting physical activity and fitness in children and adolescents aged 6 to 18}

Maureen Dobbins ${ }^{1}$, Heather Husson ${ }^{1}$, Kara DeCorby ${ }^{1}$, Rebecca L LaRocca1

1School of Nursing, McMaster University, Hamilton, Canada

Contact address: Maureen Dobbins, School of Nursing, McMaster University, 1200 Main Street West, Rm 3N25G, Hamilton, Ontario, L8N 3Z5, Canada.dobbinsm@mcmaster.ca.

Editorial group: Cochrane Metabolic and Endocrine Disorders Group.

Publication status and date: New search for studies and content updated (no change to conclusions), published in Issue 2, 2013.

Citation: Dobbins M, Husson H, DeCorby K, LaRocca RL. School-based physical activity programs for promoting physical activity and fitness in children and adolescents aged 6 to 18. Cochrane Database of Systematic Reviews 2013, Issue 2. Art. No.: CD007651. DOI: 10.1002/14651858.CD007651.pub2.

Copyright (c) 2013 The Cochrane Collaboration. Published by John Wiley \& Sons, Ltd.

\section{A B S T R A C T}

\section{Background}

The World Health Organization (WHO) estimates that 1.9 million deaths worldwide are attributable to physical inactivity and at least 2.6 million deaths are a result of being overweight or obese. In addition, WHO estimates that physical inactivity causes $10 \%$ to $16 \%$ of cases each of breast cancer, colon, and rectal cancers as well as type 2 diabetes, and $22 \%$ of coronary heart disease and the burden of these and other chronic diseases has rapidly increased in recent decades.

\section{Objectives}

The purpose of this systematic review was to summarize the evidence of the effectiveness of school-based interventions in promoting physical activity and fitness in children and adolescents.

\section{Search methods}

The search strategy included searching several databases to October 2011. In addition, reference lists of included articles and background papers were reviewed for potentially relevant studies, as well as references from relevant Cochrane reviews. Primary authors of included studies were contacted as needed for additional information.

\section{Selection criteria}

To be included, the intervention had to be relevant to public health practice (focused on health promotion activities), not conducted by physicians, implemented, facilitated, or promoted by staff in local public health units, implemented in a school setting and aimed at increasing physical activity, included all school-attending children, and be implemented for a minimum of 12 weeks. In addition, the review was limited to randomized controlled trials and those that reported on outcomes for children and adolescents (aged 6 to 18 years). Primary outcomes included: rates of moderate to vigorous physical activity during the school day, time engaged in moderate to vigorous physical activity during the school day, and time spent watching television. Secondary outcomes related to physical health status measures including: systolic and diastolic blood pressure, blood cholesterol, body mass index (BMI), maximal oxygen uptake $\left(\mathrm{VO}_{2} \mathrm{max}\right)$, and pulse rate.

\section{Data collection and analysis}

Standardized tools were used by two independent reviewers to assess each study for relevance and for data extraction. In addition, each study was assessed for risk of bias as specified in the Cochrane Handbook for Systematic Reviews of Interventions. Where discrepancies existed, discussion occurred until consensus was reached. The results were summarized narratively due to wide variations in the populations, interventions evaluated, and outcomes measured. 


\section{Main results}

In the original review, 13,841 records were identified and screened, 302 studies were assessed for eligibility, and 26 studies were included in the review. There was some evidence that school-based physical activity interventions had a positive impact on four of the nine outcome measures. Specifically positive effects were observed for duration of physical activity, television viewing, $\mathrm{VO}_{2}$ max, and blood cholesterol. Generally, school-based interventions had little effect on physical activity rates, systolic and diastolic blood pressure, BMI, and pulse rate. At a minimum, a combination of printed educational materials and changes to the school curriculum that promote physical activity resulted in positive effects.

In this update, given the addition of three new inclusion criteria (randomized design, all school-attending children invited to participate, minimum 12-week intervention) 12 of the original 26 studies were excluded. In addition, studies published between July 2007 and October 2011 evaluating the effectiveness of school-based physical interventions were identified and if relevant included. In total an additional 2378 titles were screened of which 285 unique studies were deemed potentially relevant. Of those 30 met all relevance criteria and have been included in this update. This update includes 44 studies and represents complete data for 36,593 study participants. Duration of interventions ranged from 12 weeks to six years.

Generally, the majority of studies included in this update, despite being randomized controlled trials, are, at a minimum, at moderate risk of bias. The results therefore must be interpreted with caution. Few changes in outcomes were observed in this update with the exception of blood cholesterol and physical activity rates. For example blood cholesterol was no longer positively impacted upon by school-based physical activity interventions. However, there was some evidence to suggest that school-based physical activity interventions led to an improvement in the proportion of children who engaged in moderate to vigorous physical activity during school hours (odds ratio (OR) $2.74,95 \%$ confidence interval (Cl), 2.01 to 3.75 ). Improvements in physical activity rates were not observed in the original review. Children and adolescents exposed to the intervention also spent more time engaged in moderate to vigorous physical activity (with results across studies ranging from five to $45 \mathrm{~min}$ more), spent less time watching television (results range from five to 60 min less per day), and had improved $\mathrm{VO}_{2} \max$ (results across studies ranged from 1.6 to $3.7 \mathrm{~mL} / \mathrm{kg}$ per $\mathrm{min}$ ). However, the overall conclusions of this update do not differ significantly from those reported in the original review.

\section{Authors' conclusions}

The evidence suggests the ongoing implementation of school-based physical activity interventions at this time, given the positive effects on behavior and one physical health status measure. However, given these studies are at a minimum of moderate risk of bias, and the magnitude of effect is generally small, these results should be interpreted cautiously. Additional research on the long-term impact of these interventions is needed.

\section{PLAIN LANGUAGE SUMMARY}

\section{School-based physical activity programs for promoting physical activity and fitness in children and adolescents aged 6 to 18}

It is estimated that as many at 1.9 million deaths worldwide are attributable to physical inactivity, and that inactivity is a key risk factor in the development of most chronic diseases and cancers. This is alarming particularly because it is known that physical activity patterns track from childhood into adulthood.

There is some evidence to suggest that school-based physical activity interventions are effective in increasing the number of children engaged in moderate to vigorous physical activity, as well as how long they spend engaged in these activities. There is also evidence to suggest that these interventions reduce the amount of time spent watching television.

This review included 44 studies that evaluated the impact of school-based interventions focused on increasing physical activity among 36,593 children and adolescents. Participants were between the ages of six and 18 living in Australia, South America, Europe, China, and North America. Duration of interventions ranged from 12 weeks to six years. No two school-based physical activity promotion programs had the same combination of interventions. Furthermore, the duration, frequency, and intensity of interventions varied greatly across studies. Data collection methods for outcomes were reported to be valid and reliable in a little over half of the included studies.

There is some evidence that school-based physical activity interventions are effective in increasing duration of physical activity from five to $45 \mathrm{~min}$ more per day, reducing time spent watching television from five to $60 \mathrm{~min}$ less per day, and increasing maximal oxygen uptake or aerobic capacity, reflecting physical fitness level of an individual. The evidence also suggests that children exposed to school-based physical activity interventions are approximately three times more likely to engage in moderate to vigorous physical activity during the school day than those not exposed. At a minimum, a combination of printed educational materials and changes to the school curriculum that promote physical activity during school hours result in positive effects for these outcomes. School-based interventions are not effective in increasing physical activity rates among adolescents, or in reducing systolic and diastolic blood pressure, blood cholesterol, body mass index, and pulse rate. 


\section{SUMMARY OF FINDINGS}

\section{Summary of findings for the main comparison. School-based physical activity programs for promoting physical} activity and fitness in children and adolescents aged 6 to 18 years

\section{School-based physical activity programs for promoting physical activity and fitness in children and adolescents aged 6 to 18}

\section{Patient or population: children and adolescents aged 6 to 18 years}

Settings: primarily within the school setting

Intervention: educational, health promotion, counseling, and management strategies focused on the promotion of physical activity and fitness

Comparison: standard, currently existing physical education programs in schools

\begin{tabular}{|c|c|c|c|}
\hline Outcomes & Range of effects & $\begin{array}{l}\text { No of participants } \\
\text { (studies) }\end{array}$ & $\begin{array}{l}\text { Quality of the evi- } \\
\text { dence } \\
\text { (GRADE) }\end{array}$ \\
\hline $\begin{array}{l}\text { Television viewing } \\
\text { (minutes spent watching TV) } \\
\text { [follow-up: end of intervention to } 4 \text { years] }\end{array}$ & $\begin{array}{l}\text { Intervention: } 85 \text { to } 285 \\
\text { Control: } 89 \text { to } 288\end{array}$ & $\begin{array}{l}9372 \\
(16)\end{array}$ & $\begin{array}{l}\oplus \oplus \ominus \ominus \\
\text { lowa }\end{array}$ \\
\hline $\begin{array}{l}\text { Physical activity rates } \\
\text { (\% of participants physically active) } \\
\text { [follow-up: end of intervention to } 1 \text { year] }\end{array}$ & $\begin{array}{l}\text { Intervention: } 53 \text { to } 92 \\
\text { Control: } 44 \text { to } 91\end{array}$ & $\begin{array}{l}4123 \\
(5)\end{array}$ & $\begin{array}{l}\oplus \oplus \odot \odot \\
\text { lowa }\end{array}$ \\
\hline $\begin{array}{l}\text { Physical activity duration } \\
\text { (minutes engaged in physical activity) } \\
\text { [follow-up: end of intervention to } 4 \text { years] }\end{array}$ & $\begin{array}{l}\text { Intervention: } 3 \text { to } 158 \\
\text { Control: } 3 \text { to } 143\end{array}$ & $\begin{array}{l}15743 \\
(23)\end{array}$ & $\begin{array}{l}\oplus \oplus \odot \ominus \\
\text { lowa }\end{array}$ \\
\hline $\begin{array}{l}\text { Mean systolic / diastolic blood pressure } \\
\text { ( } \mathrm{mm} \mathrm{Hg} \text { ) } \\
\text { [follow-up: end of intervention to } 4 \text { years] }\end{array}$ & $\begin{array}{l}\text { Intervention: } 96 \text { to } 138 \text { / } 50 \text { to } \\
73 \\
\text { Control: } 97 \text { to } 139 \text { / } 50 \text { to } 76\end{array}$ & $\begin{array}{l}13,739 \\
(16)\end{array}$ & $\begin{array}{l}\oplus \oplus \ominus \ominus \\
\text { low } \boldsymbol{a}\end{array}$ \\
\hline $\begin{array}{l}\text { Body mass index (BMI) } \\
\left(\mathrm{kg} / \mathrm{m}^{2}\right) \\
\text { [follow-up: end of intervention to } 4 \text { years] }\end{array}$ & $\begin{array}{l}\text { Intervention: } 11.3 \text { to } 26.0 \\
\text { Control: } 12.0 \text { to } 26.1\end{array}$ & $\begin{array}{l}27,567 \\
(32)\end{array}$ & $\begin{array}{l}\oplus \oplus \odot \odot \\
\text { lowa }\end{array}$ \\
\hline
\end{tabular}

GRADE Working Group grades of evidence

High quality: Further research is very unlikely to change our confidence in the estimate of effect.

Moderate quality: Further research is likely to have an important impact on our confidence in the estimate of effect and may change the estimate.

Low quality: Further research is very likely to have an important impact on our confidence in the estimate of effect and is likely to change the estimate.

Very low quality: We are very uncertain about the estimate.

a Substantial heterogeneity between trials regarding type of intervention and measured outcomes; wide and overlapping range of effects. 


\section{B A C K G R O U N D}

\section{Description of the condition}

International public health and health promotion organizations have identified the health risks across the lifespan associated with physical inactivity. The World Health Organization (WHO) estimates that 1.9 million deaths throughout the world are attributable to physical inactivity and at least 2.6 million deaths are a result of being overweight or obese (WHO 2004a). Globally, physical inactivity is estimated to cause $10 \%$ to $16 \%$ of cases each of breast cancer, colon, and rectal cancers as well as type 2 diabetes, and $22 \%$ of coronary heart disease and the burden of these and other chronic diseases has rapidly increased in recent decades (WHO 2004a). In addition, the literature indicates that an elevated body mass index (BMI) places children and adolescents at greater risk for cardiovascular disease (CVD) as adults (Haque 2008; USDHHS 2008), and that diet and physical activity are important factors in maintaining a healthy BMI range (Elgar 2005). Recognizing the unique opportunity that exists to formulate and implement an effective strategy to reduce deaths and disease burden worldwide substantially by improving diet and promoting physical activity, WHO adopted, in May 2004, the "Global Strategy on Diet, Physical Activity and Health". Since its adoption, WHO has been working with stakeholders providing technical assistance and support to facilitate implementation of this global strategy.

The promotion of physical activity is an essential public health and health promotion strategy to improve the health of individuals and populations (WHO 2004a). In fact several systematic reviews have been published highlighting the benefits of physical activity among healthy children (Armstrong 1994; Brown 2009; CDC 1997; CDC 1999; McMurray 2002; Thakor 2004; Tolfrey 2000; Whitt-Glover 2009 ; Zahner 2006). To ensure sustained progress toward major improvements in chronic disease prevention, the WHO called on public health organizations within and between countries to work collaboratively with key partners, including educators and health professional bodies, educational institutions, consumer groups, the research community, and the private sector, in providing a comprehensive strategy to promote physical activity among children and adolescents (WHO 2004a). The WHO specifically identified schools as a target setting for the promotion of physical activity among children and youth. To this end, activities include the provision of collaboration on the development of healthrelated curricula; educational policy and guideline development; professional development opportunities for educators and other partners; and, research, evaluation, and knowledge exchange to facilitate the development of evidence-informed policies, programs, and practices.

This systematic review was first published in 2009. Since that time, several new trials have been published and have been included in this update. While addition of these new studies contributed further to the evidence-base, they did not substantively alter the findings of the original review or change recommendations made for promoting physical activity and fitness in children and adolescents within the school system. The purpose of this update is to synthesize new data on the effectiveness of school-based physical activity interventions with data included in the original review. This update includes evaluations of published studies indexed up to and including 21 October 2011. While evidence exists documenting the benefits of physical activity for healthy children, at the time the original review was conducted, no other reviews had systematically examined the effectiveness of various combinations of school-based interventions in promoting physical activity and fitness in children. In addition, since one of the goals of the public health system is to reduce obesity-related mortality and morbidity (OMoH 1997; WHO 2008), it is important to identity and then implement effective strategies to address obesity and overweight among children.

\section{Magnitude of the problem}

Physical inactivity is one of the leading causes of the major chronic diseases, and largely contributes to the burden of disease, death, and disability in developing and developed countries (WHO 2004a). Elimination of modifiable risk factors including an unhealthy diet, tobacco use, and physical inactivity would prevent $80 \%$ of premature heart disease, $80 \%$ of premature stroke, $80 \%$ of type 2 diabetes, and $40 \%$ of cancer (WHO 2008). Physical inactivity has been identified as a serious problem and major public health concern for people of all ages (Health Canada 2007; USDHHS 2008). In fact, physical activity was labeled as "today's best buy in public health" almost two decades ago (Morris 1994) with a suggestion that significant savings in health care could result from a mere $10 \%$ increase in physical activity population wide (CFLRI 1997; Katzmarzyk 2000; Katzmarzyk 2004). Despite these assertions, physical inactivity rates have risen rather than decreased in the past two decades. In addition to significant savings, being physically active is stated to be one of the most important steps people can take to improve their health (USDHHS 2008). Yet, according to the latest international Health Behaviour in Schoolaged Children (HBSC) study, less than two-thirds of all young people report participating in sufficient physical activity to meet current guidelines (CDC 2008; WHO 2004b). Previous reports have concluded that the intensity, frequency, and duration of physical activity contribute to overall physical health status and suggest that a 'threshold' must be maintained in order to produce positive health effects (CDC 1997; CDC 1999; McMurray 2002; Pate 1994; Shephard 1997; Thakor 2004; Tolfrey 2000; Zahner 2006). In fact, a positive linear association between duration of physical activity and positive health effects has been established, with longer duration associated with increased physical health (Pate 1994; Shephard 1997). Maximal oxygen uptake $\left(\mathrm{VO}_{2} \mathrm{max}\right)$ is a standard measure associated with fitness levels, with increasing values expected as fitness level improves, and is an important indicator of successful physical activity interventions. Current guidelines suggest that children and adolescents should engage in $60 \mathrm{~min}$ or more of active play per day (Janssen 2010; USDHHS 2008; WHO 2004b) and that the majority of this time should be spent engaged in aerobic activity. The guidelines also recommend that adolescents should engage in three or more sessions per week of activities that last $20 \mathrm{~min}$ or more at a time, that require moderate to vigorous levels of exertion.

Examples of moderate to vigorous activities include brisk walking, jogging, stair climbing, basketball, racquet sports, soccer, dance, swimming laps, skating, strength training, lawn mowing, strenuous housework, cross-country skiing, and cycling. Research suggests that the best primary strategy for improving the long-term health of children and adolescents through exercise may be creating a lifestyle pattern of regular physical activity that will carry over to the adult years (Freedson 1992; Telama 2005; Twisk 2000). Longitudinal data have shown that for each weekday that normal weight adolescents participated in physical education (PE), the odds of 
becoming overweight in adulthood decreased by 5\% (Menschik 2008). It is therefore of primary importance to identify approaches that will be effective in increasing and sustaining activity levels of children and adolescents during school hours.

International surveys of physical activity (Cale 1992; CFLRI 1997; CFLRI 2007; Kannas 1992; Marella 1992; WHO 2004b) highlight the epidemic of physical inactivity among children. Despite many methodological differences, these surveys have consistently reported that fewer than $50 \%$ of boys and girls are active enough to produce health benefits, that a considerably smaller proportion of girls than boys are sufficiently active, and that activity participation declines with age during adolescence (Adams 1995; CDC 1997; CDC 1999; CDC 2008; WHO 2004b). However, it is not clear at what age the decline begins, if the rate of decline is linear (Sallis 2000; Stone 1998), and if the decline is greater in girls than boys (Story 2009 ; WHO 2004b).

These data are alarming for several reasons: a) changes in riskrelated behaviors (e.g. increasing physical activity) may modify risk factors for chronic diseases such as hypertension or raised blood lipids among children (Arbeit 1992; Ball 2003; Gutin 1997; Hagberg 1983; Hansen 1991; Harrell 1996; Killen 1989; Walter 1988); b) physical activity affects physical and psychosocial health as physically active adolescents had lower prevalence of anxiety and depression (Summerbell 2005); c) physical activity patterns track from childhood into adulthood (CDC 2008; Dennison 1988; Kelder 1994; Klepp 1993; Malina 1996; Malina 2001; Raitakari 1994; Sallis 1992; Summerbell 2005); d) children are increasingly exhibiting risk factors for CVD, such as obesity (Hill 1998; Katz 2009; Moran 1999; Troiano 1995; Warden 1997), elevated blood lipids (Lee 1986), and hypertension (Fernandes 2000; Katz 2009), conditions that are known to track into adulthood (Gonzalez-Suarez 2009; Kemper 1990; Lauer 1989; Mahoney 1991; Nicklas 1995; Porkka 1991; Power 1997; Shear 1986; Webber 1983; Webber 1991; Whitaker 1997); and d) atherosclerotic fatty streaks in the coronary arteries, indicative of coronary heart disease, have been found in overweight adolescents (Haque 2008), and postmortem in children (Berenson 1992).

\section{Determinants of physical activity among children}

Increasing physical activity among children and adolescents is difficult as behavior is influenced by several factors including: personal factors; institutional, community, and public policy; and the physical environment (CIHR 2004). Lindquist 1999, basing their work on Kohl 1998, provided a typology for understanding the multitude of factors that may influence children's physical activity patterns. This classification considers determinants at four levels: physiological, psychological, sociocultural, and ecological.

Physiological determinants of physical activity among children and adolescents include age, gender, and ethnicity (Hudson 2008; Lindquist 1999; Pate 1994; Reynolds 1990; Sallis 1993; Sallis 2000). Specifically, girls have been found to be less active than boys, older children and adolescents less active than younger children, and black girls less active than white girls (Adams 1995; CDC 1997; Kelder 1995b; Ogden 2006; Robinson 1995; Zakarian 1994). Psychological determinants of physical activity include confidence in one's ability to engage in exercise (self efficacy) (Dishman 2004), perception of physical or sport competence (Sallis 2000), having a positive attitude toward physical activity (Trost 1997), enjoyment of physical activity (Dishman 2005), and perceiving benefits from engaging in physical activity (Ferguson 1989; Tappe 1990; Zakarian
1994). Conversely, perceived barriers to physical activity, such as lack of time or feeling tired, are negatively associated with physical activity among adolescents (Tappe 1990; Zakarian 1994). Sociocultural influences include support for and participation in physical activity of peers and siblings (Sallis 1988), parental level of physical activity (Adkins 2004; Andersen 1992; Biddle 1992; Butcher 1985; Freedson 1992; Garcia 1995; McMurray 1993; Moore 1991; Poest 1989; Reynolds 1990; Sallis 1988; Sallis 1992; Stucky-Ropp 1993; Zakarian 1994), parental support (Sallis 2000), and parental income. Ecological determinants of physical activity include access to play spaces, facilities, availability of equipment (Stucky-Ropp 1993), and transportation to activities or programs (Sallis 1992). In addition, time spent outdoors in the early years is positively correlated with physical activity levels among children (Sallis 1993).

\section{Description of the intervention}

The school setting is an ideal environment for population-based physical activity interventions as no other institution has as much influence on children during their first two decades of life (Story 2009). Physical activity in schools has also been shown to be indirectly associated with academic achievement including lower drop-out rates, better classroom behavior, self-esteem and engagement in school, and on-task behavior (Mahar 2006; Trudeau 2008). While the schools alone cannot solve the problem of inactivity, they do have the potential to become the central element in a community that ensures students participate in the recommended amount of time engaged in physical activity (Koplan 2005; Pate 2006). Schools provide benefit to children from all risk groups (Harrell 1996; WHO 2004a), particularly those with limited or no access to play areas (McKenzie 1996); and avoids stigmatization of at-risk children (Harrell 1998). Leading organizations recommend that schools implement policies that require daily PE; elementary school recess; and physical activity before, during, and after school (Pate 2006). However, it is not clear what the most effective strategies are to promote life-long healthy behaviors.

Worrisome trends in the school setting are occurring concurrently with the increasing prevalence of obesity including a decline in physically active transport to and from school, recess duration, and enrolment in PE classes (Pate 2006). Although most schools require $\mathrm{PE}$ as part of their curriculum, PE classes may occur infrequently and children are often relatively inactive in them (McKenzie 1995; Pate 2006; Simons-Morton 1990; Simons-Morton 1994). Increasing the frequency and duration of PE is not always feasible given competing curriculum demands. It is thus essential to promote physical activity throughout the school day during classes, lunch times, and recess, and to develop strategies to promote more efficient use of PE class time.

The studies included in the original review and now in this update, all implemented different combinations of physical activity promotion interventions in schools, with some also implementing interventions concurrently in the community as well as in the home. Generally the interventions focused on providing students with information about the benefits of physical activity and healthy nutrition, the risks associated with inactivity and unhealthy food choices, and increasing the amount of time students were engaged in physical activity during the school day, as well as ensuring they expended greater amounts of energy during physical activity sessions. The interventions targeted school curriculum (related to PE classes specifically and whole curriculum generally), teacher 
training, educational materials, changes to the format of the school day, and accessibility to exercise equipment. Interventions included: training sessions for teachers (to learn more effective ways to promote physical activity and to incorporate it into curricula); training materials including kits, packages of materials to be used in curricula, and materials to be given to students and parents. Packages included teaching notes on exercise, how the body works, healthy eating and nutrition. They also targeted $P E$ classes by increasing the level of activity students engaged in during these classes, introduced activities geared to the age and level of development of the child, and put greater emphasis on games. Students were also encouraged to be more active outside of school during leisure time. The curriculum focused on creating a positive self-image through awareness of physical activity benefits. Curriculum changes were also implemented in other courses, such as science, where discussions of healthy eating and physical activity were incorporated. Some interventions also included changes to the food provided in school cafeterias so as to increase the number of healthy food choices. Other strategies included a risk factor assessment of students to identify students with established risk factors and develop a plan to reduce their risk through increased physical activity, healthy nutrition, and goal attainment.

\section{Adverse effects of the intervention}

There are a number of advantages to school-based physical activity promotion strategies. For example, school-based strategies targeting all students through curriculum, ensures $100 \%$ of students are exposed to the intervention, thereby increasing the reach of these interventions. In addition, targeting the interventions at all students in a school could avoid stigmatizing children who are overweight, obese, or with established risk factors for chronic diseases. Stigmatization of children and adolescents has been shown to have a negative impact on self esteem, self worth, and mental health. Therefore interventions directed at entire school populations could effectively avoid these negative impacts. However, it is also likely that stigmatization will not be avoided, particularly when unfit students must engage in rigorous physical activity in front of their peers. In fact the more rigorous the activity, the greater the likelihood that certain students will be identified as being particularly unfit by their peers, and potentially subjected to ridicule. In addition, having to change clothes to engage in physical activity may be particularly stressful for overweight and obese students and it is difficult to identify strategies to reduce issues associated with changing clothes that would not further stigmatize these students. Another potential adverse effect of school-based physical activity promotion interventions arises from 'forcing' students to engage in rigorous activity when they do not want to. Instead of promoting positive perceptions of exercise this intervention could produce the opposite effect resulting in students not wanting to engage in any activity, and having very negative perceptions. This may result in worse outcomes with respect to activity levels. Furthermore, being made to engage in certain behavior may result in reactance, which means students will do the exact opposite. In both instances it is possible that an even further reduction in physical activity levels could occur. Another adverse effect of school-based interventions related to the development of a reward system, such as a grade, is the loss of the intrinsic motivation to engage in an activity that was previously viewed as fun. In other words students might become unmotivated to engage in physical activity because they now perceive it to be 'work', or they require larger and larger rewards for doing a behavior they previously engaged in for no reward. Finally, it is possible that soft tissue injuries might occur among students associated with the increased rigorous physical activity.

\section{How the intervention might work}

Given school-aged children spend a significant amount of their wakeful hours either in transit to or in the school setting, and that in many countries, all children attend school until they reach adolescence, school-based physical activity promotion interventions have potential to reduce population-wide chronic diseases. School-based interventions can target simultaneously, children both at risk and not at risk for future chronic diseases, and can increase both knowledge and behavior conducive to healthier lifestyles. The intent of school-based physical activity interventions is to increase the overall percentage of children and adolescents engaged in physical activity each day and to increase the duration of moderate to vigorous activity engaged in on a weekly basis. The aim is to create a school environment that is more conducive to achieving higher rates of physical activity among children and adolescents as well as increasing the time spent engaged in moderate to vigorous physical activity. Generally this means significant changes to school curriculum that support increased time for physical activity as well as increased levels of activity during this time. There is an important opportunity through school-based interventions to ensure greater attention to improving knowledge of chronic disease prevention and health promotion, and by providing students with both knowledge and the opportunity to be more active during the school day, children will develop healthier behaviors that may track in adulthood.

\section{Why it is important to do this review}

A number of reviews have been conducted on similar topics. For example, Summerbell 2005 explored the impact of interventions to prevent obesity in children, and Thomas 2004a assessed the impact of strategies to promote healthy body weight in children and adolescents. Both reviews are of rigorous methodological quality and provide important direction for healthy body weight promotion policies and programs. What is difficult to ascertain from these reviews is the specific impact of school-based strategies on healthy body weight, as well as the specific role of physical activity in reducing risk factors associated with chronic diseases. In both the Summerbell 2005 and Thomas 2004a reviews, interventions were multifaceted, meaning the interventions targeted multiple behaviors including diet and physical activity simultaneously, and that they were implemented congruently in multiple settings such as the community, schools, and public places. In both reviews it is unclear what specific contribution the school setting had on intervention effectiveness as well as the individual contribution of physical activity on improved health status measures, such as blood pressure, blood lipids, weight, and fitness measures.

However, given school-aged children spend such a significant amount of time in the school setting, and that many barriers exist to participation in physical activity outside of the school setting (e.g. resources, availability), it is particularly important to understand the extent to which school-based physical activity promotion interventions are effective in increasing activity and fitness levels. When school-based interventions are combined with broader community-based interventions, it is difficult to ascertain the impact of school-based strategies. However, in developing 
comprehensive physical activity or chronic disease prevention strategies, it is crucial to incorporate effective school-based strategies. Therefore, it is timely, given the worldwide attention to physical inactivity, that a review focused solely on the effectiveness of school-based physical activity interventions be conducted and regularly updated.

\section{OB JECTIVES}

The purpose of this systematic review was to assess, analyze, and draw conclusions about the effectiveness of school-based interventions in promoting physical activity and fitness in schoolattending children and adolescents aged 6 to 18 years. The specific objectives were:

- to evaluate the effects of school-based interventions on promoting physical activity and fitness in children and adolescents;

- to evaluate the effects of school-based interventions on improving measures of physical health status;

- to determine if certain combinations or components (or both) of school-based interventions are more effective than others in promoting physical activity and fitness in this target population.

\section{MET HOD S}

\section{Criteria for considering studies for this review Types of studies}

In the original review and this update the following criteria were used to select studies. The intervention had to be relevant to public health practice (meaning the focus was on health promotion from an individual or population-wide perspective, was not physician or clinic based); b) the intervention could be implemented, facilitated, or promoted by staff in local public health units, meaning interventions that were only relevant to other health professionals (e.g. physicians), or fitness experts (e.g. personal trainers) were not considered 'regular' practice for public health professionals; c) the intervention was implemented in a school setting and was aimed at increasing physical activity and fitness in children and adolescents.

Furthermore, in this update we included data only from randomized controlled trials (RCTs) with a minimum intervention duration of 12 weeks.

Three unique changes were made to the protocol of this update in comparison to the original review.

1. Due to the availability of numerous RCTs, both those included in the original review and those that became available after the original review was published in The Cochrane Library, the inclusion/exclusion criteria were modified to include only those studies that were RCTs. This change in inclusion criterion resulted in a number of non-RCTs included in the original review being excluded from the update.

2. Studies had to have at a minimum an intervention duration of at least 12 weeks otherwise they were excluded from the update. Again this resulted is some studies included in the original review being excluded from the update.

3. Studies not aimed at the general population (e.g. studies including obese children only, or only low-active children) were excluded from this update. Again this resulted in a small number of studies included in the original review being excluded in the update.

The review authors are aware that post hoc questions are susceptible to bias (Higgins 2011); however, in light of the growing body of literature on the effectiveness of school-based physical activity promotion interventions, we believe the changes in inclusion and exclusion criteria were necessary to ensure the most rigorous evidence answering our research question was included in this update.

\section{Types of participants}

Studies that included school-attending children and adolescents between the ages of 6 to 18 years were included in this review. This included all otherwise healthy children and adolescents whether they were overweight, obese, or not. We excluded studies where participants received a physical activity intervention as part of a treatment regimen for a specific critical illness or comorbidity (e.g. diabetes).

\section{Types of interventions}

\section{Strategies}

Any study that assessed educational, health promotion, counseling, and management strategies focused on the promotion of physical activity and fitness, that were or could be provided by public health professionals was included in this review.

\section{Interventions included}

The range of interventions included changes to school curriculum; changes in school routines to increase time spent by students being physically active; increase in the time students engaged in vigorous physical activity during PE classes; provision of equipment; training for teachers in incorporating physical activity into school curriculum and routines; and educational materials for teachers, students, and parents. In some instances the intervention included strategies to engage parents in the intervention, as well as community-based strategies, mass media, and policy development.

\section{Setting}

Studies where the interventions were targeted primarily within the school setting were included in this review. In some instances interventions were also implemented in the community and home setting in addition to the school-based interventions, although the primary focus had to be the school setting. We excluded studies when the intervention was conducted entirely outside of the school setting (e.g. community setting, public place, recreation facility, physician office, camp setting).

\section{Types of comparisons}

Generally, these programs were compared to standard, currently existing PE programs in schools.

\section{Intervention personnel}

The interventions were implemented by a variety of professionals including PE teachers, classroom teachers, research staff, health professionals, peers and in a few studies parents. 


\section{Indicators of theory and process}

In a number of studies the development of the intervention was guided by one or more theories such as the health-belief model, social-cognitive theory, stages of change, or a combination. Where theory informed the development of the intervention this was noted.

\section{Interventions excluded}

Interventions excluded from this review included those that were not focused on changing physical activity and fitness levels or were not implemented primarily in the school setting among healthy children aged 6 to 18 years or were implemented by physicians, or fitness experts.

\section{Types of outcome measures}

To be included, studies had to report one or more of the following outcomes, presenting a baseline and a post intervention measurement. These data were used to evaluate change from baseline if not reported in the study.

\section{Primary outcomes}

- Rate of moderate to vigorous physical activity (MVPA) (per cent of sample engaged in MVPA). The rate of MVPA was assessed either through self-report or through the use of accelerometers during both school or non-school (or both) time. The rate was calculated by dividing the number of students engaged in MVPA by the total number of students allocated to either the intervention or control group.

- Duration of physical activity (time spent engaged in MVPA). Duration of physical activity was measured as the total minutes per hour or week spent engaged in MVPA generally through self-report, although some studies collected these data via accelerometers.

- Television viewing (time spent watching TV). Television viewing was measured by self-report or parental report as the minutes per hour or week spent watching television, outside of school.

\section{Secondary outcomes}

- Mean systolic blood pressure $(\mathrm{mmHg})$. This outcome was measured either manually using a mercury sphygmomanometer or via a Dinamap machine. The timing of when blood pressure was measured differed significantly across studies with timing varying between 5 and 15 min following active periods during school hours. Additionally, in some studies the average of three measures taken one minute apart were used, in others five measures were averaged, and in others the second and third of three measures were averaged.

- Mean diastolic blood pressure $(\mathrm{mmHg})$. This outcome was measured in the same way as systolic blood pressure.

- Mean blood cholesterol (mg/dL). Blood samples were taken for some studies after fasting, and for others with no fasting. Blood samples were taken by health professionals trained to follow a given protocol and sent for processing.

- BMI $\left(\mathrm{kg} / \mathrm{m}^{2}\right)$. This outcome was measured by trained health professionals using calibrated scales. However, differences existed across studies in which clothes were worn by participants during measurement; and when height and weight were measured during school time.

- Maximal oxygen consumption $\left(\mathrm{VO}_{2} \max \right)$ ( $\mathrm{mL} / \mathrm{kg} /$ minute). This outcome was measured in different ways by trained professionals. In some instances pulse rate recovery was used as a proxy for $\mathrm{VO}_{2}$ max and in other instances actual maximal oxygen uptake was measured.

- Pulse rate (beats/minute). This outcome was measured by trained professionals during school time, during seated rest. It was usually taken at the same time as blood pressure.

\section{Timing of outcome measurement}

Outcomes were primarily measured at baseline and immediately post intervention. In a small subset of studies outcomes were measured six months, nine months, 12 months, and, in one study, up to four years post intervention.

\section{Search methods for identification of studies}

\section{Electronic searches}

The search strategy, was developed to be inclusive and rigorous (Higgins 2011) and consistent with The Cochrane Collaboration methodology for conducting a comprehensive search of the literature.

For the original review the following databases were searched from 1985 to July 2007: MEDLINE, BIOSIS, CINAHL, EMBASE, SPORTDiscus, PsycINFO, Sociological Abstracts and the Cochrane Central Register of Controlled Trials (CENTRAL). For the updated review, the same databases were searched again to capture studies published between July 2007 to October 2011. Search strategies for each database are included in Appendix 1. Additional key words of relevance were detected during initial electronic searches. The search strategies were then modified to incorporate these terms. The MEDLINE search strategy was adapted for use in the above databases. Studies were not excluded on the basis of language. For an overview of the search process see Figure 1 . 
Figure 1. Study flow diagram.

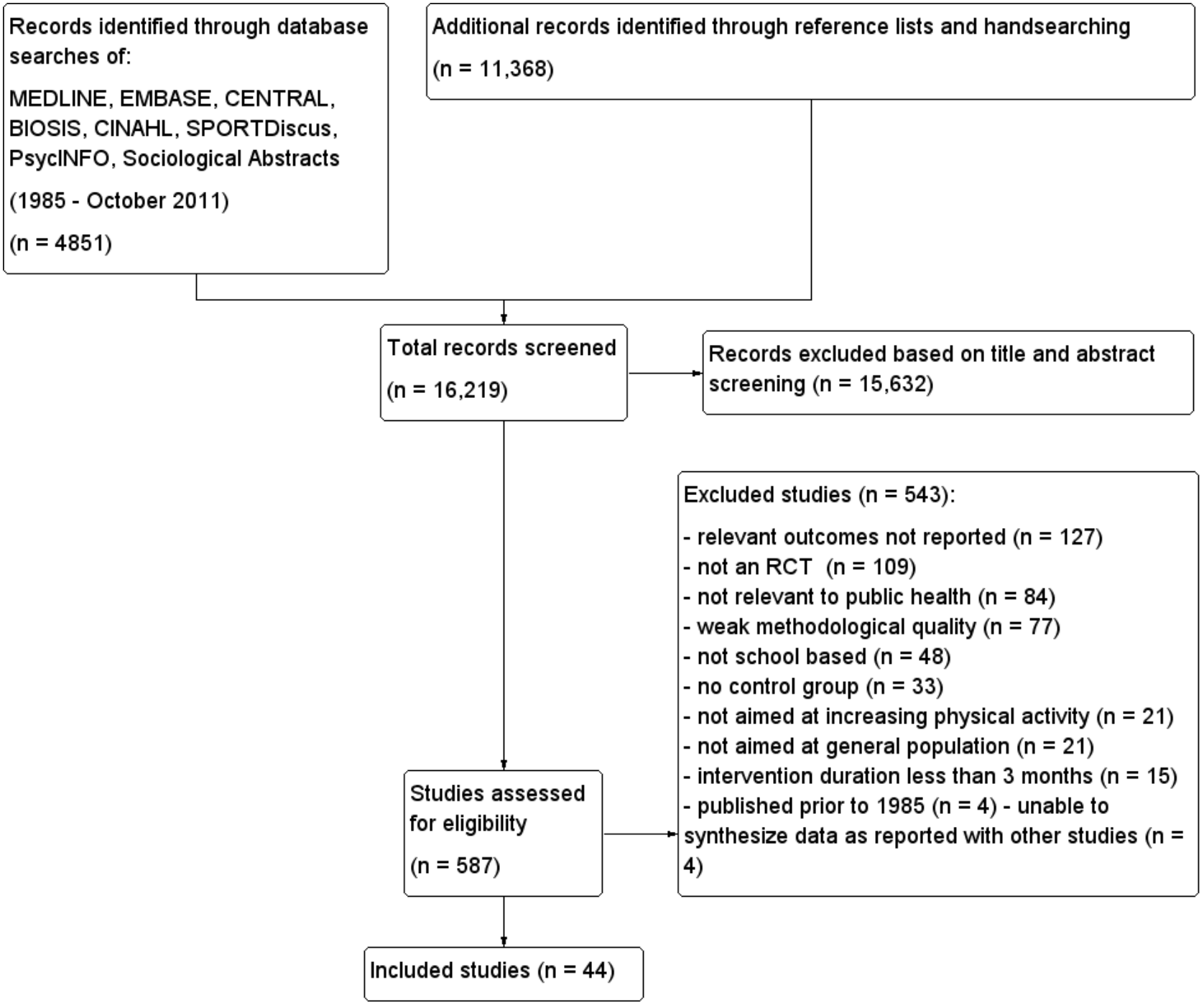

\section{Searching other resources}

\section{Contacting experts}

Experts in the field of physical activity promotion in children and adolescents were contacted with a view to seeking additional references.

\section{Reference lists checked}

We identified additional studies by searching the reference lists of included studies and (systematic) reviews, meta-analyses, and health technology assessment reports.

\section{Data collection and analysis}

\section{Selection of studies}

The review team was composed of a health services researcher (MD), a project coordinator (KD), program manager $(\mathrm{HH})$, and research assistants (DT, PR, for the original review and RL, for this update) from an academic research center. Where multiple publications for the same study existed, a project account was created and relevant data extracted from all articles.
The abstracts from all search strategies were imported into Reference Manager and screened independently by RL, HH, and KD. Project accounts (studies) judged as being potentially relevant were retrieved in their entirety and assessed for relevance independently by two review authors (MD, RL) using a standardized tool. Where disagreement occurred, discussion ensued until consensus was achieved. Selection criteria for the original review included: a) an intervention relevant to public health practice was described (meaning the focus was on health promotion from an individual or population-wide perspective, was not physician or clinic based); b) the intervention could be implemented, facilitated, or promoted by staff in local public health units, meaning interventions that were only relevant to other health professionals (e.g. physicians), or fitness experts (e.g. personal trainers) were not considered 'regular' practice for public health professionals; c) the intervention was implemented in a school setting and was aimed at increasing physical activity and fitness in children and adolescents; d) outcomes were reported for children and adolescents (aged 6 to 18 years); and e) the study design was prospective and included a control group. New selection criteria were added for the update including: f) the study was an RCT; g) the intervention was targeted at all school children; and h) the intervention was implemented 
for 12 or more weeks. All criteria had to be met for a study to be included in the review. Those studies that were deemed relevant were then assessed for risk of bias. An adapted PRISMA (preferred reporting items for systematic reviews and meta-analyses) flowchart of study selection is attached (Figure 1) (Liberati 2009).

\section{Data extraction and management}

For this update three review authors (MD, RL, KD) independently abstracted relevant population and intervention characteristics for all new studies using standard data extraction templates (see Characteristics of included studies, Table 1, Appendix 3, and Appendix 4). All disagreements were resolved by discussion. Any relevant missing information was sought from the primary author of the study. Data from all new studies were extracted using the same data extraction tool as used in the original review (Thomas 2004b). Extracted data included year and country of study, research design, sample, intervention (descriptors, theoretical framework, provider, setting, target group, target group size, consumer involvement), intervention duration and intensity, length of followup, and outcome data.

\section{Dealing with duplicate publications}

Where multiple publications for the same study existed, a project account was created and relevant data extracted from all articles. The article containing the most complete data on the project was identified as the primary article for a project account. All other related articles were identified as companion articles for a project account. All primary and companion article groupings are available in the section Included studies. The final data collection point for each outcome in each study has been used to assess intervention effectiveness.

\section{Assessment of risk of bias in included studies}

In the original review the methodological rigor of included studies was assessed using a previously developed and tested quality assessment tool (Thomas 2004b). For the update all studies from the original review as well as studies identified for this update were assessed independently for risk of bias by two of three review authors (MD, RL, KD). MD assessed all studies for risk of bias while $\mathrm{RL}$ and $\mathrm{KD}$ each conducted risk of bias on approximately half of the studies. Critical assessments were made separately for each of seven domains with judgments of low risk of bias, high risk of bias, and unclear risk of bias (Higgins 2011). The following domains were assessed: sequence generation, allocation concealment, blinding, incomplete outcome data, selective outcome reporting, and two 'other issues': control of confounders, and data collection methods, which were two criteria used in the original review to assess methodological quality (Thomas 2004b). Disagreements were resolved through discussion until consensus was reached.

We assessed if the allocation sequence was adequately generated and likely to produce comparable groups. If the investigators utilized and described a random component in the sequence generation process we a

ssigned a judgment of low risk of bias. If there was no description of allocation sequence given beyond a statement claiming to allocate participants randomly, a rating of unclear risk of bias was given.

We also assessed whether the allocation sequence was adequately concealed prior to and during recruitment. If the investigators utilized and described an adequate process for concealing the allocation sequence we assigned a judgment of low risk of bias. If the process was not adequate a rating of high risk of bias was assigned. If there was no description of the process of allocation concealment a rating of unclear risk of bias was given.

For blinding, we assessed whether any steps were taken to blind participants, intervention providers, and outcome assessors to which group participants were allocated. If adequate blinding occurred a rating of low risk of bias was given. If blinding was not adequate, we assigned a judgment of high risk of bias, and if it was not described, a judgment of unclear risk of bias.

We assessed whether incomplete data were adequately addressed. Where studies did not report intention-to-treat (ITT) analysis, review authors assessed how data related to attrition and exclusions were reported and whether the data were comparable to the total randomized number. A judgment of low risk of bias was given when incomplete data were addressed adequately. A judgment of high risk of bias was given when incomplete data were not addressed adequately and unclear risk of bias if incomplete data were not addressed.

For selective outcome reporting, we assessed whether reports of the study were free of suggestion of selective outcome reporting. Where all outcomes identified a priori were reported upon a rating of low risk of bias was given. When prespecified outcomes were not reported or outcomes were not prespecified and given no justification, a rating of high risk of bias was given. If there was insufficient information to permit judgment, we assigned a rating of unclear risk of bias.

We assessed the extent to which potential confounders were assessed in the primary studies and whether differences at baseline in these variables across groups were accounted for in the analysis. Studies that assessed all important confounders and accounted for differences at baseline (if relevant) were given a rating of low risk of bias. Those that did not assess for and take into account all relevant confounders and those that either did not assess most relevant confounders or did not account for differences at baseline in the analysis (or both) were given a rating of high risk of bias. Where there was not enough information to assess this criteria, we assigned a rating of unclear risk of bias.

The reliability and validity of all data collection measures were also assessed and data extracted only for those outcomes for which some degree of reliability and validity was demonstrated. However, in this literature the degree to which validity was established in the most rigorous sense, for self-reported physical activity levels was limited to construct or face validity. The majority of studies measured physical activity rates through self-report. Therefore, this criterion was not overly helpful in discriminating studies of lower risk of bias.

Although in the original review, studies judged as having significant limitations were removed, none of the new studies identified for this update were removed from further analysis as a result of being judged to have a high risk of bias.

\section{Measures of treatment effect}

No recalculations were performed. Unless otherwise stated, all data are presented in the format mean and standard deviation (SD) with 
$95 \%$ confidence intervals $(\mathrm{Cl})$, where provided. Results with $\mathrm{P}>0.05$ are reported as not significant (NS).

\section{Unit of analysis issues}

Generally the unit of analysis was either classes or schools depending on how groups were allocated to intervention and control groups. Attention was paid to the extent to which the appropriate unit of analysis was used in data analysis. However, in some studies individuals were randomly allocated to intervention and control groups and this was noted as needed in the risk of bias assessment.

\section{Dealing with missing data}

Relevant missing data were sought from the primary authors. Evaluation of important numerical data such as screened, eligible, and randomized participants as well as ITT and per-protocol (PP) populations was conducted. Attrition rates, for example drop-outs, losses to follow-up, and withdrawals, were investigated.

\section{Assessment of heterogeneity}

Variation in the interventions, populations, and outcomes measured made it inappropriate to combine the results statistically across studies, therefore the results are synthesized narratively. For example, the populations studied varied greatly in socioeconomic status, ethnicity, and country. No two school-based physical activity promotion programs had the same combination of interventions. Furthermore, the duration, frequency, and intensity of interventions varied greatly across studies. Finally, the outcomes were measured differently across studies: some measured television viewing as minutes per hour while some measured in minutes per week. Due to this level of variation among studies, meta-analysis was deemed inappropriate even for those outcomes such as systolic and diastolic blood pressure, BMI, and blood cholesterol where greater standardization of the measurement existed. Heterogeneity across studies was assessed by visually evaluating the results for each outcome in tables. When heterogeneity was suspected, we assessed potential reasons for the differences by examining individual study characteristics and those of subgroups of the main body of evidence.

\section{Assessment of reporting biases}

Assessment for reporting biases was conducted. However, published protocols for all of the studies included in this update were not identified through our search strategy. Therefore, it is not possible to know with certainty if all outcomes that were meant to be reported on actually were in the published reports. It appears, from the published reports included in this update, that all studies reported on the outcomes that they intended to as reported in the Methods sections of the published papers.

\section{Data synthesis}

Each study was summarized and described according to variables such as characteristics of participants, characteristics of interventions, follow-up, and outcomes measured. Results are summarized narratively across all outcomes.

\section{Subgroup analysis and investigation of heterogeneity}

Only those subgroup analyses conducted in the primary studies are reported on. This was limited to age and gender.

\section{Sensitivity analysis}

Given meta-analysis was not conducted sensitivity analyses were not conducted in this review.

\section{RESULTS}

\section{Description of studies}

A total of 13,841 records related to physical activity interventions with children and adolescents were identified in the original review. Of these, 302 studies were assessed for eligibility, and 26 were deemed of sufficient quality to be included in the original review. The most common reasons studies were judged as not relevant were data on relevant outcomes for children and adolescents (aged 6 to 18 years) were not reported, and the intervention was not an intervention normally performed by public health professionals. For example, the intervention was conducted by a physician in a physician's office, or by a fitness specialist in a fitness center.

For the update, when the new inclusion and exclusion criteria were applied (i.e. RCTs only, all children in a school, and intervention duration of 12 weeks), 12 of the original 26 studies were excluded: nine because they were not RCTs (Alexandrov 1988; Berenson 1993; Graf 2005; Klepp 1994; Lionis 1991; Manios 1999; Marcus 1987; Plotnikoff 1999; Sallis 1997); one was excluded because the study sample included overweight or obese children only (Carrel 2005a) and two others were excluded because the intervention was shorter than 12 weeks (Eliakim 1996; Fardy 1996). Therefore, this update includes 14 of the original 26 studies (Bayne-Smith 2004; Burke 1998; Bush 1989; Ewart 1998; Haerens 2006; Luepker 1996; Petchers 1988; Robinson 1999; Simon 2004; Stephens 1998; Stone 2003; Trevino 2004; Verstraete 2006; Walter 1988).

In addition, the search strategy for this update from July 2007 to October 2011 identified 2378 records related to physical activity interventions with children and adolescents. Of these, 285 unique studies were assessed for eligibility. Of the 285 unique studies, 30 met all relevance criteria and were included in this update (Angelopoulos 2009; Araujo-Soares 2009; Barbeau 2007; ColinRamirez 2010; Dishman 2004; Donnelly 2009; Dorgo 2009; Gentile 2009; Haerens 2009; Jones 2008; Kipping 2008; Kriemler 2010; Li 2010; Lubans 2009; Martinez 2008; McManus 2008; NeumarkSztainer 2009; Neumark-Sztainer 2010; Peralta 2009; Reed 2008; Salmon 2008; Singh 2009; Singhal 2010; Walther 2009; Wang 2008; Webber 2008; Weeks 2008; Williamson 2007; Wilson 2011; Young 2006). The most common reasons studies were judged as not relevant were: the design was not an RCT; data on relevant outcomes for children and adolescents (aged 6 to 18 years) were not reported; or the intervention was not school based. This update includes 44 studies ( 14 from the original review and 30 from the update), and represents complete data for 36,593 study participants. A flow diagram depicting these results is presented in Figure 1. Citations for the 543 excluded studies are available in the Excluded studies section, and reasons for exclusion are provided in the Characteristics of excluded studies table.

In addition to the information in the characteristics of Included studies tables, more detail is provided for each study in Table 1 (overview of included studies), Appendix 3 (summary of baseline characteristics for each included study), and Appendix 4 (Matrix of endpoints for each study). 
The majority of studies were conducted in the US (24), Australia (5), Belgium (3), China (2), and Greece (1). Several other countries, mostly in Europe, conducted one study each, as well as one study from Canada and one from India. All but 11 studies involved children 12 years of age and under at baseline, three of which included participants who were 16 years at baseline. The majority of children were between nine to 11 years of age at baseline. Others also targeted to receive interventions during these studies included parents, teachers, and cafeteria staff. The majority of studies evaluated outcomes immediately following the intervention ( $\mathrm{n}$ = 34), with one study evaluating outcomes two weeks post intervention (Wilson 2011), one at three months (Haerens 2009), three at six months (Burke 1998; Gentile 2009; McManus 2008), one at nine months (Araujo-Soares 2009), and four at 12 months (Li 2010; Petchers 1988; Salmon 2008; Singh 2009). The samples were comprised of multiple ethnicities including AfricanAmerican, Asian, Australian, European, First Nations/Aboriginal, Greek, Hispanic, Scandinavian, and white participants. Generally, the interventions were implemented in urban centers among all socioeconomic classes.

All studies had intervention components that were delivered in the school setting. Some projects provided additional interventions in the home, community, physician offices, local theatre, and via the telephone or computer. A number of studies $(n=15)$ focused primarily on grade school programs that included some parental involvement (Burke 1998; Bush 1989; Colin-Ramirez 2010; Ewart 1998; Gentile 2009; Haerens 2006; Lubans 2009; Luepker 1996; Neumark-Sztainer 2010; Petchers 1988; Reed 2008; Robinson 1999; Stone 2003; Trevino 2004; Young 2006). The three most common intervention providers across the 44 included studies were classroom teachers $(n=28)$, members of the research team $(n=13)$, and PE teachers $(n=9)$. Specialist teachers, nurses, social workers, physicians, volunteers, psychologists, dentists, nutritionists, and peers were occasionally identified as intervention providers.

All studies included a control group that represented either a school or group of schools from a different community, city, or state that did not receive the school-based intervention. However, in some studies the control schools received other physical activity promotion interventions provided through other health organizations or venues or standard PE curriculum. The duration of the interventions varied greatly from a minimum of 12 weeks to six years, with six studies reporting intervention periods of three years or greater (Bush 1989; Donnelly 2009; Luepker 1996; Simon 2004; Walter 1988; Wang 2008).

Several theoretical models were used to develop the physical activity interventions, although in several studies it was unclear if a theoretical model had been used. The most commonly used theories were social cognitive theory and the health-belief model while self-determination theory, PRECEDE, social learning theory, and the transtheoretical model were used to a lesser extent. Social cognitive theory suggests that motivations and actions are controlled by thought and in order for behavior change to occur, an individual will anticipate an outcome by considering: perceived self-efficacy (the belief in one's capabilities); situation- outcome (belief that consequences will occur without interfering personal action); and action-outcome (belief a behavior will lead to an outcome) (Bandura 1982; Luszczynska 2005). The healthbelief model (Rosenstock 1966) acts on the premise that an individual's behaviors are affected by perceived susceptibility of developing health problems, perceived impact of health problems on one's quality of life, and the belief that changing behavior will be beneficial in avoiding the health problem (Hochbaum 1958; Rosenstock 1966). PRECEDE uses cues, prompts, and reinforcements to alter behavior (Skinner 1953). This framework is a cost-benefit evaluation that provides a comprehensive structure for assessing health and quality of life needs for designing, implementing, and evaluating health promotion programs (Green 1974). Social learning theory proposes that behavior change is affected by environmental influences, personal factors, and attributes of the behavior itself (Bandura 1977). The transtheoretical model suggests that individuals progress through six stages (precontemplation, contemplation, preparation, action, maintenance, and termination) to enable health behavior change and the individual's stage of change must match the messages in order to be effective in changing the behavior (Prochaska 1997).

The studies reported in this review differed in funding levels, the number of project staff, and the resources available to deliver the program or training provided for the delivery of the program. Further, although all of the projects were primarily school-based, none of the projects used the same combination of interventions with the same intensity, making each project unique. However, some similarities with respect to the ways in which the interventions were delivered were observed. For example, almost all studies implemented curricula focused on increasing time spent in physical activity and on increasing knowledge about the benefits of an active lifestyle. The majority of studies also distributed printed or audio-visual educational materials primarily to students, but sometimes to parents as well, often in association with educational sessions. About a quarter of the studies involved school-based activities other than school curricula (e.g. school fun nights, walkathons, educational materials or sessions (or both) for school staff and parents, game equipment). Communitybased interventions, such as training sessions and workshops for parents and parent involvement in home-based physical activities (homework), were used in conjunction with school-based interventions in about half of the studies. Finally, some studies also reported the use of counseling, health screening, and support groups.

\section{Risk of bias in included studies}

The results of the risk of bias assessment for the 44 studies are presented in Figure 2 and Figure 3. The most notable methodological weakness of these studies was the lack of blinding of participants, providers, outcome assessors, and data analysts. More specifically most studies in this review did not have blinded outcome assessors. For example, for behavioral outcomes in most studies the data were collected through student selfreport (e.g. time engaged in physical activity, time spent watching television). It was also likely, though difficult to determine, that the students were aware of the outcomes being assessed. 
Figure 2. Risk of bias graph: review authors' judgements about each risk of bias item presented as percentages across all included studies.

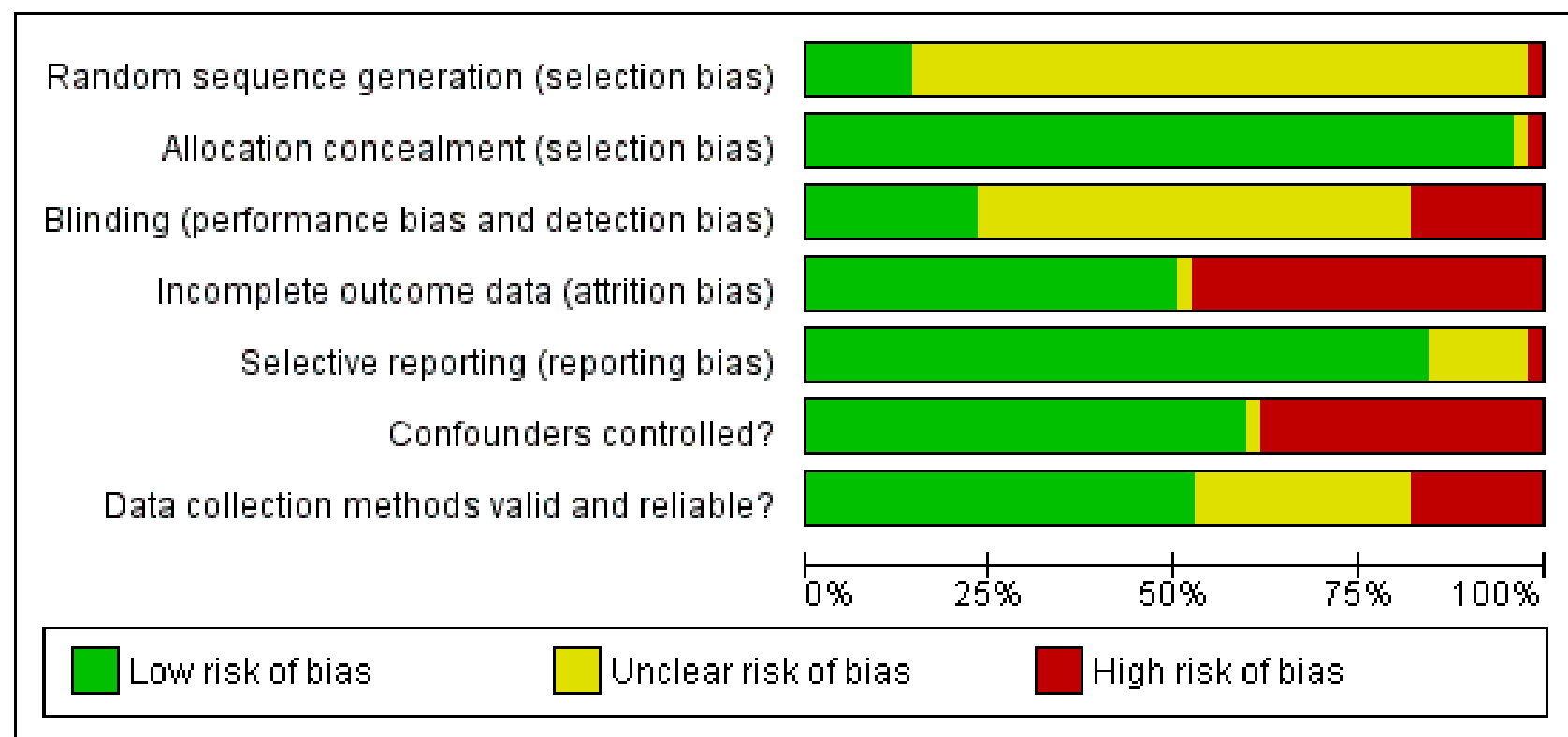


Figure 3. Risk of bias summary: review authors' judgements about each risk of bias item for each included study.

\begin{tabular}{|c|c|c|c|c|c|c|c|}
\hline & 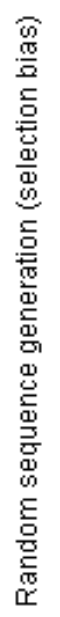 & 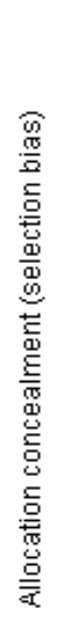 & 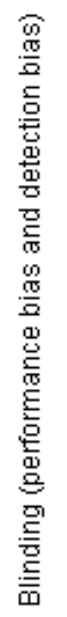 & 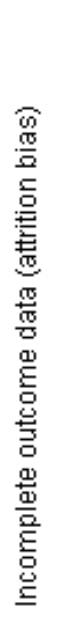 & 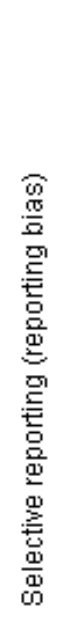 & 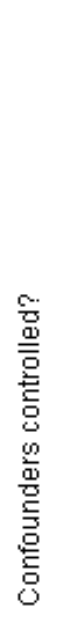 & 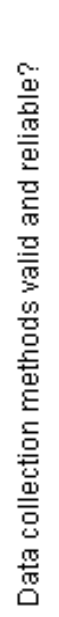 \\
\hline Angelopoulos 2009 & $\odot$ & $\odot$ & $?$ & $\odot$ & $\odot$ & $\odot$ & $\odot$ \\
\hline Araujo-Soares 2009 & $?$ & + & $?$ & $\odot$ & + & $\odot$ & + \\
\hline Barbeau 2007 & $?$ & $\oplus$ & $?$ & $\odot$ & $\odot$ & $\odot$ & $\odot$ \\
\hline Bayne-Smith 2004 & $?$ & $\odot$ & $?$ & $?$ & $\odot$ & $\odot$ & $\odot$ \\
\hline Burke 1998 & $?$ & + & $?$ & $\odot$ & + & 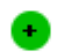 & $\odot$ \\
\hline Bush 1989 & $?$ & + & $?$ & $\odot$ & + & + & $?$ \\
\hline Colin-Ramirez 2010 & $?$ & $\oplus$ & $\odot$ & $\odot$ & $?$ & $\odot$ & $?$ \\
\hline Dishman 2004 & $?$ & + & $?$ & $\odot$ & + & + & + \\
\hline Donnelly 2009 & $?$ & $\oplus$ & $\odot$ & $\odot$ & + & + & $\oplus$ \\
\hline Dorgo 2009 & $?$ & + & $?$ & $\odot$ & + & $\odot$ & 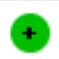 \\
\hline Ewart 1998 & $?$ & $\oplus$ & $\odot$ & $\odot$ & + & $?$ & $?$ \\
\hline Gentile 2009 & $?$ & + & $?$ & $\odot$ & + & $\oplus$ & $\oplus$ \\
\hline Haerens 2006 & $?$ & $\oplus$ & $?$ & $\odot$ & + & 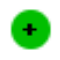 & $\odot$ \\
\hline Haerens 2009 & $?$ & 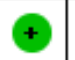 & $?$ & $\odot$ & + & $\oplus$ & $\odot$ \\
\hline Jones 2008 & $?$ & $\odot$ & $\Theta$ & $\odot$ & $\odot$ & $\odot$ & $\oplus$ \\
\hline Kipping 2008 & $?$ & + & $\odot$ & $\odot$ & $\odot$ & $\odot$ & $\odot$ \\
\hline Kriemler 2010 & $\odot$ & 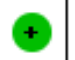 & $\odot$ & $\odot$ & $\odot$ & $\oplus$ & $\odot$ \\
\hline Li 2010 & $?$ & $\odot$ & $\odot$ & $\odot$ & $?$ & $\odot$ & $?$ \\
\hline Lubans 2009 & $?$ & 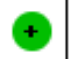 & $\odot$ & $\odot$ & $\odot$ & $\odot$ & $\odot$ \\
\hline Luepker 1996 & $?$ & $\odot$ & $?$ & $\odot$ & $\odot$ & $\odot$ & $\odot$ \\
\hline Martinez 2008 & $\odot$ & + & $\Theta$ & $\odot$ & + & 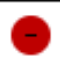 & + \\
\hline McManus 2008 & $\odot$ & + & - & - & $\odot$ & $\oplus$ & $\oplus$ \\
\hline
\end{tabular}


Figure 3. (Continued)

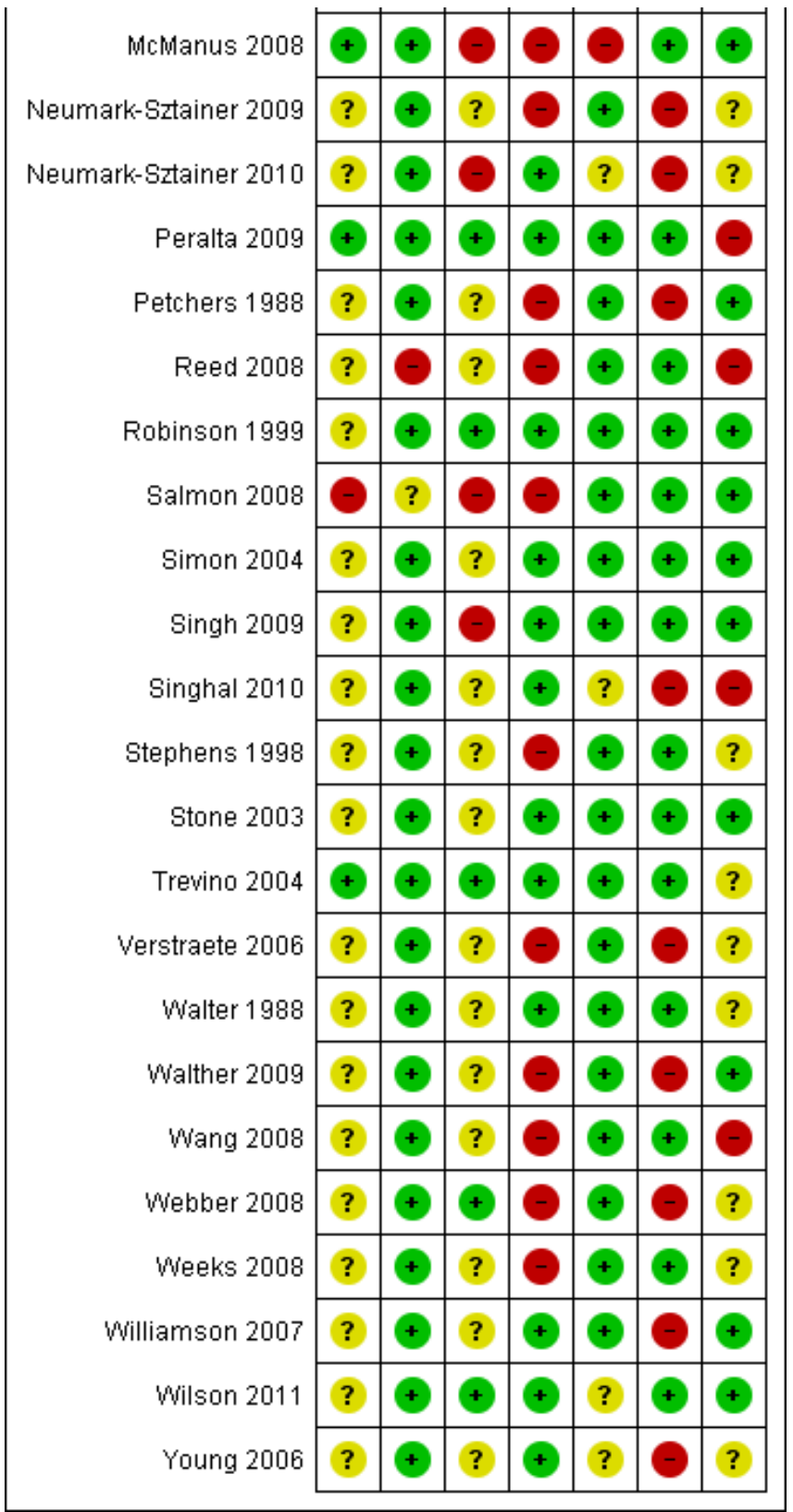

Another important limitation of this literature was the lack of consistency in how outcomes were measured across studies. While the data collection procedures for the physical health measures (blood pressure, cholesterol, BMI, pulse, and maximal oxygen uptake $\left(\mathrm{VO}_{2} \mathrm{max}\right)$ ) were generally more objective than the behavioral measures, there were still significant differences in how the data were collected. Even BMI, which was measured most consistently across studies, differed in terms of the amount of clothing worn by participants. Blood pressure measures were least consistent where in some studies blood pressure was taken manually using a mercury sphygmomanometer, and in others electronically using a Dinamap machine. Furthermore, the timing of when blood pressure was measured differed significantly across studies with timing varying between 5 and 15 min following active periods during school hours. Additionally, in some studies the average of three measures taken one minute apart were used, in others five measures were averaged, and in others the second and third of three measures were averaged. For cholesterol, while the procedures for taking a blood sample and analyzing the sample were similar, about half the studies used nonfasting blood samples and the other half used fasting blood samples. Finally, for the six studies measuring $\mathrm{VO}_{2}$ max half measured blood gases following exertion, while the other half used pulse rate recovery as a proxy for maximal oxygen uptake. Data collection methods were reported to be valid and reliable in a little over half of the included studies. In the remaining studies it was either unclear whether methods were valid and reliable or methods were used that were subject to bias.

While all of the studies were RCTs, generally there was little description across studies of how the randomization sequence 
was generated. Another limitation of this literature was unit of allocation errors. In some of the studies allocation was often by institution (e.g. school) or classroom, but assessment occurred at the level of the individual. Furthermore, in very few cases were measures taken to account for clustering effects within schools and only just over a third of studies $(n=16)$ reported that they conducted an ITT analysis. This, along with the other risks of bias identified in this literature, has likely resulted in an overestimation of treatment effects.

Components for which many studies were considered to have low risk of bias were only observed for allocation concealment. For all but one study, allocation to treatment or intervention groups occurred at one point in time after study recruitment, and was unknown in one other. Studies were also found to be free of selective reporting; however, because many of these studies did not have published protocols it is impossible to know for certain if all outcomes were reported on. For over $90 \%$ of studies, all of the study's prespecified outcomes of interest were reported upon. For the most part, confounders were adequately controlled in over $50 \%$ of studies although for some studies important confounders such as socioeconomic status and parental education were not accounted for. Finally, many studies attempted to evaluate the extent to which the intervention was implemented as intended (intervention integrity), and some conducted process evaluations in addition to evaluating intervention effectiveness. However cost-effectiveness was assessed in only one study. Finally, adverse effects associated with exposure to the school-based physical activity interventions were generally not addressed in the published reports of studies.

\section{Effects of interventions}

See: Summary of findings for the main comparison Schoolbased physical activity programs for promoting physical activity and fitness in children and adolescents aged 6 to 18 years

The outcomes included in this review represent two broad outcome categories: behavior and physical health status. Specific outcomes related to behavior included: physical activity rates (five studies), duration of physical activity (23 studies), and time spent watching television (16 studies). Specific outcomes of physical health status included: mean systolic blood pressure (16 studies), mean diastolic blood pressure (16 studies), blood cholesterol level (10 studies), $\mathrm{BMI}$ (32 studies), $\mathrm{VO}_{2} \mathrm{max}$ (six studies), and pulse rate (six studies).

\section{Primary outcomes: behavior (physical activity)}

\section{Physical activity rates}

Seven studies reported results for physical activity rates in the original review (Alexandrov 1988; Fardy 1996; Klepp 1994; Marcus 1987; Petchers 1988; Simon 2004; Verstraete 2006). However, four of these were excluded from this update (Alexandrov 1988; Fardy 1996; Klepp 1994; Marcus 1987). In this update an additional two studies have been added to the results presented in Appendix 5 (Colin-Ramirez 2010; Dishman 2004). In total, this update includes five studies evaluating the impact of school-based physical activity interventions on physical activity rates.

Of these, four studies focused on grade school children only (ColinRamirez 2010; Petchers 1988; Simon 2004; Verstraete 2006), and one reported on grade school and secondary school students (Dishman 2004). All studies reported results for a mixed sample of boys and girls combined, except for Dishman 2004, who included girls only. All but one study evaluated impact on physical activity rates immediately following the intervention, while Colin-Ramirez 2010, evaluated impact one year post intervention.

The results were mixed. Two of the studies reported statistically significant positive effects on physical activity rates of children (Simon 2004; Verstraete 2006), and three did not report statistically significant effects (Colin-Ramirez 2010; Dishman 2004; Petchers 1988). Simon 2004 reported a statistically significant increase in physical activity rates in those exposed to the intervention compared to those in the control group $(P<0.0001)$, and found that intervention group children were almost three times more likely to be physically active outside of school compared to controls (OR 2.74). The $95 \% \mathrm{Cl}$ ranged from 2.01 to 3.75 . Verstraete 2006, who measured MVPA using accelerometers, also reported a statistically significant difference in moderate to vigorous physical activity (MVPA) among children in the intervention group compared to those in the control group $(P<0.01)$, although an effect size and $95 \% \mathrm{Cl}$ were not provided. Children in the intervention group experienced a smaller decrease in MVPA from baseline to followup (57\% to $53 \%$ ) compared to the control group (56\% to $44 \%$ ). The results reported by Colin-Ramirez 2010 and Dishman 2004 did not illustrate a trend toward a positive effect, and data to make this assessment were not available for Petchers 1988. The sample sizes of the five studies ranged from 235 to 2111 participants. It is likely all studies had significant power to detect a moderately large treatment effect. With the exception of Simon, the magnitude of effect is relatively small.

Of the two studies reporting statistically significant positive effects the intervention ranged from three months (Verstraete 2006) to four school years (Simon 2004), while for those reporting no effect the intervention ranged from one school year to 12 months. Interventions across all studies sought to increase MVPA in children during school hours, and all but one study (Verstraete 2006) included changes to the curriculum. Among the two studies showing statistically significant positive effects, one involved a comprehensive, intensive intervention comprised of school curriculum changes, printed education materials, greater time spent engaged in MVPA during the school day, audiovisual materials, and community-based strategies, while the second provided printed education materials, game equipment for children to play on, with play cards illustrating how the equipment was to be used. Intervention providers also varied widely from research staff, to teachers, to physical education (PE) teachers, nutritionists, and peers. One of the two studies reporting a statistically significant positive effect used accelerometers to measure physical activity rates (Verstraete 2006), while all other studies used self-report.

Generally, those studies not reporting a statistically significant effect on physical activity rates implemented similar combinations of interventions, (i.e. school curricula, physical activity sessions, parental involvement, and some community-based activities). Studies reporting a statistically significant positive effect differed slightly from those not reporting an effect on intervention provider, with the former using PE teachers and research staff, while the latter used classroom teachers to implement the intervention. 


\section{Duration of physical activity}

Duration of physical activity was reported in seven studies in the original review and all but one, Manios 1999, remained in this update (Bayne-Smith 2004; Ewart 1998; Haerens 2006; Luepker 1996; Robinson 1999; Stone 2003). Interestingly there was no overlap in studies between those that studied physical activity rates, and those that studied duration of physical activity. In this update 16 additional studies were identified that measured the impact of a school-based intervention on duration of physical activity (Araujo-Soares 2009; Barbeau 2007; Donnelly 2009; Haerens 2009; Jones 2008; Kriemler 2010; Lubans 2009; McManus 2008; Neumark-Sztainer 2009; Neumark-Sztainer 2010; Peralta 2009; Salmon 2008; Webber 2008; Weeks 2008; Williamson 2007; Wilson 2011). In addition, the results of one study in the original review, for which four-year post intervention data were published in 2008 have been added (Simon 2004). The results are presented in Appendix 6 . In total this update includes 23 studies reporting the impact of school-based physical activity interventions on physical activity duration.

Of these, 17 studies reported results for grade school children only (Araujo-Soares 2009; Barbeau 2007; Donnelly 2009; Haerens 2006; Haerens 2009; Jones 2008; Kriemler 2010; Luepker 1996; McManus 2008; Neumark-Sztainer 2009; Peralta 2009; Robinson 1999; Salmon 2008; Stone 2003; Webber 2008; Williamson 2007; Wilson 2011), two included grade school and secondary school students (Lubans 2009; Weeks 2008), and three reported results for adolescents only (Bayne-Smith 2004; Ewart 1998; NeumarkSztainer 2010). The majority of studies reported results for a mixed sample of boys and girls combined, two reported results for boys and girls separately, and three included girls only. Most studies measured impact on physical activity duration immediately post intervention, while one study measured impact at two weeks post intervention, one at five months, one at six months, one at nine months, one at 12 months, and one at four years. The length of the intervention ranged from 12 weeks to six years, with the median being one to two school years. Two studies in the original review (Ewart 1998; Stone 2003), and six in the update measured duration of physical activity using accelerometers (Kriemler 2010; Lubans 2009; McManus 2008; Peralta 2009; Webber 2008; Wilson 2011), although the majority still relied on self report.

Among the studies evaluating duration of physical activity among grade school children only, 12 studies reported statistically significant positive effects (Araujo-Soares 2009; Barbeau 2007; Donnelly 2009; Ewart 1998; Haerens 2006; Kriemler 2010; Luepker 1996; McManus 2008; Salmon 2008; Simon 2004; Stone 2003; Webber 2008), two of which measured duration of physical activity with accelerometers. However, while Haerens 2006 reported a statistically significant effect overall, further subgroup analysis demonstrated a significant effect for boys only. The remaining studies $(n=5)$ did not report a statistically significant effect on physical activity duration among grade school children. Among the two studies including both grade school and secondary school children, one did not report statistically significant effects (Lubans 2009), while the second reported a statistically significant effect in favor of the control group (Weeks 2008). One of three studies evaluating impact on adolescent girls reported a statistically significant positive effect (Ewart 1998) and two did not (BayneSmith 2004; Neumark-Sztainer 2010). The sample size of the studies ranged from 33 participants to 4019. There did not appear to be a trend indicating that studies with smaller sample sizes reported non-significant (NS) results more often than larger studies. However, it is possible that some studies with smaller sample sizes were underpowered to detect statistically significant changes in physical activity duration.

The magnitude of effect varied across studies reporting statistically significant effects from just under five $\mathrm{min}$ to $45 \mathrm{~min}$ more per week of MVPA, and the Cls ranged from as little as 1.4 min to approximately $90 \mathrm{~min}$ more per week of MVPA. Similar to physical activity rates, these findings generally represent a relatively modest magnitude of effect. In some studies participants in the intervention group engaged in MVPA longer than control group participants at follow-up, while in other studies, those in the intervention group had a smaller decrease in duration of physical activity in comparison to control group participants. Of the 14 studies in total reporting statistically significant positive effects for children and adolescents combined, the intervention was implemented over 18 weeks to several years. Generally, studies reporting statistically significant effects implemented the intervention over a longer period of time in comparison to those not reporting statistically significant effects. While specific combinations of interventions varied there were some similarities across the studies reporting positive effects. The intervention in all studies reporting statistically significant effects included changes to school curricula, and in many studies printed educational materials. Other interventions included education sessions, audiovisual materials, support groups, self contracts, and communitybased interventions. The intervention provider in the majority of studies was classroom teachers; however, other intervention providers included PE teachers, research workers, peers, and physical activity instructors. Generally, those studies not reporting statistically significant effects on duration of physical activity implemented similar combinations of interventions (i.e. printed educational materials, school curricula), by classroom teachers, but for a shorter period of time (i.e. 12 weeks to 10 months).

\section{Time spent watching television}

The impact of school-based interventions on television viewing was formerly reported by four studies all of which were included in this update (Burke 1998; Haerens 2006; Robinson 1999; Simon 2004). In this update 12 additional studies were added (Colin-Ramirez 2010; Gentile 2009; Jones 2008; Kipping 2008; Lubans 2009; NeumarkSztainer 2009; Neumark-Sztainer 2010; Peralta 2009; Salmon 2008; Singh 2009; Webber 2008; Williamson 2007). In addition four-year follow-up results for Simon 2004 published in 2008 have been included in this update. The results are presented in Appendix 7. In total this update includes 16 studies evaluating the impact of school-based physical activity interventions on television viewing.

Of these, 13 studies focused on grade school children only (Burke 1998; Colin-Ramirez 2010; Gentile 2009; Haerens 2006; Jones 2008; Kipping 2008; Neumark-Sztainer 2009; Peralta 2009; Robinson 1999; Salmon 2008; Simon 2004; Webber 2008; Williamson 2007), two reported on participants aged 12 to 14 (Lubans 2009; Singh 2009), and one reported on adolescents only (Neumark-Sztainer 2010). The results were generally reported for boys and girls combined, with results for girls only being reported in three studies (Jones 2008; Neumark-Sztainer 2010; Webber 2008), and one for boys only (Peralta 2009). Just over half of the studies measured television viewing immediately post intervention, with three measuring impact at six months (Gentile 2009; Peralta 2009; Neumark-Sztainer 2010) and four at 12 months (Colin-Ramirez 2010; Salmon 2008; 
Singh 2009; Webber 2008). All studies measured television viewing through self-report. The length of the intervention ranged from 12 weeks to two school years, with half of the studies implementing interventions for 20 weeks or less.

In total seven studies reported statistically significant positive effects on time spent watching television (Burke 1998; Gentile 2009; Jones 2008; Robinson 1999; Simon 2004; Singh 2009; Webber 2008), and one reported a statistically significant effect in favor of the control group (Salmon 2008). For the two studies reporting results for boys and girls separately, one study found a significant effect in grade school boys six months post intervention, but not in girls (Burke 1998), and the second study did not report a statistically significant effect (Haerens 2006). Of the six studies reporting statistically significant positive results, all demonstrated a significant decrease in the amount of time children spent watching television, compared to the control group. The magnitude of effect ranged from as little as five min less per day to as much as 60 min less per day of television viewing. For example Robinson 1999 reported a 50-minute decrease in television viewing per day, compared to $10 \mathrm{~min}$ per day in the control group $(P<0.001)$. Simon 2004 reported that participants exposed to the intervention were half as likely (OR 0.49) to spend more than three hours per day watching television compared to those in the control group $(\mathrm{P}<$ 0.0001 ); the $95 \% \mathrm{Cl}$ ranged from 0.35 to 0.69 . Burke 1998 reported that six months post intervention boys exposed to the intervention watched five min less per day of television compared to those in the control group $(P<0.01)$. Two studies, Singh 2009 and Webber 2008 , reported results at one year post intervention ( 3 hours and 1 hour less per week, respectively), while a third study, Gentile 2009 , reported results at six months post intervention ( 2 hours less per week). Only one study not reporting a statistically significant effect may have been underpowered to detect a significant effect. In studies reporting $95 \% \mathrm{Cls}$, reduction in television viewing ranged from approximately one minute less per week to two hours less per week, generally suggesting modest impact on television viewing, and drawing into question whether these reductions would result in reduced risk for the development of chronic diseases.

Among the seven studies reporting statistically significant effects the length of the interventions varied from 12 weeks to four years. Generally, there did not appear to be noteworthy differences in length of the intervention between studies reporting a statistically significant effect and those not. School curriculum was a component in all studies reporting statistically significant effects, with printed education materials, education sessions, and community-based strategies being implemented in almost all studies reporting statistically significant effects. Interventions occurring in only one study included: counseling, teacher training, physical activity sessions, audio-visuals materials, mass media, and support groups. Among studies reporting a statistically significant positive effect the intervention was more likely to be implemented by a member of the research team, followed by classroom teachers. Among studies not reporting a statistically significant effect, the intervention providers were somewhat more likely to be classroom teachers.

\section{Secondary outcomes: physical health status}

\section{Mean systolic blood pressure}

Ten studies reported results for mean systolic blood pressure in the original review (Alexandrov 1988; Bayne-Smith 2004; Burke
1998; Bush 1989; Ewart 1998; Graf 2005; Lionis 1991; Luepker 1996; Stephens 1998; Walter 1988). However, three were excluded from the update (Alexandrov 1988; Graf 2005; Lionis 1991). In this update eight additional studies have been added to the results presented in Appendix 8 (Angelopoulos 2009; Kriemler 2010; Martinez 2008; McManus 2008; Reed 2008; Walther 2009; Wang 2008; Young 2006). In addition, four-year post intervention results for Simon 2004, published in 2008 have been included for a total of 16 studies evaluating the impact of school-based physical activity interventions on mean systolic blood pressure.

Thirteen of 16 studies reported results for grade school children only (Angelopoulos 2009; Burke 1998; Bush 1989; Kriemler 2010; Luepker 1996; Martinez 2008; McManus 2008; Reed 2008; Simon 2004; Stephens 1998; Walter 1988; Walther 2009; Wang 2008), and three on children attending secondary school (Bayne-Smith 2004; Ewart 1998; Young 2006). All but two of the 13 studies involving grade school children reported results for the whole sample (Burke 1998; Martinez 2008), and all three studies involving students in secondary school included girls only (Bayne-Smith 2004; Ewart 1998; Young 2006). Twelve studies evaluated impact on mean systolic blood pressure immediately post intervention, while two measured the outcome at six months (Burke 1998; McManus 2008) one at nine months post intervention (Angelopoulos 2009) and one 4 years post intervention Simon 2004. Nine of the studies (Angelopoulos 2009; Burke 1998; Kriemler 2010; Luepker 1996; Martinez 2008; Reed 2008; Simon 2004; Wang 2008; Young 2006), measured blood pressure using an automated sphygmomanometer and the remainder were taken manually.

Four of the 16 studies reported statistically significant positive effects on mean systolic blood pressure (Angelopoulos 2009; Bayne-Smith 2004; Ewart 1998; Reed 2008), two of which used an automated sphygmomanometer (Angelopoulos 2009; Reed 2008). Two studies, Angelopoulos 2009 and Reed 2008, reported statistically significant positive effects on grade school children, and two studies, Ewart 1998 and Bayne-Smith 2004, on secondary school girls. On average, the intervention group experienced a 2 to $5 \mathrm{mmHg}$ reduction in systolic blood pressure in comparison to the control group. The sample sizes of the 12 studies not reporting statistically significant effects ranged from 90 to 4019 participants. It is likely that some of these studies were underpowered to detect a statistically significant effect. Furthermore, only one study (Wang 2008) appeared to demonstrate a trend toward a positive effect, while the remaining studies showed little to no difference in systolic blood pressure between the intervention and control groups.

Of the four studies reporting statistically significant positive effects the interventions were implemented for 12 weeks (BayneSmith 2004), 18 weeks (Ewart 1998), 11 months (Reed 2008), and 12 months (Angelopoulos 2009). Among studies reporting no effect, interventions ranged from 12 weeks to six years. Changes to the school curriculum were the only consistent component across all four studies reporting a positive effect. Communitybased strategies were used in two studies, and printed education materials and education sessions were used in one study each. In three of the four studies reporting a positive effect the intervention was provided by members of the research staff (Angelopoulos 2009; Ewart 1998; Reed 2008), and was not stated in the fourth study (Bayne-Smith 2004). Generally, the studies not reporting a statistically significant effect on mean systolic blood pressure used similar combinations of interventions, but tended to use classroom 
and PE teachers more often, and tended to be implemented for longer periods of time, in comparison to studies reporting statistically significant positive effects.

\section{Mean diastolic blood pressure}

Nine studies reported results for mean diastolic blood pressure in the original review (Bayne-Smith 2004; Burke 1998; Bush 1989; Ewart 1998; Graf 2005; Lionis 1991; Luepker 1996; Stephens 1998; Walter 1988). However, two were excluded from this update (Graf 2005; Lionis 1991). In this update an additional nine studies have been added to the results in Appendix 9 (Angelopoulos 2009; Kriemler 2010; Martinez 2008; McManus 2008; Reed 2008; Walther 2009; Wang 2008; Young 2006), including four-year post intervention results for Simon 2004 published in 2008.

Thirteen of 16 studies reported results for grade school children only (Angelopoulos 2009; Burke 1998; Bush 1989; Kriemler 2010; Luepker 1996; Martinez 2008; McManus 2008; Reed 2008; Simon 2004; Stephens 1998; Walter 1988; Walther 2009; Wang 2008), and three on children attending secondary school (Bayne-Smith 2004; Ewart 1998; Young 2006). All but two of the 13 studies involving grade school children reported results for the whole sample (Burke 1998; Martinez 2008), and all three studies involving students in secondary school included girls only (Bayne-Smith 2004; Ewart 1998; Young 2006). Twelve studies evaluated impact on mean diastolic blood pressure immediately post intervention, while two measured the outcome at six months (Burke 1998; McManus 2008) one at nine months post intervention (Angelopoulos 2009) and one at four years post intervention (Simon 2004). Nine of the studies (Angelopoulos 2009; Burke 1998; Kriemler 2010; Luepker 1996; Martinez 2008; Reed 2008; Simon 2004; Wang 2008; Young 2006) measured blood pressure using an automated sphygmomanometer and the remainder were taken manually.

Three of the 16 studies reported statistically significant positive effects on mean diastolic blood pressure (Angelopoulos 2009; Bayne-Smith 2004; Bush 1989), one of which used an automated sphygmomanometer (Angelopoulos 2009). Two studies (Angelopoulos 2009; Bush 1989) reported statistically significant positive effects on grade school children, while Martinez 2008 reported a statistically significant negative effect on grade school boys and no effect on girls. Bayne-Smith 2004 reported a significant positive effect on secondary school girls. Among the three studies reporting positive effects, on average the intervention group experienced a 3 to $4 \mathrm{mmHg}$ reduction in mean diastolic blood pressure in comparison to the control group. Martinez 2008 found boys in the control group had a $2 \mathrm{mmHg}$ greater reduction in mean diastolic blood pressure in comparison to boys in the intervention group. The remaining 12 studies did not report statistically significant effects on mean diastolic blood pressure, and no studies showed a trend toward a positive effect. The sample sizes of the studies ranged from 90 to 4019 participants. It is likely that some of the studies were underpowered to detect a statistically significant effect.

Of the three studies reporting statistically significant positive effects the interventions were implemented for 12 weeks (BayneSmith 2004), 12 months (Angelopoulos 2009), and four years (Bush 1989). Among studies not reporting a statistically significant effect, interventions ranged from 12 weeks to six years. Changes to the school curriculum were the only consistent component across all three studies reporting statistically significant positive effects.
Printed education materials were used in two of the three studies, and counseling was also used in one study. Intervention providers included members of the research staff (Angelopoulos 2009; Bush 1989; Martinez 2008) for studies showing both statistically significant positive and negative effects. Classroom teachers were also used in one study reporting a positive effect. Generally, the studies not reporting a statistically significant effect on mean diastolic blood pressure used similar combinations of interventions, but tended to use classroom and PE teachers more often, in comparison to studies reporting a statistically significant positive effect.

\section{Mean blood cholesterol level}

Seven studies reported results for mean total blood cholesterol level in the original review (Alexandrov 1988; Bayne-Smith 2004; Bush 1989; Lionis 1991; Luepker 1996; Manios 1999; Walter 1988). However, three of them have been excluded from this update (Alexandrov 1988; Lionis 1991; Manios 1999). In this update an additional five studies have been added to the results in Appendix 10 (Martinez 2008; Reed 2008; Walther 2009; Wang 2008; Young 2006). In addition, four-year post intervention results for Simon 2004, published in 2008, have been added. In total 10 studies evaluating the impact of school-based physical activity interventions on mean blood cholesterol $(\mathrm{mg} / \mathrm{dL})$ were included in this update.

All but two studies focused on grade school children, with BayneSmith 2004 and Young 2006 including girls in secondary school only. One of the eight studies focused on grade school children reported results for boys and girls separately (Martinez 2008), the remainder reported results for boys and girls combined. All of the studies evaluated impact on mean blood cholesterol immediately post intervention. Most studies measured fasting blood cholesterol.

Only one of the 10 studies reported a statistically significant positive effect on mean blood cholesterol (Walter 1988), and in that study only schools in the intervention group from a higher socioeconomic status reported a statistically significant positive effect. No other studies reported statistically significant changes in mean blood cholesterol at the end of the intervention in comparison to controls. Walter 1988 reported a $2 \mathrm{mg} / \mathrm{dL}$ decrease in mean blood cholesterol among boys and girls of higher socioeconomic status in comparison to children in the control group. The sample sizes of these studies ranged from 188 to 4019 participants. It is likely that some of these studies were underpowered to detect a statistically significant effect. There also did not appear to be a trend toward a positive effect.

There were no differences between the one study reporting a statistically significant positive effect (Walter 1988) and the remaining studies not reporting a statistically significant effect with respect to intervention strategies or duration. All studies measuring mean blood cholesterol $(\mathrm{mg} / \mathrm{dL})$ used school curriculum, and the majority also used printed educational materials. Some also used community-based strategies (Bush 1989; Luepker 1996; Simon 2004; Walter 1988). The duration ranged from 12 weeks to four years.

\section{Body mass index (BMI)}

Fourteen studies reported results for BMI in the original review (Alexandrov 1988; Bayne-Smith 2004; Burke 1998; Bush 1989; Carrel 
2005a; Ewart 1998; Haerens 2006; Lionis 1991; Luepker 1996; Manios 1999; Robinson 1999; Sallis 1997; Stone 2003; Walter 1988). However, five of these were excluded from this update (Alexandrov 1988; Carrel 2005a; Lionis 1991; Manios 1999; Sallis 1997). In this update an additional 22 studies have been added to the results presented in Appendix 11 (Angelopoulos 2009; Barbeau 2007; Donnelly 2009; Dorgo 2009; Gentile 2009; Kipping 2008; Kriemler 2010; Li 2010; Martinez 2008; McManus 2008; Neumark-Sztainer 2009; Neumark-Sztainer 2010; Peralta 2009; Reed 2008; Salmon 2008; Singh 2009; Singhal 2010; Wang 2008; Webber 2008; Weeks 2008; Williamson 2007; Young 2006). In addition, four year post intervention results for Simon 2004 published in 2008 have been added. In total, this update includes 32 studies evaluating the impact of school-based physical activity interventions on BMI.

Of these, 23 studies focused on grade school children only (Angelopoulos 2009; Barbeau 2007; Burke 1998; Bush 1989; Donnelly 2009; Gentile 2009; Haerens 2006; Kipping 2008; Kriemler 2010; Luepker 1996; Martinez 2008; McManus 2008; NeumarkSztainer 2009; Peralta 2009; Reed 2008; Robinson 1999; Salmon 2008; Simon 2004; Stone 2003; Walter 1988; Wang 2008; Webber 2008; Williamson 2007), seven on adolescents in secondary school only (Bayne-Smith 2004; Dorgo 2009; Ewart 1998; Li 2010; NeumarkSztainer 2010; Singhal 2010; Young 2006), and two with both grade school and secondary school children (Singh 2009; Weeks 2008). Twenty-one of the studies reported results for a mixed sample of boys and girls combined, five for boys and girls separately (Burke 1998; Haerens 2006; Martinez 2008; Singh 2009; Weeks 2008), six studies included girls only (Barbeau 2007; Bayne-Smith 2004; Ewart 1998; Neumark-Sztainer 2010; Webber 2008; Young 2006), and one included only boys (Peralta 2009). Twenty-four of the thirty-two studies evaluated impact on BMI immediately post-intervention, three at approximately six months post-intervention (Gentile 2009; Neumark-Sztainer 2010; Peralta 2009), three at 12 months (Li 2010; Salmon 2008; Singh 2009), one at three years post-intervention (Luepker 1996) and one at four years post intervention Simon 2004.

Overall eight of the 32 studies reported statistically significant positive effects on BMI in favor of the intervention (Angelopoulos 2009; Barbeau 2007; Burke 1998; Haerens 2006; Kriemler 2010; Li 2010; Robinson 1999; Salmon 2008), while one study reported a statistically significant effect in favor of the control group (Weeks 2008). One additional study showed a strong trend toward a positive effect following four years of intervention (Simon 2004), while most did not appear to have a trend toward a positive effect. Five studies reported statistically significant positive effects on a mixed sample of boys and girls (Angelopoulos 2009; Kriemler 2010; Li 2010; Robinson 1999; Salmon 2008), one for boys only (Burke 1998), and two for girls only (Barbeau 2007; Haerens 2006). All studies reporting a statistically significant positive effect on BMI, demonstrated a smaller increase in BMI from baseline to followup for those in the intervention group compared to those in the control group. On average, the intervention group experienced an increase of 0.1 to $1.0 \mathrm{~kg} / \mathrm{m}^{2}$ less in comparison to those in the control group. In only one study (Salmon 2008) was a larger effect size noted, with the intervention group gaining $1.5 \mathrm{~kg} / \mathrm{m}^{2}$ less than the control group, with the $95 \% \mathrm{Cl}$ ranging from -2.8 to $-0.2 \mathrm{~kg} /$ $\mathrm{m}^{2}$. The effect of baseline weight as a moderating variable varied among studies. In one study (Singh 2009), a statistically significant effect on BMI was observed among non-overweight children in the intervention group, but not among those who were overweight or obese at baseline. In contrast, another study found the intervention was only effective in preventing weight gain (increased BMI) among those children in the intervention group who were overweight or obese at baseline but not among those who were not overweight (Li 2010). The sample sizes of the studies ranged from 32 to 4120 participants. While it is likely that some of the studies not reporting statistically significant effects were underpowered to detect a statistically significant effect, the majority did have sufficient power to see a significant effect.

Of the eight studies reporting statistically significant positive effects, the intervention was implemented for six months in one study (Robinson 1999), nine months in two studies (Burke 1998; Kriemler 2010), 10 months in one study (Barbeau 2007), one year in three studies (Angelopoulos 2009; Li 2010; Salmon 2008), and two years in one study (Haerens 2006). While specific combinations of interventions varied there were some similarities across the eight studies. For example, the intervention in all studies included changes to the school curriculum. All studies used printed education materials, while three studies included community-based strategies (Burke 1998; Haerens 2006; Kriemler 2010), and three included education sessions (Burke 1998; Kriemler 2010; Salmon 2008). Two studies used audio-visual materials (Li 2010; Robinson 1999), and two included physical activity sessions (Barbeau 2007; Li 2010). Other strategies used by only one study included support groups (Haerens 2006), counseling (Burke 1998), and self contracts (Salmon 2008). In four of the studies reporting a statistically significant positive effect the intervention providers were classroom teachers (Barbeau 2007; Burke 1998; Haerens 2006; Robinson 1999), while in two studies PE teachers were primarily responsible for implementing the intervention (Kriemler 2010; Salmon 2008). In two studies the intervention was provided by either members of the research staff or a psychologist,

PE teacher, or a multidisciplinary healthcare team. Generally, the 24 studies not reporting a statistically significant effect on BMI used similar combinations of interventions implemented by similar combinations of providers for similar lengths of time.

\section{Maximal oxygen consumption $\left(\mathrm{VO}_{2}\right.$ max $)$}

Five studies reported results for $\mathrm{VO}_{2} \mathrm{max}$ in the original review (Bayne-Smith 2004; Carrel 2005a; Eliakim 1996; Fardy 1996; Trevino 2004). However, three were excluded from this update (Carrel 2005a; Eliakim 1996; Fardy 1996). In this update four additional studies have been added to the results presented in Appendix 12 (Barbeau 2007; McManus 2008; Walther 2009; Wang 2008). In total six studies evaluating the impact of school-based physical activity interventions on $\mathrm{VO}_{2 \max }$ were included.

Of these, five studies focused on grade school children (Barbeau 2007; McManus 2008; Trevino 2004; Walther 2009; Wang 2008) and one on those attending secondary school (Bayne-Smith 2004). Four studies reported results for boys and girls combined (McManus 2008; Trevino 2004; Walther 2009; Wang 2008), and two included girls only (Barbeau 2007; Bayne-Smith 2004). All but one study evaluated impact on $\mathrm{VO}_{2}$ max immediately post intervention, with the one study reporting results at six months post intervention (McManus 2008). Two studies measured $\mathrm{VO}_{2}$ max through blood gases after exertion (Barbeau 2007; McManus 2008), and four measured heart rate recovery following exertion as a proxy for $\mathrm{VO}_{2}$ max (Bayne-Smith 2004; Trevino 2004; Walther 2009; Wang 2008). 
Four of the six studies reported statistically significant positive effects on $\mathrm{VO}_{2} \max$ (Barbeau 2007; Trevino 2004; Walther 2009; Wang 2008). Statistically significant positive effects were observed among grade school children only. The results illustrate a positive improvement in $\mathrm{VO}_{2}$ max across studies ranging from 1.6 to $3.7 \mathrm{~mL} /$ $\mathrm{kg}$ per min, while a fourth study reported a lower heart rate by 4 beats/min after strenuous exercise following the intervention. Barbeau 2007 found children in the intervention group increased their $\mathrm{VO}_{2}$ max by $1.6 \mathrm{~mL} / \mathrm{kg}$ per min, while Trevino 2004 reported an increase of $1.9 \mathrm{~mL} / \mathrm{kg}$ per min, and Walther 2009 reported an increase of $3.7 \mathrm{~mL} / \mathrm{kg}$ per min. The $95 \% \mathrm{Cls}$ ranged from 0.2 to 7.2 $\mathrm{mL} / \mathrm{kg}$ per min. The sample sizes of these two studies ranged from 182 to 1221 participants. It is possible that one of the two studies not reporting a statistically significant effect was underpowered to detect a significant differences.

Studies reporting a positive effect made changes to the school curriculum, two also included printed education materials, and one included education sessions. Classroom teachers implemented the intervention in two of the studies reporting positive effects and were unknown in the remaining studies. Generally, the two studies not reporting statistically significant effects used similar combinations of interventions implemented for similar lengths of time, although the intervention provider is unknown in these studies.

\section{Pulse rate}

Five studies reported results for pulse rate in the original review (Bush 1989; Ewart 1998; Luepker 1996; Stephens 1998; Walter 1988). All of these studies were retained in this update. One additional study was added in this update (McManus 2008). In total six studies were included in this update evaluating the impact of school-based physical activity interventions on pulse rate.

Of these, five studies focused on grade school children (Bush 1989; Luepker 1996; McManus 2008; Stephens 1998; Walter 1988), and one on adolescents (Ewart 1998). The results are summarized in Appendix 13. One study included adolescent females in secondary school only (Ewart 1998), and the other five studies reported results for a sample of boys and girls combined. All studies evaluated impact on pulse rate immediately post intervention.

Only one study reported a statistically significant positive effect on pulse rate (Luepker 1996). One other study (Stephens 1998) reported a statistically significant positive effect, but on pulse rate during maximal exercise and recovery $(P<0.05)$, rather than resting pulse rate. Interestingly, Luepker 1996 did not observe a statistically significant effect immediately following the three-year intervention, but rather at three years post intervention $(P<0.03)$. All five remaining studies did not report a statistically significant effect. The sample sizes of the studies ranged from 88 to 4019 participants. It is likely that some of the studies were underpowered to detect a statistically significant effect. Furthermore, of those that provided data on pulse rate, one demonstrated a trend toward a positive effect, and the others did not.

\section{DISCUSSION}

\section{Summary of main results}

Generally the results of this update are for the most part unchanged from those reported in the original review with two exceptions.
Whereas in the original review we found school-based physical activity interventions had a positive impact on duration of MVPA, television viewing, blood cholesterol, and $\mathrm{VO}_{2}$ max, in this update, the positive effect on blood cholesterol was no longer observed. However, the magnitude of effect for duration of MVPA, television viewing, and $\mathrm{VO}_{2} \mathrm{max}$, remained the same in the update as in the original review. Also, in this review there is some limited evidence to suggest that school-based physical activity interventions may have a positive effect on physical activity rates in children, meaning there was some limited evidence to suggest that school-based interventions were effective in increasing the proportion of children who engaged in MVPA during school hours. This was not observed in the original review. There is also some limited evidence in this update that these positive effects are maintained in the longer term, (i.e. six months to four years), although only a small number of studies measured outcomes beyond the end of the intervention. However, this also demonstrates an improvement from the original review in that evidence now exists, where it did not previously, that positive effects can be maintained in the longer term on outcomes such as duration and rate of physical activity, and $\mathrm{VO}_{2}$ max.

The evidence suggests that school-based physical activity interventions of longer duration may be needed to effect change in duration and rate of physical activity and $\mathrm{VO}_{2}$ max among grade school children. However, the evidence is less convincing for those attending secondary school. The evidence also suggests that effective school-based interventions include some combination of school curricula, printed educational materials, and likely, though there is less evidence to support it, educational sessions, physical activity specific sessions, and community-based initiatives. In order to produce sustainable effects, it may be necessary to widen the scope of the intervention to include the community so as to promote multiple environments that support active living as children move from childhood to adolescence to adulthood. Community-based strategies have been shown to be somewhat effective in promoting healthy behavior among populations (Dobbins 2011). Careful consideration of the similarities between the study population and local populations may be helpful in ascertaining the likelihood of local initiatives achieving a positive effect if the same intervention was implemented. There is only limited evidence that boys and girls respond differently to school-based interventions as well as different components of interventions from the studies included in this review. Given known gender differences in determinants of physical activity (DiLorenzo 1998), future research in this field should test various genderspecific strategies within the school setting.

Given the primary focus of many of the studies was to promote physical activity it was surprising only five studies reported physical activity rates as an outcome. In addition, it is interesting to note that there was no overlap in studies measuring rates of physical activity and those measuring duration. However, in this update significantly more studies measured duration of MVPA ( $\mathrm{n}$ = 23) representing a positive trend toward the measurement of important outcomes when evaluating the effectiveness of physical activity promotion interventions.

In this update there continues to be limited overlap between those studies measuring physical activity rate or duration and $\mathrm{VO}_{2}$ max. For example, there was only one study that measured both physical activity rate and $\mathrm{VO}_{2}$ max in the original review and one other that 
measured duration of physical activity and $\mathrm{VO}_{2}$ max. After excluding studies based on the revised inclusion/exclusion criteria, in this update there were no studies measuring both physical activity rate and $\mathrm{VO}_{2} \mathrm{max}$, and only three studies measuring both physical activity duration and $\mathrm{VO}_{2}$ max.

While new evidence suggests some promise with respect to the longer-term impact of school-based physical activity interventions on physical activity duration and rate, and $\mathrm{VO}_{2} \mathrm{max}$, ongoing efforts to evaluate impact in the long term are needed. It is important, especially for those interventions having positive effects, for outcomes to be measured in the long term so that these results can better inform policy and program decision making at multiple levels.

All of the interventions included in this review were multifaceted interventions focused on changing multiple risk behaviors associated with adult-onset CVD. Some of the multiple components addressed in these studies were physical activity, nutrition, and smoking. Although empirical evidence (Thomas 1999) and theoretical frameworks suggest that CVD risk reduction strategies should target multiple high-risk behaviors simultaneously, it is unclear from the results of this update how these multicomponent strategies interact to impact on indicators of physical activity or fitness measures. Given that exposure (dose) to the physical activity interventions was assessed in just a small number of studies, it is conceivable that more emphasis was placed on CVD risk reduction strategies other than physical activity, thereby providing insufficient exposure to physical activity interventions to produce significant behavioral or fitness changes. An alternative hypothesis might be that children and adolescents have a limited capacity at any given time to adopt new behaviors and absorb new knowledge, and interventions simultaneously addressing multiple factors such as nutrition, physical activity, and smoking, may be overwhelming.

At this time there is some limited evidence to suggest that schoolbased physical activity interventions have a small to moderate impact on behavioral outcomes related to physical activity as well as on one physical health status measure. However, at best the evidence is of moderate risk of bias, and therefore must be used cautiously. Furthermore, adverse effects as a result of the schoolbased physical activity interventions were generally not reported upon by the studies included in this update. Future studies should seek to determine if there are any adverse effects experienced by children and adolescents as a result of the intervention.

\section{Overall completeness and applicability of evidence}

A comprehensive search of RCTs was conducted. While it is possible that some studies were missed by our search strategy, we anticipate that this number would be small, and that the results of our review have not been significantly impacted upon. The studies included in this review are generally applicable to public health practice in developed countries. However, it is not clear if these findings are applicable to low- and middle-income countries particularly among those where the public health sector system or school systems (or both) are different, or when cultural differences are taken into account. Future research should evaluate schoolbased physical activity interventions in low- and middle-income countries.

\section{Quality of the evidence}

As discussed previously there are a number of limitations inherent in the studies included in this review that reduce the overall methodological quality of this evidence. As such the results must be interpreted cautiously and likely overestimate the true treatment effect. Specific limitations include: lack of blinding particularly of outcome assessors, lack of consistency in how outcomes are measured, reliance on self-reported outcomes for most behavioral outcomes, and a lack of description of the process used to randomly allocate participants to intervention and control groups. Furthermore, a number of studies experienced high attrition rates as well as incomplete outcome data. This as well likely contributed to an overestimation of the treatment effect, given those engaging in the intervention may have been more likely to complete the study and data collection, and therefore biasing the results toward a positive effect. However, on a positive note, significant improvements in the quality of the evidence were observed from the original review to this update.

While the majority of outcomes were assessed using measures with at least some degree of demonstrated reliability and validity, most of the behavioral outcomes were measured through selfreport (except for a small, albeit growing, number of studies using accelerometers), while the physical health status outcomes were measured through more objective means. In only nine of 25 studies were more objective outcome measurements obtained from pedometers or accelerometers on time spent engaged in physical activity, and only one of 14 studies did not rely on selfreport to measure time spent watching television. For physical health status measures such as systolic and diastolic blood pressure and BMI, in almost all studies it is unclear if the outcome assessors were blinded to study allocation. This represents an important risk of bias for this literature and likely resulted in either overestimating the treatment effect or finding a statistically significant positive effect where one did not exist. This alone may explain why a positive impact was observed for the behavioral outcomes, while a positive effect was observed for only one of the six physical health status outcomes.

However, the explanation cannot be so simplistic, at least not for duration of physical activity. For this outcome, 14 of 23 studies demonstrated a positive effect, and of those five studies measured duration of physical activity with an accelerometer. This detracts from the argument that the ways in which the outcomes were measured is responsible for the difference in positive effects observed between the behavioral outcomes versus the physical health status outcomes.

\section{Potential biases in the review process}

It is possible that bias was introduced during the review process despite the implementation of strategies to reduce bias. Most notably, it was not possible to conduct searches in databases that are not English. For example articles published in Chinese that were not indexed in English language databases were not eligible for inclusion. However, the review team recognizes a growing body of evidence in physical activity promotion being produced in Chinese. It is likely in subsequent updates that additional search strategies to ensure non-English publications are assessed for eligibility. Given a meta-analysis was not conducted, it is possible that the review team may have overestimated treatment effects when interpreting the results across studies. While efforts were 
undertaken to minimize this bias (multiple review authors were involved in interpreting the results and provided comments on drafts of this update) it is still possible that we have interpreted the results to be more positive than they actually are. Consumers of this review are cautioned therefore to examine the results carefully across studies.

The variability in these findings may be indicative of the limitations and difficulties inherent in doing community-based research where randomization to treatment groups, blind assessment, reliable and valid outcome measures, and prevention of co-intervention are difficult to control. It also demonstrates the difficulty in measuring outcomes associated with physical activity, both from a physiologic as well as a behavior perspective. Inconsistent findings in these studies can further be attributed to: a) variability in strategies used and in the frequency, intensity, and duration of interventions; b) the use of various theoretical models to guide the intervention; c) using a variety of instruments with varying reliability and validity to assess physical activity or physical fitness (or both); and d) follow-up periods of different durations. Many of these studies have reported modest change in levels of physical activity, physical fitness rates, or both. Lack of change in leisure time physical activity or physical fitness, in turn, has been attributed most often to issues of: a) inadequate dose (Tolfrey 2000); b) poor compliance (Baranowski 1990); c) inattention to the multiplicity of risk factors for physical inactivity and subsequent overly simplistic, unidimensional interventions; d) methodologic errors in measuring fitness (e.g. assessing heart rate only after, as opposed to during, activity); and e) a failure to control for potentially confounding variables (Tolfrey 2000).

\section{Agreements and disagreements with other studies or reviews}

The findings of this update are consistent with the findings of reviews conducted by Flynn 2006, Reilly 2003, Thomas 2004a, and Waters 2011, who reported mixed results regarding the effectiveness of interventions to prevent obesity, promote healthy eating, and promote physical activity in children and adolescents. An additional review by Hillsdon 2005 also reported similar results among adults for interventions to promote physical activity. Furthermore, a review of studies evaluating the impact of physical activity interventions reported increased physical activity among adolescent girls (Brown 2009), and another found a positive effect on fitness measures in children generally (Trudeau 2008). Others have found that while children and adolescents can experience increased levels of MVPA, this does not necessarily translate into reduced BMI (Cawley 2007; Gonzalez-Suarez 2009; Harris 2009). Similar results were reported by Summerbell 2005, who found little to no impact of obesity prevention interventions in children. However, an update to this review by Waters 2011 indicated there is evidence to suggest that obesity prevention strategies are effective in reducing BMI among children aged 6 to 12 years. However, it is important to point out that there was significant heterogeneity of results across studies and that overall, the magnitude of effect reported by Waters 2011 generally was small. Another meta-analysis of school-based obesity prevention interventions found a positive effect on weight, and clearly argued the need for ongoing school-based intervention (Katz 2009). While these additional reviews suggest that school-based interventions may be effective in preventing and reducing obesity in children, the result of our update indicate that focusing on physical activity may be insufficient to address issues of healthy weight adequately, and that a comprehensive approach focused on physical activity and diet, at a minimum, may be needed to impact weight in children significantly. Furthermore, the results of Waters 2011 illustrate that strategies outside of the school setting in addition to schoolbased strategies are likely needed. The findings of this update as well as other reviews suggest that schools are an important setting in which to promote physical activity. Almost all recent reviews illustrate that school-based physical activity interventions do result in children and adolescents spending more time engaged in MVPA and in some instances this translates into improved fitness measures. The finding in this review that changes to BMI were not observed, does not suggest that school-based interventions are not effective, but may suggest that a more comprehensive approach (e.g. home, community, policy) is needed and as suggested in the original review, that BMI may not be an appropriate measure to evaluated the effectiveness of interventions to promote physical activity among children. Future reviews should consider additional outcomes such as percentage body fat and abdominal girth.

\section{AUTHORS' CONCLUSIONS}

\section{Implications for practice}

The implications for public health practice, based on the findings of this update, are not as clear as one might wish. Nonetheless, the following are suggestions for consideration by public health practitioners, decision makers, and policy makers at this time.

1. Since school-based physical activity interventions are associated with some positive effects, such activities should continue and be encouraged by public health to local schools and school boards.

2. School-based physical activity interventions should be focused on fostering positive attitudes toward physical activity and should be geared toward the developmental level of students.

3. Teachers and school staff should encourage children and adolescents to be more physically activity during the course of the school day. This may require some dramatic changes within the working environment of teachers and school staff.

4. Parental involvement could be an integral part of school-based interventions.

5. More emphasis should be placed on promoting physical activity within school-based interventions (i.e. making physical activity a priority along with other healthy behaviors).

6. Public health staff should work in collaboration with teachers, schools, and school boards to lobby local and provincial policy makers to increase resources for the promotion of physical activity within the school system.

\section{Implications for research}

There are many gaps in the literature that require considerable exploration, and subsequently, systematic reviews.

1. Research must take care to assess the impact of school-based physical activity interventions more often on physical activity rates and duration and intensity of physical activity.

2. More research is needed to assess the validity and appropriateness of outcomes that represent program effectiveness of school-based physical activity interventions for children and adolescents. Additional outcomes that should be 
assessed to evaluate intervention effectiveness should include: student satisfaction, health-related quality of life, self-esteem, self-efficacy for physical activity, reduction in alcohol/drug consumption, involvement in extracurricular activities, and cost-effectiveness.

3. Research is needed to assess the impact of physical activity strategies that take into account the known barriers and facilitators of physical activity among children and adolescents, particularly among those of various socioeconomic status and ethnicity and urban/rural location.

4. Additional subgroup analysis including an examination of the differences in physical activity by gender as well as age and ethnicity, and the impact of strategies that take into account the different factors that affect physical activity among males and females and children and adolescents must be examined.

5. All outcomes related to the impact of school-based physical activity interventions require follow-up data so that the longterm impact of these interventions can be determined.
6. To increase the depth of knowledge in this field, national granting agencies need to make research related to physical activity promotion a major priority and recognize the need to fund projects that span multiple years of intervention implementation and evaluation.

\section{ACKNOWLEDGEMENTS}

We gratefully acknowledge the support and contribution of the Effective Public Health Practice Project in the initial systematic review of this literature in 1999, upon which this updated systematic review stems from, as well as the contribution of Elena Goldblatt, City of Hamilton Public Health Librarian, who developed the original search strategies. We also gratefully acknowledge Paula Robeson and Daiva Tirilis who contributed as authors to the original review published in The Cochrane library. 


\section{R E F E R E N C E S}

\section{References to studies included in this review}

Angelopoulos 2009 \{published data only\}

* Angelopoulos PD, Milionis HJ, Grammatikaki E, Moschonis G, Manios Y. Changes in BMI and blood pressure after a school based intervention: the CHILDREN study. European Journal of Public Health 2009;19(3):319-25.

\section{Araujo-Soares 2009 \{published data only\}}

* Araujo-Soares V, McIntyre T, MacLennan G, Sniehotta FF. Development and exploratory cluster-randomised opportunistic trial of a theory-based intervention to enhance physical activity among adolescents. Psychology \& Health 2009;24(7):805-22.

\section{Barbeau 2007 \{published data only\}}

* Barbeau P, Johnson MH, Howe CA, Allison J, Davis CL, Gutin B, et al. Ten months of exercise improves general and visceral adiposity, bone, and fitness in black girls. Obesity 2007;15(8):2077-85

\section{Bayne-Smith 2004 \{published data only\}}

* Bayne-Smith M, Fardy PS, Azzollini A, Magel J, Schmitz KH, Agin D. Improvements in heart health behaviors and reduction in coronary artery disease risk factors in urban teenaged girls through a school-based intervention: the PATH program. American Journal of Public Health 2004;94(9):1538-43.

Burke 1998 \{published data only\}

* Burke V, Milligan RA, Thompson C, Taggart AC, Dunbar DL, Spencer $\mathrm{MJ}$, et al. A controlled trial of health promotion programs in 11-year-olds using physical activity "enrichment" for higher risk children. Journal of Pediatrics 1998;132(5):840-8.

\section{Bush 1989 \{published data only\}}

* Bush PJ, Zuckerman AE, Theiss PK, Taggart VS, Horowitz C, Sheridan MJ, et al. Cardiovascular risk factor prevention in black schoolchildren: two-year results of the "Know Your Body" program. American Journal of Epidemiology 1989;129(3):466-82.

Taggart VS, Bush PJ, Zuckerman AE. A process evaluation of the District of Columbia "Know Your Body" project. Journal of School Health 1990;60(2):60-6.

\section{Colin-Ramirez 2010 \{published data only\}}

Colin-Ramirez E, Castillo-Martinez L, Orea-Tejeda A, Vergara A, Villa AR. Impact of a school-based intervention to cardiovascular risk factors prevention (RESCATE) on physical activity and diet in Mexican children aged 8-10 years [Efecto de una intervencion escolar basada en actividad fisica y dieta para la prevencion de factores de riesgo cardiovascular (RESCATE) en ninos mexicanos de 8 a 10 anos]. Revista Espanola de Nutricion Comunitaria 2009;15(2):71-80.

Colin-Ramirez E, Castillo-Martinez L, Orea-Tejeda A, VergaraCastaneda A, Keirns-Davis C, Villa-Romero A. Outcomes of a school-based intervention (RESCATE) to improve physical activity patterns in Mexican children aged 8-10 years. Health Education Research 2010;25(6):1042-9.
Dishman 2004 \{published data only\}

* Dishman RK, Motl RK, Saunders R, Felton G, Ward DS, Dowda M. Self-efficacy partially mediates the effect of a schoolbased physical-activity intervention among adolescent girls. Preventive Medicine 2004;38(5):628-36.

Pate RR, Ward DS, Saunders RP. Promotion of physical activity among high-school girls: a randomized controlled trial. American Journal of Public Health 2005;95:1582-7.

Saunders RP, Ward D, Felton GM, Dowda M, Pate RR. Examining the link between program implementation and behavior outcomes in the Lifestyle Education for Activity Program (LEAP). Evaluation and Program Planning 2006;29(4):352-63.

Ward DS, Saunders R, Felton GM, Williams E, Epping JN, Pate RR. Implementation of a school environment intervention to increase physical activity in high school girls. Health Education Research 2006;21(6):896-910.

\section{Donnelly 2009 \{published data only\}}

* Donnelly JE, Greene JL, Gibson CA, Smith BK, Washburn RA, Sullivan DK, et al. Physical Activity Across the Curriculum (PAAC): a randomized controlled trial to promote physical activity and diminish overweight and obesity in elementary school children. Preventive Medicine 2009;49(4):336-41.

DuBose KD, Eisenmann JC, Donnelly JE. Aerobic fitness attenuates the metabolic syndrome score in normal-weight at-risk-for-overweight, and overweight children. Pediatrics 2007;120:e1262-68.

DuBose KD, Mayo MS, Gibson CA, Green JL, Hill JO, Jacobsen DJ, et al. Physical activity across the curriculum (PAAC): rationale and design. Contemporary Clinical Trials 2008;29(1):83-93.

Dubose KD, Stewart EE, Charbonneau SR, Mayo MS, Donnelly JE. Prevalence of the metabolic syndrome in elementary school children. Acta Paediatrica 2006;95:1005-11.

Eisenmann JC, DuBose KD, Donnelly JE. Fatness, fitness, and insulin sensitivity among 7 - to 9 -year-old children. Obesity 2007;15(8):2135-44.

Gibson CA, Smith BK, DuBose KD, Greene JL, Bailey BW, Williams SL, et al. Physical activity across the curriculum: year one process evaluation results. International Journal of Behavioral Nutrition and Physical Activity 2008;5:36.

Honas JJ, Washburn RA, Smith BK, Greene JL, Donnelly JE. Energy expenditure of the physical activity across the curriculum intervention. Medicine \& Science in Sports \& Exercise 2008;40(8):1501-5.

Dorgo 2009 \{published data only\}

* Dorgo S, King GA, Candelaria NG, Bader JO, Brickey GD, Adams CE. Effects of manual resistance training on fitness in adolescents. Journal of Strength \& Conditioning Research 2009;23(8):2287-94. 


\section{Ewart 1998 \{published data only\}}

Ewart CK, Loftus KS, Hagberg JM. School-based exercise to lower blood pressure in high-risk African American girls: project design and baseline findings. Journal of Health Education 1995;26(2):S99-105.

* Ewart CK, Young DR, Hagberg JM. Effects of school-based aerobic exercise on blood pressure in adolescent girls at risk for hypertension. American Journal of Public Health 1998;88(6):949-51.

\section{Gentile 2009 \{published data only\}}

Eisenmann JC, Gentile DA, Welk GJ, Callahan R, Strickland S, Walsh M, et al. SWITCH: rationale, design, and implementation of a community, school, and family-based intervention to modify behaviors related to childhood obesity. BMC Public Health 2008;8:223.

* Gentile DA, Welk G, Eisenmann JC, Reimer RA, Walsh DA, Russell DW, et al. Evaluation of a multiple ecological level child obesity prevention program: Switch What you Do, View, and Chew. BMC Medicine 2009; 7:49.

\section{Haerens 2006 \{published data only\}}

Haerens L, Cerin E, Maes L, Cardon G, Deforche B, De Bourdeaudhuij I. Explaining the effect of a 1-year intervention promoting physical activity in middle schools: a mediation analysis. Public Health Nutrition 2007;11(5):501-12.

Haerens L, De Bourdeaudhuij I, Maes L, Cardon G, Deforche B. School-based randomized controlled trial of a physical activity intervention among adolescents. Journal of Adolescent Health 2007;40(3):258-65.

* Haerens L, Deforche B, Maes L, Cardon G, Stevens V, De Bourdeaudhuij I. Evaluation of a 2-year physical activity and healthy eating intervention in middle school children. Health Education Research 2006;2(6):911-21.

Haerens L, Deforche B, Maes L, Stevens V, Cardon G, De Bourdeaudhuij I. Body mass effects of a physical activity and healthy food intervention in middle schools. Obesity 2006;14(5):847-54.

\section{Haerens 2009 \{published data only\}}

* Haerens L, Maes L, Vereecken C, De Henauw S, Moreno L, De Bourdeaudhuij I. Effectiveness of a computer tailored physical activity intervention in adolescents compared to a generic advice. Patient Education \& Counseling 2009;77(1):38-41.

Jones 2008 \{published data only\}

* Jones D, Hoelscher DM, Kelder SH, Hergenroeder A, Sharma SV. Increasing physical activity and decreasing sedentary activity in adolescent girls - the Incorporating More Physical Activity and Calcium in Teens (IMPACT) Study. International Journal of Behavioral Nutrition and Physical Activity 2008;5:42.

\section{Kipping 2008 \{published data only\}}

* Kipping RR, Payne C, Lawlor DA. Randomised controlled trial adapting US school obesity prevention to England. Archives of Disease in Childhood 2008;93(6):469-73.

\section{Kriemler 2010 \{published data only\}}

* Kriemler S, Zahner L, Schindler C, Meyer U, Hartmann T, Hebestreit $\mathrm{H}$, et al. Effect of school based physical activity programme (KISS) on fitness and adiposity in primary schoolchildren: cluster randomised controlled trial. British Medical Journal 2010;340:c785.

Puder J, Zahner L, Schindler C, Meyer U, Hebestreit H, Rocca H, et al. A school-based physical activity program increases fitness and decreases adiposity and cardiovascular risk factors in primary school children: a cluster-randomized trial. Diabetologia 2009;52(Suppl 1):S330-1.

\section{Li 2010 \{published data only\}}

Li YP, Hu XQ, Schouten EG, Liu AL, Du SM, Li LZ, et al. Report on childhood obesity in China (8): effects and sustainability of physical activity intervention on body composition of Chinese youth. Biomedical and Environmental Sciences 2010;23:180-7.

\section{Lubans 2009 \{published data only\}}

Lubans D, Morgan P. Evaluation of an extra-curricular school sport programme promoting lifestyle and lifetime activity for adolescents. Journal of Sports Sciences 2008;26(5):519-29.

Lubans D, Morgan P. The 'Learning to Enjoy Activity with Friends' programme. Education \& Health 2007;25(1):10-4.

* Lubans DR, Morgan PJ, Callister R, Collins CE. Effects of integrating pedometers, parental materials, and E-mail support within an extracurricular school sport intervention. Journal of Adolescent Health 2009;44(2):176-83.

Lubans DR, Morgan PJ, Callister R, Collins CE, Plotnikoff RC. Exploring the mechanisms of physical activity and dietary behavior change in the Program $\mathrm{X}$ intervention for adolescents. The Journal of Adolescent Health 2010;47(1):83-91.

Lubans DR, Sylva K. Mediators of change following a senior school physical activity intervention. Journal of Science \& Medicine in Sport 2009;12(1):134-40.

\section{Luepker 1996 \{published data only\}}

Belcher JD, Ellison RC, Shepard WE, Bigelow C, Webber LS, Wilmore $\mathrm{JH}$, et al. Lipid and lipoprotein distributions in children by ethnic group, gender, and geographic location--preliminary findings of the Child and Adolescent Trial for Cardiovascular Health (CATCH). Preventive Medicine 1993;22(2):143-53.

Coleman KJ, Tiller CL, Sanchez J, Heath EM, Oumar S, Milliken G, et al. Prevention of the epidemic increase in child risk of overweight in low-income schools. Archives of Pediatric and Adolescent Medicine 2005;159(3):217-24.

Edmundson E, Parcel GS, Feldman HA, Elder J, Perry CL, Johnson CC, et al. The effects of the Child and Adolescent Trial for Cardiovascular Health upon psychosocial determinants of diet and physical activity behavior. Preventive Medicine 1996;25:442-54.

Edmundson EW, Luton SC, McGraw SA, Kelder SH, Layman AK, Smyth M, et al. CATCH: classroom process evaluation in a multicenter trial. Health Education Quarterly 1994;Suppl 2:S27-50. 
Elder JP, McGraw SA, Stone EJ, Reed DB, Harsha DW, Greene T, et al. CATCH: process evaluation of environmental factors and programs. Health Education Quarterly 1994;Suppl 2:S107-27.

Hoelscher DM, Feldman HA, Johnson CC, Lytle LA, Osganian SK, Parcel GS, et al. School-based health education programs can be maintained over time: results from the CATCH institution study. Preventive Medicine 2004;38:594-606.

Johnson CC, Osganian SK, Budman SB, Lytle LA, Barrera EP, Bonura SR, et al. CATCH: family process evaluation in a multicenter trial. Health Education Quarterly 1994;Suppl 2:S91-106.

* Luepker RV, Perry CL, McKinlay SM, Nader PR, Parcel GS, Stone EJ, et al. Outcomes of a field trial to improve children's dietary patterns and physical activity. The Child and Adolescent Trial for Cardiovascular Health (CATCH) collaborative group. JAMA 1996;275(10):768-76.

Lytle LA. Lessons from the Child and Adolescent Trial for Cardiovascular Health (CATCH): interventions with children. Current Opinion in Lipidology 1998;9(1):29-33.

Lytle LA, Ward J, Nader PR, Pedersen SA, Williston BJ. Maintenance of a health promotion program in elementary schools: results from the CATCH-ON study key informant interviews. Health Education and Behavior 2003;30(4):503-18.

McGraw SA, Stone EJ, Osganian SK, Elder JP, Perry CL, Johnson CC, et al. Design of process evaluation within the Child and Adolescent Trial for Cardiovascular Health (CATCH). Health Education Quarterly 1994;Suppl 2:S5-26.

McKenzie TL, Li D, Derby CA, Webber LS, Luepker LRV, Cribb P. Maintenance of effects of the CATCH physical education program: results from the CATCH-on study. Health Education \& Behavior 2003;30(4):447-62.

McKenzie TL, Nader PR, Strikmiller PK, Yang M, Stone EJ, Perry CL, et al. School physical education: effect of the Child and Adolescent Trial for Cardiovascular Health. Preventive Medicine 1996;25(4):423-31.

McKenzie TL, Stone EJ, Feldman HA, Epping JN, Yang M, Strikmiller PK, et al. Effects of the CATCH physical education intervention: teacher type and lesson location. American Journal of Preventive Medicine 2001;21(2):101-9.

McKenzie TLF, Li D, Derby C, Webber LS, Luepker LRV, Cribb P. Sustainability of a health-related physical education intervention in 76 elementary schools: CATCH. Medicine \& Science in Sports \& Exercise 2002;34(5):301.

Nader PR, Sellers DE, Johnson CC, Perry CL, Stone EJ, Cook KC, et al. The effect of adult participation in a school-based family intervention to improve children's diet and physical activity: the Child and Adolescent Trial for Cardiovascular Health (CATCH). Preventive Medicine 1996;25:455-64.

Nader PR, Stone EJ, Lytle LA, Perry CL, Osganian SK, Kelder S, et al. Three-year maintenance of improved diet and physical activity: the CATCH cohort. Archives of Pediatrics \& Adolescent Medicine 1999;153(7):695-704.
Perry CL, Sellers DE, Johnson CC, Pedersen SA, Bachman KJ, Parcel GS, et al. The Child and Adolescent Trial for Cardiovascular Health (CATCH): intervention, implementation, and feasibility for elementary schools in the United States. Health Education and Behavior 1997;24(6):716-35.

Perry CL, Stone EJ, Parcel GS, Ellison RC, Nader PR, Webber LS, et al. School-based cardiovascular health promotion: the Child and Adolescent Trial for Cardiovascular Health (CATCH). Journal of School Health 1990;60:406-13.

Stone EJ, Osganian SK, McKinlay SM, Wu MC, Webber LS, Luepker RV, et al. Operational design and quality control in the CATCH multicenter trial. Preventive Medicine 1996;25(4):384-99.

Webber LS, Osganian SK, Feldman HA, Wu M, McKenzie TL, Nichaman $\mathrm{M}$, et al. Cardiovascular risk factors among children after a 2 1/2-year intervention: the CATCH study. Preventive Medicine 1996;25(4):432-41.

\section{Martinez 2008 \{published data only\}}

* Martinez VM, Aguilar FS, Gutierrez RF, Martinez MS, Lopez MS, Martinez SS, et al. Assessment of an after-school physical activity program to prevent obesity among 9 - to 10 -year-old children: a cluster randomized trial. International Journal of Obesity 2008;32:12-22.

\section{McManus 2008 \{published data only\}}

* McManus AM, Masters RSW, Laukkanen RMT, Yu CCW, Sit CHP, Ling FCM. Using heart-rate feedback to increase physical activity in children. Preventive Medicine 2008;47(4):402-8.

\section{Neumark-Sztainer 2009 \{published data only\}}

* Neumark-Sztainer D, Haines J, Robinson-O'Brien R, Hannan PJ, Robins M, Morris B, et al. 'Ready. Set. ACTION!' A theater-based obesity prevention program for children: a feasibility study. Health Education Research 2009;24(3):407-20.

\section{Neumark-Sztainer 2010 \{published data only\}}

Neumark-Sztainer DR, Friend SE, Flattum CF, Hannan PJ, Story MT, Bauer KW, et al. New moves-preventing weightrelated problems in adolescent girls a group-randomized study. American Journal of Preventive Medicine 2010;39(5):421-32.

\section{Peralta 2009 \{published data only\}}

* Peralta LR, Jones RA, Okely AD. Promoting healthy lifestyles among adolescent boys: the Fitness Improvement and Lifestyle Awareness Program RCT. Preventive Medicine 2009;48(6):537-42.

Petchers 1988 \{published data only\}

* Petchers MK, Hirsch EZ, Bloch BA. A longitudinal study of the impact of a school heart health curriculum. Journal of Community Health 1988;13(2):85-94.

\section{Reed 2008 \{published data only\}}

Ahamed Y, Macdonald H, Reed K, Naylor P-J, Liu-Ambrase T, McKay H. School-based physical activity does not compromise children's academic performance. Medicine \& Science in Sports \& Exercise 2007;39(1):371-6.

Naylor PJ, Macdonald HM, Warburton DE, Reed KE, McKay HA. An active school model to promote physical activity in 
elementary schools: Action Schools! BC. British Journal of Sports Medicine 2008;42(5):338-43.

* Reed KE, Warburton DE, Macdonald HM, Naylor PJ, McKay HA. Action Schools! BC: a school-based physical activity intervention designed to decrease cardiovascular disease risk factors in children. Preventive Medicine 2008;46(6):525-31.

\section{Robinson 1999 \{published data only\}}

* Robinson TN. Reducing children's television viewing to prevent obesity: a randomized controlled trial. Journal of the American Medical Association 1999;282(16):1561-7.

Robinson TN, James KS. Can a school-based intervention to reduce television use decrease adiposity in children in grades 3 and 4?. The Western Journal of Medicine 2000;173(1):40.

\section{Salmon 2008 \{published data only\}}

Salmon J, Ball K, Crawford D, Booth M, Telford A, Hume C, et al. Reducing sedentary behaviour and increasing physical activity among 10-year-old children: overview and process evaluation of the 'Switch-Play' intervention. Health Promotion International 2005;20(1):7-17.

* Salmon J, Ball K, Hume C, Booth M, Crawford D. Outcomes of a group-randomized trial to prevent excess weight gain, reduce screen behaviours and promote physical activity in 10year-old children: Switch-Play. International Journal of Obesity 2008;32:601-12.

\section{Simon 2004 \{published data only\}}

* Simon C, Schweitzer B, Oujaa M, Wagner A, Arveiler D, Triby E, et al. Successful overweight prevention in adolescents by increasing physical activity: a 4-year randomized controlled intervention. [Erratum appears in International Journal of Obesity 2008;32(10):1606]. International Journal of Obesity 2008;32(10):1489-98.

Simon C, Wagner A, DiVita C, Rauscher E, Klein-Platat C, Arveiler D, et al. Intervention centred on adolescents' physical activity and sedentary behaviour (ICAPS): concept and 6-month results. International Journal of Obesity \& Related Metabolic Disorders 2004;28(Suppl 3):S96-103.

Simon C, Wagner A, Platat C, Arveiler D, Schweitzer B, Schlienger JL, et al. ICAPS: a multilevel program to improve physical activity in adolescents. Diabetes \& Metabolism 2006;32(1):41-9.

\section{Singh 2009 \{published data only\}}

* Singh AS, Chin A, Paw MJ, Brug J, van Mechelen W. Dutch obesity intervention in teenagers: effectiveness of a schoolbased program on body composition and behavior. Archives of Pediatrics \& Adolescent Medicine 2009;163(4):309-17.

\section{Singhal 2010 \{published data only\}}

Singhal N, Misra A, Shah P, Gulati S. Effects of controlled schoolbased multi-component model of nutrition and lifestyle interventions on behavior modification, anthropometry and metabolic risk profile of urban Asian Indian adolescents in North India. European Journal of Clinical Nutrition 2010;64(6):364-73.

\section{Stephens 1998 \{published data only\}}

* Stephens M, Wentz S. Supplemental fitness activities and fitness in urban elementary school classrooms. Family Medicine 1998;30(3):220-3.

\section{Stone 2003 \{published data only\}}

Caballero B, Clay T, Davis SM, Ethelbah B, Rock BH, Lohman T, et al. Pathways: a school-based, randomized controlled trial for the prevention of obesity in American Indian school children. American Journal of Clinical Nutrition 2003;78(5):1030-8.

Caballero B, Clay TE, Davis SM, Ethelbah R, Holyrock B, Lohman TG, et al. The Pathways obesity prevention study: overview of design and measurements. FASEB Journal 2001;15(5):A1091.

Caballero B, Davis SM, Davis CE, Ethelbah R, Evans MA, Lohman TG, et al. Pathways: a school-based program for the primary prevention of obesity in American Indian children. Journal of Nutritional Biochemistry 1998;9(9):535-43.

Davis CE, Hunsberger S, Murray DM, Fabsitz RR, Himes JH, Stephenson LK, et al. Design and statistical analysis for the Pathways study. American Journal of Clinical Nutrition 1999;69(4 Suppl):S760-3.

Davis SM. Pathways curriculum and family interventions to promote healthful eating and physical activity in American Indian schoolchildren. Preventive Medicine 2003;37(6 Pt 2):S24-34

Steckler A, Ethelbah B, Martin CJ, Stewart D, Pardilla M, Gittelsohn J, et al. Pathways process evaluation results: a school-based prevention trial to promote healthful diet and physical activity in American Indian third, fourth, and fifth grade students. Preventive Medicine 2003;37(6 part 2):S80-90.

Stevens J. The impact of the Pathways intervention on psychosocial variables related to diet and physical activity in American Indian school children. Preventive Medicine 2003;37(6 Pt 2):S70-9.

* Stone EJ, Norman JE, Davis SM, Stewart D, Clay TE, Caballero B, et al. Design, implementation, and quality control in the Pathways American-Indian multicenter trial. Preventive Medicine 2003;37(Suppl):S13-23.

Teufel N, Perry CL, Story M, Flint-Wagner HG, Levin S, Clay TE, et al. Pathways family intervention for third-grade American Indian children. American Journal of Clinical Nutrition 1999;69(4 Suppl):S803-9.

\section{Trevino 2004 \{published data only\}}

* Trevino RP, Yin Z, Hernandez A, Hale DE, Garcia OA, Mobley C. Impact of the Bienestar school-based diabetes mellitus prevention program on fasting capillary glucose levels: a randomized controlled trial. Archives of Pediatrics \& Adolescent Medicine 2004;158(9):911-7.

\section{Verstraete 2006 \{published data only\}}

* Verstraete SJ, Cardon GM, De Clercq DL, De Bourdeaudhuij IMM. Increasing children's physical activity levels during recess periods in elementary schools: the effects 
of providing game equipment. European Journal of Public Health 2006;16(4):415-9.

\section{Walter 1988 \{published data only\}}

Walter HJ, Hofman A, Barrett LT, Connelly PA, Kost KL, Walk EH, et al. Primary prevention of cardiovascular disease among children: three year results of a randomized intervention trial. In: Hetzel B, Berenson GS editor(s). Cardiovascular Risk Factors in Childhood: Epidemiology and Prevention. Amsterdam: Elsevier Science Publishers B.V. (Biomedical Division), 1987:161-81.

Walter HJ, Hofman A, Connelly PA, Barrett LT, Kost KL. Coronary heart disease prevention in childhood: one-year results of a randomized intervention study. American Journal of Preventive Medicine 1986;2(4):239-45.

Walter HJ, Hofman A, Connelly PA, Barrett LT, Kost KL. Primary prevention of chronic disease in childhood: changes in risk factors after one year of intervention. American Journal of Epidemiology 1985;122(5):772-81.

* Walter HJ, Hofman A, Vaughan RD, Wynder EL. Modification of risk factors for coronary heart disease: five-year results of a school-based intervention trial. New England Journal of Medicine 1988;318(17):1093-100.

Walter HJ, Wynder EL. The development implementation evaluation and future directions of a chronic disease prevention program for children: the "know your body" studies. Preventive Medicine 1989;18(1):59-71.

\section{Walther 2009 \{published data only\}}

* Walther C, Gaede L, Adams V, Gelbrich G, Leichtle A, Erbs S, et al. Effect of increased exercise in school children on physical fitness and endothelial progenitor cells: a prospective randomized trial. Circulation 2009;120(22):2251-9.

\section{Wang 2008 \{published data only\}}

Gutin B, Yin Z, Johnson M, Barbeau P. Preliminary findings of the effect of a 3-year after-school physical activity intervention on fitness and body fat: the Medical College of Georgia Fitkid Project. International Journal of Pediatric Obesity 2008;3:3-9.

* Wang LY, Gutin B, Barbeau P, Moore J, Hanes J, Johnson M, et al. Cost-effectiveness of a school-based obesity prevention program. Journal of School Health 2008;78(12):619-24.

Yin Z, Gutin B, Johnson MB, Hanes J, Moore JB, Cavnar M, et al. An environmental approach to obesity prevention in children: Medical College of Georgia FitKid project year 1 results. Obesity Research 2005;13(12):2153-61.

Yin Z, Hanes J, Moore JB, Humbles P, Barbeau P, Gutin B. An after-school physical activity program for obesity prevention in children: the Medical College of Georgia FitKid project. Evaluation \& The Health Professions 2005;28(1):67-89.

\section{Webber 2008 \{published data only\}}

Elder JP, Lytle L, Sallis JF, Young DR, Steckler A, SimonsMorton D. A description of the social-ecological framework used in the Trial of Activity for adolescent Girls (TAAG). Health Education Research 2007;22(2):155-65.
Elder JP, Shuler L, Moe SG, Grieser M, Pratt C, Cameron S, et al. Recruiting a Diverse Group of Middle School Girls Into the Trial of Activity for Adolescent Girls. Journal of School Health 2008;78(10):523-31.

Lytle LA, Murray DM, Evenson KR, Moody J, Pratt CA, Metcalfe L, et al. Mediators affecting girls' levels of physical activity outside of school: findings from the Trial of Activity in Adolescent Girls. Annals of Behavioral Medicine 2009;38(2):124-36.

McKenzie TL, Catellier DJ, Conway T, Lytle LA, Grieser M, Webber LA, et al. Girls' activity levels and lesson contexts in middle school physical education: TAAG baseline. Medicine and Science in Sports and Exercise 2006;38(7):1229-35.

Moe SG, Pickrel J, McKenzie TL, Strikmiller PK, Coombs D, Murrie D. Using school-level interviews to develop a multisite $\mathrm{PE}$ intervention program. Health Education \& Behavior 2006;33:52-65.

Saunders RP, Moody J. Community agency survey formative research results from the TAAG study. Health Education \& Behavior 2006;33(1):12-24.

Stevens J, Murray DM, Catellier DJ, Hannan PJ, Lytele LA, Elder JP, et al. Design of the Trial of Activity in Adolescent Girls (TAAG). Contemporary Clinical Trials 2005;26:223-33.

Webber LS, Catellier DJ, Lytle LA, Murray DM, Pratt CA, Young DR, et al. Outcomes of a randomized controlled field trial to promote physical activity in middle-school girls: Trial of Activity for Adolescent Girls. Circulation 2007;115(8):e221.

* Webber LS, Catellier DJ, Lytle LA, Murray DM, Pratt CA, Young DR, et al. Promoting physical activity in middle school girls: Trial of Activity for Adolescent Girls. American Journal of Preventive Medicine 2008;34(3):173-84.

Young DR, Felton GM, Grieser M, Elder J, Johnson C, Lee J, et al. Policies and opportunities for physical activity in middle school environments. Journal of School Health 2007;77(1):41-7.

Young DR, Johnson CC, Steckler A, Gittelsohn J, Saunders RP, Saksvig BI, et al. Data to action: using formative research to develop intervention programs to increase physical activity in adolescent girls. Health Education \& Behavior 2006;33:97-111.

Young DR, Steckler A, Cohen S, Pratt C, Felton G, Moe SG, et al. Process evaluation results from a school- and communitylinked intervention: the Trial of Activity for Adolescent Girls (TAAG). Health Education Research 2008;23(6):976-86.

Weeks 2008 \{published data only\}

* Weeks BK, Young CM, Beck BR. Eight months of regular inschool jumping improves indices of bone strength in adolescent boys and girls: the POWER PE study. Journal of Bone \& Mineral Research 2008;23(7):1002-11.

Williamson 2007 \{published data only\}

* Williamson DA, Copeland AL, Anton SD, Champagne C, Han H, Lewis $L$, et al. Wise Mind project: a school-based environmental approach for preventing weight gain in children. Obesity 2007;15(4):906-17. 
Wilson 2011 \{published data only\}

Wilson DK, Van Horn ML, Kitzman-Ulrich H, Saunders R, Pate R, Lawman HG, et al. Results of the "Active by Choice Today" (ACT) randomized trial for increasing physical activity in low-income and minority adolescents. Health Psychology 2011;30(4):463-71.

\section{Young 2006 \{published data only\}}

Young DR, Phillips JA, Yu T, Haythornthwaite JA. Effects of a life skills intervention for increasing physical activity in adolescent girls. Archives of Pediatrics and Adolescent Medicine 2006;160(12):1255-61.

\section{References to studies excluded from this review}

\section{Abbott 1989 \{published data only\}}

* Abbott J, Farrell J. A health-related exercise project in primary schools. Education and Health 1989;7(2):33-7.

\section{Aburto 2011 \{published data only\}}

Aburto NJ, Fulton JE, Safdie M, Duque T, Bonvecchio A, Rivera JA. Effect of a school-based intervention on physical activity: cluster-randomized trial. Medicine \& Science in Sports \& Exercise 2011;43(10):1898-906.

\section{Adeniran 1988 \{published data only\}}

* Adeniran SA, Toriola AL. Effects of continuous and interval running programmes on aerobic and anaerobic capacities in school girls aged 13 to 17 years. Journal of Sports Medicine and Physical Fitness 1988;28(3):260-6.

Adeniran SA, Toriola AL. Effects of different running programmes on body fat and blood pressure in schoolboys aged 13-17 years. Journal of Sports Medicine and Physical Fitness 1988;28(3):267-73.

\section{Aganovic 2002 \{published data only\}}

Aganovic I, Jovanovic Z, Crncevic-Orlic Z, Dordevic V, Gosev M, Nagy $L$, et al. The effect of weight loss on cardiovascular risk factors: "Healthy Weight Loss School". International Journal of Obesity 2002;26(Suppl 1):S200.

\section{Agron 2002 \{published data only\}}

Agron P, Takada E, Purcell A. California project LEAN's food on the run program: an evaluation of a high school-based student advocacy nutrition and physical activity program. Journal of the American Dietetic Association 2002;102(3 Suppl):S103-5.

\section{Alexandrov 1988 \{published data only\}}

Alexandrov AA, Isakova G, Maslennikova GY. Prevention of atherosclerosis among 11-year old school children in two Moscow administrative districts. Health Psychology 1988;7(Suppl):247-52

\section{Alexandrov 1992 \{published data only\}}

Alexandrov AA, Maslennikova GY, Kulikov SM, Propirnij GA, Perova NV. Primary prevention of cardiovascular disease: 3 year intervention results in boys of 12 years of age. Preventive Medicine 1992;21(1):53-62.
Alhassan 2007 \{published data only\}

Alhassan S, Sirard JR, Robinson TN. The effects of increasing outdoor play time on physical activity in Latino preschool children. International Journal of Pediatric Obesity 2007;2:153-8.

\section{Allensworth 1997 \{published data only\}}

Allensworth D. Improving the health of youth through a coordinated school health programme. Promotion \& Education $1997 ; 4(4): 42-7$.

Allison 1999 \{published data only\}

Allison KR, Dwyer JJM, Makin S. Self-efficacy and participation in vigorous physical activity by high school students. Health Education and Behavior 1999;26(1):12-24.

\section{Allison 2000 \{published data only\}}

Allison KR, Adlaf EM. Structured opportunities for student physical activity in Ontario elementary and secondary schools. Canadian Journal of Public Health 2000;91(5):371-5.

Al-Nakeeb 2007 \{published data only\}

Al-Nakeeb Y, Duncan MJ, Lyons M, Woodfield L. Body fatness and physical activity levels of young children. Annals of Human Biology 2007;34(1):1-12.

Andersen 1998 \{published data only\}

Andersen RE, Crespo CJ, Bartlett SJ, Cheskin LJ, Pratt M. Relationship of physical activity and television watching with body weight and level of fatness among children: results from the Third National Health and Nutrition Examination Survey. JAMA 1998;279(12):938-42.

\section{Andersen 2003 \{published data only\}}

Andersen LB, Wedderkopp N, Hansen HS, Cooper AR, Frobergb K. Biological cardiovascular risk factors cluster in Danish children and adolescents: the European Youth Heart Study. Preventive Medicine 2003;37:363-37.

\section{Andersen 2006 \{published data only\}}

Andersen LB, Harro M, Sardinha LB, Froberg K, Ekelund Ulf, Brage $S$, et al. Physical activity and clustered cardiovascular risk in children: a cross-sectional study (The European Youth Heart Study). Lancet 2006;368(9532):299-304.

\section{Anderson 1999 \{published data only\}}

Anderson S, Gauvin L, Potvin L, Paradis G. Longitudinal impact of family support and access to community facilities on children's physical activity. Medicine and Science in Sports and Exercise 1999;31(5 Suppl):S272.

\section{Andreacci 2008 \{published data only\}}

Andreacci JL, Dixon CB, Rompolski K, vanGorden KM. The effect of an acute after-school exercise bout on percentage of body fat using leg-to-leg bioelectrical impedance analysis in children. Research Quarterly for Exercise \& Sport 2008;79(4):535-9.

\section{Annesi 2004 \{published data only\}}

Annesi JJ. Relationship between self-efficacy and changes for 9-to 12-yr old children enrolled in a 12-wk after-school physical activity program. Perceptual and Motor Skills 2004;99:191-4. 


\section{Ara 2006 \{published data only\}}

Ara I, Vicente-Rodriguez G, Perez-Gomez J, Jimenez-Ramirez J, Serrano-Sanchez JA, Dorado C, et al. Influence of extracurricular sport activities on body composition and physical fitness in boys: a 3-year longitudinal study. International Journal of Obesity 2006;30:1062-71.

\section{Arau jo-Soares 2009 \{published data only\}}

Araújo-Soares V, McIntyre T, Sniehotta FF. Predicting changes in physical activity among adolescents: the role of self-efficacy, intention, action planning and coping planning. Health Education Research 2009;24(1):128-39.

\section{Arborelius 1988 \{published data only\}}

Arborelius E, Bremberg S. It is your decision. Behavioral effects of a student-centered health education model at school for adolescents. Journal of Adolescence 1988;11(4):287-98.

\section{Ardoy 2010 \{published data only\}}

Ardoy DN, Fernandez-Rodriguez JM, Chillon P, Artero EG, Espana-Romero V, Jimenez-Pavon D, et al. Physical fitness enhancement through education, EDUFIT study: background, design, methodology and dropout analysis [Educando para mejorar el estado de forma fisica, estudio EDUFIT: antecedentes, diseno, metodologia y analisis del abandono/ adhesion al estudio]. Revista Espanola de Salud Publica 2010;84(2):151-68

Ardoy DN, Fernandez-Rodriguez JM, Ruiz JR, Chillon P, EspanaRomero V, Castillo MJ, et al. Improving physical fitness in adolescents through a school-based intervention: the EDUFIT study [Mejora de la condicion fisica en adolescentes a traves de un programa de intervencion educativa: Estudio EDUFIT]. Revista Espanola de Cardiologia 2011;64(6):484-91.

\section{Armstrong 2000 \{published data only\}}

Armstrong N, Welsman JR, Kirby BJ. Longitudinal changes in 11-13-year-olds' physical activity. Acta Paediatrica 2000;89:775-80.

\section{Babin 2001 \{published data only\}}

Babin J, Katic R, Ropac D, Bonacin D. Effect of specially programmed physical and health education on motor fitness of seven-year-old school children. Collegium Antropologicum 2001;25(1):153-65.

\section{Bal 1990 \{published data only\}}

Bal LV, Shugaeva EN, Deev AA, Maslova AR, Aleksandrov AA. Results of a three-year trial of arterial hypertension prevention in a population of children aged $11-15$ years by overweight control. Cor et Vasa 1990;32(6):448-56.

\section{Baquet 2001 \{published data only\}}

* Baquet G, Berthoin S, Gerbeaux M, Van Praagh E. Highintensity aerobic training during a 10 week one-hour physical education cycle: effects on physical fitness of adolescents aged 11 to 16. International Journal of Sports Medicine 2001;22(4):295-300.

\section{Baquet 2002 \{published data only\}}

Baquet G, Berthoin S, Van Praagh E. Are intensified physical education sessions able to elicit heart rate at a sufficient level to promote aerobic fitness in adolescents?. Research Quarterly for Exercise \& Sport 2002;73(3):282-8.

\section{Baranowski 2002 \{published data only\}}

Baranowski T, Cullen KW, Nicklas T, Thompson D, Baranowski J. School-based obesity prevention: a blueprint for taming the epidemic. American Journal of Health Behavior 2002;26(6):486-93.

\section{Baranowski 2005 \{published data only\}}

Baranowski T, Jago R. Understanding the mechanisms of change in children's physical activity programs. Exercise and Sport Sciences Reviews 2005;33(4):163-8.

Barthold 1993 \{published data only\}

Barthold J, Pearson J, Ellsworth A, Mason C, Hohensee T, McLaud B, et al. A cardiovascular health education program for rural schools. Journal of School Health 1993;63(7):298-301.

\section{Baxter 1997 \{published data only\}}

Baxter AP, Milner PC, Hawkins S, Leaf M, Simpson C, Wilson KV, et al. The impact of heart health promotion on coronary heart disease lifestyle risk factors in schoolchildren: lessons learnt from a community-based project. Public Health 1997;111(4):231-7.

\section{Beighle 2006 \{published data only\}}

Beighle A, Pangrazi RP. Measuring children's activity levels: the association between step-counts and activity time. Journal of Physical Activity and Health 2006;3:221-9.

\section{Belansky 2006 \{published data only\}}

Belansky ES, Romaniello C, Morin C, Uyeki T, Sawyer RL, Scarbro S, et al. Adapting and implementing a long-term nutrition and physical activity curriculum to a rural, lowincome, biethnic community. Journal of Nutrition Education and Behavior 2006;38(2):106-13.

\section{Benson 2008 \{published data only\}}

Benson AC, Torode ME, Fiatarone Singh MA. The effect of high-intensity progressive resistance training on adiposity in children: a randomized controlled trial. International Journal of Obesity 2008;32(6):1016-27.

\section{Berenson 1993 \{published data only\}}

Arbeit ML, Johnson CC, Mott DS, Harsha DW, Nicklas TA, Webber LS, et al. The Heart Smart cardiovascular school health promotion: behavior correlates of risk factor change. Preventive Medicine 1992;21(1):18-32.

* Berenson GS. Prevention of heart disease beginning in childhood through comprehensive school health: the Heart Smart Program. Preventive Medicine 1993;22(4):507-12.

Butcher AH, Frank GC, Harsha DW, Serpas DC, Little SD, Nicklas TA, et al. Heart Smart: a school health program meeting the 1990 objectives for the nation. Health Education Quarterly 1988;5(1):17-34. 


\section{Berenson 1993a \{published data only\}}

Berenson GS, Schnakenberg D, Harsha DW, Webber LS, Johnson CC, Nicklas TA. Fort Polk Heart Smart Program. Part I: background design and significance. Military Medicine 1993;158(5):304-8.

\section{Berenson 2001 \{published data only\}}

Berenson GS, Srinivasan SR. Emergence of obesity and cardiovascular risk for coronary artery disease: the Bogalusa Heart Study. Preventive Cardiology 2001;4(3):116-21.

\section{Berg-Kelly 1997 \{published data only\}}

Berg-Kelly K, Alven B, Erdes L, Erneholm T, Johannisson I, Mattsson-Elofson E. Health habits and risk behavior among youth in three communities with different public health approach. Scandinavian Journal of Social Medicine 1997;25(3):149-55.

\section{Bergmann 2010 \{published data only\}}

Bergmann L, Clifford D, Wolff C. Edutainment and teen modeling may spark interest in nutrition \& physical activity in elementary school audiences. Journal of Nutrition Education \& Behavior 2010;42(2):139-41.

\section{Biddle 2004 \{published data only\}}

Biddle SJH, Gorely T, Stensel DJ. Health-enhancing physical activity and sedentary behavior in children and adolescents. Journal of Sports Sciences 2004;22:679-701.

Bindler 2000 \{published data only\}

Bindler RM, Short RA, Cooney SK, Domitor P, Garabedian H, Hain $\mathrm{R}$, et al. Interventions to decrease cardiovascular risk factors in children: the Northwest Pediatric Heart project. National Academies of Practice Forum: Issues in Interdisciplinary Care 2000;2(1):43-8.

\section{Bischoff 1987 \{published data only\}}

Bischoff JA, Lewis KA. A cross-sectional study of fitness levels in a movement education program. Research Quarterly for Exercise and Sport 1987;58(3):348-53.

\section{Blank Sherman 1992 \{published data only\}}

Blank Sherman J, Alexander MA, Gomez D, Kim M, Marole P. Intervention program for obese children. Journal of Community Health Nursing 1992;9:183-90.

\section{Blessing 1994 \{published data only\}}

Blessing DL, Williford HN, Barksdale J, Wang N, Teel S. Effects of a 15-wk school physical fitness program on blood lipids and lipoprotein in children. Medicine and Science in Sports and Exercise 1994;26(5 Suppl):S149.

\section{Bonhauser 2005 \{published data only\}}

Bonhauser M, Fernandez G, Puschel K, Yanez F, Montero J, Thompson B, et al. Improving physical fitness and emotional well-being in adolescents of low socioeconomic status in Chile: results of a school-based controlled trial. Health Promotion International 2005;20(2):113-22.
Booth 2001 \{published data only\}

Booth SL, Mayer J, Sallis JF, Ritenbaugh C, Hill J, Birch LL, et al. Environmental and societal factors affect food choice and physical activity: rationale, Influences, and leverage points. Nutrition Reviews 2001;59(3):S21-39.

\section{Boreham 2001 \{published data only\}}

Boreham C, Riddoch C. The physical activity, fitness and health of children. Journal of Sports Sciences 2001;19:915-29.

Boyd 1997 \{published data only\}

* Boyd KR, Hrycaiko DW. The effect of a physical activity intervention package on the self-esteem of pre-adolescent and adolescent females. Adolescence 1997;32(127):693-708.

Boyle-Holmes 2010 \{published data only\}

Boyle-Holmes T, Grost L, Russell L, Laris BA, Robin L, Haller E, et al. Promoting elementary physical education: results of a school-based evaluation study. Health Education \& Behavior 2010;37(3):377-89.

\section{Briancon 2010 \{published data only\}}

Briancon S, Bonsergent E, Agrinier N, Tessier S, Legrand K, Lecomte E, et al. PRALIMAP: study protocol for a high schoolbased, factorial cluster randomised interventional trial of three overweight and obesity prevention strategies. Trials 2010;11:119.

\section{Brown 2004 \{published data only\}}

Brown SJ, Schoenly L. Test of an educational intervention for osteoporosis prevention with U.S. adolescents. Orthopaedic Nursing 2004;23(4):245-51.

\section{Brownell 1982 \{published data only\}}

Brownell KD, Kaye FS. A school-based behavior modification, nutrition education, and physical activity program for obese children. American Journal of Clinical Nutrition 1982;35(2):277-83.

Buchan 2011 \{published data only\} Buchan DS, Ollis S, Young JD, Thomas NE, Cooper S-M, Tong TK, et al. The effects of time and intensity of exercise on novel and established markers of CVD in adolescent youth. American Journal of Human Biology 2011;23(4):517-26.

\section{Bungum 1997 \{published data only\}}

Bungum TJ, Vincent ML. Determinants of physical activity among female adolescents. American Journal of Preventive Medicine 1997;13(2):115-22.

\section{Burgeson 2001 \{published data only\}}

Burgeson CR, Wechsler H, Brener ND, Young JC, Spain CG. Physical activity and education: results from the School Health Policies and Programs Study 2000. The Journal of School Health 2001;71(7):279-93.

\section{Burgess 2006 \{published data only\}}

Burgess G, Grogan S, Burwitz L. Effects of a 6-week aerobic dance intervention on body image and physical selfperceptions in adolescent girls. Body Image 3 2006;3:57-66. 
Bush 2010 \{published data only\}

Bush PL, Laberge S, Laforest S. Physical activity promotion among underserved adolescents: "make it fun, easy, and popular". Health Promotion Practice 2010;11(Suppl 3):79s-87s.

\section{Butcher 2007 \{published data only\}}

Butcher Z, Fairclough S, Stratton G, Richardson D. The effect of feedback and information on children's pedometer step counts at school. Pediatric Exercise Science 2007;19(1):29-38.

\section{Byrd-Williams 2010 \{published data only\}}

Byrd-Williams CE, Belcher BR, Spruijt MD, Davis JN, Ventura EE, Kelly $L$, et al. Increased physical activity and reduced adiposity in overweight Hispanic adolescents. Medicine \& Science in Sports \& Exercise 2010;42(3):478-84.

\section{Cale 2000 \{published data only\}}

Cale L. Physical activity promotion in secondary schools. European Physical Education Review 2000;6(1):71-90.

\section{Calfas 1991 \{published data only\}}

Calfas KJ, Sallis JF, Nader PR. The development of scales to measure knowledge and preference for diet and physical activity behavior in 4- to 8-year old children. Journal of Developmental and Behavioral Pediatrics 1991;12(3):185-90.

\section{Calfas 1994 \{published data only\}}

Calfas KJ, Taylor WC. Effects of physical activity on psychological variables in adolescents. Pediatric Exercise Science 1994;6:406-23.

\section{Caravella 1996 \{published data only\}}

Caravella T, Pretasky BJ, Detert RA, Oganowski JL. The Wisconsin Elementary Health Education Pilot Project: years one and two diffusion activities. Journal of Health Education 1996;27(3):170-7.

\section{Cardon 2002 \{published data only\}}

Cardon GM, De Bourdeaudhuij IMM. Physical education and physical activity in elementary schools in Flanders. Physical Education \& Sport Pedagogy 2002;7(1):5-18.

Cardon 2004 \{published data only\}

Cardon G, Verstraete S, De Clereq D, De Bourdeaudhuij I. Physical activity levels in elementary-school physical education: a comparison of swimming and nonswimming classes. Journal of teaching in physical education 2004;23:252-63.

\section{Carlson 2008 \{published data only\}}

Carlson SA, Fulton JE, Lee SM, Maynard M, Brown D, Kohl HW, et al. Physical education and academic achievement in elementary school: data from the Early Childhood longitudinal study. American Journal of Public Health 2008;98(4):721-7.

\section{Carrel 2005a \{published data only\}}

Carrel AL, Clark R, Peterson SE, Nemeth BA, Sullivan J, Allen DB. Improvement of fitness, body composition, and insulin sensitivity in overweight children in a school-based exercise program - a randomized, controlled study. Archives of Pediatrics \& Adolescent Medicine 2005;159(10):963-8.

\section{Carrel 2005b \{published data only\}}

Carrel A, Meinen A, Garry C, Storandt R. Effects of nutrition education and exercise in obese children: the Ho-Chunk Youth Fitness Program. WMJ 2005;104(5):44-7.

\section{Casazza 2007 \{published data only\}}

Casazza K, Ciccazzo M. The method of delivery of nutrition and physical activity information may play a role in eliciting behavior changes in adolescents. Eating Behaviors 2007;8:73-82

\section{Cass 2006 \{published data only\}}

Cass $Y$, Price P. Moorefit - increasing physical activity in adolescent girls using the Health Promoting Schools framework. Education and Health 2006;24(1):3-7.

\section{Castelli 2007 \{published data only\}}

Castelli DM, Hillman CH, Buck SM, Erwin HE. Physical fitness and academic achievement in third- and fifth-grade students. Journal of Sport \& Exercise Psychology 2007;29:239-52.

\section{Cawley 2007 \{published data only\}}

Cawley J, Meyerhoefer M, Newhouse D. The impact of state physical education requirements on youth physical activity and overweight. Health Economics 2007;16:1287-1301.

\section{Chad 1999 \{published data only\}}

Chad KE, Humbert ML, Jackson PL. The effectiveness of the Canadian Quality Daily Physical Education program on school physical education. Research Quarterly for Exercise and Sport 1999;70(1):55-64

\section{Challener 1990 \{published data only\}}

Challener J. Health education in secondary schools - is it working? A study of 1,418 Cambridgeshire pupils. Public Health 1990;104(3):195-205.

\section{Chatzisarantis 2009 \{published data only\}}

Chatzisarantis N, Hagger MS. Effects of an intervention based on self-determination theory on self-reported leisure-time physical activity participation. Psychology \& Health 2009;24(1):29-48.

\section{Chavarro 2005 \{published data only\}}

Chavarro JE, Peterson KE, Sobol AM, Wiecha JL, Gortmaker SL. Effects of a school-based obesity-prevention intervention on menarche (United States). Cancer Causes and Control 2005;16(10):1245-52.

\section{Chomitz 2003 \{published data only\}}

Chomitz VR, Collins J, Kim J, Kramer E, McGowan R. Promoting healthy weight among elementary school children via a health report card approach. Archives of Pediatrics and Adolescent Medicine 2003;157(8):765-72.

\section{Choudhuri 2002 \{published data only\}}

Choudhuri D, Choudhuri S, Kulkarni VA. Physical fitness: a comparative study between students of residential (Sainik) and non-residential schools (aged 12-14 years). Indian Journal of Physiology \& Pharmacology 2002;46(3):328-32. 
Chow 2001 \{published data only\}

Chow C, Lindner K. Testing Ajzen's theory of planned behavior on the physical activity participatory behavior of Hong Kong children and youth: a pilot study. In: Chin MK, Hensley LD, Liu YK editor(s). Innovation and Application of Physical Education and Sports Science in the New Millennium - An Asia-Pacific Perspective Hong Kong. Hong Kong: Hong Kong Institute of Education, 2001:373-86.

\section{Ciccomascolo 2008 \{published data only\}}

Ciccomascolo LE, Grossi LM. The effect of an 8-week educational curriculum and physical activity program on attitudes toward physical activity and body image of urban adolescent girls. Women in Sport \& Physical Activity Journal 2008;17(2):17-23.

\section{Cirignano 2010 \{published data only\}}

Cirignano SM, Du L, Morgan KT. Promoting youth physical activity in the classroom through a comprehensive walking program. Family and Consumer Sciences Research Journal 2010;39(2):161-72.

\section{Clark 2008 \{published data only\}}

Clark, J. Effects of medicine ball training in fitness performance of high school physical education students. The Journal of Physical Education, Recreation \& Dance 2008;79(4):9-9.

\section{Coe 2005 \{published data only\}}

Coe DP, Pivarnik JM, Womack CJ, Reeves MJ, Malina RM. Effect of physical education class enrollment and seasonality on physical activity levels in middle school children. Pediatric Exercise Science 2005;17(1):93-4.

\section{Coe 2006 \{published data only\}}

Coe DP, Pivarnik JM, Womack CJ, Reeves MJ, Malina RM. Effect of physical education and activity levels on academic achievement in children. Medicine \& Science in Sports \& Exercise 2006;38(8):1515-9.

\section{Cohen 1991 \{published data only\}}

Cohen CJ, McMilan CS, Samuelson DR. Long-term effects of lifestyle modification exercise program on the fitness of sedentary obese children. Journal of Sports Medicine and Physical Fitness 1991;31:183-8.

\section{Colchico 2000 \{published data only\}}

Colchico K, Zybert P, Basch CE. Effects of after-school physical activity on fitness, fatness, and cognitive self-perceptions: a pilot study among urban, minority adolescent girls. American Journal of Public Health 2000;90(6):977-8.

\section{Collins 1988 \{published data only\}}

Collins ME. Education for healthy body weight: helping adolescents balance the cultural pressure for thinness. Journal of School Health 1988;58(6):227-31.

\section{Collins 1995 \{published data only\}}

Collins JL, Small ML, Kann L, Pateman BC, Gold RS, Kolbe LJ. School health education. Journal of School Health 1995;65(8):302-11.
Connor 1986 \{published data only\}

* Connor MK, Smith LG, Fryer A, Erickson S, Fryer S, Drake J. Future Fit: a cardiovascular health education and fitness project in an after-school setting. Journal of School Health 1986;56(8):329-33.

\section{Contento 2010 \{published data only\}}

Contento IR, Koch PA, Lee H, Calabrese BA. Adolescents demonstrate improvement in obesity risk behaviors after completion of choice, control \& change, a curriculum addressing personal agency and autonomous motivation. Journal of the American Dietetic Association 2010;110(12):1830-9.

\section{Cornelius 1991 \{published data only\}}

Cornelius LJ. Health habits of school-age children. Journal of Health Care 1991;2(3):374-95.

\section{Cottrell 2005 \{published data only\}}

Cottrell L, Spangler-Murphy E, Minor V, Downes A, Nicholson P, Neal WA. A kindergarten cardiovascular risk surveillance study: CARDIAC-Kinder. American Journal of Health Behavior 2005;29(6):595-606.

\section{Cox 2006 \{published data only\}}

Cox M, Schofield G, Greasley N, Kolt GS. Pedometer steps in primary school-aged children: a comparison of school-based and out-of-school activity. Journal of Science and Medicine in Sport 2006;9(1-2):91-7.

\section{Crawford 1997 \{published data only\}}

Crawford PB, O'Neill KJ, Wolfe T, Obarzanek E. An approach to providing dietary and physical-activity dairy instruction to adolescent girls enrolled in a longitudinal study: the National Heart, Lung and Blood Institute Growth and Health Study. American Journal of Clinical Nutrition 1997;65(4 Suppl):S1297-8.

\section{Dale 2000 \{published data only\}}

* Dale D, Corbin CB. Physical activity participation of high school graduates following exposure to conceptual or traditional physical education. Research Quarterly for Exercise and Sport 2000;71(1):61-8.

Dale D, Corbin CB, Cuddihy TF. Can conceptual physical education promote physically active lifestyles?. Pediatric Exercise Science 1998;10:97-109.

\section{Davis 1995 \{published data only\}}

Davis K, Christoffel KK. Obesity in preschool and school-age children: treatment early and often may be best. Archives of Pediatrics and Adolescent Medicine 1994;148(12):1257-61.

Davis K, Christoffel KK, Vespa H, Pierleoni MP, Papanastassiou R. Early frequent treatment in prevention of childhood obesity: how we do it. Annals of the New York Academy of Sciences 1993;699:260-1.

* Davis SM, Lambert LC, Gomez Y, Skipper B. Southwest cardiovascular curriculum project: study findings for American Indian elementary students. Journal of Health Education 1995;26(2):81. 


\section{DeBar 2006 \{published data only\}}

DeBar LL, Ritenbaugh C, Aickin M, Orwoll E, Elliot D, Dickerson J, et al. YOUTH: a health plan-based lifestyle intervention increases bone mineral density in adolescent girls. Archives of Pediatrics \& Adolescent Medicine 2006;160(12):1269-76.

\section{de Barros 2009 \{published data only\}}

de Barros MV, Nahas MV, Hallal PC, de Farias J, Florindo AA, Honda de Barros SS. Effectiveness of a school-based intervention on physical activity for high school students in Brazil: the Saude na Boa project. Journal of Physical Activity \& Health 2009;6(2):163-9.

\section{De Bourdeaudhuij 2010 \{published data only\}}

De Bourdeaudhuij I, Maes L, De Henauw S, De Vriendt T, Moreno LA, Kersting M, et al. Evaluation of a computer-tailored physical activity intervention in adolescents in six European countries: the Activ-O-Meter in the HELENA intervention study. Journal of Adolescent Health 2010;46(5):458-66.

Deforche 2004 \{published data only\}

Deforche B, De Bourdeaudhuij I, Tanghe A, Hills AP, Bode PD. Changes in physical activity and psychosocial determinants of physical activity in children and adolescents treated for obesity. Patient Education and Counseling 2004;55(3):407-15.

\section{Dehar 1991 \{published data only\}}

Dehar M, Duignan P, Casswell S. Evaluation of Heartbeat New Zealand. Health Promotion International 1991;6(1):13-9.

\section{Del Ben 1991 \{published data only\}}

Del Ben M, Angelico F, Fabiani L. Management of childhood obesity through a school-based programme of general health and nutrition education. Public Health 1991;105(393):398.

\section{Dellinger 2002 \{published data only\}}

Dellinger AM. Barriers to children walking and biking to school United States, 1999. JAMA 2002;288(11):1343-4.

\section{DeMarco 1989 \{published data only\}}

DeMarco T, Sidney K. Enhancing children's participation in physical activity. Journal of School Health 1989;59(8):337-40.

\section{De Meij 2010 \{published data only\}}

De Meij SB. Promoting physical activity in children: the stepwise development of the primary school-based JUMP-in intervention applying the RE-AIM evaluation framework. British Journal of Sports Medicine 2010;44(12):879-87.

\section{Dempsey 1993 \{published data only\}}

Dempsey JM, Kimiecik JC, Horn TS. Parental influence on children's moderate to vigorous physical activity participation: an expectancy-value approach. Pediatric Exercise Science 1993;5:151-67.

\section{Dencker 2006 \{published data only\}}

Dencker M, Thorsson O, Karlsson MK, Linden C, Eiberg S, Wollmer P, et al. Daily physical activity related to body fat in children aged 8-11 years. The Journal of Pediatrics 2006;149(1):38-42.

\section{Dennison 2004 \{published data only\}}

Dennison BA, Russo TJ, Burdick PA, Jenkins PL. An intervention to reduce television viewing by preschool children. Archive of Pediatric Adolescent Medicine 2004;158:170-6.

\section{Derri 2004 \{published data only\}}

Derri V, Aggeloussis N, Petraki C. Health-related fitness and nutritional practices: can they be enhanced in upper elementary school students?. Physical Educator 2004;61(1):35.

\section{DeVault 2009 \{published data only\}}

DeVault N, Kennedy T, Hermann J, Mwavita M, Rask P, Jaworsky A. It's all about kids: preventing overweight in elementary school children in Tulsa, OK. Journal of the American Dietetic Association 2009;109(4):680-7.

\section{Devis 1992 \{published data only\}}

Devis J, Peiro C. Exercise and health in a Spanish PE curriculum: a modified programme of 'the exercise challenge'. In: Williams T, Almond L, Sparkes A editor(s). Sport \& Physical Activity: Moving Towards Excellence. London: E \& FN Spon, 1992:418-28.

\section{Diaz 1997 \{published data only\}}

Diaz FJ, Garcia R, Melchor T, Montano G, Moreno F. The effect of diet and exercise upon cardiovascular risk factor in adolescents. Medicine and Science in Sports and Exercise 1997;29(5 Suppl):S237.

Diehl 1998 \{published data only\}

Diehl HA. Coronary risk reduction through intensive community-based lifestyle intervention: the Coronary Health Improvement Project (CHIP) experience. American Journal of Cardiology 1998;82(10B):T83-7.

\section{Dishman 2005 \{published data only\}}

Dishman RK, Motl RW, Saunders R, Felton G, Ward DS, Dowda M, et al. Enjoyment mediates effects of a school-based physicalactivity intervention. Medicine \& Science in Sports \& Exercise 2005;37(3):478-87.

\section{Dishman 2010 \{published data only\}}

Dishman RK, Dunn AL, Sallis JF, Vandenberg RJ, Pratt CA. Socialcognitive correlates of physical activity in a multi-ethnic cohort of middle-school girls: two-year prospective study. Journal of Pediatric Psychology 2010;35(2):188-98.

\section{Donnelly 1996 \{published data only\}}

* Donnelly JE, Jacobsen DJ, Whatley JE, Hill JO, Swift LL, Cherrington $\mathrm{A}$, et al. Nutrition and physical activity program to attenuate obesity and promote physical and metabolic fitness in elementary school children. Obesity Research 1996;4(3):229-43.

\section{Dowda 2001 \{published data only\}}

Dowda M, Ainsworth BE, Addy CL, Saunders RP, Riner W. Environmental influences, physical activity, and weight status in 8- to 16-year-olds. Archives of Pediatrics and Adolescent Medicine 2001;155(6):711-7. 
Drews 2009 \{published data only\}

Drews KL, Harrell JS, Thompson D, Mazzuto SL, Ford EG, Carter $\mathrm{M}$, et al. Recruitment and retention strategies and methods in the HEALTHY study. International Journal of Obesity 2009;33:S21-8.

\section{Dudley 2010 \{published data only\}}

Dudley DA, Okely AD, Pearson P, Peat J. Engaging adolescent girls from linguistically diverse and low income backgrounds in school sport: a pilot randomised controlled trial. Journal of Science and Medicine in Sport 2010;13(2):217-24.

Dunbar 1998 \{published data only\}

Dunbar JA, Vincent DS, Dunbar AP, Glass W. Implementing the North Karelia project in Scotland. Scottish Medical Journal 1998;43(4):99-101.

\section{Duncan 1983 \{published data only\}}

Duncan B, Boyce WT, Itami R, Puffenbarger N. A controlled trial of a physical fitness program for fifth grade students. Journal of School Health 1983;53(8):467-71.

\section{Duncan 2004 \{published data only\}}

Duncan MJ, Al-Nakeeb Y, Nevill A, Jones MV. Body image and physical activity in British secondary school children. European Physical Education Review 2004;10(3):243-60.

Duncan MJ, Al-Nakeeb Y, Nevill AM, Jones MV. Body dissatisfaction, body fat and physical activity in British children. International Journal of Pediatric Obesity 2006;1(2):89-95.

\section{Duncan 2009 \{published data only\}}

Duncan MJ, Al-Nakeeb Y, Nevill AM. Effects of a 6-week circuit training intervention on body esteem and body mass index in British primary school children. Body Image 2009;6(3):216-20.

\section{Duncan 2010 \{published data only\}}

Duncan MJ, Staples V. The impact of a school-based active video game play intervention on children's physical activity during recess. Human Movement 2010;11(1):95-9.

\section{Dunn 2006 \{published data only\}}

Dunn C, Thomas C, Ward D, Pegram L, Webber K, Cullitan C. Design and implementation of a nutrition and physical activity curriculum for child care settings. Preventing Chronic Disease 2006;3(2):1-8.

\section{DuShaw 1984 \{published data only\}}

DuShaw ML. A comparative study of three model comprehensive elementary school health education programs. Journal of School Health 1984;54:397-400.

\section{Dwyer 1979 \{published data only\}}

Dwyer T, Coonan WE, Worsley A, Leitch DR. An assessment of the effects of two physical activity programs on coronary heart disease risk factors in primary school children. Community Health Studies 1979;3:196-202.

\section{Dwyer 1983 \{published data only\}}

Dwyer T, Coonan WE, Leitch DR, Hetzel BS, Baghurst RA. An investigation of the effects of daily physical activity on the health of primary school students in South Australia. International Journal of Epidemiology 1983;12(3):308-13.

Dwyer 1991 \{published data only\}

Dwyer T, Viney R, Jones M. Assessing school health education programs. International Journal of Technology Assessment in Health Care 1991;7(3):286-95.

\section{Dwyer 2003 \{published data only\}}

Dwyer JJM, Hansen B, Barrera M, Allison K, Ceolin-Celestini S, Koenig D, et al. Maximizing children's physical activity: an evaluability assessment to plan a community-based, multistrategy approach in an ethno-racially and socio-economically diverse city. Health Promotion International 2003;18(3):199-208.

Dyson 1998 \{published data only\}

Dyson B, O'Sullivan M. Innovation in two alternative elementary school programs: why it works. Research Quarterly for Exercise and Sport 1998;69(3):242-53.

\section{Dzewaltowski 2002 \{published data only\}}

Dzewaltowski DA, Estabrooks PA, Johnston JA. Healthy youth places promoting nutrition and physical activity. Health Education Research 2002;17(5):541-51.

Dzewaltowski 2007 \{published data only\}

Dzewaltowski DA, Karteroliotis K, Welk G, Johnston JA, Nyaronga D, Estabrooks PA. Measurement of self-efficacy and proxy efficacy for middle school youth physical activity. Journal of Sport \& Exercise Psychology 2007;29(3):310-32.

Dzewaltowski 2009 \{published data only\}

* Dzewaltowski DA, Estabrooks PA, Welk G, Hill J, Milliken G, Karteroliotis $\mathrm{K}$, et al. Healthy youth places: a randomized controlled trial to determine the effectiveness of facilitating adult and youth leaders to promote physical activity and fruit and vegetable consumption in middle schools. Health Education \& Behavior 2009;36(3):583-600.

\section{Economos 2007 \{published data only\}}

Economos CD, Hyatt RR, Goldberg JP, Must A, Naumova EN, Collins JJ, et al. A community intervention reduces BMI z-score in children: Shape up Somerville first year results. Obesity 2007;15(5):1325-36

\section{Edwards 2005 \{published data only\}}

Edwards B. Childhood obesity: a school-based approach to increase nutritional knowledge and activity levels. Nursing Clinics of North America 2005;40:661-9.

\section{Eisenmann 2007 \{published data only\}}

Eisenmann JC, DuBose KD, Donnelly JE. Fatness, fitness, and insulin sensitivity among 7 - to 9 -year-old children. Obesity 2007;15(8):2135-44.

\section{Ekelund 2004 \{published data only\}}

Ekelund U, Sardinha LB, Anderssen SA, Harro M, Franks PW, Brage $S$. Associations between objectively assessed physical activity and indicators of body fatness in 9- to 10-y-old European children: a population-based study from 4 distinct 
regions in Europe (the European Youth Heart Study). American Journal of Clinical Nutrition 2004;80:584-90.

\section{Eliakim 1996 \{published data only\}}

Eliakim A, Barstow TJ, Brasel JA, Ajie H, Lee WN, Renslo R, et al. Effect of exercise training on energy expenditure, muscle volume, and maximal oxygen uptake in female adolescents. Journal of Pediatrics 1996;129(4):537-43.

\section{Eliakim 1997 \{published data only\}}

Eliakim A, Raisz LG, Brasel JA, Cooper DM. Evidence for increased bone formation following a brief endurance-type training intervention in adolescent males. Journal of Bone \& Mineral Research 1997;12(10):1708-13.

\section{Epstein 2000 \{published data only\}}

* Epstein LH, Paluch RA, Gordy CC, Dorn J. Decreasing sedentary behaviors in treating pediatric obesity. Archives of Pediatrics and Adolescent Medicine 2000;154(3):220-6.

Epstein LH, Saelens BE, Meyers MD, Vito D. Effects of decreasing sedentary behaviours on activity choice in obese children. Health Psychology 1997;16:107-13.

Epstein LH, Valoski AM, Vara LS, McCurley J, Wisniewski L, Kalarchian MA, et al. Effects of decreasing sedentary behavior and increasing activity on weight change in obese children. Health Psychology 1995;14(2):109-15.

\section{Ericsson 2011 \{published data only\}}

Ericsson I. Effects of increased physical activity on motor skills and marks in physical education: an intervention study in school years 1 through 9 in Sweden. Physical Education \& Sport Pedagogy 2011;16(3):313-29.

Ernst 1999 \{published data only\}

* Ernst MP, Pangrazi RP. Effects of a physical activity program on children's activity levels and attraction to physical activity. Pediatric Exercise Science 1999;11(4):393-405.

\section{Ernst 2003 \{published data only\}}

Ernst M. Examination of physical activity during a physical activity intervention and recess. Research Quarterly for Exercise \& Sport 2003;74(1 Suppl):A43.

\section{Errecart 1991 \{published data only\}}

Errecart MT, Walberg HJ, Ross JG, Gold RS, Fiedler JL, Kolbe LJ. Effectiveness of teenage health teaching modules. Journal of School Health 1991;61(1):26-30.

\section{Erwin 2011 \{published data only\}}

Erwin HE, Beighle A, Morgan CF, Noland M. Effect of a low-cost, teacher-directed classroom intervention on elementary students' physical activity. Journal of School Health 2011;81(8):455-61.

\section{Escobar 2010 \{published data only\}}

Escobar Chaves SL, Markham CM, Addy RC, Greisinger A, Murray NG, Brehm B. The Fun Families Study: intervention to reduce children's TV viewing. Obesity 2010;18(Suppl 1):S99-101.

\section{Everhart 2002 \{published data only\}}

Everhart B, Harshaw C, Everhart B, Kermodie M, Stubblefield E. Multimedia software's effects on high school physical education students' fitness patterns. Physical Educator 2002;59(3):151-7.

\section{Ewart 1998 \{published data only\}}

Ewart CK, Young DR, Hagberg JM. Effects of school-based aerobic exercise on blood pressure in adolescent girls at risk for hypertension. American Journal of Public Health 1998;88(6):949-51.

\section{Ezendam 2007 \{published data only\}}

Ezendam NP, Oenema A, van de Looij-Jansen PM, Brug J. Design and evaluation protocol of "FATaintPHAT", a computer-tailored intervention to prevent excessive weight gain in adolescents. BMC Public Health 2007;7:324-34.

Faigenbaum 1999 \{published data only\}

Faigenbaum AC, Westcott WL, Loud RL, Long C. The effects of different resistance training protocols on muscular strength and endurance development in children. Pediatrics 1999;104(1):e5.

Faigenbaum 2001 \{published data only\}

Faigenbaum AD, Chu DA. Plyometric training for children and adolescents. American College of Sports Medicine 2001;December:1-2

Faigenbaum 2003 \{published data only\}

Faigenbaum AD. Youth Resistance Training. Research Digest: President's Council on Physical Fitness and Sports 2003; Vol. 4, issue $3: 1-8$

Faigenbaum 2007 \{published data only\} Faigenbaum AD, McFarland JE, Keiper FB, Tevlin W, Ratamess NA, Jie K, et al. Effects of a short-term plyometric and resistance training program on fitness performance in boys age 12 to 15 years. Journal of Sports Science \& Medicine 2007;6(4):519-25

Faigenbaum 2009 \{published data only\}

Faigenbaum AD, Farrell AC, Radler T, Zbojovsky D, Chu DA, Ratamess NA, et al. "Plyo Play": a novel program of short bouts of moderate and high intensity exercise Improves physical fitness in elementary school children. Physical Educator 2009;66(1):37-44.

\section{Fairclough 2002 \{published data only\}}

Fairclough S. Promoting lifetime physical activity through physical education. Are we providing the right opportunities?. British Journal of Teaching Physical Education 2002;32(2):38-42.

Fairclough 2005 \{published data only\}

Fairclough S, Stratton G. "Physical education makes you fit and healthy". Physical education's contribution to young people's physical activity levels. Health Education Research 2005;20(1):14-23.

Faludi 1999 \{published data only\}

Faludi J, Farkas A, Zsidegh M, Petrekanits M, Pavlik G. Characteristics influencing changes in aerobic performance 
of children aged 7-9. Acta Physiologica Hungarica 1999;86(3-4):229-35.

\section{Fardy 1996 \{published data only\}}

Fardy PS, Azzollini A, Magel JR, Pitsikoulis C. Effects of schoolbased health promotion on obesity: the Path program. Medicine and Science in Sports and Exercise 2002;34(5 Suppl):S68.

Fardy PS, Azzollini A, Magel JR, White RE, Schmitz MK, Agin D, et al. Gender and ethnic differences in health behaviors and risk factors for coronary disease among urban teenagers: the PATH program. Journal of Gender-Specific Medicine 2000;3(2):59-68.

Fardy PS, White RE, Haltiwanger-Schmitz K, Magel JR, McDermott KJ, Clark LT, et al. Coronary disease risk factor reduction and behavior modification in minority adolescents: the PATH program. Journal of Adolescent Health 1996;18(4):217-53.

\section{Fisher 2011 \{published data only\}}

Fisher A, Hill C, Webber L, Purslow L, Wardle J. MVPA is associated with lower weight gain in 8-10 year old children: a prospective study with 1 year follow-up. PloS One 2011;6(4):e18576.

\section{Fitzgibbon 2005 \{published data only\}}

Fitzgibbon ML, Stolley MR, Schiffer L, Van Horn L, KauferChistoffel K, Dyer A. Two-year follow-up results for HipHop to Health Jr: a randomized controlled trial for overweight prevention in preschool minority children. The Journal of Pediatrics 2005;146(5):618-25.

\section{Fitzgibbon 2011 \{published data only\}}

Fitzgibbon ML, Stolley MR, Schiffer LA, Braunschweig CL, Gomez SL, Van Horn L, et al. Hip-Hop to Health Jr. obesity prevention effectiveness trial: postintervention results. Obesity 2011;19(5):994-1003.

\section{Fleming 2000 \{published data only\}}

Fleming TL, Green JL, Martin JC, Wicks MW. Effectiveness of a cardiovascular health promotion education intervention on the attitudes of urban African American school-age children. Journal of Community Health Nursing 2000;17(1):49-60.

Flores 1995 \{published data only\}

* Flores R. Dance for health: improving fitness in African American and Hispanic adolescents. Public Health Reports 1995;110(2):189-93.

\section{Foster 1985 \{published data only\}}

Foster GD, Wadden TA, Brownell KD. Peer-led program for the treatment and prevention of obesity in the schools. Journal of Consulting and Clinical Psychology 1985;53(4):538-40.

\section{Foster 2008 \{published data only\}}

Foster GD, Sherman S, Borradaile KE, Grundy KM, Vander Veur SS, Nachmani J, et al. A policy-based school intervention to prevent overweight and obesity. Pediatrics 2008;121(4):e794-802.

\section{Fox 2004 \{published data only\}}

Fox K, Cooper A, McKenna J. The school and promotion of children's health enhancing physical activity. Journal of Teaching in Physical Education 2004;23:338-58.

\section{Francis 2010 \{published data only\}}

Francis M, Nichols SS, Dalrymple N. The effects of a schoolbased intervention programme on dietary intakes and physical activity among primary-school children in Trinidad and Tobago. Public Health Nutrition 2010;13(5):738-47.

\section{Frauhiger 2002 \{published data only\}}

Frauhiger $L$. The effects of daily physical activity on student academic achievement and physical health. [Thesis] 2002.

\section{Frenn 2003 \{published data only\}}

Frenn M, Malin S. Addressing health disparities in middle school students nutrition and exercise. Journal of Community Health Nursing 2003;20(1):1-14.

\section{Frenn 2005 \{published data only\}}

Frenn M, Malin S, Brown RL, Greer Y, Fox J, Greer J, et al. Changing the tide: an internet/video exercise and low-fat diet intervention with middle-school students. Applied Nursing Research 2005;18:13-21.

\section{Fuchs 2002 \{published data only\}}

Fuchs RK, Bauer JJ, Snow CM. Jumping improves hip and lumbar spine bone mass in prepubescent children: a randomized controlled trial. Journal of Bone \& Mineral Research 2001;16(1):148-56

* Fuchs RK, Snow CM. Gains in hip bone mass from highimpact training are maintained: a randomized controlled trial in children. Journal of Pediatrics 2002;141:357-62.

\section{Fullerton 2007 \{published data only\}}

Fullerton G, Tyler C, Johnston CA, Vincent JP, Harris GE, Foreyt JP. Quality of life in Mexican-American children following a weight management program. Obesity 2007;15(11):2553-6.

\section{Gallotta 2009 \{published data only\}}

Gallotta MC, Marchetti R, Baldari C, Guidetti L, Pesce C. Linking co-ordinative and fitness training in physical education settings. Scandinavian Journal of Medicine \& Science in Sports 2009;19(3):412-8

\section{Giralt 2011 \{published data only\}}

Giralt M, Albaladejo R, Tarro L, Morina D, Arija V, Sola R. A primary-school-based study to reduce prevalence of childhood obesity in Catalunya (Spain) - EDAL-Educacion en alimentacion: study protocol for a randomised controlled trial. Trials 2011;12:54

\section{Goldfine 1993 \{published data only\}}

* Goldfine BD, Nahas MV. Incorporating health-fitness concepts in secondary physical education curricula. Journal of School Health 1993;63(3):142-6. 


\section{Goran 1999 \{published data only\}}

Goran MI, Reynolds KD, Lindquist CH. Role of physical activity in the prevention of obesity in children. International Journal of Obesity and Related Metabolic Disorders 1999;23(Suppl 3):S18S33.

\section{Goran 2005 \{published data only\}}

Goran MI, Reynolds K. Interactive multimedia for promoting physical activity (IMPACT) in children. Obesity Research 2005;13(4):762-71

\section{Gore 1996 \{published data only\}}

Gore CJ, Owen N, Pederson D, Clarke A. Educational and environmental interventions for cardiovascular health promotion in socially disadvantaged primary schools. Australian \& New Zealand Journal of Public Health 1996;20(2):188-94.

\section{Gortmaker 1999a \{published data only\}}

* Gortmaker SL, Cheung LWY, Peterson KE, Chomitz G, Cradle JH, Dart H, et al. Impact of a school-based interdisciplinary intervention on diet and physical activity among urban primary school children: eat well and keep moving. Archives of Pediatrics and Adolescent Medicine 1999;153(9):975-83.

\section{Gortmaker 1999b \{published data only\}}

* Gortmaker SL, Peterson KE, Wiecha J, Sobol AM, Dixit S, Fox MK, et al. Reducing obesity via a schoolbased interdisciplinary intervention among youth: Planet Health. Archives of Pediatrics and Adolescent Medicine 1999;153(4):409-18.

Kerr CM. A school based, interdisciplinary curriculum in grades 6 and 7 reduced obesity in girls. Evidence-Based Nursing 2000;3(1):13.

\section{Graf 2005 \{published data only\}}

Graf C, Rost SV, Koch B, Heinen S, Falkowski G, Dordel S, et al. Data from the StEP TWO programme showing the effect on blood pressure and different parameters for obesity in overweight and obese primary school children. Cardiology in the Young 2005;15(3):291-8.

\section{Graf 2008 \{published data only\}}

Graf C, Koch B, Falkowski G, Jouck S, Christ H, Staudenmaier K, et al. School-based prevention: effects on obesity and physical performance after 4 years. Journal of Sports Sciences 2008;26(10):987-94

\section{Grafner 1987 \{published data only\}}

* Grafner L, Heinrich J, Knappe J, Holtz H. Atherosclerosis precursors in school children: results of a two-year intervention study. Cor Vasa 1987;29(8):421-7.

\section{Graham 2008 \{published data only\}}

Graham DJ, Schneider M, Cooper DM. Television viewing: moderator or mediator of an adolescent physical activity intervention?. American Journal of Health Promotion 2008;23(2):88-91.

\section{Graham 2008a \{published data only\}}

Graham D, Appleton S, Rush E, McLennan S, Reed P, Simmons D. Increasing activity and improving nutrition through a schoolsbased programme: Project Energize. 1. Design, programme, randomisation and evaluation methodology. Public Health Nutrition 2008;11(10):1076-84.

\section{Greene 1995 \{published data only\}}

Greene JC, Ignico AA. The effect of a ten-week physical fitness program on fitness profiles, self-concept, and body-esteem in children. Journal of the International Council for Health, Physical Education, Recreation, Sport \& Dance 1995;31(4):42-7.

Greening 2011 \{published data only\}

Greening L, Harrell KT, Low AK, Fielder CE. Efficacy of a schoolbased childhood obesity intervention program in a rural southern community: TEAM Mississippi Project. Obesity 2011;19(6):1213-19.

\section{Grey 2004 \{published data only\}}

Grey M, Berry D, Davidson M, Galasso P, Gustafson E, Melkus $G$. Preliminary testing of a program to prevent type 2 diabetes among high-risk youth. Journal of School Health 2004;74(1):10-5.

\section{Grey 2009 \{published data only\}}

Grey M, Jaser SS, Holl MG, Jefferson V, Dziura J, Northrup V. A multifaceted school-based intervention to reduce risk for type 2 diabetes in at risk youth. Preventive Medicine 2009;49(2-3):122-8.

\section{Grund 2001 \{published data only\}}

Grund A, Krause H, Siewers M, Rieckert H, Muller MJ. Is TV viewing an index of physical activity and fitness in overweight and normal weight children?. Public Health Nutrition 2001;4(6):1245-51.

\section{Guldbrandsson 2009 \{published data only\}}

Guldbrandsson K, Modig Wennerstad K, Rasmussen F. Municipal policies and plans of action aiming to promote physical activity and healthy eating habits among school children in Stockholm, Sweden: a cross-sectional study. Implementation Science 2009;4:47.

\section{Gunter 2008 \{published data only\}}

Gunter K, Baxter-Jones AD, Mirwald RL, Almstedt H, Fuchs RK, Durski S, et al. Impact exercise increases BMC during growth: an 8-year longitudinal study. Journal of Bone \& Mineral Research 2008;23(7):986-93.

\section{Gutin 1993 \{published data only\}}

Gutin B, Manos TM. Physical activity in the prevention of childhood obesity. Annals of the New York Academy of Sciences 1993;699:115-26

\section{Gutin 1995 \{published data only\}}

Gutin B, Cucuzzo N, Islam S, Smith C, Moffatt R, Pargman D. Physical training improves body composition of black obese 7 to 11-year-old girls. Obesity Research 1995;3(4):305-12. 
Gutin 1999 \{published data only\}

Gutin B, Ramsey L, Barbeau P, Cannady W, Ferguson M, Litaker M, et al. Plasma leptin concentrations in obese children: changes during 4-month periods with and without physical training. American Journal of Clinical Nutrition 1999;69(3):388-94.

\section{Gutin 2002 \{published data only\}}

Gutin B, Barbeau P, Owens ST, Lemmon CR, Bauman M, Allison J, et al. Effects of exercise intensity on cardiovascular fitness, total body composition, and visceral adiposity of obese adolescents. American Journal of Clinical Nutrition 2002;75(5):818-26

\section{Gutin 2005 \{published data only\}}

Gutin B, Yin Z, Humphries MC, Barbeau P. Relations of moderate and vigorous physical activity to fitness and fatness in adolescents. American Journal of Clinical Nutrition 2005;81:746-50.

\section{Haerens 2007 \{published data only\}}

Haerens L, Deforche B, Vandelanotte C, Maes L, De Bourdeaudhuij I. Acceptability, feasibility and effectiveness of a computer-tailored physical activity intervention in adolescents. Patient Education \& Counseling 2007;66(3):303-10.

\section{Haines 2006 \{published data only\}}

Haines J, Neumark-Sztainer D, Perry CL, Hannan PJ, Levine MP. V.I.K. (Very Important Kids): a school-based program designed to reduce teasing and unhealthy weight-control behaviors. Health Education Research 2006;21(6):884-95.

\section{Halfon 1988 \{published data only\}}

Halfon ST, Bronner S. The influence of a physical ability intervention program on improved running time and increased sport motivation among Jerusalem schoolchildren. Adolescence 1988;23(90):405-16

\section{Hansen 1991 \{published data only\}}

Hansen HS, Froberg K, Hyldebrandt N, Nielsen JR. A controlled study of eight months of physical training and reduction of blood pressure in children: the Odense schoolchild study. BMJ 1991;303(6804):682-5.

\section{Hansen 2005 \{published data only\}}

Hansen SE, Hasselstrom H, Gronfeldt V, Froberg K, Andersen L. Cardiovascular disease risk factors in 6-7-year-old Danish children: the Copenhagen school child intervention study. Preventive Medicine 2005;40(6):740-6.

\section{Hardman 2011 \{published data only\}}

Hardman CA, Horne PJ, Fergus LC. Effects of rewards, peermodelling and pedometer targets on children's physical activity: a school-based intervention study. Psychology \& Health 2011;26(1):3-21.

\section{Hardy 2007 \{published data only\}}

Hardy LL, Bass SL, Booth ML. Changes in sedentary behavior among adolescent girls: a 2.5-year prospective cohort study. Journal of Adolescent Health 2007;40:158-65.

\section{Harrell 1998 \{published data only\}}

Harrell JS, Gansky SA, McMurray RG, Bangdiwala SI, Frauman AC, Bradley CB. School-based interventions improve heart health in children with multiple cardiovascular disease risk factors. Pediatrics 1998;102(2 Pt 1):371-80.

\section{Harris 1998 \{published data only\}}

Harris KJ, Richter KP, Schultz J, Johnston J. Formative, process, and intermediate outcome evaluation of a pilot school-based 5-a-day for Better Health Project. American Journal of Health Promotion 1998;12(6):378-81.

Hart 2003 \{published data only\}

Hart KH, Herriot A, Bishop JA, Truby H. Promoting healthy diet and exercise patterns amongst primary school children: a qualitative investigation of parental perspectives. Journal of Human Nutrition \& Dietetics 2003;16(2):89-96

\section{Hartmann 2010 \{published data only\}}

Hartmann T, Zahner L, Puhse U, Puder JJ, Kriemler S. Effects of a school-based physical activity program on physical and psychosocial quality of life in elementary school children: a cluster-randomized trial. Pediatric Exercise Science 2010;22(4):511-22.

Hartmann T, Zahner L, Puhse U, Schneider S, Puder JJ, Kriemler S. Physical activity, bodyweight, health and fear of negative evaluation in primary school children. Scandinavian Journal of Medicine \& Science in Sports 2010;20(1):e27-34.

\section{Hasselstrom 2008 \{published data only}

Hasselstrom HA, Karlsson MK, Hansen SE, Gronfeldt V, Froberg K, Andersen LB. A 3-year physical activity intervention program increases the gain in bone mineral and bone width in prepubertal girls but not boys: the prospective Copenhagen School Child Interventions Study (CoSCIS). Calcified Tissue International 2008;83(4):243-50.

\section{Hastie 2007 \{published data only\}}

Hastie PA, Sluder B, Buchanan AM. Impact of a sport education "obstacle course" season on students' cardiovascular fitness. Research Quarterly for Exercise \& Sport 2007;78(1):-.

\section{Heale 2008 \{published data only\}}

Heale R. A group intervention for parents and children achieved greater weight loss in obese children than routine care. Evidence-Based Nursing 2008;11(2):43.

\section{HEALTHY Study Group 2010 \{published data only\}}

HEALTHY Study Group, Foster GD, Linder B, Baranowski T, Cooper DM, Goldberg L, et al. A school-based intervention for diabetes risk reduction. New England Journal of Medicine 2010;363(5):443-53.

\section{Henaghan 2008 \{published data only\}}

Henaghan J, McWhannell N, Foweather L, Cable NT, Batterham AM, Stratton G, et al. The effect of structured exercise classes and a lifestyle intervention on cardiovascular risk factors in primary schoolchildren: an exploratory trial (The ACLASS Project). Pediatric Exercise Science 2008;20(2):169-80. 
Hipsky 2002 \{published data only\}

Hipsky J, Kirk S. HealthWorks! Weight management program for children and adolescents. Journal of the American Dietetic Association 2002;102(3 Suppl):S64-7.

\section{Hoelscher 2010 \{published data only\}}

Hoelscher DM, Springer AE, Ranjit N, Perry CL, Evans AE, Stigler M, et al. Reductions in child obesity among disadvantaged school children with community involvement: The Travis County CATCH Trial. Obesity 2010;18(Suppl 1):S36-44.

\section{Holcomb 1998 \{published data only\}}

* Holcomb JD, Lira J, Kingery PM, Smith DW, Lane D, Goodway J. Evaluation of Jump Into Action: a program to reduce the risk of non-insulin dependent diabetes mellitus in school children on the Texas-Mexico border. Journal of School Health 1998;68(7):282-8.

\section{Hollar 2010 \{published data only\}}

Hollar D, Messiah SE, Lopez-Mitnik G, Hollar TL, Almon M, Agatston AS. Effect of a two-year obesity prevention intervention on percentile changes in body mass index and academic performance in low-income elementary school children. American Journal of Public Health 2010;100(4):646-53.

Hollar D, Messiah SE, Lopez-Mitnik G, Hollar TL, Almon M, Agatston AS. Healthier options for public schoolchildren program improves weight and blood pressure in 6- to 13year-olds. Journal of the American Dietetic Association 2010;110(2):261-7.

\section{Hopper 1992 \{published data only\}}

Hopper CA, Gruber MB, Munoz KD, Herb RA. Effect of including parents in a school-based exercise and nutrition program for children. Research Quarterly for Exercise \& Sport 1992;63(3):315-21.

\section{Hopper 1996 \{published data only\}}

Hopper CA, Gruber MB, Munoz KD, MacConnie SE. Schoolbased cardiovascular exercise and nutrition programs with parent participation. Journal of Health Education 1996;27(5 Suppl):S32-9.

* Hopper CA, Munoz KD, Gruber MB, MacConnie SE, Schonfeldt B, Shunk T. A school-based cardiovascular exercise and nutrition program with parent participation: an evaluation study. Children's Health Care 1996;25(3):221-35.

\section{Hopper 2001 \{published data only\}}

Hopper CA, Gruber MB, Munoz KD, MacConnie SE, Pfingston YM, Nguyen K. Relationship of blood cholesterol to body composition, physical fitness, and dietary intake measures in third-grade children and their parents. Research Quarterly for Exercise and Sport 2001;72(2):182-8.

\section{Hopper 2005 \{published data only\}}

Hopper CA, Munoz KD, Gruber MB, Nguyen KP. The effects of a family fitness program on the physical activity and nutrition behaviors of third-grade children. Research Quarterly for Exercise \& Sport 2005;76(2):130-9.

\section{Howard 1996 \{published data only\}}

* Howard JK, Bindler RM, Synoground G, Van Gemert FC. A cardiovascular risk reduction program for the classroom. Journal of School Nursing 1996;12(4):4-11.

\section{Howe 2003 \{published data only\}}

Howe C, Gutin B, Litaker M, Barbeau P. Effect of a physical activity intervention on heart rate variability in black girls: relative changes in fitness and fatness. Medicine \& Science in Sports \& Exercise 2003;35(5 Supplement):S70.

\section{Huang 2007 \{published data only\}}

Huang SH, Weng KP, Hsieh KS, Ou SF, Lin CC, Chien KJ, et al. Effects of a classroom-based weight-control intervention on cardiovascular disease in elementary-school obese children. Acta Paediatrica Taiwanica 2007;48(4):201-6.

Huberty 2011 \{published data only\}

Huberty JL, Siahpush M, Beighle A, Fuhrmeister E, Silva P, Welk G. Ready for recess: a pilot study to increase physical activity in elementary school children. Journal of School Health 2011;81(5):251-7.

\section{Huguet 1997 \{published data only\}}

Huguet G, Touitou Y, Reinberg A. Morning versus afternoon gymnastic time and diurnal and seasonal changes in psychophysiological variables of school children. Chronobiology International 1997;14(4):371-84.

Ingle 2006 \{published data only\} Ingle L, Sleap M, Tolfrey K. The effect of a complex training and detraining programme on selected strength and power variables in early pubertal boys. Journal of Sports Sciences 2006;24(9):987-97.

Irwin 2010 \{published data only\} Irwin CC, Irwin RL, Miller ME, Somes GW, Richey PA. Get Fit With the Grizzlies: a community-school-home initiative to fight childhood obesity. Journal of School Health 2010;80(7):333-9.

\section{Jackson 2001 \{published data only\}} Jackson DM, Williamson A, Grant S, Paton JY, Reilly JJ. Effects of a physical activity programme on activity and motor skills in young children: a controlled trial. FASEB Journal 2001;15(5):A951.

\section{Jago 2009 \{published data only\}} Jago R, McMurray RG, Bassin S, Pyle L, Bruecker S, Jakicic JM, et al. Modifying middle school physical education: piloting strategies to increase physical activity. Pediatric Exercise Science 2009;21(2):171-85

\section{James 2007 \{published data only\}}

James J, Thomas P, Kerr D. Preventing childhood obesity: two year follow-up results from the Christchurch obesity prevention programme in schools (CHOPPS). British Medical Journal 2007;335(7623):762,763-764

\section{Jamner 2004 \{published data only\}}

Jamner MS, Spruijt-Metz D, Bassin S, Cooper DM. A controlled evaluation of a school-based intervention to promote physical 
activity among sedentary adolescent females: Project FAB. Journal of Adolescent Health 2004;34(4):279-89.

\section{Jansen 2008 \{published data only\}}

Jansen W, Raat H, Zwanenburg EJ, Reuvers I, van Walsem R, Brug J. A school-based intervention to reduce overweight and inactivity in children aged 6-12 years: study design of a randomized controlled trial. BMC Public Health 2008;8:257-66.

\section{Janz 2002 \{published data only\}}

Janz KF, Dawson JD, Mahoney LT. Increases in physical fitness during childhood improve cardiovascular health during adolescence: the Muscatine Study. International Journal of Sports Medicine 2002;23 Suppl 1:S15-21.

\section{Jekal 2009 \{published data only\}}

Jekal Y, Kim ES, Im JA, Park JH, Lee MK, Lee SH, et al. Interaction between fatness and fitness on CVD risk factors in Asian youth. International Journal of Sports Medicine 2009;30(10):733-40.

\section{Jemmott 2011 \{published data only\}}

Jemmott JB, Jemmott LS, O'Leary A, Ngwane Z, Icard L, Bellamy S, et al. Cognitive-behavioural health-promotion intervention increases fruit and vegetable consumption and physical activity among South African adolescents: a cluster-randomised controlled trial. Psychology \& Health 2011;26(2):167-85.

\section{Jiang 2007 \{published data only\}}

Jiang J, Xia X, Greiner T, Wu G, Lian G, Rosenqvist U. The effects of a 3-year obesity intervention in schoolchildren in Beijing. Child: Care, Health \& Development 2007;33(5):641-6.

\section{Johns 1999 \{published data only\}}

Johns DP, Ha AS. Home and recess physical activity of Hong Kong children. Research Quarterly for Exercise and Sport 1999;70(3):319-23.

\section{Johnson-Down 1997 \{published data only\}}

Johnson-Down L, O'Loughlin J, Koski KG, Gray-Donald K. High prevalence of obesity in low income and multiethnic schoolchildren: a diet and physical activity assessment. Journal of Nutrition 1997;127(12):2310-5.

\section{Johnston 2007 \{published data only\}}

Fullerton G, Tyler C, Johnston CA, Vincent JP, Harris GE, Foreyt JP. Quality of life in Mexican-American children following a weight management program. Obesity 2007;15(11):2553-6.

Johnston CA, Tyler C, Fullerton G, McFarlin BK, Poston WS, Haddock CK, et al. Effects of a school-based weight maintenance program for Mexican-American children: results at 2 years. Obesity 2010;18(3):542-7.

* Johnston CA, Tyler C, Fullerton G, Poston WS, Haddock CK, McFarlin B, et al. Results of an intensive school-based weight loss program with overweight Mexican American children. International Journal of Pediatric Obesity 2007;2(3):144-52.

\section{Jones 1988 \{published data only\}}

Jones T, Kozinetz C, Bermudez A, Mazur L, Kaplowitz H. Regular aerobic exercise and blood pressure in children. An efficacy school-based randomized clinical trial. American Journal of Epidemiology 1988;128(4):898-9.

\section{Jones 2007 \{published data only\}}

Jones G, Stuart J, Parkins G, Millar C, Stewart K, Murray A, et al. The effect of a 16-week implementation of intervention strategies into after-school activity lesson plans on the aerobic fitness and percentage body fat of children aged 8-14 years old. British Journal of Sports Medicine 2007;41(2):119.

\section{Jordan 1995 \{published data only\}}

Jordan MC. A comparison of intermittent exercise and relaxation versus steady state exercise on fitness levels and attitudes in seventh grade girls. [Thesis]. Brigham Young University 1995.

\section{Jurg 2006 \{published data only\}}

Jurg ME, Kremers SPJ, Candel MJJ, Van der Wal MF, Meij JSB. A controlled trial of a school-based environmental intervention to improve physical activity in Dutch children: JUMP-in, kids in motion. Health Promotion International 2006;21(4):320-30.

\section{Kain 2004 \{published data only\}}

Kain J, Albala RU, Vio F, Cerda R, Leyton B. School-based obesity prevention in Chilean primary school children: methodology and evaluation of a controlled study. International Journal of Obesity 2004;28(4):483-93.

\section{Kain 2008 \{published data only\}}

Kain J, Leyton B, Cerda R, Vio F, Uauy R. Two-year controlled effectiveness trial of a school-based intervention to prevent obesity in Chilean children. Public Health Nutrition 2008;12(9):1451-61.

\section{Kann 2000 \{published data only\}}

Kann L, Brener ND, Allensworth DD. Health education: results from the School Health Policies and Programs Study 2000. Journal of School Health 2000;71(7):266-78.

\section{Kaplan 1996 \{published data only\}}

Kaplan TA, Campbell MH, Moccia-Loos G. Effects of a 3month exercise and nutrition program for childhood obesity on anthropometrics, physical fitness, and serum lipids. International Pediatrics 1996;11(1):31-7.

\section{Karabourniotis 2002 \{published data only\}}

Karabourniotis D, Evaggelinou C, Tzetzis G, Kourtessis T. Curriculum enrichment with self-testing activities in development of fundamental movement skills of first-grade children in Greece. Perceptual \& Motor Skills 2002;94(3 Pt 2):1259-70.

\section{Katz 2010 \{published data only\}}

Katz DL, Cushman D, Reynolds J, Njike V, Treu JA, Walker J, et al. Putting physical activity where it fits in the school day: preliminary results of the $A B C$ (Activity Bursts in the Classroom) for fitness program. Preventing Chronic Disease 2010;7(4):A82.

\section{Kawabe 2000 \{published data only\}}

Kawabe H, Murata K, Shibata H, Hirose H, Tsujioka M, Saito I, et al. Participation in school sports clubs and related effects

School-based physical activity programs for promoting physical activity and fitness in children and adolescents aged 6 to 18 (Review) 
on cardiovascular risk factors in young males. Hypertension Research 2000;23(3):227-32.

\section{Keays 1995 \{published data only\}}

Keays JJ, Allison KR. The effects of regular moderate to vigorous physical activity on student outcomes: a review. Canadian Journal of Public Health 1995;86(1):62-5.

\section{Kelder 1995a \{published data only\}}

Kelder SH, Perry CL, Lytle LL, Klepp KI. Gender differences in the class of 1989 study: the school component of the Minnesota Heart Health Program. Journal of Health Education 1995;26:S36S44.

\section{Kelder 2004 \{published data only\}}

Kelder S, Hoelscher DM, Barroso CS, Walker JL, Cribb P, Hu S. The CATCH Kids Club: a pilot after-school study for improving elementary students' nutrition and physical activity. Public Health Nutrition 2004;8(2):133-40.

\section{Kijboonchoo 1999 \{published data only\}}

Kijboonchoo K, Thasanasuwan W, Yamborisut U. Nutrifit programme to improve health-related fitness among young Thai schoolchildren. Food Nutrition Bulletin 1999;2:231-7.

\section{Killen 1989 \{published data only\}}

* Killen JD, Robinson TN, Telch MJ, Saylor KE, Maron DJ, Rich T, et al. The Stanford Adolescent Heart Health Program. Health Education Quarterly 1989;16(2):263-83.

Killen JD, Taylor CB, Hammer LD, Litt I, Wilson DM, Rich T, et al. An attempt to modify unhealthful eating attitudes and weight regulation practices of young adolescent girls.. International Journal of Eating Disorders 1993;13(4):369-84.

Killen JD, Telch MJ, Robinson TN, Maccoby N, Taylor CB, Farquhar JW. Cardiovascular disease risk reduction for tenth graders. a multiple-factor school-based approach. Journal of the American Medical Association 1988;260(12):1728-33.

\section{Kimm 1997 \{published data only\}}

Kimm SYS, Glynn NW, Similo S, Kriska A, Fitzgerald S, Aaron DJ, et al. Longitudinal assessment of physical activity (PA) in young girls. American Journal of Epidemiology 1997;145(11 Suppl):S25.

\section{Kimm 2005 \{published data only\}}

Kimm SYS, Glynn NW, Obarzanek E, Kriska AM, Daniels SR, Barton BA, et al. Relation between the changes in physical activity and body-mass index during adolescence: a multicentre longitudinal study. The Lancet 2005;366(9482):301-7.

\section{Kiran 2010 \{published data only\}}

Kiran A, Knights J. Traditional indigenous games promoting physical activity and cultural connectedness in primary schools - cluster randomised control trial. Health Promotion Journal of Australia 2010;21(2):149-51.

\section{Kirkcaldy 2002 \{published data only\}}

Kirkcaldy BD, Shephard RJ, Siefen RG. The relationship between physical activity and self-image and problem behaviour among adolescents. Social Psychiatry and Psychiatric Epidemiology 2002;37(11):544-50.

\section{Klein-Platat 2005 \{published data only\}}

Klein-Platat C, Oujaa M, Wagner A, Haan MC, Arveiler D, Schlienger JL, et al. Physical activity is inversely related to waist circumference in 12-y-old French adolescents. International Journal of Obesity 2005;29(1):9-14.

Klepp 1994 \{published data only\}

Klepp KI, Oygard L, Tell Grethe S, Vellar Odd D. Twelve year follow-up of a school-based health education programme. European Journal of Public Health 1994;4:195-200.

Tell GS, Vellar OD. Physical fitness, physical activity, and cardiovascular disease risk factors in adolescents: the Oslo Youth Study. Preventive Medicine 1988;17:12-24.

\section{Knox 2009 \{published data only\}}

Knox G, Baker JS, Davies B, Faulkner S, Rance J, Rees A, et al. A cross-curricular physical activity intervention to combat cardiovascular disease risk factors in 11-14 year olds: 'activity knowledge circuit'. BMC Public Health 2009;9:466.

Kolbe 1995 \{published data only\}

Kolbe LJ, Kann L, Collins JL, Small ML, Pateman BC, Warren CW. The School Health Policies and Programs Study (SHPPS): context, methods, general findings, and future efforts. Journal of School Health 1995;65(8):339-43.

\section{Kong 2009 \{published data only\}}

Kong AS, Sussman AL, Negrete S, Patterson N, Mittleman R, Hough R. Implementation of a walking school bus: lessons learned. Journal of School Health 2009;79(7):319-25.

\section{Kouli 2009 \{published data only\}}

Kouli O, Rokka S, Mavridis G, Derri V. The effects of an aerobic program on health-related fitness and intrinsic motivation in elementary school pupils. Studies in Physical Culture \& Tourism 2009;16(3):301-6.

Koutedakis 2003 \{published data only\}

Koutedakis Y, Bouziotas C. National physical education curriculum: motor and cardiovascular health related fitness in Greek adolescents. British Journal of Sports Medicine 2003;37(4):311-4.

Kovacs 2009 \{published data only\}

Kovacs VA, Fajcs Zs, Gabor A, Martos E. School-based exercise program improves fitness, body composition and cardiovascular risk profile in overweight/obese children. Acto Physiologica Hungarica 2009;96(3):337-47.

Kremers 2005 \{published data only\}

Kremers SPJ, Visscher TLS, Brug J, Chin MJM, Paw A, Schouten EG, et al. Netherlands research programme weight gain prevention (NHF-NRG): rationale, objectives and strategies. European Journal of Clinical Nutrition 2005;59(4):498-507.

Kriemler 2011 \{published data only\}

Kriemler S, Meyer U, Martin E, van Sluijs EM, Andersen LB, Martin BW. Effect of school-based interventions on physical activity and fitness in children and adolescents: a review 
of reviews and systematic update. British Journal of Sports Medicine 2011;45(11):923-30.

\section{Kristensen 2010 \{published data only\}}

Kristensen PL, Moeller NC, Korsholm L, Kolle E, Wedderkopp N, Froberg $\mathrm{K}$, et al. The association between aerobic fitness and physical activity in children and adolescents: the European youth heart study. European Journal of Applied Physiology 2010;110(2):267-75

\section{Kwon 2007 \{published data only\}}

Kwon MS, Hwang KS. Effects of an exercise program on body composition, cardiopulmonary function, and physical fitness for obese children. Taehan Kanho Hakhoe Chi 2007;37:568-75.

\section{Lal 1991 \{published data only\}}

Lal S, Saini RK, Khanna P, Malik JS. Empowering young girls for health and development. Indian Journal of Pediatrics 1991;58(3):357-62.

\section{La Torre 2006 \{published data only\}}

La Torre G, Masala D, De Vito E, Langiano E, Capelli G, Walter R, et al. Extra-curricular physical activity and socioeconomic status in Italian adolescents. BMC Public Health 2006;6:22.

\section{Lawman 2011 \{published data only\}}

Lawman HG, Wilson DK, Van Horn ML, Resnicow K, KitzmanUlrich $\mathrm{H}$. The relationship between psychosocial correlates and physical activity in underserved adolescent boys and girls in the ACT trial. Journal of Physical Activity \& Health 2011;8(2):253-61.

\section{Lazarus 2000 \{published data only\}}

Lazarus R, Wake M, Hesketh K, Waters E. Change in body mass index in Australian primary school children, 1985 - 1997. International Journal of Obesity 2000;24(6):679-84.

\section{Lee 2010 \{published data only\}}

Lee A, Mandy H, Vera K. Healthy school as an ecological model for prevention of childhood obesity. Research in Sports Medicine 2010;18(1):49-61.

\section{Le Masurier 2005 \{published data only\}}

Le Masurier GC, Beighle A, Corbin CB. Pedometer determined physical activity levels of youth. Journal of Physical Activity and Health 2005;2(2):159-68.

\section{LeMura 2000 \{published data only\}}

LeMura LM, Andreacci J, Carlonas R, Klebez JM, Chelland S. Evaluation of physical activity measured via accelerometry in rural fourth-grade children. Perceptual and Motor Skills 2000;90(1):329-37.

\section{Levin 2002 \{published data only\}}

Levin S, Martin MW, McKenzie TL, DeLouise AC. Assessment of a pilot video's effect on physical activity and heart health for young children. Family and Community Health 2002;25(3):10-7.

\section{Lien 2010 \{published data only\}}

Lien N, Bjelland M, Bergh IH, Grydeland M, Anderssen SA, Ommundsen Y, et al. Design of a 20-month comprehensive, multicomponent school-based randomised trial to promote healthy weight development among 11-13 year olds: the Health In Adolescents study. Scandinavian Journal of Public Health 2010;38(Suppl 5):38-51.

\section{Lindstrom 2010 \{published data only\}}

Lindstrom J, Absetz P, Hemi K, Peltomaki P, Peltonen M. Reducing the risk of type 2 diabetes with nutrition and physical activity - efficacy and implementation of lifestyle interventions in Finland. Public Health Nutrition 2010;13(6A):993-9.

\section{Lionis 1991 \{published data only\}}

Lionis C, Kafatos A, Vlachonikolis J, Vakaki M, Tzortzi M, Petraki A. The effects of a health education intervention program among Cretan adolescents. Preventive Medicine 1991;20(6):685-99.

\section{Liskova 2002 \{published data only\}}

Liskova S, Moravcova A, Kytnarova J, Hosek P. Long-term effectiveness of obesity intervention program in children. International Journal of Obesity 2002;26(Suppl 1):S10.

Lubans 2006 \{published data only\}

Lubans D, Sylva K. Controlled evaluation of a physical activity intervention for senior school students: effects of the lifetime activity program. Journal of Sport \& Exercise Psychology 2006;28(3):252-68.

\section{Lubans 2010a \{published data only\}}

Lubans DR, Sheaman C, Callister R. Exercise adherence and intervention effects of two school-based resistance training programs for adolescents. Preventive Medicine 2010;50(1-2):56-62.

\section{Lubans 2010b \{published data only\}}

Lubans DR, Morgan PJ, Dewar D, Collins CE, Plotnikoff RC, Okely AD, et al. The Nutrition and Enjoyable Activity for Teen Girls (NEAT girls) randomized controlled trial for adolescent girls from disadvantaged secondary schools: rationale, study protocol, and baseline results. BMC Public Health 2010;10:652.

\section{Lubans 2011 \{published data only\}}

Lubans DR, Morgan PJ, Aguiar EJ, Callister R. Randomized controlled trial of the Physical Activity Leaders (PALs) program for adolescent boys from disadvantaged secondary schools. Preventive Medicine 2011;52(3-4):239-46.

\section{Ludwig 2004 \{published data only\}}

Ludwig A, Doyle-Baker PK. Assessment of Calgary elementary physical education programs. Canadian Journal of Applied Physiology 2004;29 Suppl:S63.

\section{Luepker 1999 \{published data only\}}

Luepker RV. How physically active are American children and what can we do about it?. International Journal of Obesity and Related Metabolic Disorders 1999;23(Suppl 2):S12-7.

\section{Lungo 1994 \{published data only\}}

Lungo D. The effect of aerobic exercise on total cholesterol, high-density lipoprotein, apolipoprotein B, apolipoprotein AI and percent body fat in adolescent females. Brigham Young University 1994. 
Macaulay 1997 \{published data only\}

Macaulay AC, Paradis G, Potvin L, Cross EJ, Saad-Haddad C, McComber A, et al. The Kahnawake Schools Diabetes Prevention Project: intervention, evaluation, and baseline results of a diabetes primary prevention program with a native community in Canada. Preventive Medicine 1997;26(6):779-90.

\section{MacConnie 1991 \{published data only\}}

MacConnie SE, Hopper CA, Munoz KD, Gruber MB. The effect of parental inclusion in an exercise and nutrition intervention program. Medicine and Science in Sports and Exercise 1991;23(4 Suppl):S30.

\section{Macdonald 1999 \{published data only\}}

Macdonald SA. The Cardiovascular Health Education Program: assessing the impact on rural and urban adolescents' health knowledge. Applied Nursing Research 1999;12(2):86-90.

\section{Macdonald 2007 \{published data only\}}

Macdonald HM, Kontuainen SA, Khan KM, McKay HA. Is a school-based physical activity intervention effective for increasing tibial bone strength in boys and girls?. Journal of Bone and Mineral Research 2007;22:434-46.

MacKelvie 2001 \{published data only\}

MacKelvie KJ, McKay HA, Khan KM, Crocker PRE. A school-based exercise intervention augments bone mineral accrual in early pubertal girls. Journal of Pediatrics 2001;139:501-8.

\section{MacKelvie 2002 \{published data only\}}

MacKelvie KJ, McKay HA, Petit MA, Moran O, Khan KM. Bone mineral response to a 7-month randomized controlled, school-based jumping intervention in 121 prepubertal boys: associations with ethnicity and body mass index. Journal of Bone \& Mineral Research. 2002;17(5):834-44.

\section{MacKelvie 2004 \{published data only\}}

MacKelvie KJ, Petit MA, Khan KM, Beck TJ, McKay HA. Bone mass and structure are enhanced following a 2-year randomized controlled trial of exercise in prepubertal boys. Bone 2004;34(4):755-64.

\section{MacLean 2003 \{published data only\}}

* MacLean LB. Bounce at the bell: the effects of a 7-month intervention of brief bouts of moderate intensity exercise on bone mass, bone structure, and bone strength in children [M.Sc. Dissertation], 2003. circle.ubc.ca/handle/2429/14502. (accessed $12 / 12 / 2012)$

McKay HA, MacLean L, Petit M, Kelvie-O'Brien K, Janssen P, Beck T, et al. Bounce at the Bell: a novel program of short bouts of exercise improves proximal femur bone mass in early pubertal children. British Journal of Sports Medicine 2005;39(8):521-6.

McKay HA, Petit MA, Schutz RW, Prior JC, Barr SI, Khan KM. Augmented trochanteric bone mineral density after modified physical education classes: a randomized school-based exercise intervention study in prepubescent and early pubescent children. Journal of Pediatrics 2000;136(2):156-62.
Mahar 2006 \{published data only\}

Mahar MT, Murphy SK, Rowe DA, Golden J, Shields AT, Raedeke TD. Effects of a classroom-based program on physical activity and on-task behavior. Medicine and Science in Sports and Exercise 2006;38(12):2086-94.

Mahon 1993 \{published data only\}

* Mahon AD, Ignico AA, Marsh ML. The effects of daily physical education on health related physical fitness in first-grade children. Research Quarterly for Exercise and Sport 1993;March Suppl:A-43.

Mandigo 2003 \{published data only\}

Mandigo JL, Thompson LP, Spence J, Melnychuk N, Schwartz M, Causgrove-Dunn J, et al. Physical activities available at Alberta schools. Alberta Centre for Well-Being, 2003.

\section{Manios 1999 \{published data only\}}

Kafatos A, Manios Y, Moschandreas J. Health and nutrition education in primary schools of Crete: follow-up changes in body mass index and overweight status. European Journal of Clinical Nutrition 2005;59(9):1090-2.

Kafatos I, Manios Y, Moschandreas J, Kafatos A. Health and nutrition education program in primary schools of Crete: changes in blood pressure over 10 years. European Journal of Clinical Nutrition 2007;61(7):837-45.

Manios $\mathrm{Y}$, Kafatos A. Health and nutrition education in elementary schools: changes in health knowledge, nutrient intakes and physical activity over a six year period. Public Health Nutrition 1999;23(3A):445-8.

Manios Y, Kafatos I, Kafatos A. Ten-year follow-up of the Cretan Health and Nutrition Education Program on children's physical activity levels. Preventive Medicine 2006;43(6):442-6.

* Manios Y, Moschandreas J, Hatzis C, Kafatos A. Evaluation of a health and nutrition education program in primary school children of Crete over a three-year period. Preventive Medicine 1999;28(2):149-59.

Manios Y, Moschandreas J, Hatzis C, Kafatos A. Health and nutrition education in primary schools of Crete: changes in chronic disease risk factors following a 6-year intervention programme. British Journal of Nutrition 2002;88(3):315-24.

\section{Marcus 1987 \{published data only\}}

Marcus AC, Wheeler RC, Cullen JW, C. Quasi-experimental evaluation of the Los Angeles Know Your Body program: knowledge, beliefs, and self-reported behaviors. Preventive Medicine 1987;16(6):803-15.

\section{Marcus 2009 \{published data only\}}

* Marcus C, Nyberg G, Nordenfelt A, Karpmyr M, Kowalski J, Ekelund U. A 4-year, cluster-randomized controlled childhood obesity prevention study: STOPP. International Journal of Obesity 2009;33:408-17.

\section{Marks 2006 \{published data only\}}

Marks JT, Campbell MK, Ward DS, Ribisl KM, Wildemuth BM, Symons MJ. A comparison of web and print media for physical 
activity promotion among adolescent girls. Journal of Adolescent Health 2006;39(1):96-104.

\section{Martin 2010 \{published data only\}}

Martin MW, Martin S, Rosengard P. PE2GO: program evaluation of a physical activity program in elementary schools. Journal of Physical Activity \& Health 2010;7(5):677-84.

\section{Matsudo 1999 \{published data only\}}

Matsudo V, Andrade D, Matsudo S, Aramjo T, Andrade E, Figueira A, et al. Impact of a community - school intervention program on physical activity behavior of male and female adolescents. Medicine and Science in Sports and Exercise 1999;31(5 Suppl):S272.

\section{Mauriello 2010 \{published data only\}}

Mauriello LM, Ciavatta MM, Paiva AL, Sherman KJ, Castle PH, Johnson JL, et al. Results of a multi-media multiple behavior obesity prevention program for adolescents. Preventive Medicine 2010;51(6):451-6.

\section{McAuley 2010 \{published data only\}}

McAuley KA, Taylor RW, Farmer VL, Hansen P, Williams SM, Booker CS, et al. Economic evaluation of a community-based obesity prevention program in children: the APPLE project. Obesity 2010;18(1):131-6.

\section{McKay 2003 \{published data only\}}

McKay HA. Lessons learned from school-based intervention trials: UBC Healthy Bones Studies. Journal of Musculoskeletal Neuronal Interactions 2003;3(4):341-4.

\section{McKenzie 1993 \{published data only\}}

McKenzie TL, Sallis JF, Faucette FN, Roby J, Kolody B. Effects of a curriculum and inservice program on the quantity and quality of elementary physical education classes. Research Quarterly for Exercise and Sport 1993;64(2):178-87.

\section{McKenzie 2002 \{published data only\}}

McKenzie TL, Sallis JF, Prochaska JJ, Conway TL, Marshall SJ, Rosengard P. Evaluation of a two-year middle-school physical education intervention: M-SPAN. Medicine \& Science in Sports \& Exercise 2004;36(8):1382-8.

\section{McManus 1997 \{published data only\}}

McManus AM, Armstrong N, Williams CA. Effect of training on the aerobic power and anaerobic performance of prepubertal girls. Acta Pediatrica 1997;86(5):456-9.

\section{McManus 2005 \{published data only\}}

McManus AM, Cheng CH, Leung MP, Yung TC, Macfarlane DJ. Improving aerobic power in primary school boys: a comparison of continuous and interval training. International Journal of Sports Medicine 2005;26(9):781-6.

\section{McManus 2008a \{published data only\}}

McManus AM, Masters RS, Laukkanen RM, Yu C, Sit CH, Ling FC. Using heart-rate feedback to increase physical activity in children. Preventive Medicine 2008;47(4):402-8.
McMurray 2002 \{published data only\}

* McMurray RG, Harrell JS, Bangdiwala SI, Bradley CB, Deng S, Levine A. A school-based intervention can reduce body fat and blood pressure in young adolescents. Journal of Adolescent Health 2002;31(2):125-32.

\section{McMurray 2009 \{published data only\}}

Drews K, Harrell J, Thompson D, Mazzuto S, Ford E, Carter M, et al. Recruitment and retention strategies and methods in the HEALTHY study. International Journal of Obesity 2009;33(Suppl 4):S21-8.

Hirst K, Baranowski T, DeBar L, Foster GD, Kaufman F, Kennel $P$, et al. HEALTHY study rationale, design and methods: moderating risk of type 2 diabetes in multi-ethnic middle school students. International Journal of Obesity 2009;33(Suppl 4):S4S20.

* McMurray RG, Bassin S, Jago R, Bruecker S, Moe EL, Murray T, et al. Rationale, design and methods of the HEALTHY study physical education intervention component. International Journal of Obesity 2009;33(Suppl 4):S37-43.

Schneider M, Hall WJ, Hernandez AE, Hindes K, Montez G, Pham T, et al. Rationale, design and methods for process evaluation in the HEALTHY study. International Journal of Obesity 2009;33(Suppl 4):S60-7.

Venditti E, Elliot D, Faith M, Firrell L, Giles C, Goldberg L, et al. Rationale, design and methods of the HEALTHY study behavior intervention component. International Journal of Obesity 2009;33(Suppl 4):S44-51.

\section{McNeil 2009 \{published data only\}}

McNeil DA, Wilson BN, Siever JE, Ronca M, Mah JK. Connecting children to recreational activities: results of a cluster randomized trial. American Journal of Health Promotion 2009;23(6):376-87.

\section{McWhannell 2008 \{published data only\}}

McWhannell N, Henaghan J, Foweather L, Doran D, Batterham A, Reilly T, et al. The effect of a 9-week physical activity programme on bone and body composition of children aged 10-11 years: an exploratory trial. International Journal of Sports Medicine 2008;29(12):941-7.

\section{Mecredy 1993 \{published data only\}}

Mecredy D, Panaro L. Efficacy and community development: heart health interventions and adolescents. Public Health and Epidemiology Report Ontario 1993;4(1):16-9.

\section{Meininger 2000 \{published data only\}}

Meininger JC. School-based interventions for primary prevention of cardiovascular disease: evidence of effects for minority populations. Annual Review of Nursing Research 2000;18:219-44.

\section{Mellin 1987 \{published data only\}}

Mellin LM, Slinkard LA, Irwin CE. Adolescent obesity intervention: validation of the SHAPEDOWN program. Journal of the American Dietetic Association 1987;87(3):333-8. 
Melnyk 1994 \{published data only\}

Melnyk MG, Weinstein E. Preventing obesity in black women by targeting adolescents: a literature review. Journal of the American Dietetic Association 1994;94(5):536-40.

\section{Melnyk 2007 \{published data only\}}

Melnyk BM, Small L, Morrison-Beedy D, Strasser A, Spath L, Kreipe R, et al. The COPE Healthy Lifestyles TEEN program: feasibility, preliminary efficacy \& lessons learned from an after school group intervention with overweight adolescents. Journal of Pediatric Health Care 2007;21(5):315-22.

Melnyk 2009 \{published data only\}

Melnyk BM, Jacobson D, Kelly S, O'Haver J, Small L, Mays MZ. Improving the mental health, healthy lifestyle choices, and physical health of Hispanic adolescents: a randomized controlled pilot study. Journal of School Health 2009;79(12):575-84.

\section{Meredith 1991 \{published data only\}}

Meredith CN, Dwyer JT. Nutrition and exercise: effects on adolescent health. Annual Review of Public Health 1991;12:309-33.

\section{Mettler 2000 \{published data only\}}

Mettler MM, Stone WJ, Herrick AB, Klein DA. Evaluation of a community-based physical activity campaign via the transtheoretical model. Health Promotion Practice 2000;1(4):351-9.

\section{Metzker 2000 \{published data only\}}

Metzker AL. The effects of a transtheoretical model physical activity intervention program on the physical activity behavior of female adolescents. Research Quarterly for Exercise \& Sport 2000;71(1):A-78.

\section{Meunnich Cowell 1989 \{published data only\}}

Meunnich Cowell J, Montgomery AC, Talashek ML. Cardiovascular risk assessment in school-age children: a school and community partnership in health promotion. Public Health Nursing 1989;6(2):67-73.

\section{Mier 2002 \{published data only\}}

Mier CM, Dunning D. Gender differences in the effects of physical education on fitness components in middle-school children. Medicine and Science in Sports and Exercise 2002;34(5 Suppl):S142.

\section{Missouri 2003 \{published data only\}}

Missouri Department of Health and Senior Services BoCDPCHP. Home to School: using handheld palm computers to gather information on environmental factors affecting walking to school among elementary school children. Health Education and Behavior 2003;4:405-6.

\section{Moberg 1990 \{published data only\}}

Moberg DP, Piper DL. An outcome evaluation of project model health: a middle school health promotion program. Health Education Quarterly 1990;17(1):37-51.

\section{Monness 2009 \{published data only\}}

Monness E, Sjolie AN. An alternative design for small-scale school health experiments: does daily walking produce benefits in physical performance of school children?. Child: Care Health and Development 2009;35(6):858-67.

Moodie 2011 \{published data only\}

Moodie M, Haby MM, Swinburn B, Carter R. Assessing costeffectiveness in obesity: active transport program for primary school children - TravelSMART schools curriculum program. Journal of Physical Activity \& Health 2011;8(4):503-15.

Moon 1999 \{published data only\}

* Moon AM, Mullee MA, Rogers L, Thompson RL, Speller V, Roderick P. Helping schools to become health-promoting environments: an evaluation of the Wessex Healthy Schools Award. Health Promotion International 1999;14(2):111-22.

\section{Morris 1997 \{published data only\}}

Morris FL, Naughton GA, Gibbs JL, Carlson JS, Wark JD. Prospective ten-month exercise intervention in premenarcheal girls: positive effects on bone and lean mass. Journal of Bone \& Mineral Research 1997;12(9):1453-62.

\section{Mo-suwan 1998 \{published data only\}}

Mo-suwan L, Pongprapai S, Junjana C, Puetpaiboon A. Effects of a controlled trial of a school-based exercise program on the obesity indexes of preschool children. American Journal of Clinical Nutrition 1998;68(5):1006-11.

\section{Motlagh 2009 \{published data only\}}

Motlagh ME, Kelishadi R, Ardalan G, Gheiratmand R, Majdzadeh R, Heidarzadeh A. Rationale, methods and first results of the Iranian national programme for prevention of chronic diseases from childhood: CASPIAN Study. Eastern Mediterranean Health Journal 2009;15(2):302-14.

\section{Mott 1991 \{published data only\}}

Mott DS, Virgilio SJ, Warren BL, Berenson GS. Effectiveness of a personalized fitness module on knowledge, attitude, and cardiovascular endurance of fifth-grade students: "Hear Smart". Perceptual Motor Skills 1991;73:847-58.

\section{Moya 2011 \{published data only\}}

Moya MP, Sanchez LM, Lopez BJ, Escribano SF, Notario PB, Salcedo AF, et al. Cost-effectiveness of an intervention to reduce overweight and obesity in 9-10-year-olds. The Cuenca study [Coste-efectividad de un programa de actividad física de tiempo libre para prevenir el sobrepeso y la obesidad en niños de 9-10 años]. Gaceta Sanitaria 2011;25(3):198-204.

Muller 2001 \{published data only\}

Muller MJ, Asbeck I, Mast M, Langnase K, Grund A. Prevention of obesity more than an intention: concept and first results of the Kiel Obesity Prevention Study (KOPS). International Journal of Obesity 2001;25(Suppl. 1):S66-74.

\section{Muller 2005 \{published data only\}}

Muller MJ, Danielzik S, Pust S. School-and family-based interventions to prevent overweight in children. Proceedings of the Nutrition Society 2005;64(2):249-54. 
Muth 2008 \{published data only\}

Muth ND, Chatterjee A, Williams D, Cross A, Flower K. Making an IMPACT: effect of a school-based pilot intervention. North Carolina Medical Journal 2008;69(6):432-40.

\section{Nabipour 2004 \{published data only\}}

Nabipour I, Imami SR, Mohammadi MM, Heidari G, Bahramian F, Azizi F, et al. A school-based intervention to teach 3-4 grades children about healthy heart; the Persian Gulf healthy heart project. Indian Journal of Medical Sciences 2004;58(7):289-96.

\section{Nader 1992 \{published data only\}}

Madsen J, Sallis JF, Rupp JW, Senn KL, Patterson TL, Atkins CJ, et al. Process variables as predictors of risk factor changes in a family health behavior change program. Health Education Research 1993;8(2):193-204.

Madsen J, Sallis JF, Rupp JW, Senn KL, Patterson TL, Atkins CJ, et al. Relationship between self-monitoring of diet and exercise change and subsequent risk factor changes in children and adults. Patient Education and Counseling 1993;21(1-2):61-9.

* Nader PR, Sallis JF, Abramson IS, Broyles SL, Patterson TL, Senn KL, et al. Family-based cardiovascular risk reduction education among Mexican- and Anglo-Americans and Europeans. Family and Community Health 1992;15:57-74.

Nader PR, Sallis JF, Patterson TL, Abramson IS, Rupp JW, Senn KL, et al. A family approach to cardiovascular risk reduction: results from the San Diego Family Health Project. Health Education Quarterly 1989;16(2):229-44.

Nader PR, Sallis JF, Rupp JW, Atkins CJ, Patterson TL, Abramson IS. San Diego Family Health Project: reaching families through the schools. Journal of School Health 1986;56(6):227-31.

Patterson TL, Sallis JF, Nader PR, Rupp JW, McKenzie TL, Roppe BE, et al. Direct observation of physical activity and dietary behaviors in a structured environment: effects of a family-based health promotion program. Journal of Behavioral Medicine 1988;11(5):447-58.

Sallis JF, Patterson TL, Buona JJ, Nader PR. Relation of cardiovascular fitness and physical activity to cardiovascular disease risk factors in children and adults. American Journal of Epidemiology 1988;127:933-46.

\section{Nahas 2009 \{published data only\}}

Nahas MV, de Barros MV, de Assis MA, Hallal PC, Florindo AA, Konrad L. Methods and participant characteristics of a randomized intervention to promote physical activity and healthy eating among Brazilian high school students: the Saude na Boa project. Journal of Physical Activity \& Health 2009;6(2):153-62.

\section{Naylor 2006 \{published data only\}}

Naylor PJ, Macdonald HM, Zebedee JA, Reed KE, McKay HA. Lessons learned from Action Schools! BC - an "active school' model to promote physical activity in elementary schools. Journal of Science \& Medicine in Sport 2006;9(5):413-23.
NCCDP 1997 \{published data only\}

National Center for Chronic Disease Prevention and Health Promotion CfDCaP. Guidelines for school and community programs to promote lifelong physical activity among young people. Journal of School Health 1997;67(6):202-19.

\section{Nelson 2011 \{published data only\}}

Nelson L, Evans M, Guess W, Morris M, Olson T, Buckwalter J. Heart rates of elementary physical education students during the dancing classrooms program. Research Quarterly for Exercise and Sport 2011;82(2):256-63.

Nelson LP, Wilson A. Impact of dancing classrooms on elementary physical education: a school climate study of personal and social development. TAHPERD Journal 2011;79(3):12-6.

\section{NeumarkSztainer 2003 \{published data only\}}

* Neumark-Sztainer D, Story M, Hannan PJ, Rex J. New Moves: a school-based obesity prevention program for adolescent girls. Preventive Medicine 2003;37(1):41-51.

\section{Newton 2010 \{published data only\}}

Newton RL Jr, Hongmei H, Anton SD, Martin CK, Stewart TM, Lewis $L$, et al. An environmental intervention to prevent excess weight gain in African-American students: a pilot study. American Journal of Health Promotion 2010;24(5):340-3.

\section{Niederer 2009 \{published data only\}}

Niederer I, Kriemler S, Zahner L, Burgi F, Ebenegger V, Hartmann T, et al. Influence of a lifestyle intervention in preschool children on physiological and psychological parameters (Ballabeina): study design of a cluster randomized controlled trial. BMC Public Health 2009;9:94-105.

\section{Nielsen 2010 \{published data only\}}

Nielsen G, Taylor R, Williams S, Mann J. Permanent play facilities in school playgrounds as a determinant of children's activity. Journal of Physical Activity \& Health 2010;7(4):490-6.

\section{Nyberg 2011 \{published data only\}}

Nyberg G, Sundblom E, Norman A, Elinder LS. A healthy school start - parental support to promote healthy dietary habits and physical activity in children: design and evaluation of a clusterrandomised intervention. BMC Public Health 2011;11:185.

\section{O'Loughlin 1999 \{published data only\}}

O'Loughlin J, Paradis G, Kishchuk N, Barnett T, Renaud L. Prevalence and correlates of physical activity behaviors among elementary schoolchildren in multiethnic, low income, innercity neighborhoods in Montreal, Canada. Annals of Epidemiology 1999;9(7):397-407.

\section{Okely 2010 \{published data only\}}

Okely AD, Collins CE, Morgan PJ, Jones RA, Warren JM, Cliff DP, et al. Multi-site randomized controlled trial of a childcentered physical activity program, a parent-centered dietarymodification program, or both in overweight children: the HIKCUPS study. The Journal of Pediatrics 2010;157(3):388-94. 
Ostbye 2011 \{published data only\}

Ostbye T, Zucker NL, Krause KM, Lovelady CA, Evenson KR, Peterson BL, et al. Kids and Adults Now! Defeat Obesity (KAN-DO): rationale, design and baseline characteristics. Contemporary Clinical Trials 2011;32(3):461-9.

Owen 1995 \{published data only\}

Owen N, Bauman AE, Booth ML, Oldenburg B, Magnus P. Serial mass-media campaigns to promote physical activity: reinforcing or redundant?. American Journal of Public Health 1995;85(2):244-8.

\section{Oxizoglou 2005 \{published data only\}}

Oxizoglou N, Kanioglou A, Rizos S. A comparative study of a handball program and a physical education curriculum and their influence on the anthropometric characteristics formation of pupils aged 12-14. Inquiries in Sport \& Physical Education 2005;3(2):123-30.

\section{Palmer 2005 \{published data only\}}

Palmer S, Graham G, Elliott E. Effects of a web-based health program on fifth grade children's physical activity knowledge, attitudes and behavior. American Journal of Health Education 2005;36(2):86-93.

\section{Pangrazi 2003 \{published data only\}}

Pangrazi RP, Beighle A, Vehige T. Impact of Promoting Lifestyle Activity for Youth (PLAY) on children's physical activity. Journal of School Health 2003;73:317-21.

\section{Parcel 1989 \{published data only\}}

Parcel GS, Simons-Morton BG, O'Hara NM, Baranowski T, Wilson B. School promotion of healthful diet and physical activity: impact on learning outcomes and self-reported behavior. Health Education Quarterly 1989;16(2):181-99.

\section{Park 2007 \{published data only\}}

Park TG, Hong HR, Lee J, Kang HS. Lifestyle plus exercise intervention improves metabolic syndrome markers without change in adiponectin in obese girls. Annals of Nutrition \& Metabolism 2007;51(3):197-203.

\section{Parlee-Hirth 2002 \{published data only\}}

Keihner A, Meigs R, Sugerman S, Backman D, Garbolino T, Mitchell P. The Power Play! campaign's school idea \& resource kits improve determinants of fruit and vegetable intake and physical activity among fourth- and fifth-grade children. Journal of Nutrition Education \& Behavior 2011;42(4 Suppl 2):S122-9.

Parlee-Hirth M. California children's 5 a day - power play! campaign. American Journal of Health Promotion 2002;16(6):371-2.

\section{Pate 1987 \{published data only\}}

Pate RR, Corbin CB, Simons-Morton BG, Ross JG. Physical education and its role in school health promotion. Journal of School Health 1987;57(10):445-50.

\section{Pate 1994 \{published data only\}}

Pate RR, Matthews C, Alpert BS, Strong WB, DuRant RH. Systolic blood pressure to exercise in black and while preadolescent and early adolescent boys. Archive of Pediatric and Adolescent Medicine 1994;148(10):1027-31.

Pate 1995a \{published data only\}

Pate RR, Pratt M, Blair SN. Physical activity and public health: a recommendation from the Centers for Disease Control and Prevention and the American College of Sports Medicine. Journal of the American Medical Association 1995;273:402-7.

Pate 1995b \{published data only\}

Pate R, Small ML, Ross JG, Young JC, Flint KH, Warren CW. School physical education. Journal of School Health 1995;65(8):312-8.

\section{Pate 1996 \{published data only\}}

Pate RR, Heath GW, Dowda M, Trost SG. Associations between physical activity and other health behaviours in a representative sample of US adolescents. American Journal of Public Health 1996;86(11):1577-81.

\section{Pate 1999 \{published data only\}}

Pate RR, Trost SG, Dowda M, Ott AE, Ward DS, Saunders R, et al. Tracking of physical activity, physical inactivity, and healthrelated physical fitness in rural youth. Pediatric Exercise Science 1999;11(4):364-76.

\section{Pate 2003 \{published data only\}}

Pate R, Saunders RP, Ward DS, Felton G, Trost SG, Dowda M. Evaluation of a community-based intervention to promote physical activity in youth: lessons from Active Winners. American Journal of Health Promotion 2003;17(3):171-82.

\section{Pate 2006 \{published data only\}}

Pate RR, Davis MG, Robinson TN, Stone EJ, McKenzie TL, Young JC. Collaboration with the councils on cardiovascular disease in the young and on nutrition, physical activity, and metabolism (Physical Activity Committee) in schools: a scientific statement from the American Heart Association council promoting physical activity in children and youth: a leadership role for cardiovascular nursing. Circulation 2006;114:1214-24.

\section{Pena 2004 \{published data only\}}

Peña $E$. The effects of a school-based intervention on the physical activity behaviors of Latino high school students [thesis]. ACSM. Indianapolis, 2004.

\section{Peralta 2009a \{published data only\}}

Peralta LR, Jones RA, Okely AD. Promoting healthy lifestyles among adolescent boys: the Fitness Improvement and Lifestyle Awareness Program RCT. Preventive Medicine 2009;48(6):537-42.

\section{Perry 1987 \{published data only\}}

Perry CL, Klepp KI, Halper A, Dudovitz BS, Golden D, Griffin G, et al. Promoting healthy eating and physical activity patterns among adolescents: a pilot study of 'Slice of Life'. Health Education Research 1987;2(2):93-103.

\section{Petkevicius 1985 \{published data only\}}

Petkevicius RV, Grinkeviciene OK, Bojarskas JL, Sackute AA, Zaborskis AA. Preventive study of atherosclerosis and ischaemic 
heart disease risk factors among Kaunas school-children. Cor Vasa 1985;27(4):229-35.

Phillipp 1989 \{published data only\}

* Phillipp A, Piland NF, Seidenwurm J, Smith HL. Improving physical fitness in high school students: implications from an experimental course. Journal of Teaching in Physical Education 1989;9(1):58-73.

\section{Piper 1993 \{published data only\}}

Piper DL, King MJ, Moberg DP. Implementing a middle school health promotion research project: lessons our textbook didn't teach us. Evaluation and Program Planning 1993;16(3):171-80.

\section{Plachta-Danielzik 2007 \{published data only\}}

Plachta-Danielzik S, Pust S, Asbeck I, Czerwinski-Mast M, Langnäse K, Fischer C, et al. Four-year follow-up of schoolbased intervention on overweight children: the KOPS study. Obesity 2007;15(12):3159-69.

\section{Plotnikoff 1999 \{published data only\}}

Plotnikoff R, Williams P, Fein A. Effects of a school capacitybuilding intervention on children's heart health: evaluation of the Coalfields Healthy Heartbeat School Project in New South Wales, Australia. Health Education Journal 1999;58(4):389-400.

\section{Pollatschek 1989 \{published data only\}}

Pollatschek JL, O'Hagan FJO. An investigation of the psycho-physical influences of a quality physical education programme. Health Education Research, Theory and Practice 1989;4(3):341-50.

\section{Prochaska 2002 \{published data only\}}

Prochaska JJ, Rodgers MW, Sallis JF. Association of parent and peer support with adolescent physical activity. Research Quarterly for Exercise and Sport 2002;73(2):206-10.

\section{Prusak 2010 \{published data only\}}

Prusak KA, Pennington T, Graser SV, Beighle A, Morgan CF. Systemic success in physical education: the East Valley phenomenon. Journal of Teaching in Physical Education 2010;29(1):85-106.

\section{Racette 2010 \{published data only\}}

Racette SB, Cade WT, Beckmann LR. School-based physical activity and fitness promotion. Physical Therapy 2010;90(9):1214-8

\section{Raitakari 1994a \{published data only\}}

Ritakari OT, Porkka KVK, Rasanen L, Ronnemaa T, Viikari JSA. Clustering and six year cluster-tracking of serum total cholesterol, HCL-cholesterol and diastolic blood pressure in children and young adults. Journal of Clinical Epidemiology 1994;47(10):1085-93.

\section{Rakovi 2008 \{published data only\}}

Rakovi A, Aleksandrovi M, Stankovi D. Quantitative changes of functional abilities at boys under influence of experimental race walking programme [Kvantitativne promjene funkcionalnih sposobnosti dje-ceaka pod utjecajem eksperimentalnog programa sportskog hodanja]. Acta Kinesiologica 2008;2(1):66-70.

Ramsay 1990 \{published data only\}

Ramsay JA, Blimkie CJR, Smith K, Garner S, Macdougall JD, Sale DG. Strength training effects in prepubescent boys. Medicine and Science in Sports and Exercise 1990;22(5):605-14.

Ransdell 2003 \{published data only\} Ransdell LB, Oakland D, Taylor A. Increasing physical activity in girls and women. JOPERD 2003;74(1):37-55.

Reilly 2006 \{published data only\}

Reilly JJ, Kelly L, Montgomery C, Williamson A, Fisher A, $\mathrm{McC}$ oll JH, et al. Physical activity to prevent obesity in young children: cluster randomised controlled trial. BMJ 2006;333:1041.

Reinhardt 2002 \{published data only\}

Reinhardt WC, Brevard PB. Integrating the Food Guide Pyramid and Physical Activity Pyramid for positive dietary and physical activity behaviors in adolescents. Journal of the American Dietetic Association 2002;102(3 Suppl):S96-9.

Renaud 1997 \{published data only\}

Renaud L, Chevalier S, Dufour R, O'Loughlin J, Beaudet N, Bourgeois A, et al. Evaluation of the implementation of an educational curriculum: optimal interventions for the adoption of an educational program of health in elementary schools. Canadian Journal of Public Health 1997;88:351-3.

Resaland 2011 \{published data only\}

Resaland G, Andersen L, Mamen A, Anderssen S. Effects of a 2-year school-based daily physical activity intervention on cardiorespiratory fitness: the Sogndal school-intervention study. Scandinavian Journal of Medicine \& Science in Sports 2011;21(2):302-9.

Resnick 2009 \{published data only\}

Resnick EA, Bishop M, O'Connell A, Hugo B, Isern G, Timm A, et al. The CHEER study to reduce BMI in elementary school students: a school-based, parent-directed study in Framingham, Massachusetts. Journal of School Nursing 2009;25(5):361-72.

Resnicow 1992 \{published data only\}

* Resnicow KA, Cohn L, Reinhardt J, Cross D, Futterman R, Kirschner E, et al. A three-year evaluation of the Know Your Body program in inner-city schoolchildren. Health Education Quarterly 1992;19(4):463-80.

Resnicow 1993 \{published data only\}

Resnicow K. School-based obesity prevention. Annals of the New York Academy of Sciences 1993;699:154-66.

Resnicow 1996 \{published data only\}

Resnicow KA, Allensworth D. Conducting a comprehensive school health program. Journal of School Health 1996;66(2):59-63. 
Resnicow 1997 \{published data only\}

Resnicow K, Robinson TN. School-based cardiovascular disease prevention studies: review and synthesis. Annals of Epidemiology 1997;7:S14-S31.

\section{Resnicow 2000 \{published data only\}}

Resnicow KA, Yaroch AL, Davis A, Wang DT, Carter S, Slaughter L, et al. GO GIRLS!: results from a nutrition and physical activity program for low-income, overweight African American adolescent females. Health Education and Behavior 2000;27(5):616-31.

\section{Resnicow 2002 \{published data only\}}

Resnicow KA, Jackson A, Braithwaite R, Dilorio C, Blisset D, Rahotep S, et al. Healthy Body/Healthy Spirit: a church-based nutrition and physical activity intervention. Health Education Research 2002;17(5):562-73.

\section{Reybrouck 1990 \{published data only\}}

Reybrouck T, Vinckx J, Van De Berghe G, VanderschuerenLodeweyckx M. Exercise therapy and hypocaloric diet in the treatment of obese children and adolescents. Acta Paediatrica Scandinavica 1990;79:84-9.

\section{Rezvanian 2010 \{published data only\}}

Rezvanian H, Hashemipour M, Kelishadi R, Tavakoli N, Poursafa P. A randomized, triple masked, placebo-controlled clinical trial for controlling childhood obesity. World Journal of Pediatrics 2010;6(4):317-22

\section{Ridgers 2010 \{published data only\}}

Ridgers ND, Fairclough SJ, Stratton G. Twelve-month effects of a playground intervention on children's morning and lunchtime recess physical activity levels. Journal of Physical Activity \& Health 2010;7(2):167-75.

\section{Rimmer 1997 \{published data only\}}

Rimmer JH, Looney MA. Effects of an aerobic activity program on the cholesterol levels of adolescents. Research Quarterly for Exercise and Sport 1997;68(1):74-9.

\section{Robbins 2006 \{published data only\}}

Robbins LB, Greatebeck KA, Kazanis AS, Pender NJ. Girls on the move program to increase physical activity participation. Nursing Research 2006;55(3):206-16.

\section{Robinson 1999 \{published data only\}}

Robinson TN. Reducing children's television viewing to prevent obesity: a randomized controlled trial. JAMA 1999;282(16):1561-7.

\section{Robinson 2003 \{published data only\}}

Baranowski T, Baranowski JC, Cullen KW, Thompson DI, Nicklas TA, Zakeri IE, et al. The Fun, Food, and Fitness Project (FFFP): the Baylor GEMS pilot study. Ethnicity \& Disease 2003;12(1 Suppl 1):S30-9.

Kumanyika SK, Obarzanek E, Robinson TN, Beech BM. Phase 1 of the Girls health Enrichment Multi-site Studies (GEMS): conclusion. Ethnicity \& Disease 2003;13(1 Suppl 1):S88-S91.
Kumanyika SK, Story M, Beech BM, Sherwood NE, Baranowski JC, Powell TM, et al. Collaborative planning for formative assessment and cultural appropriateness in the Girls health Enrichment Multi-site Studies (GEMS): a retrospection. Ethnicity \& Disease 2003;13(1 Suppl 1):S15-S29.

Obarzanek E, Pratt CA. Girls health Enrichment Multi-site Studies (GEMS): new approaches to obesity prevention among young African-American girls. Ethnicity \& Disease 2003;13(1 Suppl 1):S1-S5.

* Robinson TN, Killen JD, Kraemer HC, Wilson DM, Matheson DM, Haskell WL, et al. Dance and reducing television viewing to prevent weight gain in African-American girls: the Stanford GEMS pilot study. Ethnicity \& Disease 2003;13(1 Suppl 1):S65-S77.

Rochon J, Klesges RC, Story M, Robinson TN, Baranowski T, Obarzanek E, et al. Common design elements of the Girls health Enrichment Multi-site Studies (GEMS). Ethnicity \& Disease 2003;13(1 Suppl 1):S6-14

Story M, Sherwood NE, Himes JH, Davis M, Jacobs DR, Cartwright $\mathrm{Y}$, et al. An after-school obesity prevention program for African-American girls: the Minnesota GEMS pilot study. Ethnicity \& Disease 2003;13(1 Suppl 1):S54-S64.

Treuth MS, Sherwood NE, Baranowski T, Butte NF, Jacobs DR, McClanahan B, et al. Physical activity self-report and accelerometry measures from the Girls health Enrichment Multi-site studies. Preventive Medicine 2004;38:S43-9.

\section{Robinson 2007 \{published data only\}}

Robinson TN, Matheson DM, Kraemer HC, Obarzanek E, Wilson DM, Haskell WL, et al. Stanford GEMS (Girls health Enrichment Multisite Studies): long-term efficacy of afterschool dance and screen time reduction in low-income AfricanAmerican girls. Circulation 2007;116:843.

Robinson 2008 \{published data only\}

* Robinson TN, Kraemer HC, Matheson DM, Obarzanek E, Wilson DM, Haskell WL, et al. Stanford GEMS phase 2 obesity prevention trial for low-income African-American girls: design and sample baseline characteristics. Contemporary Clinical Trials 2008;29(1):56-69.

Robinson TN, Matheson DM, Kraemer HC, Obarzanek E, Wilson DM, Haskell WL, et al. Stanford GEMS (Girls health Enrichment Multisite Studies): long-term efficacy of afterschool dance and screen time reduction in low-income AfricanAmerican girls. Circulation 2007;116(16 Suppl S):56-69.

Rodgers 2001 \{published data only\}

Rodgers DV, Johnson SR, Tschann JM, Chesterman EA, Mellin LM. The Evaluation of a school-based obesity prevention program among fourth grade students. San Anselmo: Center for Child Obesity, 2001.

\section{Rosenbaum 2007 \{published data only\}}

Rosenbaum M, Nonas C, Weil R, Horlick M, Fennoy I, Vargas I, et al. School-based intervention acutely improves insulin sensitivity and decreases inflammatory markers and body 
fatness in junior high school students. Journal of Clinical Endocrinology \& Metabolism 2007;92(2):504-8.

Rowland 1991 \{published data only\}

Rowland TW, Varzeas MR, Walsh CA. Aerobic responses to walking training in sedentary adolescents. Journal of Adolescent Health 1991;12(1):30-4

\section{Ruiz 2006 \{published data only\}}

Ruiz JR, Rizzo NS, Hurtig-Wennlöf A, Ortega FB, Warnberg J, Sjöström M. Relations of total physical activity and intensity to fitness and fatness in children: the European Youth Heart Study. American Journal of Clinical Nutrition 2006;84(2):299-303.

\section{Saakslahti 2004 \{published data only\}}

Saakslahti A, Numminen P, Salo P, Tuominen J, Helenius H, Valimaki I. Effects of a three-year intervention on children's physical activity from age 4 to 7 . Pediatric Exercise Science 2004;16(2):167-80.

\section{Sabet-Sarvestani 2008 \{published data only\}}

Sabet-Sarvestani R, Kargar M, Kave M-H, Tabatabaee H. The effect of dietary behavior modification on anthropometric indices in obese adolescent female students. Iranian Journal of Pediatrics 2008;18(Suppl 1):71-6.

\section{Sacher 2003 \{published data only\}}

Sacher P, Hogan L, Chadwick P, Lawson M. An integrated programme of nutrition, exercise and behavioural modification in a small group of obese 7-11-year-old children. Proceedings of the Nutrition Society 2003;62(OCA-B):3A.

\section{Sadowsky 1999 \{published data only\}}

* Sadowsky HS, Sawdon JM, Scheiner ME, Sticklin AM. Eight week moderate intensity exercise intervention elicits body composition change in adolescents. Cardiopulmonary Physical Therapy Journal 1999;10(2):38-44.

\section{Sahota 2001a \{published data only\}}

Sahota P, Rudolf MC, Dixey R, Hill AJ, Barth JH, Cade J. Randomised controlled trial of primary school based intervention to reduce risk factors for obesity. $B M J$ 2001;323(7320):1029-32.

\section{Sahota 2001b \{published data only\}}

Sahota P, Rudolf MCJ, Hill AJ, Barth JH, Cade J. Evaluation of implementation and effect of primary school based intervention to reduce risk factors for obesity. BMJ 2001;323:1027-30.

\section{Saksvig 2003 \{published data only\}}

Saksvig B, Gittelsohn J, Zinman B, Hanley A, Valente T, Harris S. A successful school-based diabetes prevention intervention for native Canadian children. Diabetes 2003;52(Suppl 1):A209-10.

\section{Sakuragi 2009 \{published data only\}}

Sakuragi S, Abhayaratna K, Gravenmaker KJ, O'Reilly C, Sirkusalanukul W, Budge MM, et al. Influence of adiposity and physical activity on arterial stiffness in healthy children. Hypertension 2009;53:611-6.
Telford RD, Bass SL, Budge MM, Byrne DG, Carlson JS, Coles D, et al. The Lifestyle Of Our Kids (LOOK) project: outline of methods. Journal of Science \& Medicine in Sport 2009;12(1):156-63.

\section{Sallis 1993a \{published data only\}}

Sallis JF, Condon SA, Goggin KJ, Roby JJ, Kolody RB, Alcaraz JE. The development of self-administered physical activity surveys for 4th grade students. Research Quarterly for Exercise and Sport 1993;64(1):25-31.

\section{Sallis 1993b \{published data only\}}

Sallis JF. Epidemiology of physical activity and fitness in children and adolescents. Critical Reviews in Food, Science and Nutrition 1993;33:403-8.

\section{Sallis 1997 \{published data only\}}

Marcoux MF, Sallis JF, McKenzie TL, Marshall S, Armstrong CA, Goggin KJ. Process evaluation of a physical activity selfmanagement program for children: SPARK. Psychology and Health 1999;14:659-77.

McKenzie TL, Sallis JF, Alcaraz J, Roby J, Kolody B. Effects of a two-year health-related curriculum on the physical fitness of children. Medicine \& Science in Sports \& Exercise 1993;25(5 Suppl):S147.

McKenzie TL, Sallis JF, Faucette N, Roby JJ, Kolody B. Effects of a curriculum and inservice program on the quantity and quality of elementary physical education classes. Research Quarterly for Exercise and Sport 1993;64(2):178.

McKenzie TL, Sallis JF, Kolody B, Faucette FN. Long-term effects of a physical education curriculum and staff development program: SPARK. Research Quarterly for Exercise \& Sport 1997;68(4):280-91.

Sallis JF, McKenzie TL, Alcaraz JE, Kolody B, Faucette N, Hovell MF. The effects of a 2-year physical education program (SPARK) on physical activity and fitness in elementary school students. Sports, Play and Active Recreation for Kids. American Journal of Public Health 1997;87(8):1328-34.

Sallis JF, McKenzie TL, Alcaraz JE, Kolody B, Hovell MF, Nader PR. Project SPARK: effects of physical education on adiposity in children. Annals of the New York Academy of Science 1993;29:127-36.

Sallis JF, McKenzie TL, Kolody B, Lewis M, Marshall S, Rosengard P. Effects of health-related physical education on academic achievement: project SPARK. Research Quarterly for Exercise \& Sport 1999;70(2):127-34.

\section{Salmon 2005 \{published data only\}}

Salmon J, Ball K, Crawford D, Booth M, Telford A, Hume C, et al. Reducing sedentary behaviour and increasing physical activity among 10-year-old children: overview and process evaluation of the 'Switch Play' intervention. Health Promotion International 2005;20:7-17. 
Salmon 2010 \{published data only\}

Salmon J. Novel strategies to promote children's physical activities and reduce sedentary behavior. Journal of Physical Activity \& Health 2010;7(Suppl 3):S299-306.

\section{Samples 2010 \{published data only\}}

Samples EY. Childhood obesity. American Fitness 2010;28(6):66-7.

\section{Santiago 2007 \{published data only\}}

Santiago JA, Morales J, Rodriguez AX. Health-related fitness changes in Hispanic elementary schoolchildren after 1 year of regular physical education. Research Quarterly for Exercise \& Sport 2007;78(1):A-21.

\section{Sasaki 1987 \{published data only\}}

Sasaki J, Shindo M, Tanaka H, Ando M. A long term aerobic exercise program decreases the obesity index and increases the high density lipoprotein cholesterol concentration in obese children. International Journal of Obesity 1987;11:339-45.

\section{Schneider 2007 \{published data only\}}

Schneider M, Dunton GF, Bassin S, Graham DJ, Eliakim AF, Cooper DM. Impact of a school-based physical activity intervention on fitness and bone in adolescent females. Journal of Physical Activity \& Health 2007;4(1):17-29.

\section{Schneider 2009 \{published data only\}}

Schneider M, Hall WJ, Hernandez AE, Hindes K, Montez G, Pham T. Rationale, design and methods for process evaluation in the HEALTHY study. International Journal of Obesity 2009;33:S60-7.

\section{Schofield 2005 \{published data only\}}

Schofield L, Mummery WK, Schofield G. Effects of a controlled pedometer-intervention trial for low-active adolescent girls. Medicine \& Science in Sports \& Exercise 2005;37(8):1414-20.

Schuldheisz 1998 \{published data only\}

Schuldheisz JM. The effects of an interdependent grouporiented contingency on middle school students' physical activity levels during physical education. Microform Publications, 1998.

\section{Schwarzer 2010 \{published data only\}}

Schwarzer R, Cao DS, Lippke S. Stage-matched minimal interventions to enhance physical activity in Chinese adolescents. The Journal of Adolescent Health 2010;47(6):533-9.

\section{Scott 1988 \{published data only\}}

Scott KA, Myers AM. Impact of fitness training on native adolescents' self-evaluations and substance use. Canadian Journal of Public Health 1988;79(6):424-9.

\section{Sharma 2009 \{published data only\}}

Sharma SV, Hoelscher DM, Kelder SH, Day RS, Hergenroeder A. Psychosocial, environmental and behavioral factors associated with bone health in middle-school girls. Health Education Research 2009;24(2):173-84.

\section{Shaw 1989 \{published data only\}}

Shaw SM, Kemeny L. Fitness promotion for adolescent girls: the impact and effectiveness of promotional material which emphasizes the slim ideal. Adolescence 1989;24(95):677-87.

\section{Shea 1996 \{published data only\}}

Shea S, Basch CE, Wechsler H, Lantigua R. The Washington Heights-Inwood Healthy Heart Program: a 6-year report from a disadvantaged urban setting. American Journal of Public Health 1996;86(2):166-71.

\section{Shek 2008 \{published data only\}}

Shek DT, Sun RC, Siu AM. Interim evaluation of the Secondary 2 Program of Project P.A.T.H.S: insights based on the experimental implementation phase. Scientific World Journal 2008;8:61-72.

\section{Shephard 1992 \{published data only\}}

Shephard RJ. Effectiveness of training programmes for prepubescent children. Sports Medicine 1992;13(3):194-213.

\section{Shephard 1996 \{published data only\}}

Labarre R, Lavallee H, Shephard RJ, Jequier JC, Rajic M. Cohort effects: a possible limitation to the interpretation of longitudinal studies. American Journal of Human Biology 1993;5(3):305-10.

Shephard RJ. Long-term studies of physical activity in children: The Trois-Rivieres experience. In: Binkhorst RA, Kemper HCG, Saris WHM editor(s). Children and Exercise XI. Champaign, Illinois: Human Kinetics, 1985:252-9.

Shephard RJ, Lavallee H. Changes of physical performance as indicators of the response to enhanced physical education. Journal of Sports Medicine and Physical Fitness 1994;34(4):323-35.

* Shephard RJ, Lavallee H. Effects of enhanced physical education on lung volumes of primary school children. Journal of Sports Medicine and Physical Fitness 1996;36(3):186-94.

Shephard RJ, Lavallee H. Enhanced physical education and body fat in the primary school child. American Journal of Human Biology 1993;5(6):697-704.

Shephard RJ, Lavallee H. Impact of enhanced physical education in the prepubescent child: Trois Rivieres revisited. Pediatric Exercise Science 1993;5(2):177-89.

Trudeau F, Laurencelle L, Tremblay J, Rajic M, Shephard RJ. A long-term follow-up of participants in the Trois-Rivieres semi-longitudinal study of growth and development. Pediatric Exercise Science 1998;10:366-77.

Trudeau F, Laurencelle L, Tremblay J, Rajic M, Shephard RJ. Daily primary school physical education: effects on physical activity during adult life. Medicine and Science in Sports and Exercise 1999;31(1):111-7.

\section{Shimon 2009 \{published data only\}}

Shimon JM, Petlichkoff LM. Impact of pedometer use and selfregulation strategies on junior high school physical education students daily step counts. Journal of Physical Activity \& Health 2009;6(2):178-84. 


\section{Shingo 2002 \{published data only\}}

Shingo N, Takeo M. The educational experiments of school health promotion for the youth in Japan: analysis of the 'sport test' over the past 34 years. Health Promotion International 2002;17(2):147-60.

\section{Siegel 1984 \{published data only\}}

Siegel JA, Manfredi TG. Effects of a ten-month fitness program on children. Physician and Sports Medicine 1984;12(5):91-7.

\section{Siegrist 2011 \{published data only\}}

Siegrist M, Hanssen H, Lammel C, Haller B, Halle M. A cluster randomised school-based lifestyle intervention programme for the prevention of childhood obesity and related early cardiovascular disease (JuvenTUM 3). BMC Public Health 2011;11:258

\section{Simonetti 1986 \{published data only\}}

Simonetti D-A, Tarsitani G, Cairella M, Siani V, De Filippis S, Manicinelli S, et al. Prevention of obesity in elementary and nursery school children. Public Health 1986;100:166-73.

\section{Singh 2007 \{published data only\}}

Singh AS, Paw MJMC, Brug J, Van Mechelen W. Short-term effects of school-based weight gain prevention among adolescents. Archives of Pediatrics \& Adolescent Medicine 2007;161(6):565-71.

\section{Skybo 2002 \{published data only\}}

* Skybo TA, Ryan-Wenger N. A school-based intervention to teach third grade children about the prevention of heart disease. Pediatric Nursing 2002;28(3):223-9.

\section{Slawta 2004 \{published data only\}}

Slawta JN, Nalle DJ, Bentley JL, Smith J. The Be A Fit Kid Program: improving dietary and physical activity habits in children. Medicine and Science in Sports and Exercise 2004:36:S101-2.

\section{Slootmaker 2010 \{published data only\}}

Slootmaker SM, Chinapaw MJ, Seidell JC, van Mechelen W, Schuit AJ. Accelerometers and internet for physical activity promotion in youth? Feasibility and effectiveness of a minimal intervention. Preventive Medicine 2010;51(1):31-6.

\section{Smith 2009 \{published data only\}}

Smith H, Grogan S, Davey R, Cochrane T. Developing a successful physical activity intervention in primary school children. Education and Health 2009;27(3):63-66.

\section{Smith 2011 \{published data only\}}

Smith LH. Piloting the use of teen mentors to promote a healthy diet and physical activity among children in Appalachia. Journal for Specialists in Pediatric Nursing 2011;16(1):16-26.

\section{Sobczyk 1995 \{published data only\}}

Sobczyk W, Hazel N, Reed CD. Health Promotion Schools of Excellence: a model program for Kentucky and the nation. Journal of the Kentucky Medical Association 1995;93:142-7.

\section{Sollerhed 2008 \{published data only\}}

Sollerhed A, Ejlertsson G. Physical benefits of expanded physical education in primary school: findings from a 3-year intervention study in Sweden. Scandinavian Journal of Medicine \& Science in Sports 2008;18(1):102-7.

Soong 1997 \{published data only\} Soong PX, McGill L, Yang FL. The effects of two exercise programs on VO-2max in children in Singapore. Medicine and Science in Sports and Exercise 1997;29(5 Suppl):S14.

Sothern 1993 \{published data only\}

Sothern MS, von Almen TK, Schumacher HD, Zelman M, Farris RP, Carlisle L, et al. An effective multidisciplinary approach to weight reduction in youth. Annals of the New York Academy of Sciences 1993;699:292-4.

Sothern 1999 \{published data only\}

Sothern MS, von Almen TK, Schumacher HD, Suskind RM, Blecker U. A multidisciplinary approach to the treatment of childhood obesity. Delaware Medical Journal 1999;71(6):255-61.

Sothern 2001 \{published data only\}

Sothern MS. Exercise as a modality in the treatment of childhood obesity. Pediatric Clinics of North America 2001;48(4):995-1015.

\section{Spence 1997 \{published data only\}}

Spence JC, Poon P. Results from the Alberta Schools' Athletic Association Survey. Alberta Centre for Well-Being. Alberta Centre for Well-Being, 1997.

\section{Speroni 2007 \{published data only\}}

Speroni KG, Earley C, Atherton M. Evaluating the effectiveness of the Kids Living Fit program: a comparative study. The Journal of School Nursing 2007;23(6):329-36.

\section{Spiegel 2006 \{published data only\}}

Spiegel SA, Foulk D. Reducing overweight through a multidisciplinary school-based intervention. Obesity 2006;14(1):88-96.

\section{Standage 2005 \{published data only\}}

Standage M, Duda JL, Ntoumanis N. A test of self-determination theory in schoolphysical education. British Journal of Educational Psychology 2005;75(3):411-33.

\section{Stergioulas 1998 \{published data only\}}

Stergioulas A, Tripolitsioti A, Messinis D, Bouloukos A, Nounopoulos $C$. The effects of endurance training on selected coronary risk factors in children. Acta Paediatrica 1998;87(4):401-4.

\section{Stewart 1997 \{published data only\}}

Stewart KJ, Seemans CM, McFarland LD, Weinhofer JJ. Social learning versus traditional teaching in an elementary school cardiovascular health promotion program. American Journal of Health Promotion 1997;11(3):194-7. 
Stewart 2004 \{published data only\}

Stewart JA, Dennison DA, Kohl HW, Doyle JA. Exercise level and energy expenditure in the TAKE 10 ! in-class physical activity program. Journal of School Health 2004;74:397-400.

\section{Stock 2007 \{published data only\}}

Stock S, Miranda C, Evans S, Plessis S, Ridley J, Yeh S, et al. Healthy Buddies: a novel, peer-led health promotion program for the prevention of obesity and eating disorders in children in elementary school. Pediatrics 2007;120(4):e1059-68.

\section{Stone 1989 \{published data only\}}

Stone EJ, Perry CL, Luepker RV. Synthesis of cardiovascular behavioural research for youth health promotion. Health Education Quarterly 1989;16(2):155-69.

\section{Stone 1995 \{published data only\}}

Stone EJ, Baranowski T, Sallis JF, Cutler JA. Review of behavioural research for cardiopulmonary health: emphasis on youth, gender, and ethnicity. Journal of Health Education 1995;26 (2 Suppl):S9-17.

\section{Stone 1998 \{published data only\}}

Stone EJ, McKenzie TL, Welk GJ, Booth ML. Effects of physical activity interventions in youth: review and synthesis. American Journal of Preventive Medicine 1998;15(4):298-315.

\section{Stratton 2000 \{published data only\}}

* Stratton G. Promoting children's physical activity in primary school: an intervention study using playground markings. Ergonomics 2000;43(10):1538-46.

\section{Stratton 2005 \{published data only\}}

Stratton G, Mullan E. The effect of multicolor playground markings on children's physical activity level during recess. Preventive Medicine 2005;41(5-6):828-33.

\section{Strazzullo 1988 \{published data only\}}

Strazzullo P, Cappuccio FP, Trevisan M, De Leo A, Krogh V, Giorgione, Mancini M. Leisure time physical activity and blood pressure in schoolchildren. American Journal of Epidemiology 1988;127(4):726-33.

\section{Strong 2005 \{published data only\}}

Strong WB, Malina RM, Blimkie CJ, Daniels SR, Dishman RK, Gutin B, et al. Evidence based physical activity for school-age youth. The Journal of Pediatrics 2005;146(6):732-7.

\section{Tak 2007 \{published data only\}}

Tak YR, An JY, Kim YA, Woo HY. [The effects of a physical activity-behavior modification combined intervention (PABMintervention) on metabolic risk factors in overweight and obese elementary school children]. Taehan Kanho Hakhoe chi 2007;37:902-13.

\section{Tamir 1990 \{published data only\}}

* Tamir D, Feurstein A, Brunner S, Halfon S, Reshef A, Palti H. Primary prevention of cardiovascular disease in childhood: changes in serum total cholesterol, high density lipoprotein, and body mass index after 2 years of intervention in Jerusalem school-children age 7-9 years. Preventive Medicine 1990;19:22-30.

Tavener 1993 \{published data only\}

Tavener M, Payne W. The effect of participation in a 'Health in Primary Schools Program' on the physical fitness of children. Australian Journal of Science \& Medicine in Sport 1993;25(3):84-8.

Taylor 2006 \{published data only\}

Taylor RW, Mcauley KA, Williams SM, Barbezat W, Nielsen G, Mann Jl. Reducing weight gain in children through enhancing physical activity and nutrition: the APPLE project. International Journal of Pediatric Obesity 2006;1(3):146-52.

Taylor 2007 \{published data only\}

Taylor RW, McAuley KA, Barbezat W, Strong A, Williams SM, Mann JI. APPLE Project: 2-y findings of a community-based obesity prevention program in primary school age children. American Journal of Clinical Nutrition 2007;86(3):735-42.

Taymoori 2008 \{published data only\}

Taymoori P, Niknami S, Berry T, Lubans D, Ghofranipour F, Kazemnejad A. A school-based randomized controlled trial to improve physical activity among Iranian high school girls. International Journal of Behavioral Nutrition and Physical Activity 2008;5:18.

\section{Taymoori 2008a $\{$ published data only\}}

Taymoori P, Lubans DR. Mediators of behavior change in two tailored physical activity interventions for adolescent girls. Psychology of Sport \& Exercise 2008;9(5):605-19.

\section{Teerarungsikul 2009 \{published data only\}}

Teerarungsikul N, Phuphaibul R, Loveland-Cherry CJ, Pookboonmee R, Kijboonchoo K, Nityasuddhi D. Effectiveness of a physical activity promotion program on perceived self-efficacy, physical activity and physical fitness among Thai adolescent girls. Thai Journal of Nursing Research 2009;13(2):81-93.

Telford 2009 \{published data only\}

Telforda RD, Basse SL, Budgec MM, Byrnec DG, Carlsonm JS, Coles D, et al. The Lifestyle Of Our Kids (LOOK) project: outline of methods. Journal of Science and Medicine in Sport 2009;12:156-63.

Thakor 2004 \{published data only\}

Thakor HG, Kumar P, Desai VK. Effect of physical and mental activity on blood pressure. Indian Journal of Pediatrics 2004;71(4):307-12.

\section{Theodorakis 2008 \{published data only\}}

Theodorakis Y, Kosmidou E, Hassandra M, Goudas M. Review of the applications of a health education program "I Do not Smoke I Exercise" to elementary, junior high school and high school students. Inquiries in Sport \& Physical Education 2008;6(3):181-94. 
Thomas 2007 \{published data only\}

Thomas NE, Cooper SM, Williams SP, Baker JS, Davies B. Relationship of fitness, fatness, and coronary-heart-disease risk factors in 12- to 13-year-olds. Pediatric Exercise Science 2007;19(1):93-101.

Tolfrey 1998 \{published data only\}

Tolfrey K, Cambell IG, Batterham AM. Exercise training induced alterations in prepubertal children's lipid-lipoprotein profile. Medicine \& Science in Sports \& Exercise 1998;30(12):1684-92.

\section{Tolfrey 2004 \{published data only\}}

Tolfrey K, Jones, AM, Campbell IG. Lipid-lipoproteins in children: an exercise dose-response study. Medicine \& Science in Sports \& Exercise 2004;36(3):418-27.

\section{Toruner 2010 \{published data only\}}

Toruner EK, Savaser S. A controlled evaluation of a schoolbased obesity prevention in Turkish school children. Journal of School Nursing 2010;26(6):473-82.

Trevino 1998 \{published data only\}

Trevino RP, Pugh JA, Hernandez AE. Bienestar: a diabetes risk-factor prevention program. Journal of School Health 1998;68:62-7.

\section{Trost 1997 \{published data only\}}

Trost SG, Pate RR, Saunders R, Ward DS, Dowda M, Felton G. A prospective study of the determinants of physical activity in rural fifth-grade children. Preventive Medicine 1997;26(2):257-63.

\section{Trost 1999a \{published data only\}}

Trost SG, Pate RR, Ward DS, Saunders R, Riner W. Correlates of objectively measured physical activity in preadolescent youth. American Journal of Preventive Medicine 1999;17(2):120-6.

\section{Trost 1999b \{published data only\}}

Trost SG, Pate RR, Ward DS, Saunders R, Riner W. Determinants of physical activity in active and low-active, sixth grade AfricanAmerican youth. Journal of School Health 1999;69(1):29-33.

\section{Trudeau 1999 \{published data only\}}

Trudeau F, Laurencelle L, Tremblay J, Rajic M, Shepard RJ. Daily primary school physical education: effects on physical activity during adult life. Medicine and Science in Sports and Exercise 1999;31(1):111-7.

\section{Trudeau 2008 \{published data only\}}

Trudeau F, Shephard RJ. Physical education, school physical activity, school sports and academic performance. International Journal of Behavioral Nutrition and Physical Activity 2008;5:10.

Tsai 2009 \{published data only\}

Tsai PY, Boonpleng W, McElmurry BJ, Park CG, McCreary L. Lessons learned in using TAKE 10! with Hispanic children. Journal of School Nursing 2009;25(2):163-72.

\section{Tsorbatzoudis 2005 \{published data only\}}

Tsorbatzoudis $\mathrm{H}$. Evaluation of a school-based intervention programme to promote physical activity: an application of the theory of planned behavior. Perceptual \& Motor Skills 2005;101(3):787-802.

Tuckman 1986 \{published data only\}

* Tuckman BW, Hinkle JS. An experimental study of the physical and psychological effects of aerobic exercise on schoolchildren. Health Psychology 1986;5(3):197-207.

Tudor-Locke 2001 \{published data only\}

Tudor-Locke C, Ainsworth BE, Popkin BM. Active commuting to school: an overlooked source of children's physical activity? Sports Medicine 2001;31(5):309-13.

Tudor-Locke 2006 \{published data only\}

Tudor-Locke D, Lee SM, Morgan CF, Beighle MA, Pangrazi RP. Children's pedometer-determined physical activity during the segmented school day. Medicine \& Science in Sports \& Exercise 2006;38(10):1732-8.

Turnbull 2004 \{published data only\}

Turnbull A, Barry D, Wickens K, Crane J. Changes in body mass index in 11-12-year-old children in Hawkes Bay, New Zealand (1989-2000). Journal of Paediatrics and Child Health 2004;40(1-2):33-7.

\section{Uzunovic 2008 \{published data only\}}

Uzunovic S. The transformation of strength, speed, and coordination under the influence of sport dancing [Transformacija snage, brzine I koordinacije pod uticajem modernog sportskog plesa]. Facta Universitatis [Series Physical Education \& Sport] 2008;6(2):135-46.

Vaccaro 1989 \{published data only\}

Vaccaro P, Mahon AD. The effects of exercise on coronary heart disease risk factors in children. Sports Medicine 1989;8(3):139-53.

\section{Valverde 1998 \{published data only\}}

Valverde MA, Patin RV, Oliveira FL, Lopez FA, Vitolo MR. Outcomes of obese children and adolescents enrolled in a multidisciplinary health program. International Journal of Obesity \& Related Metabolic Disorders 1998;22(6):513-9.

van Beurden 2003 \{published data only\}

* van Beurden E, Barnett LM, Zask A, Dietrich UC, Brooks LO, Beard J. Can we skill and activate children through primary school physical education lessons? "Move it Groove it" - a collaborative health promotion intervention. Preventive Medicine 2003;36(4):493-501.

\section{van Mil 1999 \{published data only\}}

van Mil E, Goris AHC, Westerterp KR. Physical activity and the prevention of childhood obesity: Europe versus the United States. International Journal of Obesity 1999;23(Suppl 3):S41-4.

\section{Velez 2010 \{published data only\}}

Velez A, Golem DL, Arent SM. The impact of a 12-week resistance training program on strength, body composition, and selfconcept of Hispanic adolescents. Journal of Strength and Conditioning Research 2010;24(4):1065-73. 
Venditti 2009 \{published data only\}

Venditti EM, Elliot DL, Faith MS, Firrell LS, Giles CM, Goldberg L. Rationale, design and methods of the HEALTHY study behavior intervention component. International Journal of Obesity 2009;33:S44-51.

\section{Verderber 2001 \{published data only\}}

Verderber JMS, Rizzo TL, Sherrill C. Assessing student intention to participate in inclusive physical education. Adapted Physical Activity Quarterly 2003;20(1):26-45.

\section{Verstraete 2007 \{published data only\}}

Verstraete SJ, Cardon GM, De Clercq DL, De Bourdeaudhuij I. A comprehensive physical activity promotion programme at elementary school: the effects on physical activity, physical fitness and psychosocial correlates of physical activity. Public Health Nutrition 2007;10(5):477-84.

\section{Verstraete 2007a \{published data only\}}

* Verstraete SJM, Cardon GM, De Clercq DLR, De Bourdeaudhuij IMM. Effectiveness of a two-year healthrelated physical education intervention in elementary schools Journal of Teaching in Physical Education 2007;26(1):20-34.

\section{Veugelers 2005 \{published data only\}}

Veugelers PJ, Fitzgerald AL. Effectiveness of school programs in preventing childhood obesity: a multilevel comparison. American Journal of Public Health 2005;95(3):432-5.

\section{Vissers 2008 \{published data only\}}

Vissers D, De Meulenaere A, Vanroy C, Vanherle K, Vande Sompel A, Truijen S, et al. Effect of a multidisciplinary school-based lifestyle intervention on body weight and metabolic variables in overweight and obese youth. e-SPEN 2008;3:e196-202.

\section{Walton 1999 \{published data only\}}

Walton J, Hoerr S, Heine L, Frost S, Roisen D, Berkimer M. Physical activity and stages of change in fifth and sixth graders. Journal of School Health 1999;69(7):285-9.

\section{Wang 2006 \{published data only\}}

Wang Y, Tussing L, Odoms-Young A, Braunschweig C, Flay B, Hedeker D, et al. Obesity prevention in low socioeconomic status urban African-American adolescents: study design and preliminary findings of the HEALTH-KIDS Study. European Journal of Clinical Nutrition 2006;60(1):92-103.

\section{Wang 2006a \{published data only\}}

Wang Y, Tussing L, Odoms-Young A, Braunschweig C, Flay B, Hedeker $D$, et al. Obesity prevention in low socioeconomic status urban African-American adolescents: study design and preliminary findings of the HEALTH-KIDS Study. European Journal of Clinical Nutrition 2006;60(1):92-103.

\section{Warren 2003 \{published data only\}}

Warren JM, Henry CJ, Lightowler HJ, Bradshaw SM, Perwaiz S. Evaluation of a pilot school programme aimed at the prevention of obesity in children. Health Promotion International 2003;18(4):287-96

\section{Watts 2004 \{published data only\}}

Watts K, Beye P, Siafarikas A, O'Driscoll G, Jones TW, Davis EA, et al. Effects of exercise training on vascular function in obese children. Journal of Pediatrics 2004;144(5):620-5.

Weber 1989 \{published data only\}

Weber MD, Johnson CA, Carter S, Dietsch B, Caldwell-Stacy L, Palmer R, et al. Project SMART parent program: preliminary results of a chronic disease risk reduction trail. Annals of Medicine 1989;21(3):231-3.

\section{Weber Cullen 1999 \{published data only\}}

Weber Cullen K, Baranowski T, Baranowski JC, Hebert D, De Moor C, Hearn MD, et al. Influence of school organizational characteristics on the outcomes of a school health promotion program. Journal of School Health 1999;69(9):376-80.

\section{Wechsler 2000 \{published data only\}}

Wechsler H, Devereaux RS, Davis M, Collins J. Using the school environment to promote physical activity and healthy eating. Preventive Medicine 2000;31(2):S121-37.

\section{Weintraub 2008 \{published data only\}}

Weintraub DL, Tirumalai EC, Haydel KF, Fujimoto M, Fulton JE, Robinson TN. Team sports for overweight children: the Stanford Sports to Prevent Obesity Randomized Trial (SPORT). Archives of Pediatrics \& Adolescent Medicine 2008;162(3):232-7.

\section{Wen 2008 \{published data only\}}

Wen LM, Fry D, Merom D, Rissel C, Dirkis H, Balafas A. Increasing active travel to school: are we on the right track? A cluster randomised controlled trial from Sydney, Australia. Preventive Medicine 2008;47(6):612-8.

\section{Werch 2005 \{published data only\}}

Werch CC, Moore MJ, DiClemente CC, Bledsoe R, Jobli E. A multihealth behavior intervention integrating physical activity and substance use prevention for adolescents. Prevention Science 2005;6(3):213-26.

\section{Werner 1988 \{published data only\}}

* Werner P, Durham R. Health related fitness benefits in upper elementary school children in a daily physical education program. The Physical Educator 1988;45(2):89-93.

Westcott 1995 \{published data only\}

Westcott WL, Tolken J, Wessner B. School-based conditioning programs for physically unfit children. Strength and Conditioning 1995;46(3):345-50.

\section{Wharf Higgins 2001 \{published data only\}}

Wharf Higgins J, Reed N. The GirlPower Project - recreation, $\mathrm{BC}$ health goals and social capital. Canadian Journal of Public Health 2001;92(6):448-52.

\section{Williden 2006 \{published data only\}}

Williden M, Taylor RW, McAuley KA, Simpson JC, Oakley M, Mann JI. The APPLE project: an investigation of the barriers and promoters of healthy eating and physical activity in New Zealand children aged 5-12 years. Health Education Journal 2006;65(2):135-48 
Wilson 2005 \{published data only\}

Wilson DK, Evans AE, Williams J, Mixon G, Sirard JR, Pate R. A preliminary test of a student-centered intervention on increasing physical activity in underserved adolescents. Annals of Behavioral Medicine. 2005;30(2):119-24.

Wilson 2006 \{published data only\}

Wilson DK, Griffin S, Saunders RP, Evans A, Mixond G, Wright M, et al. Formative evaluation of a motivational intervention for increasing physical activity in underserved youth. Evaluation and Program Planning 2006;29(3):260-8.

\section{Wilson 2008 \{published data only\}}

Wilson DK, Kitzman-Ulrich H, Williams JE, Saunders R, Griffin S, Pate R, et al. An overview of "The Active by Choice Today" (ACT) trial for increasing physical activity. Contemporary Clinical Trials 2008;29(1):21-31.

\section{Wing 1998 \{published data only\}}

Wing RR, Venditti E, Jakicic JM, Polley BA, Lang W. Lifestyle intervention in overweight individuals with a family history of diabetes. Diabetes Care 1998;21(3):350-9.

\section{Winters 2003 \{published data only\}}

Winters ER, Petosa RL, Charlton TE. Using social cognitive theory to explain discretionary, "leisure-time" physical exercise among high school students. Journal of Adolescent Health 2003;32(6):436-42.

\section{Wong 2008 \{published data only\}}

Wong PC, Chia MY, Tsou IY, Wansaicheong GK, Tan B, Wang JC, et al. Effects of a 12-week exercise training programme on aerobic fitness, body composition, blood lipids and C-reactive protein in adolescents with obesity. Annals of the Academy of Medicine Singapore 2008;37:286-93.

\section{Yin 2005 \{published data only\}}

Gutin B, Yin Z, Johnson M, Barbeau P. Preliminary findings of the effect of a 3-year after-school physical activity intervention on fitness and body fat: the Medical College of Georgia Fitkid Project. International Journal of Pediatric Obesity 2008;3:Suppl 9.

Wang LY, Gutin B, Barbeau P, Moore JB, Hanes J Jr, Johnson MH, et al. Cost-effectiveness of a school-based obesity prevention program. Journal of School Health 2008;78(12):619-24.

* Yin Z, Gutin B, Johnson MH, Hanes J, Moore JB, Cavnar M, et al. An environmental approach to obesity prevention in children: Medical College of Georgia FitKid Project year 1 results. Obesity Research 2005;13(12):2153-61.

\section{Yopp Cohen 1989 \{published data only\}}

Yopp Cohen R, Felix MRJ, Brownell KD. The role of parents and older peers in school-based cardiovascular prevention programs: implications for program development. Health Education Quarterly 1989;16(2):245-53.

\section{Young 2006a \{published data only\}}

Young DR, Phillips JA, Yu T, Haythornthwaite JA. Effects of a life skills intervention for increasing physical activity in adolescent girls. Archives of Pediatrics \& Adolescent Medicine 2006;160(12):1255-61.

\section{Young 2007 \{published data only\}}

Young DR, Felton GM, Brieser M, Elder JP, Johnson C, Lee J, et al. Policies and opportunities for physical activity in middle school environments. Journal of School Health 2007;77(1):41-7.

\section{Zahner 2006 \{published data only\}}

Zahner L, Puder JJ, Roth R, Schmid M, Guldimann R, Puhse U, et al. A school-based physical activity program to improve health and fitness in children aged 6-13 years ("Kinder-Sportstudie KISS"): study design of a randomized controlled trial. BMC Public Health 2006;6:147-58.

\section{Zeelie 2010 \{published data only\}}

Zeelie A, Moss SJ, Kruger HS, van Rooyen JM. The impact of a 10 -week physical activity intervention programme on selective metabolic syndrome markers in black adolescents. South African Journal for Research in Sport, Physical Education \& Recreation 2010;32(1):147-62.

\section{Zizzi 2006 \{published data only\}}

Zizzi S, Vitullo E, Rye J, O'Hara-Tompkins N, Abildso C, Fisher B, et al. Impact of a three-week pedometer intervention on high school students' daily step counts and perceptions of physical activity. American Journal of Health Education 2006;37(1):35-40.

\section{Zonderland 1994 \{published data only\}}

Zonderland ML, Erich WBM, Kortlandt W, Erkelens DW. Additional physical education and plasma lipids and apoproteins: a 3-year intervention study. Pediatric Exercise and Science 1994;6:128-39.

\section{Zuckerman 1989 \{published data only\}}

Zuckerman AE, Olevsky-Peleg E, Bush PJ, Horowitz C, Davidson FR, Brown DG, et al. Cardiovascular risk factors among black school children: comparisons among four Know Your Body studies. Preventive Medicine 1989;18:113-32.

\section{Additional references}

\section{Adams 1995}

Adams PF, Schoenborn CA, Moss AJ, Warren CW, Kann L. Health risk behaviors among our nation's youth: United States. Vita \& Health Statistics 1995; Vol. PHS 95-1520 Vital and Health Statistics; Series 10, no. 192.

\section{Adkins 2004}

Adkins S, Sherwood NE, Story M, Davis M. Physical activity among African-American girls: the role of parents and the home environment. Obesity Research 2004; Vol. 12, issue Suppl 1:S38-45.

\section{Andersen 1992}

Andersen N, Wold B. Parental and peer influences on leisuretime physical activity in young adolescents. Research Quarterly for Exercise and Sport 1992;63(4):341-8. 


\section{Arbeit 1992}

Arbeit ML, Johnson CC, Mott DS, Harsha DW, Nicklas TA, Webber LS, et al. The Heart Smart cardiovascular school health promotion: behavior correlates of risk factor change. Preventive Medicine 1992;21(1):18-32.

\section{Armstrong 1994}

Armstrong N, Simons-Morton B. Physical activity and blood lipids in adolescents. Pediatric Exercise Science 1994;6:381-405.

\section{Ball 2003}

Ball GDC, McCargar LJ. Childhood obesity in Canada: a review of prevalence estimates and risk factors for cardiovascular diseases and type 2 diabetes. Canadian Journal of Applied Physiology 2003;28(1):117-40.

\section{Bandura 1977}

Bandura A. Social Learning Theory. Englewood Cliff: PrenticeHall, 1977.

\section{Bandura 1982}

Bandura, A. Self-efficacy mechanism in human agency. American Psychologist 1982;37:122-47.

\section{Baranowski 1990}

Baranowski T, Simons-Morton B, Hooks P, Henske J, Tiernan K, Dunn JK, et al. A center based program for exercise change among Black-American families. Health Education Quarterly 1990;17(2):179-86.

\section{Berenson 1992}

Berenson GS, Wattingney WA, Tracey RE, Newman WP, Srinivasan SR, Webber LS. Atherosclerosis of the aorta and coronary arteries and cardiovascular risk factors in persons age 6 to 30 years. American Journal of Cardiology 1992;70:851-8.

\section{Biddle 1992}

Biddle S, Armstrong N. Children's physical activity: an exploratory study of psychological correlates. Social Science and Medicine 1992;34(3):325-31.

\section{Brown 2009}

Brown AS. Promoting physical activity amongst adolescent girls. Issues in Comprehensive Pediatric Nursing 2009;32(2):49-64.

\section{Butcher 1985}

Butcher J. Longitudinal analysis of adolescent girls' participation in physical activity. Sociology of Sport Journal 1985;2:130-43.

\section{Cale 1992}

Cale L, Almond L. Physical activity levels of secondary-aged children: a review. Health Education Journal 1992;51:192-7.

\section{CDC 1997}

Centers for Disease Control. Promote lifelong physical activity among young people, risk behavior surveillance - United States. Morbidity and Mortality Weekly Report 1997;46(RR-6):1-36.

\section{CDC 1999}

Centers for Disease Control. Chapter 6: understanding and promoting physical activity. Surgeon General's Report on Physical Activity \& Health 1999:210-59.

\section{CDC 2008}

Centers for Disease Control. Youth risk behaviour surveillance (United States). Morbidity and Mortality Weekly Report 2008; Vol. 57 , issue SS-4.

\section{CFLRI 1997}

Canadian Fitness and Lifestyle Research Institute. Foundation for joint action: reducing physical inactivity. Canadian Fitness and Lifestyle Research Institute. Ottawa, ON: A CLFRI Project initiated in partnership with Fitness/Active Living Unit, Health Canada, and the Interprovincial Sport and Recreation Council, 1997.

\section{CFLRI 2007}

Canadian Fitness and Lifestyle Research Institute. CANPLAY results. Canadian Fitness and Lifestyle Research Institute 2007.

\section{CIHR 2004}

Canadian Institutes of Health Research. Addressing childhood obesity: The evidence for action, 2004. www.paediatricchairs.ca/initiative_past_obesity.html. (accessed 12 December 2012).

\section{Dennison 1988}

Dennison BA, Straus JH, Mellits ED, Charney E. Childhood physical fitness tests: predictor of adult physical activity levels? Pediatrics 1988;82(3):324-30.

\section{DiLorenzo 1998}

DiLorenzo TM, Stucky-Ropp RC, Vander WJ, Gotham HJ. Determinants of exercise among children II: a longitudinal analysis. Preventive Medicine 1998;27(3):470-7.

\section{Dobbins 2011}

Dobbins M, Tirilis D. A synthesis of review evidence: an overview of systematic review evidence on the effectiveness of community-based interventions to promote healthy diet and nutrition, built environment, and social determinants of health. Report commissioned by the Population Health Improvement Research Network (PHIRN) December 2011.

\section{Elgar 2005}

Elgar FJ, Roberts C, Moore L, Tudor-Smith C. Sedentary behaviour, physical activity and weight problems in adolescents in Wales. Public Health 2005;199(6):518-24.

\section{Ferguson 1989}

Ferguson KJ, Yesalis CE, Pomrehn PR, Kirkpatrick MB. Attitudes, knowledge, and beliefs as predictors of exercise intent and behavior in schoolchildren. Journal of School Health 1989;59(3):112-5.

\section{Fernandes 2000}

Fernandes E, McCrindle B. Diagnosis and treatment of hypertension in children and adolescents. Canadian Journal of Cardiology 2000;16(6):801-11. 


\section{Flynn 2006}

Flynn MA, McNeil DA, Maloff B, Mutasingwa D, Wu M, Ford C, et al. Reducing obesity and related chronic disease risk in children and youth: a synthesis of evidence with 'best practice' recommendations. Obesity Reviews 2006;7(1 Suppl):7-66.

\section{Freedson 1992}

Freedson PS, Rowland TW. Youth activity versus youth fitness: let's redirect our efforts. Research Quarterly for Exercise and Sport 1992;63(2):133-6.

\section{Garcia 1995}

Garcia AW, Broda MA, Frenn M, Coviak C, Pender NJ, Ronis DL. Gender and developmental differences in exercise beliefs among youth and prediction of their exercise behavior. Journal of School Health 1995;65(6):213-9.

\section{Gonzalez-Suarez 2009}

Gonzalez-Suarez C, Worley A, Grimmer-Somers K, Dones V. School-based interventions on childhood obesity a meta-analysis. American Journal of Preventive Medicine 2009;37(5):418-27.

\section{Green 1974}

Green LW. Toward cost-benefit evaluations of health education: some concepts, methods, and examples. Health Education Monographs 1974;2 (Suppl 2):34-64.

\section{Gutin 1997}

Gutin B, Owens S, Riggs S, Ferguson M, Moorehead S, Treiber R, et al. Effects of physical training on cardiovascular health in obese children. In: Armstrong B, Kirby B, Welsman J editor(s). Children and Exercise XIX. London: E \& FN Spon, 1997:382-9.

\section{Hagberg 1983}

Hagberg JM, Goldring D, Ehsani AA, Heath GW, Hernandez A, Schechtman $\mathrm{K}$, et al. Effect of exercise training on the blood pressure and hemodynamic features of hypertensive adolescents. American Journal of Cardiology 1983;52(7):763-8.

\section{Haque 2008}

Haque AK, Gadre S, Taylor J, Haque SA, Freeman D, Duarte A. Pulmonary and cardiovascular complications of obesity: an autopsy study of 76 obese subjects. Archives of Pathology and Laboratory Medicine 2008; Vol. 132:1397-404.

\section{Harrell 1996}

Harrell JS, McMurray RG, Bangdiwala SI, Frauman AC, Gansky SA, Bradley CB. Effects of a school-based intervention to reduce cardiovascular disease risk factors in elementary-school children: the Cardiovascular Health in Children (CHIC) study. Journal of Pediatrics 1996;128(6):797-805.

\section{Harris 2009}

Harris KC, Kuramoto LK, Schulzer M, Retallack JE. Effect of school-based physical activity interventions on body mass index in children: a meta-analysis. Canadian Medical Association Journal 2009;180(7):719-26.

\section{Health Canada 2007}

Health Canada. Healthy living. Health Canada 2007.

\section{Higgins 2011}

Higgins JPT, Green S (editors). Cochrane Handbook for Systematic Reviews of Interventions Version 5.1.0 [updated March 2011]. The Cochrane Collaboration, 2011. Available from www.cochrane-handbook.org. ..

\section{Hill 1998}

Hill JO, Trowbridge FL. Childhood obesity: future directions and research priorities. Pediatrics 1998;101:570-4.

\section{Hillsdon 2005}

Hillsdon M, Foster C, Thorogood M. Interventions for promoting physical activity. Cochrane Database of Systematic Reviews 2005, Issue 1. [DOI: 10.1002/14651858.CD003180.pub2]

\section{Hochbaum 1958}

Hochbaum GM. Public participation in medical screening programs: a sociopsychological study. US Public Health Services, PHS publication 572. (PHS) 572. Washington, DC: U.S. Public Health Service, 1958; Vol. 572.

\section{Hudson 2008}

Hudson CE. An integrative review of obesity prevention in African American children. Issues in Comprehensive Pediatric Nursing 2008;31(4):147-70.

\section{Janssen 2010}

Janssen I, LeBlanc AG. Systematic review of the health benefits of physical activity and fitness in school-aged children and youth. International Journal of Behavioral Nutrition and Physical Activity 2010;7(40):1-16.

\section{Kannas 1992}

Kannas L, Tynjala J, Aaro LE. Leisure-time physical activity and related behavior in four European countries. Cuneo, Italy. In Cale L, Almond L: Physical activity levels of secondary-aged children: a review. Health Education Journal 1992;51:192-7.

\section{Katz 2009}

Katz DL. School-based interventions for health promotion and weight control: not just waiting on the world to change. Annual Review of Public Health 2009;30:253-72.

\section{Katzmarzyk 2000}

Katzmarzyk PT, Perusse L, Rao DC, Bouchard C. Familial risk of overweight and obesity in the Canadian population using the WHO/NIH criteria. Obesity Research 2000;8(2):194-7.

\section{Katzmarzyk 2004}

Katzmarzyk PT, Janssen I. The economic cost associated with physical inactivity and obesity in Canada: an update. Canadian Journal of Applied Physiology 2004;29(1):90-115.

\section{Kelder 1994}

Kelder SH, Perry CL, Klepp KI, Lytle LL. Longitudinal tracking of adolescent smoking, physical activity, and food choice behaviors. American Journal of Public Health 1994;84(7):1121-6.

\section{Kelder 1995b}

Kelder SH, Perry CL, Lytle LA, Klepp KI. Community-wide youth nutrition education: long-term outcomes of the

School-based physical activity programs for promoting physical activity and fitness in children and adolescents aged 6 to 18 (Review) 
Minnesota Heart Health Program. Health Education Research 1995;10(2):119-31.

\section{Kemper 1990}

Kemper HCG, Snel J, Verschuur R, Storm-Van-Essen L. Tracking of health and risk indicators of cardiovascular diseases from teenager to adult: Amsterdam Growth and Health study. Preventive Medicine 1990;19:642-55.

\section{Klepp 1993}

Klepp KI, Oygard L, Tell GS, Vellar OD. The Oslo Youth Study: a 12 year follow-up study of a school-based health education program. Proceedings, Health behavior in adolescents: Implications for prevention of coronary heart disease. Bergen, Norway: University of Bergen, 1993:94-105.

\section{Kohl 1998}

Kohl HW, Hobbs KE. Development of physical activity behaviors among children and adolescents. Pediatrics 1998;3:S549-54.

\section{Koplan 2005}

Committee on Prevention of Obesity in Children and Youth. In: Koplan JP, Liverman CT, Krakk VI editor(s). Preventing Childhood Obesity: Health in the Balance. Washington, D.C.: National Academies Press, 2005.

\section{Lauer 1989}

Lauer RM, Lee J, Clarke WR. Predicting adult cholesterol levels from measurements in childhood and adolescence: the Muscatine study. Bulletin of the New York Academy of Medicine 1989;65:1127-42

\section{Lee 1986}

Lee J, Lauer RM, Clarke WR. Lipoproteins in the progeny of young men with coronary artery disease: children with increased risk. Pediatrics 1986;78:330-7.

\section{Liberati 2009}

Liberati A, Altman DG, Tetzlaff J, Mulrow C, Gøtzsche PC, Ioannidis JPA, et al. The PRISMA statement for reporting systematic and meta-analyses of studies that evaluate interventions: explanation and elaboration. PLoS Med 1999;6(7):1-28. [DOI: 10.1371/journal.pmed.1000100]

\section{Lindquist 1999}

Lindquist CH, Reynolds KD, Goran MI. Sociocultural determinants of physical activity among children. Preventive Medicine 1999;29(4):305-12.

\section{Luszczynska 2005}

Luszczynska A, Schwarzer R. Social cognitive theory. In: Conner M, Norman P editor(s). Predicting Health Behaviour. 2nd Edition. New York: Open University Press, 2005:127-69.

\section{Mahoney 1991}

Mahoney LT, Lauer RM, Lee J, Clarke WR. Factors affecting tracking of coronary heart disease risk factors in children: the Muscatine study. Annals of the New York Academy of Sciences 1991;623:120-32

\section{Malina 1996}

Malina RM. Tracking of physical activity and physical fitness across the lifespan. Research Quarterly for Exercise and Sport 1996;67(3 Suppl):S48-57.

\section{Malina 2001}

Malina RM. Physical activity and fitness: pathways from childhood to adulthood. American Journal of Human Biology 2001;13(2):162-72.

\section{Marella 1992}

Marella M, Colli T, Faina M. Evaluation de l'aptitude physique: eurofit, batterie experientagle. Rome: Scuola Dello Slopoer. In Cale \& Almond. Physical activity levels of secondary-aged children: a review. Health Education Journal 1992;51:192-7.

\section{McKenzie 1995}

McKenzie TL, Feldman H, Woods SE, Romero KA, Dahlstrom V, Stone EJ, et al. Children's activity levels and lesson context during third-grade physical education. Research Quarterly for Exercise and Sport 1995;66(3):184-93.

\section{McKenzie 1996}

McKenzie TL, Nader PR, Strikmiller PK, Yang M, Stone EJ, Perry CL, et al. School physical education: effect of the Child and Adolescent Trial for Cardiovascular Health. Preventive Medicine 1996;25(4):423-31.

\section{McMurray 1993}

McMurray RG, Bradley CB, Harrell JS, Bernthal PR, Frauman AC Bangdiwala SI. Parental influences on childhood fitness and activity patterns. Research Quarterly for Exercise and Sport 1993;64(3):249-55.

\section{Menschik 2008}

Menschik D, Ahmed S, Alexander MH, Blum RW. Adolescent physical activities as predictors of young adult weight. Archives of Pediatrics \& Adolescent Medicine 2008;162(1):29-33.

\section{Moore 1991}

Moore LL, Lombardi DA, White MJ, Campbell JL, Oliveria SA, Ellison RC. Influence of parents' physical activity levels on activity levels of young children. Journal of Pediatrics 1991;118(2):215-9.

\section{Moran 1999}

Moran R. Evaluation and treatment of childhood obesity. American Family Physician 1999;59(4):861-8.

\section{Morris 1994}

Morris JN. Exercise in the prevention of coronary heart disease: today's best buy in public health. Medicine and Science in Sports and Exercise 1994;26(7):807-14.

\section{Nicklas 1995}

Nicklas TA, Webber LS, Johnson CC, Srinivasan SR, Berenson GS. Foundations for health promotion with youth: a review of observations from the Bogalusa Health Study. Journal of Health Education 1995;26(2):S18-26. 


\section{Ogden 2006}

Ogden CL Carroll MD Curtin LR McDowell MA Tabak CJ, Flegal KM. Prevalence of overweight and obesity in the United States, 1999-2004. Journal of the American Medical Association 2006; Vol. 295, issue 13:1549-55.

\section{OMOH 1997}

Ontario Ministry of Health PHB. Mandatory health program and services guidelines. Ministry of Health/Public Health Branch. Toronto, Ontario: Queen's Printer for Ontario, 1997.

\section{Poest 1989}

Poest CA. Physical activity patterns of preschool children. Early Childhood Research Quarterly 1989;4:367-76.

\section{Porkka 1991}

Porkka KVK, Viikari JSA, Akerblom HK. Tracking of serum HDLcholesterol and other lipids in children and adolescence: the cardiovascular risk in young Finns study. Preventive Medicine 1991;20:713-24.

\section{Power 1997}

Power C, Lake JK, Cole TJ. Measurement and long-term health risks of child and adolescent fatness. International Journal Observational Related Metabolism Disorder 1997;59(4):507-26.

\section{Prochaska 1997}

Prochaska JO, Velicer WF. The transtheoretical model of health behaviour change. American Journal of Health Promotion 1997;12(1):39-48.

\section{Raitakari 1994}

Raitakari OT, Porkka KV, Taimela S, Telama R, Rasanen L, Viikari JS. Effects of persistent physical activity and inactivity on coronary risk factors in children and young adults: the cardiovascular risk in young Finns study. American Journal of Epidemiology 1994;140(3):195-205.

\section{Reilly 2003}

Reilly JJ, McDowell ZC. Physical activity interventions in the prevention and treatment of paediatric obesity: systematic review and critical appraisal. Proceedings of the Nutrition Society 2003;62(3):611-9.

\section{Reynolds 1990}

Reynolds KD, Killen JD, Bryson SW, Maron DJ, Taylor CB, Maccoby N, et al. Psychosocial predictors of physical activity in adolescents. Preventive Medicine 1990;19(5):541-51.

\section{Robinson 1995}

Robinson TN, Killen JD. Ethnic and gender differences in the relationships between television viewing and obesity, physical activity, and dietary fat intake. Journal of Health Education 1995;26 (2 Suppl):S91-8.

\section{Rosenstock 1966}

Rosenstock LM. Why people use health services?. Milbank Memorial Fund Quarterly 1966;44:94-127.

\section{Sallis 1988}

Sallis JF, Patterson TL, Buono MJ, Atkins CJ, Nader PR. Aggregation of physical activity habits in Mexican-American and Anglo families. Journal of Behavioral Medicine 1988;11(1):31-41.

\section{Sallis 1992}

Sallis JF, Alcaraz JE, McKenzie TL, Hovell MF, Kolody B, Nader PR. Parental behavior in relation to physical activity and fitness in 9-year-old children. American Journal of Diseases of Children 1992;146(11):1383-8.

\section{Sallis 1993}

Sallis JF, McKenzie TL, Alcaraz JE, Kolody B, Hovell MF, Nader PR. Project SPARK: effects of physical education on adiposity in children. Annals of the New York Academy of Sciences 1993;699:127-36.

\section{Sallis $\mathbf{2 0 0 0}$}

Sallis JF, Prochaska JJ, Taylor WC. A review of correlates of physical activity of children and adolescents. Medicine and Science in Sports and Exercise 2000;32(5):963-75.

\section{Shear 1986}

Shear CL, Burke GL, Freedman DS, Berenson GS. Value of childhood blood pressure measurements and family history in predicting future blood pressure status: results from 8 years of follow-up in the Bogalusa heart study. Pediatrics 1986;77:862-9.

\section{Shephard 1997}

Shephard RJ. What is the optimal type of physical activity to enhance health?. Journal of Sports Medicine 1997;31:277-84.

\section{Simons-Morton 1990}

Simons-Morton BG, O'Hara NM, Parcel GS, Huang IW, Baranowski T, Wilson B. Children's frequency of participation in moderate to vigorous physical activities. Research Quarterly for Exercise and Sport 1990;61(4):307-14.

\section{Simons-Morton 1994}

Simons-Morton BG, Taylor WC, Snider SA, Huang IW, Fulton JE. Observed levels of elementary and middle school children's physical activity during physical education classes. Preventive Medicine 1994;23(4):437-41.

\section{Skinner 1953}

Skinner BF. Science and Human Behavior. New York: Free Press, 1953.

\section{Stone 1998}

Stone EJ, McKenzie TL, Welk GJ, Booth ML. Effects of physical activity interventions in youth: review and synthesis. American Journal of Preventive Medicine 1998;15(4):298-315.

\section{Story 2009}

Story M, Nanney MS, Schwartz MB. Schools and obesity prevention: creating school environments and policies to promote healthy eating and physical activity. The Milbank Quarterly 2009; Vol. 87, issue 1:71-100. 


\section{Stucky-Ropp 1993}

Stucky-Ropp RC, DiLorenzo TM. Determinants of exercise in children. Preventive Medicine 1993;22(6):880-9.

\section{Summerbell 2005}

Summerbell CD, Waters E, Edmunds LD, Kelly S, Brown T, Campbell KJ. Interventions for preventing obesity in children. Cochrane Database of Systematic Reviews 2005, Issue 3. [CENTRAL: CD001871; DOI: 10.1002/14651858.CD001871]

\section{Tappe 1990}

Tappe MK, Duda JL, Menges-Ehrnwald P. Personal investment predictors of adolescent motivational orientation toward exercise. Canadian Journal of Sport Sciences 1990;15(3):185-92.

\section{Telama 2005}

Telama R, Yang X, Viikari J, Vimki I, Wanne O, Raitakari O. Physical activity from childhood to adulthood: a 21-year tracking study. American Journal of Preventative Medicine 2005; Vol. 28:267-73.

\section{Thomas 1999}

Thomas H, Siracusa L, Ross G, Beath L, Hanna L, Michaud M, et al. Effectiveness of school-based interventions in reducing adolescent risk behaviors: a systematic review of reviews. Effective Public Health Practice Project (EPHPP). Hamilton: Effective Public Health Practice Project, 1999.

\section{Thomas 2004a}

Thomas H, Ciliska D, Micucci S, Wilson-ABra J, Dobbins M. Effectiveness of physical activity enhancement and obesity prevention programs in children and youth. Effective Public Health Practice Project (EPHPP). Effective Public Health Practice Project, 2004:1-206.

\section{Thomas 2004b}

Thomas H, Ciliska D, Dobbins M, Micucci S. A process for systematically reviewing the literature: Providing the research evidence for public health nursing interventions. Worldviews on Evidence-Based Nursing 2004;1(3):176-84.

\section{Tolfrey 2000}

Tolfrey K, Jones AM, Campbell IG. The effect of aerobic exercise training on the lipid-lipoprotein profile of children and adolescents. Sports Medicine 2000;29(2):99-112.

\section{Troiano 1995}

Troiano RP, Flegal KM, Kuczmarski RJ, Campbell SM, Johnson $\mathrm{Cl}$. Overweight prevalence and trends for children and adolescents. Archives of Pediatrics and Adolescent Medicine 1995;149:1085-91.

\section{Twisk 2000}

Twisk JW, Kemper HC, van Mechelen W. Tracking of activity and fitness and the relationship with cardiovascular disease risk factors. Medicine and Science in Sports and Exercise 2000; Vol. 32:1455-61

\section{USDHHS 2008}

Physical Activity Guidelines Advisory Committee. 2008 Physical Activity Guidelines for Americans, 2008. www.health.gov/ paguidelines/. U.S. Department of Health \& Human Services. Washington, D.C.: The Secretary of Health and Human Services, Vol. (accessed 12 December 2012).

\section{Warden 1997}

Schonfeld-Warden N, Warden GH. Pediatric obesity: an overview of etiology and treatment. Pediatric Endocrinology 1997;44(2):339-61.

\section{Waters 2011}

Waters E, de Silva-Sanigorski A, Hall BJ, Brown T, Campbell K, Gao G, et al. Interventions for preventing obesity in children. Cochrane Database of Systematic Reviews 2011, Issue 12. [DOI: 10.1002/14651858.CD001871.pub3]

\section{Webber 1983}

Webber LS, Cresanta JL, Voors AW, Berenson GS. Tracking of cardiovascular disease risk factor variables in school age children. Journal of Chronic Diseases 1983;36:647-60.

\section{Webber 1991}

Webber LS, Srinivasan SR, Wattingney WA, Berenson GS. Tracking of serum lipids and lipoproteins from childhood to adulthood. American Journal of Epidemiology 1991;133:884-99.

\section{Whitaker 1997}

Whitaker RC, Wright JA, Pepe MS, Seidel KD, Dietz WH. Predicting obesity in young adulthood from childhood and parental obesity. New England Journal of Medicine 1997;337:869-73.

\section{Whitt-Glover 2009}

Whitt-Glover MC, Kumanyika SK. Systematic review of interventions to increase physical activity and physical fitness in African-Americans. American Journal of Health Promotion 2009;23(6):S33-56.

\section{WHO 2004a}

World Health Organization (WHO). Global Strategy on Diet, Physical Activity and Health, 2004. www.who.int/ dietphysicalactivity/strategy/eb11344/en/. (accessed 12 December 2012).

\section{WHO 2004b}

World Health Organization. Young people's health in context. Health Behaviour in School-aged Children (HBSC) study: international report from the 2001/2002 survey. World Health Organization (WHO). Health Policy for Children and Adolescents, No. 4. Copenhagen, Edinburgh, 3 June 2004, 2004; Vol. Health Policy for Children and Adolescents, No. 4.

\section{WHO 2008}

World Health Organization (WHO). Diet and physical activity: a public health priority, 2008. www.who.int/dietphysicalactivity/ en/. (accessed 12 December 2012).

\section{Zakarian 1994}

Zakarian JM, Hovell MF, Hofstetter CR, Sallis JF, Keating KJ. Correlates of vigorous exercise in a predominantly low SES and minority high school population. Preventive Medicine 1994;23(3):314-21. 


\section{CHARACTERISTICS OF STUDIES}

Characteristics of included studies [ordered by study ID]

Angelopoulos 2009

\begin{tabular}{|c|c|}
\hline Methods & $\begin{array}{l}\text { Design: cluster randomized controlled trial } \\
\text { Theoretical framework: Theory of Planned Behavior } \\
\text { Number of intervention groups: } 1 \\
\text { Number of control groups: } 1 \\
\text { Follow-up: immediately post-intervention }\end{array}$ \\
\hline Participants & $\begin{array}{l}\mathrm{N} \text { (intervention): } 321 \\
\mathrm{~N} \text { (control): } 325 \\
\text { Age (mean): } 10.3 \text { years } \\
\text { Sex: male and female } \\
\text { Ethnicity: Greek }\end{array}$ \\
\hline Interventions & $\begin{array}{l}\text { Country: Greece } \\
\text { Setting: school, urban and rural } \\
\text { Provider: classroom teachers } \\
\text { Duration: } 12 \text { months } \\
\text { Intervention: } 12 \text {-month program (January } 2005 \text { to January 2006) integrated in the existing school cur- } \\
\text { riculum in combination with physical education (PE) and science and environmental classes, providing } \\
\text { the least possible disturbance. Program material included a student's workbook and teacher's manu- } \\
\text { al, which offered activities for use in class in an appendix. The manual covered: self-esteem, body im- } \\
\text { age, nutrition, physical activity, fitness and environmental issues, and materials were used } 1 \text { to } 2 \mathrm{~h} \text { per } \\
\text { week. Motivational methods and strategies were used to increase knowledge (i.e. discussion, active } \\
\text { learning, cues), increase skills and self efficacy (i.e. modeling, guided practice, enactment), achieve bet- } \\
\text { ter self-monitoring (i.e. problem solving, goal setting), improve attitudes and beliefs (i.e. self re-eval- } \\
\text { uation, environmental re-evaluation, arguments, modeling, direct experience), and modify social in- } \\
\text { fluence (i.e. modeling, mobilizing social support). School teachers trained by the research team deliv- } \\
\text { ered the intervention and there was a home component for which parental involvement was required } \\
\text { to provide reinforcement } \\
\text { Control: not specified }\end{array}$ \\
\hline
\end{tabular}

Outcomes

Mean systolic blood pressure $(\mathrm{mmHg})$

Mean diastolic blood pressure $(\mathrm{mmHg})$

$\operatorname{BMI}\left(\mathrm{kg} / \mathrm{m}^{2}\right)$

Notes

Risk of bias

\begin{tabular}{lll}
\hline Bias & Authors' judgement & Support for judgement \\
\hline $\begin{array}{l}\text { Random sequence genera- } \\
\text { tion (selection bias) }\end{array}$ & Low risk & Comment: random digits used to develop allocation sequence \\
\hline $\begin{array}{l}\text { Allocation concealment } \\
\text { (selection bias) }\end{array}$ & Low risk & $\begin{array}{l}\text { Comment: criterion not applicable because all participants were allocated at } \\
1 \text { point in time following recruitment, so at time of recruitment allocation was } \\
\text { not known }\end{array}$ \\
\hline
\end{tabular}

Blinding (performance Unclear risk

Comment: no information given, likely not done

bias and detection bias) 
Angelopoulos 2009 (Continued)

All outcomes

\begin{tabular}{|c|c|c|}
\hline $\begin{array}{l}\text { Incomplete outcome data } \\
\text { (attrition bias) }\end{array}$ & High risk & $\begin{array}{l}\text { Comment: cannot determine how many students started the study only know } \\
\text { how many finished }\end{array}$ \\
\hline
\end{tabular}

All outcomes

Selective reporting (re- Low risk Comment: all outcomes identified a priori were reported on
porting bias)
porting bias)

\begin{tabular}{lll}
\hline Confounders controlled? & Low risk & Comment: all relevant confounders were controlled for \\
\hline $\begin{array}{l}\text { Data collection methods } \\
\text { valid and reliable? }\end{array}$ & Low risk & Comment: data collection methods valid and reliable \\
\hline
\end{tabular}

\section{Araujo-Soares 2009}

\begin{tabular}{|c|c|}
\hline Methods & $\begin{array}{l}\text { Design: cluster randomized controlled trial } \\
\text { Theoretical framework: Social Cognitive Theory } \\
\text { Number of intervention groups: } 1 \\
\text { Number of control groups: } 1 \\
\text { Follow-up: } 9 \text { months post-intervention }\end{array}$ \\
\hline \multirow[t]{5}{*}{ Participants } & N (intervention): 105 \\
\hline & $\mathrm{N}$ (control): 90 \\
\hline & Age (mean): 12.1 years \\
\hline & Sex: male and female \\
\hline & Ethnicity: unstated \\
\hline \multirow[t]{5}{*}{ Interventions } & Country: Portugal \\
\hline & Setting: school, unstated if urban or rural \\
\hline & Provider: research worker, psychologist, physical education teacher \\
\hline & Duration: 12 weeks \\
\hline & $\begin{array}{l}\text { Intervention: } 2 \text { classroom-based physical activity sessions of } 90 \text { min each, along with homework, de- } \\
\text { livered by a trained psychologist, assisted by a sports education teacher. The psychologist received } \\
\text { workshop training from the research team. A member of the research team served as supervisor to help } \\
\text { prepare the sessions. In the week proceeding both physical activity sessions, adolescents were asked } \\
\text { to keep a self-monitoring diary as homework, to keep track of daily physical activities in detail. After } \\
\text { the intervention they were encouraged to maintain the diary for } 2 \text { more weeks. During sessions, work- } \\
\text { sheets and a 3-min film were used. At the end of the sessions, each student received a pamphlet rein- } \\
\text { forcing main topics of the session } \\
\text { Control: not specified }\end{array}$ \\
\hline
\end{tabular}

Outcomes Duration of physical activity

\section{Notes}

\section{Risk of bias}

\begin{tabular}{lll}
\hline Bias & Authors' judgement & Support for judgement \\
\hline $\begin{array}{l}\text { Random sequence genera- } \\
\text { tion (selection bias) }\end{array}$ & Unclear risk & Comment: randomization process not reported \\
\hline
\end{tabular}


Araujo-Soares 2009 (Continued)

Allocation concealment Low risk Comment: criterion not applicable because all participants were allocated at (selection bias) 1 point in time following recruitment, so at time of recruitment allocation was not known

Blinding (performance $\quad$ Unclear risk $\quad$ Comment: no information given, likely not done
bias and detection bias)

bias and detection bias)

All outcomes

Incomplete outcome data Low risk Comment: unsure if intention to treat conducted at 9-month follow-up
(attrition bias)

(attrition

All outcomes

\begin{tabular}{lll}
\hline $\begin{array}{l}\text { Selective reporting (re- } \\
\text { porting bias) }\end{array}$ & Low risk & Comment: all outcomes identified a priori were reported on \\
\hline Confounders controlled? & High risk & Comment: not all relevant confounders accounted for \\
\hline $\begin{array}{l}\text { Data collection methods } \\
\text { valid and reliable? }\end{array}$ & Low risk & Comment: data collection tools reported to be valid and reliable \\
\hline
\end{tabular}

Barbeau 2007

\begin{tabular}{ll}
\hline Methods & Design: randomized controlled trial \\
Theoretical framework: unstated \\
Number of intervention groups: 1 \\
Number of control groups: 1 \\
Follow-up: immediately following intervention \\
\hline Participants & $\mathrm{N}$ (intervention): 118 \\
$\mathrm{~N}($ control): 83 \\
Age (mean): 9.5 years \\
Sex: female \\
Ethnicity: African-American
\end{tabular}

Interventions

Country: US

Setting: school, unstated whether urban or rural

Provider: classroom teachers and teaching assistants

Duration: 10 months

Intervention: 10-month after-school physical activity (PA) program on body composition and cardiovascular fitness in young black girls, offered every school day during the school year with transportation (i.e. school bus service) provided to encourage participation. 30 min of homework time while subjects received a free, healthy snack, and $80 \mathrm{~min}$ of PA. Snacks were individually packaged, and every day offered something salty (e.g. crackers and cheese), something sweet (e.g. low-fat cookies), or a fruit or vegetable. Subjects chose 1 snack with the option of another if they wished. The PA included 25 min of skill development, 35 min of moderate to vigorous physical activity (MVPA), with 20 min of toning and stretching. Subjects wore Polar Accurex Plus HR monitors (Port Washington, NY) every day and were instructed to maintain their heart rate above 150 beats/min during the MVPA. MVPA activities included games such as basketball, tag, softball, relay races, etc., modified for activity of all subjects through the 35-min period. Subjects received small weekly prizes for behavior and attitude, and for having no more than 1 unexcused absence. A student of the month in each school received a slightly larger prize with the prizes intended to reward good behavior, participation, and effort. Parents were called when students had 2 consecutive unexcused absences, with reasons discussed and parents encouraged to send their daughter back to the program. Teachers mostly worked the intervention in their own school and in some cases were assigned to work in a different school. Teachers received formal training with background information on childhood obesity, PA, and cardiovascular risk factors, study 
Barbeau 2007 (Continued)

goals, and the study protocol and types of activities appropriate for each segment of the intervention. Role playing was a large component of the training; teachers were asked to prepare a lesson plan for 1 day and did a shortened simulation of it, so feedback could be provided. A Manual of Procedures for each school included all information needed to implement the intervention, including several potential activities. Teachers hired after the training received one-on-one training on the theoretical aspects and observed several sessions before their own implementation Control: not specified

\begin{tabular}{ll}
\hline Outcomes & Duration of physical activity \\
& $\mathrm{BMI}\left(\mathrm{kg} / \mathrm{m}^{2}\right)$ \\
$\mathrm{VO}_{2} \mathrm{ax}(\mathrm{mL} / \mathrm{kg} /$ minute $)$ \\
\hline
\end{tabular}

Notes

\section{Risk of bias}

\begin{tabular}{|c|c|c|}
\hline Bias & Authors' judgement & Support for judgement \\
\hline $\begin{array}{l}\text { Random sequence genera- } \\
\text { tion (selection bias) }\end{array}$ & Unclear risk & Comment: randomization process not reported \\
\hline $\begin{array}{l}\text { Allocation concealment } \\
\text { (selection bias) }\end{array}$ & Low risk & $\begin{array}{l}\text { Comment: allocation occurred after testing, therefore concealed. It was not } \\
\text { known or determined at time of entry to study which group the next partici- } \\
\text { pant would go }\end{array}$ \\
\hline $\begin{array}{l}\text { Blinding (performance } \\
\text { bias and detection bias) } \\
\text { All outcomes }\end{array}$ & Unclear risk & Comment: no information given, likely not done \\
\hline $\begin{array}{l}\text { Incomplete outcome data } \\
\text { (attrition bias) } \\
\text { All outcomes }\end{array}$ & High risk & Comment: incomplete outcome data not addressed \\
\hline $\begin{array}{l}\text { Selective reporting (re- } \\
\text { porting bias) }\end{array}$ & Low risk & Comment: all outcomes identified a priori were reported on \\
\hline Confounders controlled? & High risk & $\begin{array}{l}\text { Comment: important variables like socioeconomic status not assessed or con- } \\
\text { trolled for }\end{array}$ \\
\hline $\begin{array}{l}\text { Data collection methods } \\
\text { valid and reliable? }\end{array}$ & High risk & Comment: reliability and validity of most outcomes not stated \\
\hline
\end{tabular}

Bayne-Smith 2004

\begin{tabular}{ll} 
Methods & Design: randomized controlled trial \\
& Theoretical framework: unstated \\
& Number of intervention groups: 1 \\
Number of control groups: 1 \\
Follow-up: immediately post-intervention \\
\hline Participants & $\mathrm{N}$ (intervention): 310 \\
& $\mathrm{~N}($ control): 132 \\
& $\begin{array}{l}\text { Age (mean): } 16.1 \text { years } \\
\text { Sex: female }\end{array}$
\end{tabular}


Bayne-Smith 2004 (Continued)

Ethnicity: mixed

Interventions

\section{Country: US}

Setting: urban

Provider: unstated

Duration: 12 weeks

Intervention: the PATH curriculum was taught as a personal wellness course that integrated vigorous exercise, health and nutrition education, and behavior modification. PATH student manuals were developed to provide students with information about the anatomy and physiology of the heart, cardiovascular risk factors, the heart disease process, proper exercise and nutrition, stress management, cigarette smoking avoidance and cessation techniques, and strategies for modifying high-risk health behaviors. PATH teacher manuals were provided to physical education (PE) teachers containing instructions for teaching the program curriculum and assessing outcomes. PE teachers using the PATH curriculum received in-service training from the investigation team before and during the intervention. The PATH program consisted of 30-min classes conducted 5 days per week for 12 weeks. Individual classes began with a 5- to 10-min lecture and discussion featuring a topic on cardiovascular health and fitness and suggestions for modifying health behaviors. In addition, students frequently were given homework assignments designed to enhance or clarify lecture material through use of the PATH manuals. The lecture and discussion were followed by 20 to $25 \mathrm{~min}$ of vigorous physical activity in the form of either resistance exercise to improve muscular strength and endurance or aerobic exercise to improve cardiovascular fitness. Students alternated resistance and aerobic training each day. Resistance exercise consisted of a vigorous program of circuit weight training at a variety of isotonic and isokinetic exercise stations. Students performed 90 - to 120 -second bouts of weight lifting at $50 \%$ to $70 \%$ of the 1 repetition maximum (the maximum resistance that can be lifted 1 time). Aerobic training included a variety of vigorous exercises, such as stationary bicycling, stair stepping, rope jumping, fast walking, jogging, step aerobics, and aerobic dance. Students were instructed to exercise continuously at $70 \%$ to $85 \%$ of their age-predicted maximum heart rate. Students were taught how to self-monitor heart rates during or immediately upon cessation of exercise by palpation of the radial or carotid pulse Control: the frequency and duration of traditional PE classes were identical to those of PATH classes. Since PE classes did not have lecture and discussion, they had approximately 5 min more physical activity per class than PATH classes

$\begin{array}{ll}\text { Dutcomes } & \text { Dean systolic blood pressure }(\mathrm{mmHg}) \\ \text { Mean diastolic blood pressure }(\mathrm{mmHg}) \\ \text { Mean blood cholesterol level }(\mathrm{mg} / \mathrm{dL}) \\ \mathrm{BMI}\left(\mathrm{kg} / \mathrm{m}^{2}\right) \\ \mathrm{VO}_{2} \mathrm{max}(\mathrm{mL} / \mathrm{kg} / \text { minute })\end{array}$

Notes

\section{Risk of bias}

\begin{tabular}{lll}
\hline Bias & Authors' judgement & Support for judgement \\
\hline $\begin{array}{l}\text { Random sequence genera- } \\
\text { tion (selection bias) }\end{array}$ & Unclear risk & Comment: randomization process not reported \\
\hline $\begin{array}{l}\text { Allocation concealment } \\
\text { (selection bias) }\end{array}$ & Low risk & $\begin{array}{l}\text { Comment: criterion not applicable because all participants were allocated at } \\
1 \text { point in time following recruitment, so at time of recruitment allocation was } \\
\text { not known }\end{array}$ \\
\hline
\end{tabular}

Blinding (performance Unclear risk Comment: no information given, likely not done

bias and detection bias)

All outcomes

Incomplete outcome data Unclear risk Comment: incomplete outcome data not addressed
(attrition bias)
All outcomes

School-based physical activity programs for promoting physical activity and fitness in children and adolescents aged 6 to 18 (Review) 
Bayne-Smith 2004 (Continued)

Selective reporting (re- Low risk $\quad$ Comment: all outcomes identified a priori were reported on
porting bias)

\begin{tabular}{ll}
\hline Confounders controlled? High risk & $\begin{array}{l}\text { Comment: while there were no significant differences in most confounders, } \\
\text { there were a few small differences which were not accounted for }\end{array}$
\end{tabular}

Data collection methods High risk Comment: reliability and validity of most outcomes not stated
valid and reliable?

valid and reliable?

\section{Burke 1998}

$\begin{array}{ll}\text { Methods } & \text { Design: cluster randomized controlled trial } \\ \text { Theoretical framework: unstated } \\ \text { Number of intervention groups: } 5 \\ \text { Number of control groups: } 1 \\ \text { Follow-up: } 6 \text { months post-intervention }\end{array}$

$\begin{array}{ll}\text { Participants } & \text { N (total): } 720 \\ & \text { Age (mean): } 11 \text { years } \\ \text { Sex: male and female } \\ \text { Ethnicity: unstated }\end{array}$

Interventions Country: Australia

Setting: school, home, unstated if urban or rural

Provider: teachers, research staff, parents

Duration: 9 months

Intervention 1: standard physical activity (PA) and nutrition program (WASPAN) in 6 schools, which consisted of classroom lessons to establish a rationale, plus 20-min fitness sessions daily by means of small group activities that allowed for individual fitness levels and provided a range of options by means of progression through graded activities. Four fitness sessions per week were considered a realistic expectation. The nutrition program aimed to improve children's diets by prompting families to review their diets; reducing consumption of fat, sugar, and salt; increasing fiber intake; and creating links between home and school for health promotion. The nutrition program is built around 4 comic books in which 2 space creatures must discover the dietary habits of humans. It includes a Teachers' Handbook, Home-based Mission Booklet, Class Activities Booklet, Incentives, and a Recipe Booklet that presents recipes written for children by children. Home-based Missions and Class Activities are combined in activities such as planning a week's grocery shopping on the basis of advertised prices and in learning strategies to resist peer pressure. The Incentives Booklet includes a progress chart, stickers, and a completion certificate to encourage participation from children and parents. Duration of nutrition class activities aimed for 1 hour per week.

Intervention 2: standard WASPAN program plus a PA-enrichment program for higher-risk children in 7 schools, which consisted of incorporating the teacher-parent-student triad and allowed for PA needs and preferences to be met outside the setting of the whole class. Children kept regular, but not continuous, 7-day PA diaries, which were used by teachers to identify preferred activities and ways these might be increased in duration or frequency. Teachers and students worked together to establish goals and decide on how these might be attained. Parents were asked to monitor completion of the diaries and to encourage increased levels of PA

Control: no program in 5 schools

$\begin{array}{ll}\text { Outcomes } & \text { Television viewing (minutes spent watching television) } \\ & \text { Mean systolic blood pressure }(\mathrm{mmHg}) \\ & \text { Mean diastolic blood pressure }(\mathrm{mmHg}) \\ & \mathrm{BMI}\left(\mathrm{kg} / \mathrm{m}^{2}\right)\end{array}$


Burke 1998 (Continued)

Risk of bias

\begin{tabular}{lll}
\hline Bias & Authors' judgement & Support for judgement \\
\hline $\begin{array}{l}\text { Random sequence genera- } \\
\text { tion (selection bias) }\end{array}$ & Unclear risk & Comment: randomization process not reported \\
\hline $\begin{array}{l}\text { Allocation concealment } \\
\text { (selection bias) }\end{array}$ & Low risk & $\begin{array}{l}\text { Comment: criterion not applicable because all participants were allocated at } \\
1 \text { point in time following recruitment, so at time of recruitment allocation was } \\
\text { not known }\end{array}$ \\
\hline $\begin{array}{l}\text { Blinding (performance } \\
\text { bias and detection bias) } \\
\text { All outcomes }\end{array}$ & Unclear risk & Comment: no information given, likely not done \\
\hline $\begin{array}{l}\text { Incomplete outcome data } \\
\text { (attrition bias) } \\
\text { All outcomes }\end{array}$ & Low risk & Comment: outcome data complete \\
\hline $\begin{array}{l}\text { Selective reporting (re- } \\
\text { porting bias) }\end{array}$ & Low risk & Comment: all outcomes identified a priori were reported on \\
\hline $\begin{array}{l}\text { Confounders controlled? } \\
\text { Data collection methods }\end{array}$ & Low risk & High risk \\
\begin{tabular}{l} 
valid and reliable? \\
\hline
\end{tabular} & Comment: all relevant confounders were accounted for \\
\hline
\end{tabular}

Bush 1989

Mesign: cluster randomized controlled trial
Theoretical framework: PRECEDE, Social Learning Theory
Number of intervention groups: 2
Number of control groups: 1
Follow-up: immediately post-intervention
N: 431
Age (mean): 10.5 years
Sex: male and female
Ethnicity: African-American
Country: US
Setting: school, home, community, physician office, mix of urban and rural
Provider: teachers, research staff, volunteers, advisory board
Duration: 4 years
Intervention 1: 'Know Your Body' curriculum. Focus on nutrition, fitness, and the prevention of ciga-
rette smoking. Curriculum to motivate students to attain and maintain life styles that will that will re-
duce the students' risk of developing heart disease and cancer. Includes a personalized health screen-
ing with each student receiving results on a 'health passport'. Parents are involved through several
mechanisms, they are mailed 2 copies of their children's screening results, 1 copy to keep and 1 for the
child's physician, copies of a quarterly 'Know Your Body' newsletter, and the program is introduced by
staff at parent-teacher association meetings
Intervention 2: received the same intervention as Intervention 1, but only their parents received the
results of their cholesterol tests and the students were not provided with the results to enter on their
'health passports' with other screening results


Bush 1989 (Continued)

Control: did not receive the 'Know Your Body' curriculum and were not provided with any of their screening results. Only parents of control subjects received the screening results

\begin{tabular}{ll}
\hline Outcomes & Mean systolic blood pressure $(\mathrm{mmHg})$ \\
& Mean diastolic blood pressure $(\mathrm{mmHg})$ \\
& Mean blood cholesterol level $(\mathrm{mg} / \mathrm{dL})$ \\
& BMI $\left(\mathrm{kg} / \mathrm{m}^{2}\right)$ \\
& Pulse rate (beats/minute)
\end{tabular}

\section{Notes}

\section{Risk of bias}

\begin{tabular}{|c|c|c|}
\hline Bias & Authors' judgement & Support for judgement \\
\hline $\begin{array}{l}\text { Random sequence genera- } \\
\text { tion (selection bias) }\end{array}$ & Unclear risk & Comment: no description of the randomization process given \\
\hline $\begin{array}{l}\text { Allocation concealment } \\
\text { (selection bias) }\end{array}$ & Low risk & $\begin{array}{l}\text { Comment: criterion not applicable because all participants were allocated at } \\
1 \text { point in time following recruitment, so at time of recruitment allocation was } \\
\text { not known }\end{array}$ \\
\hline $\begin{array}{l}\text { Blinding (performance } \\
\text { bias and detection bias) } \\
\text { All outcomes }\end{array}$ & Unclear risk & Comment: no information given, likely not done \\
\hline $\begin{array}{l}\text { Incomplete outcome data } \\
\text { (attrition bias) } \\
\text { All outcomes }\end{array}$ & High risk & $\begin{array}{l}\text { Quote: "Only } 431 \text { ( } 41.4 \% \text { of participants were rescreened } 2 \text { years after forming } \\
\text { the cohort. Students who had moved from a control to an intervention school } \\
\text { or vice versa were dropped from the analysis" (Bush 1989, p472) }\end{array}$ \\
\hline $\begin{array}{l}\text { Selective reporting (re- } \\
\text { porting bias) }\end{array}$ & Low risk & Comment: all outcomes identified a priori were reported on \\
\hline Confounders controlled? & Low risk & $\begin{array}{l}\text { Quote: Multiple regression analysis was used to adjust the observed difference } \\
\text { in scores between the control and intervention groups for these confounder- } \\
\text { s" (Bush 1989, p472) }\end{array}$ \\
\hline $\begin{array}{l}\text { Data collection methods } \\
\text { valid and reliable? }\end{array}$ & Unclear risk & Comment: insufficient data to determine reliability and validity \\
\hline
\end{tabular}

Colin-Ramirez 2010

$\begin{array}{ll}\text { Methods } & \text { Design: cluster randomized controlled trial } \\ \text { Theoretical framework: not stated } \\ \text { Number of intervention groups: } 1 \\ \text { Number of control groups: } 1 \\ \text { Follow-up: immediately post-intervention }\end{array}$

$\begin{array}{ll}\text { Participants } & \text { N (intervention): } 245 \\ & \text { N (control): } 253 \\ & \text { Age (mean): } 9.4 \text { years }\end{array}$


Colin-Ramirez 2010 (Continued)

Sex: male and female

Ethnicity: Mexican

Interventions
Country: Mexico
Setting: grade school, urban
Provider: mixed - a) health teams including a physician, dentist, psychologist, nurse, social worker, b)
classroom teachers, physical education (PE) teachers
Duration: 2 academic years
Intervention: RESCATE program, included physical activity and nutritional components. Physical activ-
ity was addressed at 3 levels: individual, school, and family. At the 'individual level', classroom lessons
and exercise breaks were implemented. The educational component in the classroom involved weekly
30-min lessons that emphasized the importance of physical activity, delivered by trained health teams
(a physician, a dentist, a psychologist, a nurse and a social worker). Exercise breaks in the classroom
lasting 2-10 min were designed to increase energy output and promote physical activity in the class-
room. The TAKE 10 program of classroom physical activity was adapted for this purpose and included
in the procedure manual for the classroom teachers who led the exercises. 'School-level' intervention
included PE classes. The aim of this component of the program was to increase the length of time that
children participated in moderate to strenuous exercise during PE classes. For 30 min twice a week,
there was a substitution of regular exercise during PE classes for new ones that required moderate to
vigorous energy output. PE teachers received a manual with the appropriate exercise options. 'Family
level' involved family members in support and reinforcement of classroom lessons. Each child received
a book of activities to take home with exercises that corresponded to the lessons at school and was im-
plemented with collaboration with his parents. In addition, the parents received recommendations for
achieving a more active lifestyle. Recommendations included decreasing time spent on sedentary ac-
tivities such as watching television, using a computer or playing video games
Control: no physical activity/nutrition program

Outcomes Physical activity rates (\% of sample physically active)

Television viewing (minutes spent watching television)

\section{Notes}

\section{Risk of bias}

\begin{tabular}{lll}
\hline Bias & Authors' judgement & Support for judgement \\
\hline $\begin{array}{l}\text { Random sequence genera- } \\
\text { tion (selection bias) }\end{array}$ & Unclear risk & Comment: no description of the randomization process given \\
\hline $\begin{array}{l}\text { Allocation concealment } \\
\text { (selection bias) }\end{array}$ & Low risk & $\begin{array}{l}\text { Comment: criterion not applicable because all schools were allocated at } 1 \\
\text { point in time following recruitment, so at time of recruitment allocation was } \\
\text { not known }\end{array}$
\end{tabular}

Blinding (performance High risk Comment: data collected through self report from participants
bias and detection bias)
All outcomes

\begin{tabular}{lll}
\hline $\begin{array}{l}\text { Incomplete outcome data } \\
\text { (attrition bias) }\end{array}$ & Low risk & \\
All outcomes & & \\
\hline $\begin{array}{l}\text { Selective reporting (re- } \\
\text { porting bias) }\end{array}$ & Unclear risk & Comment: no information given, likely not done \\
\hline
\end{tabular}


Colin-Ramirez 2010 (Continued)

\begin{tabular}{lll} 
Confounders controlled? & High risk & Comment: confounders not addressed \\
\hline $\begin{array}{l}\text { Data collection methods } \\
\text { valid and reliable? }\end{array}$ & Unclear risk & $\begin{array}{l}\text { Comment: authors state reliability and validity of questionnaire has been re- } \\
\text { ported previously and validated for a Spanish population, but no details pro- } \\
\text { vided other than a citation }\end{array}$
\end{tabular}

Dishman 2004

Design: cluster randomized controlled trial
Theoretical framework: Social Cognitive Theory
Number of intervention groups: 1
Number of control groups: 1
Followup: immediately post-intervention

N: 2111
Participants (mean): 13.6 years
Sex: female
Ethnicity: White and African American

Interventions Country: US

Setting: school, community, mixed urban and rural

Provider: classroom teachers

Duration: 1 year

Intervention: Lifestyle Education for Activity Program (LEAP), a comprehensive school-based intervention that emphasized changes in instruction and the school environment. Designed to increase physical activity in high-school girls by creating a school environment that supported the unique physical activity needs and interests of adolescent girls. Aimed to increase girls' self-efficacy for physical activity, via physical education (PE), school environment, health education, school health services, faculty or staff health promotion, and parent and community involvement. The intervention staff assisted teachers to develop curricula designed to help adolescent girls enhance physical activity self-efficacy through successful experiences with physical activity both inside and outside of school and develop physical and behavioral skills necessary to adopt a physically active lifestyle during the teenage years and to maintain it through adulthood. Teachers at each school developed behavioral skill instructional units that emphasized the acquisition and practice of self-regulatory behaviors (e.g. goal setting, time management, identifying and overcoming barriers, and self-reinforcement); the units were implemented in health education, biology, family and consumer science, or PE, depending on how each school provided health education. The PE component developed motor skills in a variety of physical activities that were popular with high-school girls including aerobics, weight training, dance, and self-defence using approaches that favored small groups and cooperative and successful learning experiences. In addition to facilitating noncompetitive mastery of skills, the instruction also used modeling of success, encouragement, and moderately intense exercise directed toward enhancing self-efficacy

Control: standard PE as part of school curriculum

\section{Risk of bias}

\begin{tabular}{lll}
\hline Bias & Authors' judgement & Support for judgement \\
\hline $\begin{array}{l}\text { Random sequence genera- } \\
\text { tion (selection bias) }\end{array}$ & Unclear risk & Comment: randomization process not reported \\
\hline
\end{tabular}


Dishman 2004 (Continued)

$\begin{array}{ll}\text { Allocation concealment } & \text { Low risk } \\ \text { (selection bias) } & \text { Comment: criterion not applicable because all participants were allocated at } \\ & \text { not known }\end{array}$

\begin{tabular}{lll}
\hline $\begin{array}{l}\text { Blinding (performance } \\
\text { bias and detection bias) } \\
\text { All outcomes }\end{array}$ & Unclear risk & Comment: no information given, likely not done \\
\hline $\begin{array}{l}\text { Incomplete outcome data } \\
\text { (attrition bias) } \\
\text { All outcomes }\end{array}$ & Low risk & Comment: missing data for physical activity at follow-up were imputed \\
\hline $\begin{array}{l}\text { Selective reporting (re- } \\
\text { porting bias) }\end{array}$ & Low risk & Comment: all outcomes identified a priori were reported on \\
\hline $\begin{array}{l}\text { Confounders controlled? } \\
\text { Low risk }\end{array}$ & Comment: relevant confounders were controlled including age, ethnicity, \\
\hline $\begin{array}{l}\text { Data collection methods } \\
\text { valid and reliable? }\end{array}$ & Low risk & Cody mass index \\
\hline
\end{tabular}

Donnelly 2009

\begin{tabular}{|c|c|}
\hline Methods & $\begin{array}{l}\text { Design: cluster randomized controlled trial } \\
\text { Theoretical framework: unstated } \\
\text { Number of intervention groups: } 1 \\
\text { Number of control groups: } 1 \\
\text { Follow-up: immediately post-intervention }\end{array}$ \\
\hline \multirow[t]{4}{*}{ Participants } & N (intervention): 792 \\
\hline & $N($ control): 698 \\
\hline & Age (mean): 8.2 years \\
\hline & $\begin{array}{l}\text { Sex: male and female } \\
\text { Ethnicity: White }\end{array}$ \\
\hline \multirow[t]{6}{*}{ Interventions } & Country: US \\
\hline & Setting: school, urban \\
\hline & Provider: classroom teachers \\
\hline & Duration: 3 years \\
\hline & $\begin{array}{l}\text { Intervention: Physical Activity Across the Curriculum (PAAC), provided training for classroom teach- } \\
\text { ers ( } 6 \text { hour in-service session) to deliver existing academic lessons taught thorough physical activity, } \\
\text { using examples from TAKE 10!, a program of the International Life Sciences Institute Research Foun- } \\
\text { dation/Center for Health Promotion. } 90 \mathrm{~min} / \text { week of moderate to vigorous physically active academic } \\
\text { lessons were delivered intermittently throughout the school day }\end{array}$ \\
\hline & Control: regular classroom instruction without physically active lessons \\
\hline
\end{tabular}

\begin{tabular}{ll}
\hline Outcomes & Duration of physical activity \\
$\mathrm{BMI}\left(\mathrm{kg} / \mathrm{m}^{2}\right)$ \\
\hline
\end{tabular}

\section{Notes}

\section{Risk of bias}

School-based physical activity programs for promoting physical activity and fitness in children and adolescents aged 6 to 18 (Review) 
Donnelly 2009 (Continued)

\begin{tabular}{|c|c|c|}
\hline Bias & Authors' judgement & Support for judgement \\
\hline $\begin{array}{l}\text { Random sequence genera- } \\
\text { tion (selection bias) }\end{array}$ & Unclear risk & Comment: no description of the randomization process given \\
\hline $\begin{array}{l}\text { Allocation concealment } \\
\text { (selection bias) }\end{array}$ & Low risk & $\begin{array}{l}\text { Comment: criterion not applicable because all participants were allocated at } \\
1 \text { point in time following recruitment, so at time of recruitment allocation was } \\
\text { not known }\end{array}$ \\
\hline $\begin{array}{l}\text { Blinding (performance } \\
\text { bias and detection bias) } \\
\text { All outcomes }\end{array}$ & Low risk & $\begin{array}{l}\text { Comment: blinding was done where possible - research assistants were blind- } \\
\text { ed to condition for measurement of the primary and secondary outcomes and } \\
\text { for data entry }\end{array}$ \\
\hline $\begin{array}{l}\text { Incomplete outcome data } \\
\text { (attrition bias) } \\
\text { All outcomes }\end{array}$ & Low risk & Comment: there was $2.5 \%$ missing data, not likely to affect results \\
\hline $\begin{array}{l}\text { Selective reporting (re- } \\
\text { porting bias) }\end{array}$ & Low risk & Comment: all outcomes identified a priori were reported on \\
\hline Confounders controlled? & Low risk & Comment: all relevant confounders taken into account \\
\hline $\begin{array}{l}\text { Data collection methods } \\
\text { valid and reliable? }\end{array}$ & Low risk & Comment: data collection tools reported to be valid and reliable \\
\hline
\end{tabular}

\section{Dorgo 2009}

\begin{tabular}{|c|c|}
\hline Methods & $\begin{array}{l}\text { Design: cluster randomized controlled trial } \\
\text { Theoretical framework: unstated } \\
\text { Number of intervention groups: } 2 \\
\text { Number of control groups: } 1 \\
\text { Follow-up: immediately post-intervention }\end{array}$ \\
\hline Participants & $\begin{array}{l}\mathrm{N} \text { (intervention): } 93 \\
\mathrm{~N} \text { (control): } 129 \\
\text { Age (mean): } 15.9 \text { years } \\
\text { Sex: male and female } \\
\text { Ethnicity: unstated }\end{array}$ \\
\hline Interventions & $\begin{array}{l}\text { Country: US } \\
\text { Setting: school, unstated if urban or rural } \\
\text { Provider: research worker, PE teachers } \\
\text { Duration: } 18 \text { weeks } \\
\text { Intervention 1: physical education (PE) program that used manual resistance training (MRT) in every } \\
\text { session. } 80 \text {-min class sessions } 3 \text { times per week, plus a 10- to 15-min warm-up segment with light car- } \\
\text { diovascular activities and dynamic stretching followed by the MRT-specific segment of approximately } \\
20 \text { to } 30 \text { min conducted and supervised by trained research assistants } \\
\text { Intervention 2: MRT PE program plus a cardiovascular endurance training segment in every session. } \\
80 \text {-min class sessions, } 3 \text { times per week, plus a } 20 \text { - to } 30 \text {-min MRT segment conducted and supervised } \\
\text { by trained research assistants, with an additional } 20 \text { - to } 30 \text {-min period devoted to cardiovascular en- } \\
\text { durance training. Cardiovascular activities included walking, jogging, step aerobics, and aerobic kick- } \\
\text { boxing } \\
\text { Control: a regular PE program that followed the usual school curriculum. } 80 \text {-min class sessions } 3 \text { times } \\
\text { per week. PE classes focused on skill development for various individual physical activities (i.e. bowl- } \\
\text { ing, badminton, tennis, table tennis, golf, various track and field events) and team physical activities }\end{array}$ \\
\hline
\end{tabular}

School-based physical activity programs for promoting physical activity and fitness in children and adolescents aged 6 to 18 (Review) 
Dorgo 2009 (Continued)

(i.e. soccer, basketball, softball/baseball, volleyball, floor hockey), as well as participation in leisure activities (i.e., hiking) and sport tournaments

\begin{tabular}{|c|c|c|}
\hline Outcomes & BMI $\left(\mathrm{kg} / \mathrm{m}^{2}\right)$ & \\
\hline \multicolumn{3}{|l|}{ Notes } \\
\hline \multicolumn{3}{|l|}{ Risk of bias } \\
\hline Bias & Authors' judgement & Support for judgement \\
\hline $\begin{array}{l}\text { Random sequence genera- } \\
\text { tion (selection bias) }\end{array}$ & Unclear risk & Comment: randomization process not reported \\
\hline $\begin{array}{l}\text { Allocation concealment } \\
\text { (selection bias) }\end{array}$ & Low risk & $\begin{array}{l}\text { Comment: criterion not applicable because all participants were allocated at } \\
1 \text { point in time following recruitment, so at time of recruitment allocation was } \\
\text { not known }\end{array}$ \\
\hline $\begin{array}{l}\text { Blinding (performance } \\
\text { bias and detection bias) } \\
\text { All outcomes }\end{array}$ & Unclear risk & Comment: no information given, likely not done \\
\hline $\begin{array}{l}\text { Incomplete outcome data } \\
\text { (attrition bias) } \\
\text { All outcomes }\end{array}$ & High risk & $\begin{array}{l}\text { Quote: "24 subjects failed to attend the post-test data collection and were not } \\
\text { included in the data analyses" (Dorgo, 2009, p2291). }\end{array}$ \\
\hline $\begin{array}{l}\text { Selective reporting (re- } \\
\text { porting bias) }\end{array}$ & Low risk & Comment: all outcomes identified a priori were reported on \\
\hline Confounders controlled? & High risk & Comment: not all relevant confounders taken into account \\
\hline $\begin{array}{l}\text { Data collection methods } \\
\text { valid and reliable? }\end{array}$ & Low risk & Comment: data collection tools reported to be valid and reliable \\
\hline
\end{tabular}

Ewart 1998

\begin{tabular}{|c|c|}
\hline Methods & $\begin{array}{l}\text { Design: randomized controlled trial } \\
\text { Theoretical framework: unstated } \\
\text { Number of intervention groups: } 1 \\
\text { Number of control groups: } 1 \\
\text { Follow-up: immediately post-intervention }\end{array}$ \\
\hline Participants & $\begin{array}{l}N \text { (intervention): } 44 \\
N \text { (control): } 44 \\
\text { Age: grade } 9 \text { (mean age not provided) } \\
\text { Sex: females } \\
\text { Ethnicity: White, African American }\end{array}$ \\
\hline Interventions & $\begin{array}{l}\text { Country: US } \\
\text { Setting: school, home, urban } \\
\text { Provider: research staff } \\
\text { Duration: } 18 \text { weeks } \\
\text { Intervention: } 50 \text {-min 'Project Heart' aerobic exercise classes including didactic instruction } \\
\text { Control: } 50 \text {-min standard physical education classes }\end{array}$ \\
\hline Outcomes & Duration of physical activity \\
\hline
\end{tabular}

School-based physical activity programs for promoting physical activity and fitness in children and adolescents aged 6 to 18 (Review) 
Ewart 1998 (Continued)

Mean systolic blood pressure $(\mathrm{mmHg})$

Mean diastolic blood pressure $(\mathrm{mmHg})$

BMI $\left(\mathrm{kg} / \mathrm{m}^{2}\right)$

Pulse rate (beats/minute)

Notes

\section{Risk of bias}

\begin{tabular}{|c|c|c|}
\hline Bias & Authors' judgement & Support for judgement \\
\hline $\begin{array}{l}\text { Random sequence genera- } \\
\text { tion (selection bias) }\end{array}$ & Unclear risk & Comment: randomization process not reported \\
\hline $\begin{array}{l}\text { Allocation concealment } \\
\text { (selection bias) }\end{array}$ & Low risk & $\begin{array}{l}\text { Comment: criterion not applicable because all participants were allocated at } \\
1 \text { point in time following recruitment, so at time of recruitment allocation was } \\
\text { not known }\end{array}$ \\
\hline $\begin{array}{l}\text { Blinding (performance } \\
\text { bias and detection bias) } \\
\text { All outcomes }\end{array}$ & Low risk & $\begin{array}{l}\text { Comment: technicians taking measurements were reported not aware of girls' } \\
\text { experimental status }\end{array}$ \\
\hline $\begin{array}{l}\text { Incomplete outcome data } \\
\text { (attrition bias) } \\
\text { All outcomes }\end{array}$ & Low risk & Comment: outcome data complete \\
\hline $\begin{array}{l}\text { Selective reporting (re- } \\
\text { porting bias) }\end{array}$ & Low risk & Comment: all outcomes identified a priori were reported on \\
\hline Confounders controlled? & Unclear risk & $\begin{array}{l}\text { Comment: authors state no differences in behavioral and familial factors were } \\
\text { observed, but do not indicate which factors these were }\end{array}$ \\
\hline $\begin{array}{l}\text { Data collection methods } \\
\text { valid and reliable? }\end{array}$ & Unclear risk & Comment: reliability and validity of data collection tools was not mentioned \\
\hline
\end{tabular}

\section{Gentile 2009}

\begin{tabular}{ll}
\hline Methods & Design: cluster randomized controlled trial \\
Theoretical framework: Social Ecological Model \\
Number of intervention groups: 1 \\
Number of control groups: 1 \\
Follow-up: 6 months post-intervention \\
\hline N: 1029 \\
Age (mean): 9.6 years \\
Sex: male and female \\
Ethnicity: White \\
Country: US \\
Setting: community, home, school, unstated if urban or rural \\
Provider: research worker, lay person, volunteer, teachers \\
Duration: 8 months \\
Intervention: 'Switch' program, promoted healthy active lifestyles by encouraging students to 'Switch \\
what you Do, Chew, and View', including: be active for 60 min or more per day, limit total screen time \\
to 2 hours or fewer per day, and to eat 5 fruits/vegetables or more per day. Community component: pro- \\
motion of awareness of healthy lifestyles and the prevention of childhood obesity included: paid adver-
\end{tabular}

School-based physical activity programs for promoting physical activity and fitness in children and adolescents aged 6 to 18 (Review) 
Gentile 2009 (Continued)

tising (e.g. billboards) and unpaid media emphasizing the key messages. School component: teachers were provided with materials and ways to integrate key concepts into their existing curricula. Family component: provided parents (and children) with materials and resources to facilitate the adoption of the healthy target behaviors. Monthly packets containing behavioral tools were provided to assist parents and children in modifying their behaviors

Control: no intentional exposure to the Switch program. May have been exposed to the community component of the intervention. Did not receive any school materials. Did not receive materials/resources, other than surveys

\begin{tabular}{l}
\hline Outcomes \\
BMl $\left(\mathrm{kg} / \mathrm{m}^{2}\right)$
\end{tabular}

\section{Notes}

\section{Risk of bias}

\begin{tabular}{lll}
\hline Bias & Authors' judgement & Support for judgement \\
\hline $\begin{array}{l}\text { Random sequence genera- } \\
\text { tion (selection bias) }\end{array}$ & Unclear risk & Comment: randomization process not reported \\
\hline $\begin{array}{l}\text { Allocation concealment } \\
\text { (selection bias) }\end{array}$ & Low risk & $\begin{array}{l}\text { Comment: criterion not applicable because all participants were allocated at } \\
1 \text { point in time following recruitment, so at time of recruitment allocation was } \\
\text { not known }\end{array}$ \\
\hline
\end{tabular}

Blinding (performance Unclear risk Comment: no information given, likely not done

bias and detection bias)

All outcomes

\begin{tabular}{|c|c|c|}
\hline $\begin{array}{l}\text { Incomplete outcome data } \\
\text { (attrition bias) } \\
\text { All outcomes }\end{array}$ & High risk & Comment: incomplete outcome data was not adequately addressed \\
\hline $\begin{array}{l}\text { Selective reporting (re- } \\
\text { porting bias) }\end{array}$ & Low risk & Comment: all outcomes identified a priori were reported on \\
\hline Confounders controlled? & Low risk & Comment: all relevant confounders taken into account \\
\hline $\begin{array}{l}\text { Data collection methods } \\
\text { valid and reliable? }\end{array}$ & Low risk & $\begin{array}{l}\text { Comment: data collection tools reported to be valid and reliable although } \\
\text { methods could have been stronger for body mass index }\end{array}$ \\
\hline
\end{tabular}

Haerens 2006

\begin{tabular}{ll} 
Methods & $\begin{array}{l}\text { Design: cluster randomized controlled trial } \\
\text { Theoretical framework: Transtheoretical Model } \\
\text { Number of intervention groups: } 2 \\
\text { Number of control groups: } 1 \\
\text { Follow-up: immediately post-intervention }\end{array}$ \\
\hline Participants & $\mathrm{N}: 2434$ \\
& $\begin{array}{l}\text { Age (mean): } 13.1 \text { years } \\
\text { Sex: male and female } \\
\text { Ethnicity: White }\end{array}$ \\
\hline Interventions & Country: Belgium
\end{tabular}

School-based physical activity programs for promoting physical activity and fitness in children and adolescents aged 6 to 18 (Review) 
Haerens 2006 (Continued)

Setting: school, urban

Provider: teachers

Duration: 2 years

Intervention 1: physical activity (PA) and nutrition intervention. The PA intervention focused on increasing levels of moderate to vigorous physical activity (MVPA) to at least $60 \mathrm{~min}$ per day. Schools received an intervention box with sports materials such as ropes, balls, and beach ball sets and were encouraged to create more noncompetitive opportunities to be physically active during breaks, at noon or during after-school hours, and to vary content of PAs offered. Children received a physical fitness test at the beginning of the second intervention year where all children had to cycle for $10 \mathrm{~min}$ on a computerized cycle ergometer, then were given information on their fitness levels and possible ways to improve it. The computer-tailored portion of the intervention was completed once each school year during 1 class hour. Children completed PA questions on a computer screen, which was immediately followed by tailored feedback on the screen (e.g. normative feedback regarding activity levels, PA recommendations). The nutrition intervention focused on 3 behavioral changes: (i) increasing fruit consumption 2+ pieces/day, (ii) reducing soft drink consumption and increasing water consumption, and, (iii) reducing fat intake. Schools were asked to sell fruit at very low prices or for free at least once a week, to offer fruit for dessert at lunch, and to offer free water via drinking fountains

Intervention 2: PA and nutrition intervention (same as Intervention 1 group) plus parental involvement. Schools invited parents for an interactive meeting on healthy food, PA and the relationship with overweight and health. Three times per year, information on healthy food and PA was published in school papers and newsletters for parents, and parents received a free $C D$ with the adult computer-tailored intervention for fat intake and PA (same as the children's computer tailored intervention) for use at home, and asked to discuss results with their child and to give their child support to create a healthier lifestyle

Control: no PA and nutrition intervention

\begin{tabular}{ll}
\hline Outcomes & Duration of PA \\
& Television viewing (minutes spent watching television) \\
& BMI $\left(\mathrm{kg} / \mathrm{m}^{2}\right)$
\end{tabular}

Notes

\section{Risk of bias}

\begin{tabular}{lll}
\hline Bias & Authors' judgement & Support for judgement \\
\hline $\begin{array}{l}\text { Random sequence genera- } \\
\text { tion (selection bias) }\end{array}$ & Unclear risk & Comment: randomization process not reported \\
\hline $\begin{array}{l}\text { Allocation concealment } \\
\text { (selection bias) }\end{array}$ & Low risk & $\begin{array}{l}\text { Comment: criterion not applicable because all participants were allocated at } \\
1 \text { point in time following recruitment, so at time of recruitment allocation was } \\
\text { not known }\end{array}$ \\
\hline
\end{tabular}

Blinding (performance
bias and detection bias) $\quad$ Unclear risk Comment: no information given, likely not done

All outcomes

Incomplete outcome data High risk Comment: incomplete outcome data was not adequately addressed
(attrition bias)

(attrition bias)

All outcomes

\begin{tabular}{lll}
\hline $\begin{array}{l}\text { Selective reporting (re- } \\
\text { porting bias) }\end{array}$ & Low risk & Comment: all outcomes identified a priori were reported on \\
\hline Confounders controlled? & Low risk & Comment: all relevant confounders taken into account \\
\hline $\begin{array}{l}\text { Data collection methods } \\
\text { valid and reliable? }\end{array}$ & Low risk & Comment: data collection tools reported to be valid and reliable \\
\hline
\end{tabular}


Haerens 2009

$\begin{array}{ll}\text { Methods } & \text { Design: cluster randomized controlled trial } \\ \text { Theoretical framework: Transtheoretical Model } \\ \text { Number of intervention groups: } 1 \\ \text { Number of control groups: } 1 \\ \text { Follow-up: } 3 \text { months post-intervention } \\ \text { N (intervention 1): } 433 \\ \mathrm{~N} \text { (control): } 448 \\ \text { Age (mean): } 14.6 \text { years } \\ \text { Sex: male and female } \\ \text { Ethnicity: : White } \\ \text { Country: Belgium } \\ \text { Setting: school, urban } \\ \text { Provider: N/A (computer-based intervention) } \\ \text { Duration: } 3 \text { months } \\ \text { Intervention: computer tailored physical activity (PA) program consisting of } 3 \text { parts: (a) an introduction } \\ \text { page, (b) a diagnostic tool, and (c) advice. The questionnaire used in the diagnostic tool could be filled } \\ \text { out on the computer screen and consisted of a demographic questionnaire, a PA questionnaire, and a } \\ \text { questionnaire on psychosocial determinants. After questionnaires were completed, feedback was se- } \\ \text { lected out of a database with messages for each possible combination of answers (e.g. normative feed- } \\ \text { back that related students' PA levels to the PA guidelines). } \\ \text { Control: } 1.5 p g \text { advice including information on the benefits of PA, public health recommendations, dif- } \\ \text { ferences between moderate and vigorous intensity activities, and tips on how to become more active. } \\ \text { The information was a selection of the most essential information in the tailored advice, but not tai- } \\ \text { lored to each individual. }\end{array}$

Outcomes Duration of PA

Notes

\section{Risk of bias}

Bias Authors' judgement Support for judgement

Random sequence genera- Unclear risk Comment: no description of the randomization process given tion (selection bias)

$\begin{array}{ll}\begin{array}{l}\text { Allocation concealment } \\ \text { (selection bias) }\end{array} & \text { Low risk } \\ & \begin{array}{l}\text { Comment: criterion not applicable because all participants were allocated at } \\ \text { not known }\end{array}\end{array}$

Blinding (performance Unclear risk Comment: no information given, likely not done

bias and detection bias)

All outcomes

\begin{tabular}{lll}
\hline $\begin{array}{l}\text { Incomplete outcome data } \\
\text { (attrition bias) } \\
\text { All outcomes }\end{array}$ & High risk & Comment: incomplete outcome data was not adequately addressed \\
\hline $\begin{array}{l}\text { Selective reporting (re- } \\
\text { porting bias) }\end{array}$ & Low risk & Comment: all outcomes identified a priori were reported on \\
\hline Confounders controlled? & Low risk & Comment: all relevant confounders taken into account \\
\hline
\end{tabular}


Haerens 2009 (Continued)

Data collection methods Low risk Comment: data collection tools reported to be valid and reliable valid and reliable?

Jones 2008

Design: cluster randomized controlled trial
Theoretical framework: Transtheoretical Model, Social Cognitive Theory
Number of intervention groups: 1
Number of control groups: 1
Follow-up: immediately post-intervention

$\begin{array}{ll}\text { Participants } & \text { N (intervention): } 291 \\ & \text { N (control): } 315 \\ & \text { Age (mean): } 11.6 \text { years } \\ & \text { Sex: female } \\ & \text { Ethnicity: White }\end{array}$

Interventions
Seuntry: US
Provider: peer, physical education (PE) teachers and other teachers
Duration: 1.5 school years
Intervention: the IMPACT intervention included 3 major components: 1 ) a health curriculum for grades
6 and 7 (classroom lessons and behavioral journalism); 2) a PE program; and 3) a school food service
component that emphasized calcium-rich food choices). Peer-based behavioral journalism involved
the use of media (e.g. school-based newsletter with role model stories). The intervention used a 6 th
grade health curriculum, including 16 sessions that were implemented during PE classes, 3 times per
week. The lessons in this curriculum promoted increased consumption of calcium-rich foods and in-
creased weight-bearing physical activities. The curriculum also contained behaviorally based and ac-
tive lessons adapted to the PE environment. Science-based lessons were administered during 7th
grade science classes. The PE component of the program (i.e. "IMPACTivities") was implemented in the
6th and 7th grades during PE and athletics classes. The classes contained an initial 10-min warm-up
(i.e. high-impact activities - rope-jumping, circuit training, and box-step activities)
Control: the control group participated in the usual health program

Outcomes Duration of physical activity

Television viewing (minutes spent watching television)

Notes

\section{Risk of bias}

\begin{tabular}{lll}
\hline Bias & Authors' judgement & Support for judgement \\
\hline $\begin{array}{l}\text { Random sequence genera- } \\
\text { tion (selection bias) }\end{array}$ & Unclear risk & $\begin{array}{l}\text { Comment: a computer-generated random numbers table was used for the ran- } \\
\text { domization process }\end{array}$ \\
\hline $\begin{array}{l}\text { Allocation concealment } \\
\text { (selection bias) }\end{array}$ & Low risk & $\begin{array}{l}\text { Comment: criterion not applicable because all participants were allocated at } \\
1 \text { point in time following recruitment, so at time of recruitment allocation was } \\
\text { not known }\end{array}$ \\
\hline
\end{tabular}

Blinding (performance

bias and detection bias)

High risk

Comment: no information given, likely not done

All outcomes 
Jones 2008 (Continued)

Incomplete outcome data High risk Comment: incomplete outcome data was not adequately addressed (attrition bias)

All outcomes

Selective reporting (re- Low risk $\quad$ Comment: all outcomes identified a priori were reported on
porting bias)

\begin{tabular}{lll}
\hline Confounders controlled? & Low risk & Comment: all relevant confounders taken into account \\
\hline $\begin{array}{l}\text { Data collection methods } \\
\text { valid and reliable? }\end{array}$ & Low risk & Comment: data collection tools reported to be valid and reliable \\
\hline
\end{tabular}

\section{Kipping 2008}

$\begin{array}{ll}\text { Methods } & \text { Design: cluster randomized controlled trial } \\ \text { Theoretical framework: unstated } \\ \text { Number of intervention groups: } 1 \\ \text { Number of control groups: } 1 \\ \text { Follow-up: immediately post-intervention }\end{array}$

Participants (intervention): 304
N (control): 300
Age (mean): 9.4 years
Sex: male and female
Ethnicity: unstated
Country: UK
Setting: school, unstated whether urban or rural
Provider: classroom teachers
Duration: 5 months
Intervention: the intervention included 16 lessons on healthy eating, increasing physical activity, and
reducing television viewing (adapted and abbreviated form of the 'Eat Well Keep Moving' program).
The 10 teachers providing the intervention were trained by 2 other teachers familiar with the program
and provided with further training/study materials (i.e. lesson plans for 9 physical activity lessons, 6 nu-
trition lessons and 1 lesson about screen viewing). In the physical activity lessons, the children played
games based on the food groups using photographs of food that reinforced the theory taught in the nu-
trition lessons
Control: the control school were provided with the teacher training and materials following study com-
pletion

Outcomes Television viewing (minutes spent watching television)

Body mass index $\left(\mathrm{kg} / \mathrm{m}^{2}\right)$

\section{Notes}

\section{Risk of bias}

\begin{tabular}{lll} 
Bias & Authors' judgement & Support for judgement \\
\hline $\begin{array}{l}\text { Random sequence genera- } \\
\text { tion (selection bias) }\end{array}$ & Unclear risk & $\begin{array}{l}\text { Quote: "random allocation to intervention or control school was concealed } \\
\text { and done by one of the authors" (Kipping 2008, p469) }\end{array}$
\end{tabular}


Kipping 2008 (Continued)

Comment: not stated exactly how the randomization sequence was generated by this author

\begin{tabular}{ll}
\hline $\begin{array}{l}\text { Allocation concealment } \\
\text { (selection bias) }\end{array}$ & Quote: "random allocation to intervention or control school was concealed \\
& and done by one of the authors (DAL). The investigator who did the random al- \\
& location had no prior knowledge of characteristics of any of the schools" (Kip- \\
ping 2008, p471)
\end{tabular}

$\begin{aligned} & \text { Blinding (performance } \\ & \text { bias and detection bias) }\end{aligned}$
$\begin{aligned} & \text { All outcomes } \\ & \text { Low risk }\end{aligned}$
$\begin{aligned} & \text { schools, took height and weight measurements" (Kipping 2008, p470) } \\ & \text { Comment: there was some initiative taken to blind although incomplete blind- } \\ & \text { ing could still introduce bias }\end{aligned}$

\begin{tabular}{ll}
\hline $\begin{array}{l}\text { Incomplete outcome data } \\
\text { (attrition bias) }\end{array}$ & High risk \\
All outcomes & $\begin{array}{l}\text { Quote: "all analyses were undertaken using an intention to treat protocol, re- } \\
\text { gardless of the number of lessons taught in intervention schools. However, we } \\
\text { only included in the analyses those children with complete data at baseline } \\
\text { and outcome" (Kipping 2008, p470) }\end{array}$ \\
& Comment: therefore, intention to treat not done
\end{tabular}

\begin{tabular}{|c|c|c|}
\hline $\begin{array}{l}\text { Selective reporting (re- } \\
\text { porting bias) }\end{array}$ & Low risk & Comment: all outcomes identified a priori were reported on \\
\hline Confounders controlled? & Low risk & Comment: all relevant confounders were controlled for \\
\hline $\begin{array}{l}\text { Data collection methods } \\
\text { valid and reliable? }\end{array}$ & High risk & $\begin{array}{l}\text { Comment: the physical activity instrument was not shown to be valid or reli- } \\
\text { able although other measurements were }\end{array}$ \\
\hline
\end{tabular}

Kriemler 2010

$\begin{array}{ll}\text { Methods } & \text { Design: cluster randomized controlled trial } \\ \text { Theoretical framework: Socio-ecological Conceptual Model } \\ \text { Number of intervention groups: } 1 \\ \text { Number of control groups: } 1 \\ \text { Follow-up: immediately post-intervention } \\ \text { N (intervention): } 297 \\ \mathrm{~N} \text { (control): } 205 \\ \text { Age (mean): } 6.9 \text { years } \\ \text { Sex: male and female } \\ \text { Ethnicity: : White } \\ \text { Country: Switzerland } \\ \text { Setting: school, urban and rural } \\ \text { Provider: physical education (PE) and classroom teachers } \\ \text { Duration: } 1 \text { school year (9 months) } \\ \text { Intervention: all children participated in } 3 \text { mandatory, } 45 \text {-min PE lessons per week; the intervention } \\ \text { group participated in } 2 \text { additional } 45 \text {-min PE lessons per week. The mandatory PE lessons were giv- } \\ \text { en by the usual classroom teachers according to the specified curriculum; the additional lessons were } \\ \text { taught mostly outdoors by PE teachers. Three to five } 2 \text { to 5-min activity breaks (motor skill tasks - jump- } \\ \text { ing or balancing on } 1 \text { leg, power games, coordinative tasks) were provided each day during academic } \\ \text { lessons. The children also received daily physical activity homework (10 min' worth), prepared by the } \\ \text { PE teachers, including: aerobic, strength, or motor skill tasks (e.g. brushing their teeth while standing } \\ \text { on } 1 \text { leg, hopping up and down the stairs, rope jumping, or comparable activities) }\end{array}$


Kriemler 2010 (Continued)

Control: the control group continued to participate in the usual, mandatory PE lessons (45-min, 3

times per week); they were not informed that an intervention group existed in the other schools (teach-

ers in the control group were aware but did not know the content of the intervention)

Duration of physical activity
Mean systolic blood pressure $(\mathrm{mmHg})$
Mean diastolic blood pressure $(\mathrm{mmHg})$
BMI $\left(\mathrm{kg} / \mathrm{m}^{2}\right)$

Notes

\section{Risk of bias}

\begin{tabular}{|c|c|c|}
\hline Bias & Authors' judgement & Support for judgement \\
\hline $\begin{array}{l}\text { Random sequence genera- } \\
\text { tion (selection bias) }\end{array}$ & Low risk & Comment: randomized using a random numbers table \\
\hline $\begin{array}{l}\text { Allocation concealment } \\
\text { (selection bias) }\end{array}$ & Low risk & $\begin{array}{l}\text { Comment: criterion not applicable because all participants were allocated at } \\
1 \text { point in time following recruitment, so at time of recruitment allocation was } \\
\text { not known }\end{array}$ \\
\hline $\begin{array}{l}\text { Blinding (performance } \\
\text { bias and detection bias) } \\
\text { All outcomes }\end{array}$ & High risk & $\begin{array}{l}\text { Quote: "due to the immense personnel used to perform all assessments, only } \\
\text { a part of the researchers were blinded to group allocation. Blinded measure- } \\
\text { ments included height and weight assessment, bioelectrical impedance, dual } \\
\text { energy x-ray absorptiometry, and some of the fitness tests" (Kriemler 2010, p2) } \\
\text { Comment: did not fully implement blinding }\end{array}$ \\
\hline $\begin{array}{l}\text { Incomplete outcome data } \\
\text { (attrition bias) } \\
\text { All outcomes }\end{array}$ & Low risk & Comment: intention-to-treat principle employed \\
\hline $\begin{array}{l}\text { Selective reporting (re- } \\
\text { porting bias) }\end{array}$ & Low risk & Comment: all outcomes identified a priori were reported on \\
\hline Confounders controlled? & Low risk & Comment: relevant confounders taken into account \\
\hline $\begin{array}{l}\text { Data collection methods } \\
\text { valid and reliable? }\end{array}$ & Low risk & Comment: data collection tools reported to be valid and reliable \\
\hline
\end{tabular}

Li 2010

\begin{tabular}{ll}
\hline Methods & Design: cluster randomized controlled trial \\
Theoretical framework: not stated \\
Number of intervention groups: 1 \\
Number of control groups: 1 \\
Follow-up: 1 year post-intervention \\
\hline
\end{tabular}

Participants N (intervention): 2092


Li 2010 (Continued)

N (control): 2028

Age (mean): mean 9.4

Sex: mixed

Ethnicity: Chinese

Country: China
Setting: school
Provider: classroom teachers
Duration: 1 academic year
Intervention: The Happy 10 program (based on the principle of TAKE10! - http://www.take10.net) in-
cluded 2 daily 10-min physical activity sessions during the break between classes. Teaching materi-
als provided included: activity cards (each activity card introduced 1 exercise and explained how to
perform it); video demonstrations (showing students from the pilot study performing the activities;
teachers could either demonstrate the activity or show it on a video); and tracking posters and stick-
ers (used to illustrate the progress of each class). Teachers (i.e. classroom tutors, health educators, or
both) attended a half-day training session (conducted by the staff of the National Institute for Nutri-
tion and Food Safety, China CDC) to learn how to integrate the program into the school curriculum, and
how to perform the activities. The training also included information about childhood obesity, risk fac-
tors, health consequences, and prevention. Activities (taken from TAKE 10! Program) included: "invis-
ible jump rope"; "copy cat"; "all about you"; "stories on the move!"; and "stories in space". Students,
teachers, and parents were encouraged to develop new activity models along with program staff (and
included: "story in zoo"; "story in farm"; "who is wearing yellow today"; "time like a colt"; "happy and
health"; and "little frog"). All activities were of moderate to vigorous intensities. Each 10-min session
included: 1 ) the teacher or student selected an activity card(s) - 1 to 3 activities were performed at each
session; 2 ) several children were chosen to model the exercise(s) in the front of the classroom with the
other students following along; 3) a cool-down period following the activities; and 4) the students were
taught a health message
Control: no intervention took place

Outcomes

Body mass index $\left(\mathrm{kg} / \mathrm{m}^{2}\right)$

Notes

\section{Risk of bias}

\begin{tabular}{lll}
\hline Bias & Authors' judgement & Support for judgement \\
\hline $\begin{array}{l}\text { Random sequence genera- } \\
\text { tion (selection bias) }\end{array}$ & Unclear risk & Comment: no description of the randomization process given \\
\hline $\begin{array}{l}\text { Allocation concealment } \\
\text { (selection bias) }\end{array}$ & Low risk & $\begin{array}{l}\text { Comment: criterion not applicable because all participants were allocated at } \\
1 \text { point in time following recruitment, so at time of recruitment allocation was } \\
\text { not known }\end{array}$ \\
\hline $\begin{array}{l}\text { Blinding (performance } \\
\text { bias and detection bias) }\end{array}$ & Low risk & Comment: outcome assessors blinded \\
All outcomes & Low risk & $\begin{array}{l}\text { Comment: approximately 10\% of intervention and control groups did not pro- } \\
\text { vide follow-up data (either moved away or absent on day outcomes were mea- } \\
\text { sured) }\end{array}$ \\
\hline $\begin{array}{l}\text { Incomplete outcome data } \\
\text { (attrition bias) } \\
\text { All outcomes }\end{array}$ & & \\
\hline
\end{tabular}


Li 2010 (Continued)
Selective reporting (re-
Unclear risk
Comment: no Information given, likely not done porting bias)

\begin{tabular}{lll}
\hline Confounders controlled? & High risk & Comment: did not take any confounders into account \\
\hline $\begin{array}{l}\text { Data collection methods } \\
\text { valid and reliable? }\end{array}$ & Unclear risk & $\begin{array}{l}\text { Comment: while blinded outcome assessors measured height and weight in an } \\
\text { objective way, reliability across outcome assessors was not reported. Validity } \\
\text { not addressed in article }\end{array}$ \\
\hline
\end{tabular}

Lubans 2009

$\begin{array}{ll}\text { Methods } & \text { Design: cluster randomized controlled trial } \\ \text { Theoretical framework: Social Cognitive Theory } \\ \text { Number of intervention groups: } 1 \\ \text { Number of control groups: } 1 \\ \text { Follow-up: immediately post-intervention }\end{array}$

Participants (intervention): 53
$\mathrm{~N}($ control): 53
Age (mean): 14.1 years
Sex: male and female
Ethnicity: unstated

Interventions

\begin{abstract}
Country: Australia
Setting: school, home, unstated whether urban or rural

Provider: teachers

Duration: unstated

Intervention: the intervention group (Program X intervention, based on the LEAF pilot study) included the same school sport program (as the control), however, with the following additions/alterations: 1 ) enhanced school sport program, delivered once a week for 10 weeks, focusing on lifetime physical activities that can be continued into adulthood (e.g. aerobics, weight training); 2) information sessions and interactive summary lecture focusing on physical activity and healthy eating; 3 ) pedometers for physical activity monitoring over the 6-month intervention; 4) physical activity and nutrition handbooks and monthly information newsletters for parents (designed to educate parents on strategies to support the health behaviors taught to their children in Program X); and 5) social support for physical activity and dietary behavior change using e-mail. Teachers introduced 1 of 10 physical activity and nutrition messages (selected because they represent the behaviors commonly associated with lower levels of disease risk and maintaining a healthy weight) at the beginning of each school sport session and delivered an activity reinforcing the message. These messages included: 1 ) Keep track of your physical activity (using goals/diary); 2) every step counts; 3) reduce your time spent watching television, using the computer, and playing electronic games immediately after school; 4) be active with friends and family; 5) identify excuses for not being active; 6 ) keep track of fruit and vegetable intake (using goals/ diary); 7) aim for 2 pieces of fruit and 5 servings of vegetables each day; 8) drink more water and swap sugary drinks for diet drinks; 9) reduce your portion sizes and eat at the dinner table; and 10) reduce your junk food snacks. A member of the research team delivered an interactive lecture summarizing the 10 messages following the 10-week school sport component of the study.

Control: the control group attended a 10-week school sport program and were given instructions (exercise program booklet) on how to complete the school sport sessions. They were not given any of the 'Program X messages' or additional materials or strategies to support behavior change or nutrition behaviors
\end{abstract}

Outcomes Duration of physical activity

Television viewing (minutes spent watching television)

\title{
Notes
}


Lubans 2009 (Continued)

Risk of bias

\begin{tabular}{lll}
\hline Bias & Authors' judgement & Support for judgement \\
\hline $\begin{array}{l}\text { Random sequence genera- } \\
\text { tion (selection bias) }\end{array}$ & Unclear risk & $\begin{array}{l}\text { Comment: although an envelope was used to attain concealment, having an } \\
\text { envelope with the assignment does not tell us how authors generated the ran- } \\
\text { domization sequence }\end{array}$ \\
\hline $\begin{array}{l}\text { Allocation concealment } \\
\text { (selection bias) }\end{array}$ & Low risk & $\begin{array}{l}\text { Quote: "a randomization envelope was prepared by a member of the research } \\
\text { team and schools were assigned to one of two treatment conditions" (Lubans } \\
2009, \text { p177) }\end{array}$ \\
& Comment: concealment was attained \\
\hline
\end{tabular}

Blinding (performance Low risk Comment: blinding implemented

bias and detection bias)

All outcomes

Incomplete outcome data High risk

Comment: incomplete outcome data not adequately addressed

(attrition bias)

All outcomes

\begin{tabular}{lll}
\hline $\begin{array}{l}\text { Selective reporting (re- } \\
\text { porting bias) }\end{array}$ & Low risk & Comment: all outcomes identified a priori were reported on \\
\hline Confounders controlled? & High risk & Comment: all relevant confounders were not controlled for \\
\hline $\begin{array}{l}\text { Data collection methods } \\
\text { valid and reliable? }\end{array}$ & Low risk & $\begin{array}{l}\text { Comment: tools were shown to be valid and reliable for both pedometers and } \\
\text { the method to measure television viewing }\end{array}$ \\
\hline
\end{tabular}

\section{Luepker 1996}

\begin{tabular}{ll}
\hline Methods & Design: cluster randomized controlled trial \\
Theoretical framework: Health Belief Model \\
Number of intervention groups: 2 \\
Number of control groups: 1 \\
Follow-up: immediately post-intervention \\
N (intervention): 3297 \\
$\mathrm{~N}$ (control): 722 \\
Age (mean): 8.8 years \\
Sex: male and female \\
Ethnicity: : White, African-American, Hispanic \\
Country: US \\
Setting: school, home, urban \\
Provider: teachers, research staff, cafeteria staff \\
Duration: 3 years \\
Intervention (overview): The CATCH intervention included school-based (school food service, physical \\
education, classroom curricula) and family-based (home curricula, family fun nights) components. The \\
school food service changes and physical education enhancement were ongoing throughout the 3 school \\
years whereas the classroom and home curricula were implemented (by classroom teachers) over a fixed \\
time period during each school year and addressed eating habits (grades 3 through 5), physical activity \\
(grades 4 and 5), and cigarette smoking (grade 5 only). Eat Smart, the food service intervention, provided \\
children with healthy meals that maintained recommended levels of essential nutrients and child partic-
\end{tabular}

School-based physical activity programs for promoting physical activity and fitness in children and adolescents aged 6 to 18 (Review) 
Luepker 1996 (Continued)

ipation in the school meal programs. Food service personnel attended a 1-day training session at the beginning of each school year. They were provided with more information, assistance in planning, and other support during monthly follow-up visits to the schools and booster sessions. The physical education specialists and teachers attended 1 to 1.5 days of training every school year. The classroom curricula included: the Adventures of Hearty Heart and Friends (grade 3 to 15, 30- to 40-min classes during 5 weeks); Go for Healths (grade 4 to 24, 30- to 40-mi classes during 12 weeks); and Go for Health-5 (grade 5 to 16, 30- to 40min classes during 8 weeks) and F.A.C.T.S. for Five (grade 5 - 4-session tobacco use prevention curriculum). The classroom teachers attended 1 to 1.5 days of training every year to learn how to implement the curricula. For the home curriculum, 19 activity packets (over the course of 3 school years) that complemented the classroom curricula were sent home with the students and required adult participation to complete. During grades 3 and 4, students invited their family members to a "family fun night" (dance performances, food booths, recipe distribution, games). The intervention schools were further randomized into 2 equal subgroups

Intervention 1: One group received a school-based program consisting of school food service modifications, physical education interventions, and the CATCH curricula

Intervention 2: One group received the same school-based program plus a family-based program Control: the control group received the usual health curricula, physical education, and food service programs, but none of the CATCH interventions

$\begin{array}{ll}\text { Outcomes } & \text { Duration of physical activity } \\ \text { Mean systolic blood pressure }(\mathrm{mmHg}) \\ \text { Mean diastolic blood pressure }(\mathrm{mmHg}) \\ \text { Mean blood cholesterol level }(\mathrm{mg} / \mathrm{dL}) \\ \text { BMI }\left(\mathrm{kg} / \mathrm{m}^{2}\right) \\ \text { Pulse rate (beats/minute) }\end{array}$

Notes

\section{Risk of bias}

\begin{tabular}{lll}
\hline Bias & Authors' judgement & Support for judgement \\
\hline $\begin{array}{l}\text { Random sequence genera- } \\
\text { tion (selection bias) }\end{array}$ & Unclear risk & Comment: randomization process not reported \\
\hline $\begin{array}{l}\text { Allocation concealment } \\
\text { (selection bias) }\end{array}$ & Low risk & $\begin{array}{l}\text { Comment: criterion not applicable because all participants were allocated at } \\
1 \text { point in time following recruitment, so at time of recruitment allocation was } \\
\text { not known }\end{array}$ \\
\hline $\begin{array}{l}\text { Blinding (performance } \\
\text { bias and detection bias) } \\
\text { All outcomes }\end{array}$ & Unclear risk & Comment: no information given, likely not done \\
\hline $\begin{array}{l}\text { Incomplete outcome data } \\
\text { (attrition bias) } \\
\text { All outcomes }\end{array}$ & Low risk & Comment: outcome data complete \\
\hline $\begin{array}{l}\text { Selective reporting (re- } \\
\text { porting bias) }\end{array}$ & Low risk & Comment: all outcomes identified a priori were reported on \\
\hline $\begin{array}{l}\text { Confounders controlled? } \\
\text { Data collection methods }\end{array}$ & Low risk & Low risk \\
\begin{tabular}{l} 
valid and reliable? \\
\hline
\end{tabular} & Comment: all relevant confounders were accounted for \\
\hline
\end{tabular}


Martinez 2008

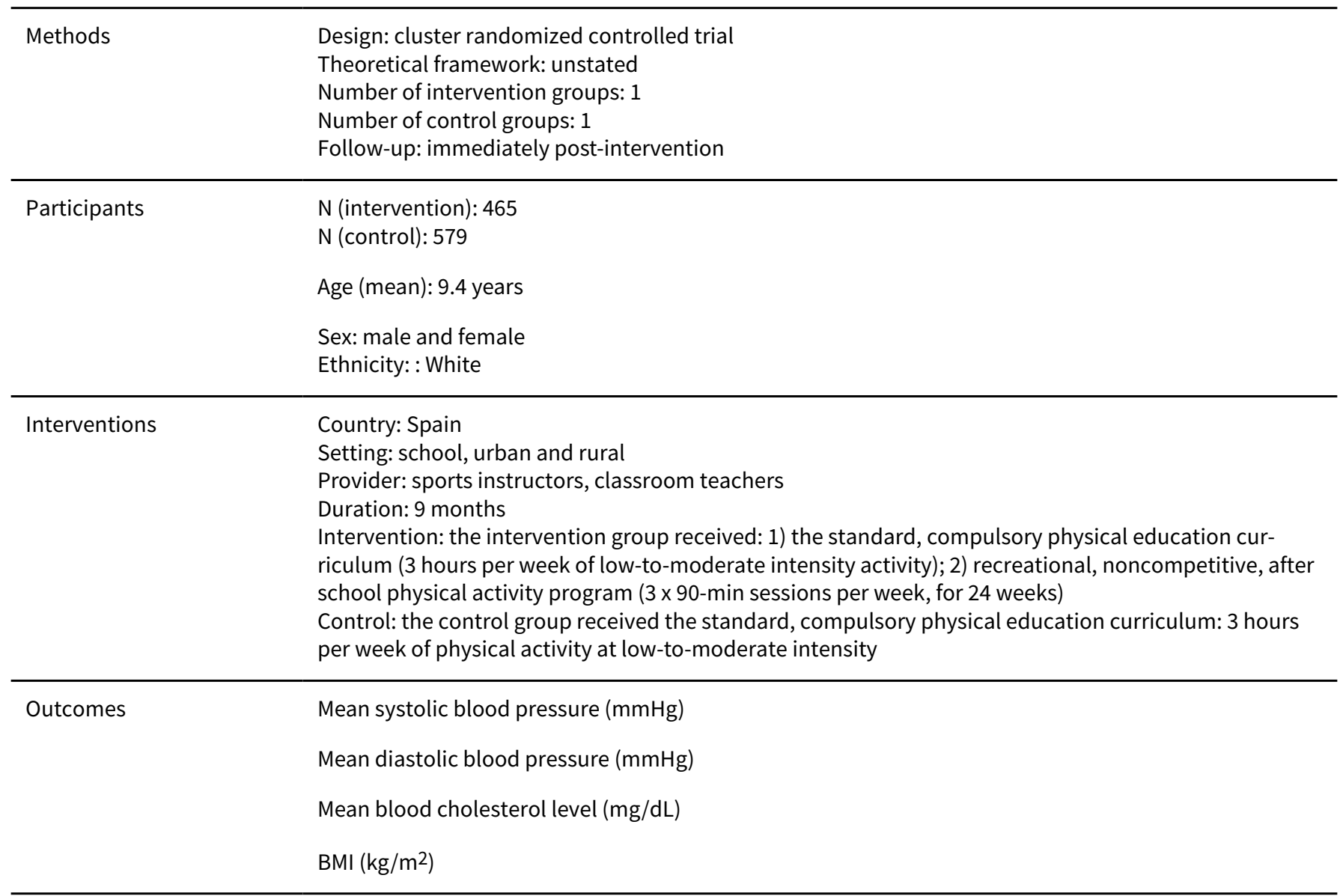

Notes

\section{Risk of bias}

\begin{tabular}{lll}
\hline Bias & Authors' judgement & Support for judgement \\
\hline $\begin{array}{l}\text { Random sequence genera- } \\
\text { tion (selection bias) }\end{array}$ & Low risk & $\begin{array}{l}\text { Comment: randomization took place using computer generated random num- } \\
\text { bers }\end{array}$ \\
\hline $\begin{array}{l}\text { Allocation concealment } \\
\text { (selection bias) }\end{array}$ & Low risk & $\begin{array}{l}\text { Comment: criterion not applicable because all participants were allocated at } \\
1 \text { point in time following recruitment, so at time of recruitment allocation was } \\
\text { not known }\end{array}$ \\
\hline $\begin{array}{l}\text { Blinding (performance } \\
\text { bias and detection bias) }\end{array}$ & High risk & $\begin{array}{l}\text { Quote: "two certified, trained nurses, who were unblinded to school allocation } \\
\text { made the anthropometric and blood pressure measurements. The laboratory } \\
\text { analysts who determined blood lipids were blinded to school allocation" (Mar- } \\
\text { tinez 2008, p14) }\end{array}$ \\
$\begin{array}{l}\text { Comment: only partial blinding implemented } \\
\begin{array}{l}\text { Incomplete outcome data } \\
\text { (attrition bias) }\end{array}\end{array}$ & Low risk & $\begin{array}{l}\text { Quote: "analyses were performed according to the intention-to-treat, with } \\
\text { children analyzed in their original randomized allocation, regardless of the } \\
\text { number of scheduled physical activity sessions attended" (Martinez 2008, p15) }\end{array}$ \\
\hline $\begin{array}{l}\text { Selective reporting (re- } \\
\text { porting bias) }\end{array}$ & Low risk & \begin{tabular}{l} 
Comment: all outcomes identified a priori were reported on \\
\hline
\end{tabular}
\end{tabular}


Martinez 2008 (Continued)

Confounders controlled? High risk Comment: not all relevant confounders accounted for

Data collection methods Low risk Comment: data collection methods were shown to be valid and reliable

valid and reliable?

McManus 2008

$\begin{array}{ll}\text { Methods } & \text { Design: cluster randomized controlled trial } \\ \text { Theoretical framework: Health Belief Model, Social Cognitive Theory, Diffusion of Innovation } \\ \text { Number of intervention groups: } 2 \\ \text { Number of control groups: } 1 \\ \text { Follow-up: } 6 \text { months post-intervention }\end{array}$

\begin{tabular}{ll}
\hline Participants & $N$ (intervention 1): 64 \\
& $N$ (intervention 2): 61 \\
& $N($ control): 68 \\
& Age (mean): 10.4 years \\
Sex: male and female \\
Ethnicity: Chinese
\end{tabular}

Interventions

\begin{abstract}
Country: China
Setting: school, urban

Provider: unstated

Duration: 2 years
\end{abstract}

Intervention 1: educational program group completed a 2-week education program using targeted materials, providing learner guidance and feedback, and promoting retention of the desired behavior. Content included heart rate monitor skills and education about heart health, goal-setting, and role play. Heart rate monitor skills and goal setting included: information about activity targets (light, moderate, vigorous); daily activity accumulation to achieve 30 to $60 \mathrm{~min}$ of moderate-to-vigorous intensity activity (MVPA); and how to use a heart rate monitor for feedback about progression to this goal. This content was taught via an active games approach and a take home booklet. Following the educational program, children in the 2 intervention groups completed 2 weeks with heart rate feedback and 2 weeks without heart rate feedback (counterbalanced)

Intervention 2: no-education program group completed a 2-week control program (physical education classes without physical activity or heart health education). Following the educational program, children in the 2 intervention groups completed 2 weeks with heart rate feedback and 2 weeks without heart rate feedback (counterbalanced). The No-education Program Group were not given any information about the heart rate signal or its meaning, but were informed of the correct position of the chest belt

Control: no intervention took place

\begin{tabular}{ll}
\hline Outcomes & Duration of physical activity \\
& Mean systolic blood pressure $(\mathrm{mmHg})$ \\
& Mean diastolic blood pressure $(\mathrm{mmHg})$ \\
& Body mass index $\left(\mathrm{kg} / \mathrm{m}^{2}\right)$ \\
$\mathrm{VO}_{2} \mathrm{max}(\mathrm{mL} / \mathrm{kg} / \mathrm{minute})$ \\
Pulse rate (beats $/ \mathrm{min})$
\end{tabular}

Notes

\title{
Risk of bias
}

School-based physical activity programs for promoting physical activity and fitness in children and adolescents aged 6 to 18 (Review) 
McManus 2008 (Continued)

\begin{tabular}{lll} 
Bias & Authors' judgement & Support for judgement \\
\hline $\begin{array}{l}\text { Random sequence genera- } \\
\text { tion (selection bias) }\end{array}$ & Low risk & $\begin{array}{l}\text { Comment: does not tell us exactly how they generated the sequence but } \\
\text { rather how they selected schools from lists and kept allocation concealed }\end{array}$ \\
\hline $\begin{array}{l}\text { Allocation concealment } \\
\text { (selection bias) }\end{array}$ & Low risk & $\begin{array}{l}\text { Comment: opaque envelopes were utilized to maintain allocation conceal- } \\
\text { ment }\end{array}$ \\
\hline $\begin{array}{l}\text { Blinding (performance } \\
\text { bias and detection bias) } \\
\text { All outcomes }\end{array}$ & High risk & Comment: partial blinding was implemented only \\
\hline $\begin{array}{l}\text { Incomplete outcome data } \\
\text { (attrition bias) } \\
\text { All outcomes }\end{array}$ & High risk & Comment: incomplete outcome data was not adequately addressed \\
\hline $\begin{array}{l}\text { Selective reporting (re- } \\
\text { porting bias) }\end{array}$ & High risk & Comment: data collected on other outcomes that were not reported (e.g. sec- \\
\hline $\begin{array}{l}\text { Confounders controlled? } \\
\text { ondary outcomes blood pressure and body mass index) }\end{array}$ & Low risk \\
$\begin{array}{l}\text { Data collection methods } \\
\text { valid and reliable? }\end{array}$ & Low risk & Comment: all relevant confounders were controlled for \\
\hline
\end{tabular}

\section{Neumark-Sztainer 2009}

$\begin{array}{ll}\text { Methods } & \text { Design: cluster randomized controlled trial } \\ & \text { Theoretical framework: Social Cognitive Theory } \\ & \text { Number of intervention groups: } 1 \\ & \text { Number of control groups: } 1 \\ \text { Follow-up: immediately post-intervention }\end{array}$

\begin{tabular}{ll}
\hline Participants & N (intervention): 51 \\
& N (control): 45
\end{tabular}

Age (mean): 10.3 years

Sex: male and female

Ethnicity: African-American

\begin{abstract}
Country: US
Setting: school, community, theatre, urban

Provider: unstated

Duration: approximately 16 weeks

Intervention: the intervention included 3 components: 1) $14 \times 2$-hour after-school theatre sessions; 2) 8 weekly after-school booster sessions; and 3) family outreach to enhance home support for behavioral changes through positive reinforcement of health behaviors, parent-child participation in physical activities, and availability of healthy foods. Each theatre session included: 1) a 'check-in' in which children were given an opportunity to share any behavioral changes they had made over the past week (e.g. eating more fruits and vegetables) and talk about how take-home packages were received by families; 2 ) easy-to-prepare healthy snacks; 3 ) a movement component of fun and easy activities requiring minimal resources (e.g. dancing or walking); and 4) theatrical ACTivities. For the initial sessions, the ACTivities component included exercises to introduce the children to theatre techniques and to build trust and cooperation. In later sessions, the ACTivities focused on enhancing knowledge and skills related to physical activity and healthy eating and promoting a positive body image through interactive activities. Children were asked to share their personal experiences related to being active and eating healthfully. The content of the script for the Ready. Set. ACTION! play was developed through these activities. During the final sessions, children were introduced to the script and began to rehearse for the final play
\end{abstract}

School-based physical activity programs for promoting physical activity and fitness in children and adolescents aged 6 to 18 (Review) 
Neumark-Sztainer 2009 (Continued)

performance. The booster sessions included activities such as: creating advertisements for fruits and vegetables; painting positive affirmations (e.g. I am special) on a mirror to take home; brainstorming ways to be active while watching television (e.g. doing jumping jacks during commercials); teaching dance and strength training exercises to their classmates; learning exercises to do at home with their families; and rehearsals for the school performance of the Ready. Set. ACTION! play. For the family outreach component, Weekly Fun and Fitness packs (i.e. a healthy food with a simple recipe or fitness incentives for the family) and a CD of the Ready. Set. ACTION! songs were sent home (each pack also had a parent postcard with information and interactive activities on a topic addressed in the after-school program). There were also 2 family events: 1) the students' performance of the play; and 2) a 'Ready. Set. ACTION! DVD Release Party' (i.e. a family viewing of the DVD recording of the play production, a short performance by the children, and a communal family dinner)

Control: the control group participated in a theater-based intervention involving performing a play focused on environmental health issues using a prepared script

\begin{tabular}{ll}
\hline Outcomes & Duration of physical activity \\
Television viewing (minutes spent watching television) \\
Body mass index $\left(\mathrm{kg} / \mathrm{m}^{2}\right)$
\end{tabular}

Notes

\section{Risk of bias}

\begin{tabular}{lll}
\hline Bias & Authors' judgement & Support for judgement \\
\hline $\begin{array}{l}\text { Random sequence genera- } \\
\text { tion (selection bias) }\end{array}$ & Unclear risk & Comment: randomization process not reported \\
\hline $\begin{array}{l}\text { Allocation concealment } \\
\text { (selection bias) }\end{array}$ & Low risk & $\begin{array}{l}\text { Comment: criterion not applicable because all participants were allocated at } \\
1 \text { point in time following recruitment, so at time of recruitment allocation was } \\
\text { not known }\end{array}$ \\
\hline
\end{tabular}

Blinding (performance Unclear risk Comment: no information given, likely not done

bias and detection bias)

All outcomes

$\begin{array}{ll}\begin{array}{l}\text { Incomplete outcome data } \\ \text { (attrition bias) }\end{array} & \text { High risk } \\ \text { All outcomes } & \begin{array}{l}\text { Comment: authors should have used intention-to-treat analysis. While they } \\ \text { did adjust for baseline differences, they only adjusted for certain characteris- } \\ \text { tics like age and sex, and not for any of the outcome variables }\end{array}\end{array}$

\begin{tabular}{lll}
\hline $\begin{array}{l}\text { Selective reporting (re- } \\
\text { porting bias) }\end{array}$ & Low risk & Comment: all outcomes identified a priori were reported on \\
\hline Confounders controlled? & High risk & $\begin{array}{l}\text { Comment: not all relevant confounders controlled for; only age, gender, and } \\
\text { race }\end{array}$ \\
\hline $\begin{array}{l}\text { Data collection methods } \\
\text { valid and reliable? }\end{array}$ & Unclear risk & Comment: survey tool is cited, but reliability and validity not reported \\
\hline
\end{tabular}

Neumark-Sztainer 2010

Design: cluster randomized controlled trial
Theoretical framework: Social Cognitive Theory, Transtheoretical Model
Number of intervention groups: 1


Neumark-Sztainer 2010 (Continued)

$$
\text { Number control groups: } 1
$$

Follow-up: immediately post-intervention

N (intervention): 177
N (control): 159
Age (mean): 15.8 years
Sex: female
Ethnicity: African-American, Causasian, Hispanic, Asian, American-Indian, mixed/other

Country: US
Setting: school, urban
Provider: physical education (PE) teachers, coaches who were trained intervention staff
Duration: 16 weeks
Intervention: the intervention group continued to participate in the all-girls PE class during the first
semester of the school year. They also received the New Moves curriculum during their PE class (ap-
proximately 16 weeks) and participated in New Moves activities throughout the rest of the school year
(maintenance period). This program included: 1) the New Moves PE class - nutrition and social sup-
port/self-empowerment sessions (physical activity (Be Fit) 4 days/week taught by school PE teachers (3
days) and community guest instructors (1 day) and nutrition (Be Fueled) or social support/self-empow-
erment (Be Fab) classes 1 day/week); 2 individual counseling sessions using motivation interviewing
techniques (to set personal goals for behavioral change based on eight New Moves objectives); 3) lunch
get-togethers ("lunch bunches") once a week during the maintenance period where participants were
served healthy food and engaged in informal discussions on New Moves topics; and 4) minimal parent
outreach activities (i.e. 6 postcards sent home to reinforce New Moves messages and a parent-daugh-
ter retreat day focused on New Moves messages during the maintenance period). PE teachers attend-
ed full-day training before the intervention and half-day training during the intervention. They also re-
ceived regular, ongoing support from New Moves staff throughout the program. New Moves interven-
tion staff ran all program components aside from the PE class. These staff received training and ongo-
ing support in motivational interviewing techniques
Control: the control group continued to participate in the all-girls PE class during the first semester of
the school year. Teachers were free to conduct their PE classes as they desired during the study period
and did not receive training on New Moves until after the study period

$\begin{array}{ll}\text { Outcomes } & \text { Duration of physical activity } \\ \text { Television viewing (minutes spent watching television) } \\ \text { Body mass index }\left(\mathrm{kg} / \mathrm{m}^{2}\right)\end{array}$

Notes

\section{Risk of bias}

\begin{tabular}{lll}
\hline Bias & Authors' judgement & Support for judgement \\
\hline $\begin{array}{l}\text { Random sequence genera- } \\
\text { tion (selection bias) }\end{array}$ & Unclear risk & Comment: no description of the randomization process given \\
\hline $\begin{array}{l}\text { Allocation concealment } \\
\text { (selection bias) }\end{array}$ & Low risk & $\begin{array}{l}\text { Comment: criterion not applicable because all participants were allocated at } \\
1 \text { point in time following recruitment, so at time of recruitment allocation was } \\
\text { not known }\end{array}$ \\
\hline
\end{tabular}


Neumark-Sztainer 2010 (Continued)

\begin{tabular}{|c|c|c|}
\hline $\begin{array}{l}\text { Blinding (performance } \\
\text { bias and detection bias) }\end{array}$ & High risk & $\begin{array}{l}\text { Comment: self-reported; unclear if trained staff taking measurements were } \\
\text { blinded to intervention allocation }\end{array}$ \\
\hline
\end{tabular}
All outcomes

$\begin{array}{ll}\text { Incomplete outcome data } & \text { Low risk } \\ \text { (attrition bias) } & \begin{array}{l}\text { Comment: less than } 10 \% \text { drop-out rate in intervention group; no details pro- } \\ \text { vided on reasons for drop-outs }\end{array}\end{array}$

All outcomes

Selective reporting (re- Unclear risk $\quad$ Comment: not discussed in report
porting bias)

\begin{tabular}{lll}
\hline Confounders controlled? & High risk & Comment: only considered baseline age, weight, and race \\
\hline $\begin{array}{l}\text { Data collection methods } \\
\text { valid and reliable? }\end{array}$ & Unclear risk & Comment: did not provide details on reliability and validity of measures \\
\hline
\end{tabular}

Peralta 2009

$\begin{array}{ll}\text { Methods } & \text { Design: randomized controlled trial } \\ & \text { Theoretical framework: Social Cognitive Theory } \\ & \text { Number of intervention groups: } 1 \\ & \text { Number of control groups: } 1 \\ \text { Follow-up: immediately post-intervention }\end{array}$

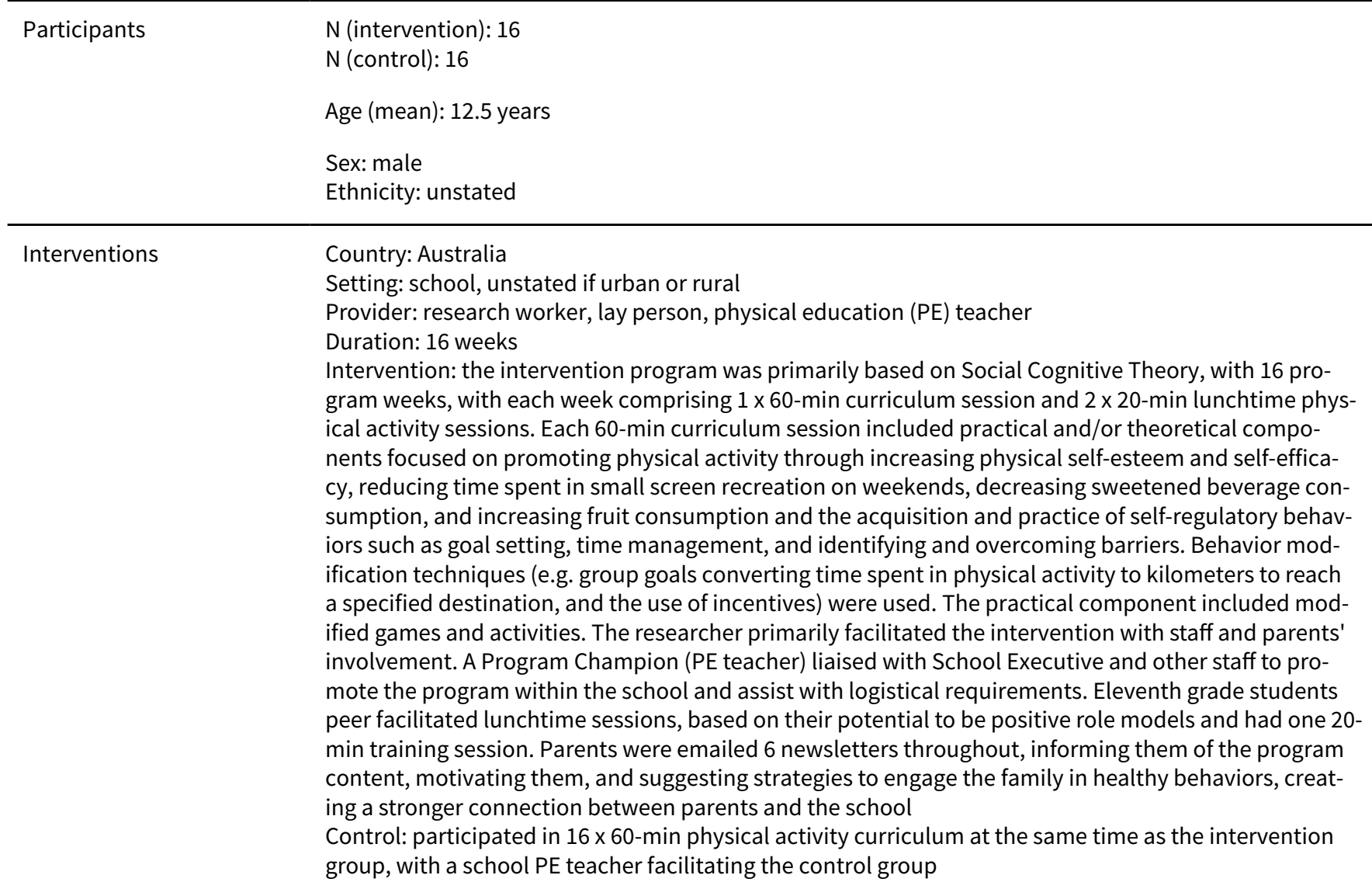

Outcomes Duration of physical activity 
Peralta 2009 (Continued)

Television viewing (minutes spent watching television)

Body mass index $\left(\mathrm{kg} / \mathrm{m}^{2}\right)$

Notes

\section{Risk of bias}

\begin{tabular}{lll}
\hline Bias & Authors' judgement & Support for judgement \\
\hline $\begin{array}{l}\text { Random sequence genera- } \\
\text { tion (selection bias) }\end{array}$ & Low risk & $\begin{array}{l}\text { Comment: participants were randomized, using a computer-based number } \\
\text { producing algorithm, to either the intervention or active comparison group }\end{array}$ \\
\hline $\begin{array}{l}\text { Allocation concealment } \\
\text { (selection bias) }\end{array}$ & Low risk & $\begin{array}{l}\text { Comment: criterion not applicable because all participants were allocated at } \\
1 \text { point in time following recruitment, so at time of recruitment allocation was } \\
\text { not known }\end{array}$ \\
\hline $\begin{array}{l}\text { Blinding (performance } \\
\text { bias and detection bias) } \\
\text { All outcomes }\end{array}$ & Low risk & $\begin{array}{l}\text { Quote: "trained independent assessors, blind to group allocation, conducted } \\
\text { the measurements" (Peralta 2009, p538) }\end{array}$ \\
\hline
\end{tabular}

\begin{tabular}{l}
\hline Incomplete outcome data Low risk Comment: outcome data complete \\
(attrition bias) \\
All outcomes
\end{tabular}

Selective reporting (re- Low risk Comment: all outcomes identified a priori were reported on
porting bias)

\begin{tabular}{lll}
\hline Confounders controlled? & Low risk & Comment: all relevant confounders were controlled for \\
\hline $\begin{array}{l}\text { Data collection methods } \\
\text { valid and reliable? }\end{array}$ & High risk & $\begin{array}{l}\text { Comment: although reliability and validity were discussed with some of the } \\
\text { data collection methods, not all were discussed }\end{array}$ \\
\hline
\end{tabular}

\section{Petchers 1988}

\begin{tabular}{|c|c|}
\hline Methods & $\begin{array}{l}\text { Design: randomized controlled trial } \\
\text { Theoretical framework: Health Behavior Model } \\
\text { Number of intervention groups: } 2 \\
\text { Number of control groups: } 1 \\
\text { Follow-up: } 1 \text { year post-intervention }\end{array}$ \\
\hline Participants & $\begin{array}{l}\text { N: } 325 \\
\text { Age (mean): } 11.1 \text { years } \\
\text { Sex: male and female } \\
\text { Ethnicity: unstated }\end{array}$ \\
\hline Interventions & $\begin{array}{l}\text { Country: US } \\
\text { Setting: school, mixed (urban, suburban and residential) } \\
\text { Provider: teachers } \\
\text { Duration: } 1 \text { school year ( } 40 \text { weeks) } \\
\text { Intervention: Chicago Heart Health Curriculum Program called "Body Power" is a 1-year-long curricu- } \\
\text { lum with modules on } 5 \text { topics: } 1 \text { ) cardiovascular system, anatomy, and physiology; } 2 \text { ) smoking; } 3 \text { ) nutri- } \\
\text { tion; 4) exercise; and 5) risk factors review. Curriculum materials and activities emphasize the inter-re- } \\
\text { lationship between students' feelings, behavior, and relationships and the risk factors of cardiovas- } \\
\text { cular disease. The curriculum was implemented by classroom teachers with each module taught dur- } \\
\text { ing at least } 3 \times 45 \text {-min sessions per week for } 4 \text { to } 6 \text { weeks. The Northeast Ohio Affiliate of the American }\end{array}$ \\
\hline
\end{tabular}


Heart Association provided training for teachers. In total, 14 training covered relevant content and humanistic education teaching techniques. Training was supplemented by a comprehensive teachers' manual with specific objectives for each module, suggested time frames and alternative activities for teachers to select those most compatible with their own teaching styles.

Control: control classes received the traditional curriculum with approximately the same amount of teaching time. Control group teachers were provided an alternative experience to the training sessions for the intervention group in the form of a separate in-service training day (general literature and lectures by a cardiologist and an educator

Outcomes Physical activity rates (\% of sample physically active)

\section{Notes}

\section{Risk of bias}

\begin{tabular}{|c|c|c|}
\hline Bias & Authors' judgement & Support for judgement \\
\hline $\begin{array}{l}\text { Random sequence genera- } \\
\text { tion (selection bias) }\end{array}$ & Unclear risk & Comment: no description of the randomization process was given \\
\hline $\begin{array}{l}\text { Allocation concealment } \\
\text { (selection bias) }\end{array}$ & Low risk & $\begin{array}{l}\text { Comment: criterion not applicable because all participants were allocated at } \\
1 \text { point in time following recruitment, so at time of recruitment allocation was } \\
\text { not known }\end{array}$ \\
\hline $\begin{array}{l}\text { Blinding (performance } \\
\text { bias and detection bias) } \\
\text { All outcomes }\end{array}$ & Unclear risk & Comment: no information given, likely not done \\
\hline $\begin{array}{l}\text { Incomplete outcome data } \\
\text { (attrition bias) } \\
\text { All outcomes }\end{array}$ & High risk & Comment: incomplete outcome data assessment \\
\hline $\begin{array}{l}\text { Selective reporting (re- } \\
\text { porting bias) }\end{array}$ & Low risk & Comment: all outcomes identified a priori were reported on \\
\hline Confounders controlled? & High risk & Comment: all relevant confounders were not accounted for \\
\hline $\begin{array}{l}\text { Data collection methods } \\
\text { valid and reliable? }\end{array}$ & Low risk & Comment: data collection tools shown to be valid and reliable \\
\hline
\end{tabular}

Reed 2008

\begin{tabular}{ll}
\hline Methods & $\begin{array}{l}\text { Design: cluster randomized controlled trial } \\
\text { Theoretical framework: unstated } \\
\text { Number of intervention groups: } 2 \\
\text { Number of control groups: } 1 \\
\text { Follow-up: immediately post-intervention }\end{array}$ \\
\hline Participants & $\mathrm{N}: 288$ \\
& $\begin{array}{l}\text { Age (mean): } 10 \text { years } \\
\text { Sex: male and female } \\
\text { Ethnicity: predominately White and Asian }\end{array}$ \\
\hline Interventions & $\begin{array}{l}\text { Country: Canada } \\
\text { Setting: school, community, home, urban } \\
\text { Provider: research staff, teachers }\end{array}$ \\
\hline
\end{tabular}

School-based physical activity programs for promoting physical activity and fitness in children and adolescents aged 6 to 18 (Review) 
Reed 2008 (Continued)

Duration: 11 months

Intervention: the Action Schools! BC model was consistent with the 'active school' framework and emphasized an integrated whole-school approach rather than traditional classroom-based health education, targeting 6 Action Zones: i) School Environment, ii) Scheduled Physical Education, iii) Extracurricular, (iv) School Spirit, v) Family and Community and vi) Classroom Action. Classroom Action was the only prescriptive component of the AS! BC model in which teachers delivered 15 min of moderate to intense physical activity daily to achieve 75 min of extra physical activity per week (in addition to $2 \times 40$ min physical education (PE) classes). Teachers provided opportunities to 'snack on physical activities' such as skipping, dancing, and resistance exercises throughout the day. A school Action Team - comprised of the school principal, teachers, or both - was convened in each school and an AS! BC facilitator worked with Action Teams to design a program with activities across the 6 Action Zones. A 1-day training workshop was held for INT teachers, who were provided a Classroom Action Bin with resources to support their Action Plan with the goal for each school to provide students with 150 min of physical activity per week ( $2 \times 40$ min PE classes and $15 \times 5$ min per day of Classroom Action)

Control: teachers in usual practice schools continued their regular program of PE and school-based physical activity

\begin{tabular}{|c|c|c|}
\hline Outcomes & \multicolumn{2}{|c|}{$\begin{array}{l}\text { Mean systolic blood pressure }(\mathrm{mmHg}) \\
\text { Mean diastolic blood pressure }(\mathrm{mmHg}) \\
\text { Mean blood cholesterol level }(\mathrm{mg} / \mathrm{dL}) \\
\text { Body mass index }\left(\mathrm{kg} / \mathrm{m}^{2}\right)\end{array}$} \\
\hline \multicolumn{3}{|l|}{ Notes } \\
\hline \multicolumn{3}{|l|}{ Risk of bias } \\
\hline Bias & Authors' judgement & Support for judgement \\
\hline $\begin{array}{l}\text { Random sequence genera- } \\
\text { tion (selection bias) }\end{array}$ & Unclear risk & $\begin{array}{l}\text { Quote: "schools were then remotely randomized to either Usual Practice or In- } \\
\text { tervention by an epidemiologist not involved in the trial" (Reed 2008, p527) } \\
\text { Comment: although it is stated who allocated schools, it does not state how } \\
\text { schools were randomized }\end{array}$ \\
\hline $\begin{array}{l}\text { Allocation concealment } \\
\text { (selection bias) }\end{array}$ & High risk & $\begin{array}{l}\text { Comment: it was reported that it was not possible for schools to be blinded to } \\
\text { random assignment and therefore concealment not attained }\end{array}$ \\
\hline $\begin{array}{l}\text { Blinding (performance } \\
\text { bias and detection bias) } \\
\text { All outcomes }\end{array}$ & Unclear risk & Comment: no information given, likely not done \\
\hline $\begin{array}{l}\text { Incomplete outcome data } \\
\text { (attrition bias) } \\
\text { All outcomes }\end{array}$ & High risk & Comment: incomplete outcome data not adequately addressed \\
\hline $\begin{array}{l}\text { Selective reporting (re- } \\
\text { porting bias) }\end{array}$ & Low risk & Comment: all outcomes identified a priori were reported on \\
\hline Confounders controlled? & Low risk & Comment: all relevant confounders controlled for \\
\hline $\begin{array}{l}\text { Data collection methods } \\
\text { valid and reliable? }\end{array}$ & High risk & $\begin{array}{l}\text { Comment: reliability and validity of the physical activity measure was not dis- } \\
\text { cussed }\end{array}$ \\
\hline
\end{tabular}

\section{Robinson 1999}

Methods Design: cluster randomized controlled trial

School-based physical activity programs for promoting physical activity and fitness in children and adolescents aged 6 to 18 (Review) 
Robinson 1999 (Continued)

Theoretical framework: Social Cognitive Theory

Number of intervention groups: 1

Number of control groups: 1

Follow-up: immediately post-intervention

\begin{tabular}{|c|c|}
\hline Participants & $\begin{array}{l}\mathrm{N} \text { (intervention): } 92 \\
\mathrm{~N} \text { (control): } 100 \\
\text { Age (mean): } 9 \text { years } \\
\text { Sex: male and female } \\
\text { Ethnicity: unstated }\end{array}$ \\
\hline Interventions & $\begin{array}{l}\text { Country: US } \\
\text { Setting: school, unstated if urban or rural } \\
\text { Provider: teachers } \\
\text { Duration: } 6 \text { months } \\
\text { Intervention: limited access to television (TV) use and budgeting TV time. Based on Bandura's Social } \\
\text { Cognitive Theory it involved } 18 \text { lessons of } 30 \text { to } 50 \text { min as part of standard curriculum, taught by reg- } \\
\text { ular classroom teachers trained by research staff. Most lessons occurred in the first } 2 \text { months of the } \\
\text { year and early lessons included self-monitoring and self-reporting for TV and video game use followed } \\
\text { by a 10-day TV turnoff challenge after which students were encouraged to follow a 7-h per week bud- } \\
\text { get. Newsletters designed to help parents motivate students and regulate time spent on TV and video } \\
\text { games for the entire family were distributed. Each household received } 1 \text { (or more if requested) TV time } \\
\text { master to regulate TV and video use } \\
\text { Control: not specified }\end{array}$ \\
\hline
\end{tabular}

$\begin{array}{ll}\text { Outcomes } & \text { Duration of physical activity } \\ & \text { TV viewing (minutes spent watching TV) } \\ & \text { Body mass index }\left(\mathrm{kg} / \mathrm{m}^{2}\right)\end{array}$

Notes

\section{Risk of bias}

\begin{tabular}{|c|c|c|}
\hline Bias & Authors' judgement & Support for judgement \\
\hline $\begin{array}{l}\text { Random sequence genera- } \\
\text { tion (selection bias) }\end{array}$ & Unclear risk & Comment: randomization process not reported \\
\hline $\begin{array}{l}\text { Allocation concealment } \\
\text { (selection bias) }\end{array}$ & Low risk & $\begin{array}{l}\text { Comment: criterion not applicable because all participants were allocated at } \\
1 \text { point in time following recruitment, so at time of recruitment allocation was } \\
\text { not known }\end{array}$ \\
\hline $\begin{array}{l}\text { Blinding (performance } \\
\text { bias and detection bias) } \\
\text { All outcomes }\end{array}$ & Low risk & $\begin{array}{l}\text { Quote: "participants and school personal including classroom teachers, were } \\
\text { informed of the intervention but were unaware of the primary hypothesis. } \\
\text { Measurements were done by trained staff blinded to the experimental de- } \\
\text { sign" (Robinson 1999, p1562) }\end{array}$ \\
\hline $\begin{array}{l}\text { Incomplete outcome data } \\
\text { (attrition bias) } \\
\text { All outcomes }\end{array}$ & Low risk & Comment: outcome data complete \\
\hline $\begin{array}{l}\text { Selective reporting (re- } \\
\text { porting bias) }\end{array}$ & Low risk & Comment: all outcomes identified a priori were reported on \\
\hline Confounders controlled? & Low risk & Comment: all relevant confounders were accounted for \\
\hline $\begin{array}{l}\text { Data collection methods } \\
\text { valid and reliable? }\end{array}$ & Low risk & Comment: data collection tools valid and reliable \\
\hline
\end{tabular}


Salmon 2008

\begin{tabular}{|c|c|}
\hline Methods & $\begin{array}{l}\text { Design: cluster randomized controlled trial } \\
\text { Theoretical framework: Social Marketing Theory, Behavioral Choice Theory } \\
\text { Number of intervention groups: } 3 \\
\text { Number of control groups: } 1 \\
\text { Follow-up: } 1 \text { year post-intervention }\end{array}$ \\
\hline Participants & $\begin{array}{l}\mathrm{N} \text { (intervention): } 213 \\
\mathrm{~N} \text { (control): } 55 \\
\text { Age (mean): } 10 \text { years } \\
\text { Sex: male and female } \\
\text { Ethnicity: unstated }\end{array}$ \\
\hline Interventions & $\begin{array}{l}\text { Country: Australia } \\
\text { Setting: school, urban } \\
\text { Provider: specialist physical education (PE) teacher } \\
\text { Duration: } 1 \text { school year } \\
\text { Intervention: students were assigned to } 1 \text { of } 4 \text { conditions: a behavioral modification group (BM; } N=69 \text { ); } \\
\text { a fundamental motor skills group (FMS; } N=73 \text { ); a combined BM and FMS group ( } \mathrm{N}=90 \text { ). Components } \\
\text { of the intervention program were developed by the study team, with others adapted from previous in- } \\
\text { terventions (SPARK), concepts outlined in Robinson's study, from Planet Health, and from the Victo- } \\
\text { rian Fundamental Motor Skills program. BM condition: included } 19 \text { sessions of } 40 \text { to } 50 \text { min' duration } \\
\text { over } 3 \text { school terms by the intervention specialist teacher, with different aims for each set of lessons } \\
\text { (e.g. increasing awareness of time-use, health benefits of physical activity, self-monitoring time spent } \\
\text { in sedentary behaviors and physical activity, raising awareness of the home and community environ- } \\
\text { ments in relation to choices and opportunities, decision-making skills, developing their own physical } \\
\text { activities and games, 'intelligent viewing', a 'Switch-off Challenge', and intermittent reinforcement } \\
\text { schedule with a small reward). FMS condition: } 19 \text { sessions of } 40 \text { to } 50 \text { min over } 3 \text { school terms taught by } \\
\text { the same intervention specialist teacher who delivered the BM intervention. The FMS intervention fo- } \\
\text { cused on } 6 \text { skills, including } 3 \text { object control skills and } 3 \text { locomotor skills. Skills were taught with an em- } \\
\text { phasis on fun through games and maximum involvement for all the children. Most lessons focused on } \\
\text { at least } 2 \text { skills, and each skill was a focus lesson in at least } 6 \text { or more sessions } \\
\text { Control: usual classroom lessons }\end{array}$ \\
\hline
\end{tabular}

\begin{tabular}{ll}
\hline Outcomes & Duration of physical activity \\
Television viewing (minutes spent watching television) \\
Body mass index $\left(\mathrm{kg} / \mathrm{m}^{2}\right)$
\end{tabular}

Notes

\section{Risk of bias}

\begin{tabular}{lll}
\hline Bias & Authors' judgement & Support for judgement \\
\hline $\begin{array}{l}\text { Random sequence genera- } \\
\text { tion (selection bias) }\end{array}$ & High risk & $\begin{array}{l}\text { Comment: participants selected a ticket from a container which specified } \\
\text { group allocation }\end{array}$ \\
\hline $\begin{array}{l}\text { Allocation concealment } \\
\text { (selection bias) }\end{array}$ & Unclear risk & Comment: it was not stated if allocation was adequately concealed \\
\hline $\begin{array}{l}\text { Blinding (performance } \\
\text { bias and detection bias) } \\
\text { All outcomes }\end{array}$ & High risk & $\begin{array}{l}\text { Comment: Two trained staff members not blinded to group assignment took } \\
\text { measurements }\end{array}$ \\
\hline
\end{tabular}


Salmon 2008 (Continued)

Incomplete outcome data High risk Comment: incomplete outcome data was not adequately addressed (attrition bias)

All outcomes

Selective reporting (re- Low risk Comment: all outcomes identified a priori were reported on
porting bias)

\begin{tabular}{lll}
\hline Confounders controlled? & Low risk & Comment: all relevant confounders were accounted for \\
\hline $\begin{array}{l}\text { Data collection methods } \\
\text { valid and reliable? }\end{array}$ & Low risk & Comment: data collection tools valid and reliable \\
\hline
\end{tabular}

Simon 2004

\begin{tabular}{ll}
\hline Methods & Design: cluster randomized controlled trial \\
Theoretical framework: unstated \\
Number of intervention groups: 1 \\
Number of control groups: 1 \\
Follow-up: immediately post-intervention \\
N (intervention): 475 \\
$\mathrm{~N}$ (control): 479 \\
Age (mean): 11.7 years \\
Sex: male and female \\
Ethnicity: White \\
Country: France \\
Setting: community, school, urban \\
Provider: teachers, physical activity (PA) instructors, peers, community groups \\
Duration: 4 school years (40 weeks per year) \\
Intervention: the ICAPS program was implemented over 4 academic years to promote PA inside and \\
outside. The intervention includes an educational component focusing on PA and sedentary behaviors, \\
new opportunities for PA during school hours (lunch break, recess), and after-school hours. Activities \\
implemented are either informal or academic with emphasis on fun and pleasure, well-being, noncom- \\
petitiveness. Sporting events, bicycle, and on-foot transport are organized, with teachers, parental or- \\
ganizations, and sport associations encouraged to participate in meetings and regular contact. Inter- \\
vention staff are informed of study objectives and work in collaboration with the different partners. The \\
ICAPS coordinators regularly visit intervention school members to inquire about difficulties and help \\
resolve material or personnel needs \\
Control: not specified
\end{tabular}

Outcomes

\author{
PA rates (\% of sample physically active) \\ Duration of physical activity \\ Television viewing (minutes spent watching televisions) \\ Body mass index $\left(\mathrm{kg} / \mathrm{m}^{2}\right)$ \\ Mean systolic blood pressure $(\mathrm{mmHg})$ \\ Mean diastolic blood pressure $(\mathrm{mmHg})$ \\ Mean cholesterol level $(\mathrm{mg} / \mathrm{dL})$
}

Notes 
Simon 2004 (Continued)

Risk of bias

\begin{tabular}{|c|c|c|}
\hline Bias & Authors' judgement & Support for judgement \\
\hline $\begin{array}{l}\text { Random sequence genera- } \\
\text { tion (selection bias) }\end{array}$ & Unclear risk & Comment: randomization process not reported \\
\hline $\begin{array}{l}\text { Allocation concealment } \\
\text { (selection bias) }\end{array}$ & Low risk & $\begin{array}{l}\text { Comment: criterion not applicable because all participants were allocated at } \\
1 \text { point in time following recruitment, so at time of recruitment allocation was } \\
\text { not known }\end{array}$ \\
\hline $\begin{array}{l}\text { Blinding (performance } \\
\text { bias and detection bias) } \\
\text { All outcomes }\end{array}$ & Unclear risk & Comment: no information given, likely not done \\
\hline $\begin{array}{l}\text { Incomplete outcome data } \\
\text { (attrition bias) } \\
\text { All outcomes }\end{array}$ & Low risk & Comment: outcome data complete \\
\hline $\begin{array}{l}\text { Selective reporting (re- } \\
\text { porting bias) }\end{array}$ & Low risk & Comment: all outcomes identified a priori were reported on \\
\hline Confounders controlled? & Low risk & Comment: all relevant confounders were accounted for \\
\hline $\begin{array}{l}\text { Data collection methods } \\
\text { valid and reliable? }\end{array}$ & Low risk & Comment: data collection tools were shown to be valid and reliable \\
\hline
\end{tabular}

Singh 2009

\begin{tabular}{|c|c|}
\hline Methods & $\begin{array}{l}\text { Design: cluster randomized controlled trial } \\
\text { Theoretical framework: Intervention Mapping Protocol } \\
\text { Number of intervention groups: } 1 \\
\text { Number of control groups: } 1 \\
\text { Follow-up: } 1 \text { year post-intervention }\end{array}$ \\
\hline Participants & $\begin{array}{l}\text { N: } 875 \\
\text { Age (mean): } 12.7 \text { years } \\
\text { Sex: male and female } \\
\text { Ethnicity: : White }\end{array}$ \\
\hline Interventions & $\begin{array}{l}\text { Country: Netherlands } \\
\text { Setting: school, unstated whether urban or rural } \\
\text { Provider: teachers although unclear } \\
\text { Duration: } 8 \text { months } \\
\text { Intervention: an interdisciplinary program with adapted curriculum including an individual compo- } \\
\text { nent (11 lessons in biology and physical education) and environmental change component including } \\
\text { encouragement for schools to increase physical education and provision of advice for schools related } \\
\text { to cafeteria changes } \\
\text { Control: regular curriculum }\end{array}$ \\
\hline
\end{tabular}

\begin{tabular}{ll}
\hline Outcomes & Body mass index $\left(\mathrm{kg} / \mathrm{m}^{2}\right)$ \\
& Television viewing (minutes spent engaged in inactivity)
\end{tabular}


Singh 2009 (Continued)

Risk of bias

\begin{tabular}{|c|c|c|}
\hline Bias & Authors' judgement & Support for judgement \\
\hline $\begin{array}{l}\text { Random sequence genera- } \\
\text { tion (selection bias) }\end{array}$ & Unclear risk & Comment: randomization process not reported \\
\hline $\begin{array}{l}\text { Allocation concealment } \\
\text { (selection bias) }\end{array}$ & Low risk & $\begin{array}{l}\text { Comment: criterion not applicable because all participants were allocated at } \\
1 \text { point in time following recruitment, so at time of recruitment allocation was } \\
\text { not known }\end{array}$ \\
\hline $\begin{array}{l}\text { Blinding (performance } \\
\text { bias and detection bias) } \\
\text { All outcomes }\end{array}$ & High risk & $\begin{array}{l}\text { Quote: "all measurements were performed within a } 6 \text {-week period according } \\
\text { to a standardized protocol by a trained research team, which was not blinded } \\
\text { to the group assignment" (Singh 2009, p310) }\end{array}$ \\
\hline $\begin{array}{l}\text { Incomplete outcome data } \\
\text { (attrition bias) } \\
\text { All outcomes }\end{array}$ & Low risk & $\begin{array}{l}\text { Quote: "all analyses were performed according to the intention-to-treat princi- } \\
\text { ple" (Singh 2009, p311) }\end{array}$ \\
\hline $\begin{array}{l}\text { Selective reporting (re- } \\
\text { porting bias) }\end{array}$ & Low risk & Comment: all outcomes identified a priori were reported on \\
\hline Confounders controlled? & Low risk & Comment: all relevant confounders were accounted for \\
\hline $\begin{array}{l}\text { Data collection methods } \\
\text { valid and reliable? }\end{array}$ & Low risk & Comment: more detail on reliability and validity could be given \\
\hline
\end{tabular}

Singhal 2010

Methods

Design: cluster randomized controlled trial

Theoretical framework: unstated

Number of intervention groups: 1

Number of control groups: 1

Follow-up: immediately post-intervention

\begin{tabular}{ll}
\hline Participants (intervention): 99 \\
N (control): 102 \\
Age (mean): 16 years \\
Sex: male and female \\
Ethnicity: Indian \\
Country: India \\
Setting: school, urban \\
Provider: trained nutritionist, teachers, student volunteers \\
Duration: 42 weeks \\
Intervention: multicomponent intervention with 7 components related to nutrition and lifestyle edu- \\
cation, including the following activities: dissemination of health-related information through lectures
\end{tabular}


and focused group discussions ( 24 weeks ( 6 months) of nutrition education), promotion of physical activity (encouragement to participate in physical activity periods in school every week for at least 30 min), other promotion of healthy lifestyle (a consecutive 8 weeks ( 30 min 5 days per week), with meal planning and discussion of healthy alternatives and quizzes), individual counseling ( $1 \mathrm{~h}$ per week per child, in groups of 4 or 5), policy-level changes in schools (school canteen serving offering healthier choices), involvement of teachers and parents (health camp for parents and telephone follow-up with counseling of 5 to 7 min per month), training of student volunteers for program sustainability (1-h session each week with 40 eleventh-grade student volunteers)

Control: no intervention

\begin{tabular}{ll}
\hline Outcomes $\quad$ Body mass index $\left(\mathrm{kg} / \mathrm{m}^{2}\right)$ \\
\hline Notes
\end{tabular}

\section{Risk of bias}

\begin{tabular}{|c|c|c|}
\hline Bias & Authors' judgement & Support for judgement \\
\hline $\begin{array}{l}\text { Random sequence genera- } \\
\text { tion (selection bias) }\end{array}$ & Unclear risk & Comment: no description of the randomization process given \\
\hline $\begin{array}{l}\text { Allocation concealment } \\
\text { (selection bias) }\end{array}$ & Low risk & $\begin{array}{l}\text { Comment: criterion not applicable because all participants were allocated at } \\
1 \text { point in time following recruitment, so at time of recruitment allocation was } \\
\text { not known }\end{array}$ \\
\hline $\begin{array}{l}\text { Blinding (performance } \\
\text { bias and detection bias) } \\
\text { All outcomes }\end{array}$ & Unclear risk & Comment: not reported if assessors were blinded \\
\hline $\begin{array}{l}\text { Incomplete outcome data } \\
\text { (attrition bias) } \\
\text { All outcomes }\end{array}$ & Low risk & Comment: participant loss minimal, reasons given in Figure 1 \\
\hline $\begin{array}{l}\text { Selective reporting (re- } \\
\text { porting bias) }\end{array}$ & Unclear risk & Comment: not clear if all a priori outcomes were reported on \\
\hline Confounders controlled? & High risk & Comment: not all confounders adequately controlled \\
\hline $\begin{array}{l}\text { Data collection methods } \\
\text { valid and reliable? }\end{array}$ & High risk & $\begin{array}{l}\text { Comment: do not provide details on how body mass index was measured, only } \\
\text { state who measured outcome }\end{array}$ \\
\hline
\end{tabular}

\section{Stephens 1998}

\begin{tabular}{ll}
\hline Methods & $\begin{array}{l}\text { Design: cluster randomized controlled trial } \\
\text { Theoretical framework: unstated } \\
\text { Number of intervention groups: } 1\end{array}$ \\
& $\begin{array}{l}\text { Number of control groups: } 1 \\
\text { Follow-up: immediately post-intervention }\end{array}$ \\
\hline Participants & $\mathrm{N}$ (intervention): 45 \\
& $\mathrm{~N}($ control): 45 \\
& $\begin{array}{l}\text { Age (mean): } 8 \text { years } \\
\text { Sex: male and female } \\
\text { Ethnicity: African-American }\end{array}$ \\
\hline Interventions & Country: US
\end{tabular}

School-based physical activity programs for promoting physical activity and fitness in children and adolescents aged 6 to 18 (Review) 
Stephens 1998 (Continued)

Setting: school, urban

Provider: medical students

Duration: 15 weeks

Intervention: 18 medical students were assigned to classrooms and given a 2-day orientation session. Each class received 3 activity sessions per week, with the fitness intervention consisting of 5 min of warm-up and stretching, followed by 20 min of aerobic activity. Activities were selected from a roster defined by the Centers for Disease Control and Prevention and incorporated repetitive movements of large muscle groups, designed to elevate the pulse rate 40 to 60 beats over resting level. Sessions ended with a 5- to 10-min cool-down when medical student teams presented educational material about nutrition, exercise, and disease prevention

Control: students in the control classroom received no additional physical activity beyond regular physical education classes

$\begin{array}{ll}\text { Outcomes } & \text { Mean systolic blood pressure }(\mathrm{mmHg}) \\ & \text { Mean diastolic blood pressure }(\mathrm{mmHg}) \\ & \text { Pulse rate (beats/minute) }\end{array}$

Notes

\section{Risk of bias}

\begin{tabular}{lll}
\hline Bias & Authors' judgement & Support for judgement \\
\hline $\begin{array}{l}\text { Random sequence genera- } \\
\text { tion (selection bias) }\end{array}$ & Unclear risk & Comment: randomization process not reported \\
\hline $\begin{array}{l}\text { Allocation concealment } \\
\text { (selection bias) }\end{array}$ & Low risk & $\begin{array}{l}\text { Comment: criterion not applicable because all participants were allocated at } \\
1 \text { point in time following recruitment, so at time of recruitment allocation was } \\
\text { not known }\end{array}$ \\
\hline $\begin{array}{l}\text { Blinding (performance } \\
\text { bias and detection bias) } \\
\text { All outcomes }\end{array}$ & Unclear risk & Comment: no information given, likely not done \\
\hline $\begin{array}{l}\text { Incomplete outcome data } \\
\text { (attrition bias) }\end{array}$ & High risk & Comment: incomplete outcome data assessment \\
\hline $\begin{array}{l}\text { All outcomes } \\
\text { pelective reporting (re- }\end{array}$ & Low risk & Comment: all outcomes identified a priori were reported \\
\hline $\begin{array}{l}\text { Confounders controlled? } \\
\text { Data collection methods }\end{array}$ & Low risk & Unclear risk \\
\begin{tabular}{l} 
valid and reliable? \\
\hline
\end{tabular} & Comment: all relevant confounders were accounted for \\
\hline
\end{tabular}

Stone 2003

Design: cluster randomized controlled trial
Theoretical framework: Social Learning Theory, incorporating Cultural Heritage of American-Indians
Number of intervention groups: 1
Number of control groups: 1
Follow-up: immediately post-intervention

Participants Intervention: 644

Control: 653 
Stone 2003 (Continued)

Age: grade 3 (mean age not provided)

Sex: male and female

Ethnicity: American-Indian

Country: US
Setting: school, unstated if urban or rural
Provider: teacher, nutritionist (for nutritional support)
Duration: 3 years (12 weeks per year)
Intervention: the intervention program was implemented during third through fifth grades, with 4
components including: food service, skills-based classroom curricula, family, and physical education
(PE). The intervention combined Social Learning Theory and principles of American Indian culture and
practices with indigenous learning modes (e.g. story telling) incorporated. Classroom component: $2 \times$
45-min lessons delivered by teachers weekly for 12 weeks during grades 3 and 4 , decreased to 8 weeks
in grade 5. Food service component: nutrient guidelines and tools for reducing fat content of school
meals while meeting nutrient requirements. Food service staff provided skill-building for planning, pur-
chasing, and preparing lower-fat school meals. PE component: a minimum of $3 \times 30$-min sessions per
week of moderate to vigorous physical activity based on SPARK. Family component: assistance creat-
ing a supportive environment with an interactive forum to discuss Pathways and additionally, 1 ) family
action packs, and 2 ) family events at schools
Control: not specified

Outcomes Duration of physical activity

Body mass index $\left(\mathrm{kg} / \mathrm{m}^{2}\right)$

Notes

\section{Risk of bias}

\begin{tabular}{|c|c|c|}
\hline Bias & Authors' judgement & Support for judgement \\
\hline $\begin{array}{l}\text { Random sequence genera- } \\
\text { tion (selection bias) }\end{array}$ & Unclear risk & Comment: randomization process not reported \\
\hline $\begin{array}{l}\text { Allocation concealment } \\
\text { (selection bias) }\end{array}$ & Low risk & $\begin{array}{l}\text { Comment: criterion not applicable because all participants were allocated at } \\
1 \text { point in time following recruitment, so at time of recruitment allocation was } \\
\text { not known }\end{array}$ \\
\hline $\begin{array}{l}\text { Blinding (performance } \\
\text { bias and detection bias) } \\
\text { All outcomes }\end{array}$ & Unclear risk & Comment: no information given, likely not done \\
\hline $\begin{array}{l}\text { Incomplete outcome data } \\
\text { (attrition bias) } \\
\text { All outcomes }\end{array}$ & Low risk & Comment: outcome data complete \\
\hline $\begin{array}{l}\text { Selective reporting (re- } \\
\text { porting bias) }\end{array}$ & Low risk & Comment: all outcomes identified a priori were reported \\
\hline Confounders controlled? & Low risk & Comment: all relevant confounders were accounted for \\
\hline $\begin{array}{l}\text { Data collection methods } \\
\text { valid and reliable? }\end{array}$ & Low risk & Comment: data collection tools shown to be valid and reliable \\
\hline
\end{tabular}

Trevino 2004

$\begin{array}{ll}\text { Methods } & \text { Design: randomized controlled trial } \\ \text { Theoretical framework: Social Cognitive Theory, Social Ecological Theory }\end{array}$

School-based physical activity programs for promoting physical activity and fitness in children and adolescents aged 6 to 18 (Review) 
Trevino 2004 (Continued)

Number of intervention groups: 1

Number of control groups: 1

Follow-up: immediately post-intervention

\begin{tabular}{ll}
\hline Participants & N (intervention): 619 \\
N (control): 602 & Age (mean): 9.8 years \\
Sex: male and female \\
Ethnicity: Hispanic \\
Country: US \\
Setting: school, urban \\
Provider: teachers \\
Duration: 7 months \\
Intervention: 50 sessions of health programing across 7 months to transmit to children 3 health be- \\
havior messages associated with diabetes mellitus control (decreased dietary saturated fat intake, in- \\
crease dietary fiber intake, increase physical activity). Taught and reinforced through classroom, home, \\
school cafeteria, and after-school care educational activities. Physical education teachers, parents, \\
school cafeteria staff, and after-school care staff were asked to encourage less dietary saturated fat, \\
more fiber intake and more physical activity, to have less saturated fat and more fiber available, and \\
more physical activity available. Children were asked to set goals aimed at accomplishing the targeted \\
behaviors and to keep records of their accomplishments. Children were also asked to encourage their \\
peers and adult caretakers to practice 3 health behaviors. Children and parents who practiced the 3 \\
health behaviors were rewarded with coupons (worth a \$\$ amount) from a store set up in the school. \\
Students could purchase merchandise with the coupons \\
Control: not specified
\end{tabular}

Outcomes $\quad \mathrm{VO}_{2} \max (\mathrm{mL} / \mathrm{kg} /$ minute $)$

Notes

\section{Risk of bias}

\begin{tabular}{|c|c|c|}
\hline Bias & Authors' judgement & Support for judgement \\
\hline $\begin{array}{l}\text { Random sequence genera- } \\
\text { tion (selection bias) }\end{array}$ & Low risk & Comment: randomization took place using a random number table \\
\hline $\begin{array}{l}\text { Allocation concealment } \\
\text { (selection bias) }\end{array}$ & Low risk & $\begin{array}{l}\text { Comment: methods ensured that no one could foresee intervention assign- } \\
\text { ment }\end{array}$ \\
\hline $\begin{array}{l}\text { Blinding (performance } \\
\text { bias and detection bias) } \\
\text { All outcomes }\end{array}$ & Low risk & $\begin{array}{l}\text { Quote: "principals of schools were informed and asked not to inform students, } \\
\text { parents or school staff of the intervention assignment" (Trevino 2004, p912) }\end{array}$ \\
\hline $\begin{array}{l}\text { Incomplete outcome data } \\
\text { (attrition bias) } \\
\text { All outcomes }\end{array}$ & Low risk & Comment: outcome data complete \\
\hline $\begin{array}{l}\text { Selective reporting (re- } \\
\text { porting bias) }\end{array}$ & Low risk & Comment: all outcomes identified a priori were reported on \\
\hline Confounders controlled? & Low risk & Comment: all relevant outcomes were accounted for \\
\hline $\begin{array}{l}\text { Data collection methods } \\
\text { valid and reliable? }\end{array}$ & Unclear risk & $\begin{array}{l}\text { Comment: reliability and validity of data collection methods not specifically } \\
\text { stated }\end{array}$ \\
\hline
\end{tabular}




\begin{tabular}{|c|c|}
\hline Methods & $\begin{array}{l}\text { Design: cluster randomized controlled trial } \\
\text { Theoretical framework: unstated } \\
\text { Number of intervention groups: } 1 \\
\text { Number of control groups: } 1 \\
\text { Follow-up: immediately post-intervention }\end{array}$ \\
\hline Participants & $\begin{array}{l}\mathrm{N} \text { (intervention): } 122 \\
\mathrm{~N} \text { (control): } 113 \\
\text { Age (mean): } 10.8 \text { years } \\
\text { Sex: male and female } \\
\text { Ethnicity: White }\end{array}$ \\
\hline Interventions & $\begin{array}{l}\text { Country: Belgium } \\
\text { Setting: school, urban } \\
\text { Provider: research staff } \\
\text { Duration: } 3 \text { months } \\
\text { Interventions: intervention: classes received a set of game equipment and 'activity cards' including ex- } \\
\text { amples of games and activities that can be performed with the equipment. Children were allowed to } \\
\text { play outdoors with the equipment during recesses and lunch break. Before providing the game equip- } \\
\text { ment, the different play toys and 'activity cards' were presented to the children of each class group by a } \\
\text { research staff member. Teachers were asked to stimulate the children to play with the game equipment } \\
\text { and agreed on rules with the children about the use and the loss or damage of the game equipment to } \\
\text { assure its endurance. The teachers were advised to divide the game equipment into different sets and } \\
\text { to exchange those sets regularly to prevent children losing interest in the equipment. Children were } \\
\text { only allowed to play with the equipment of their own class. The set of game equipment for each class } \\
\text { group included } 2 \text { jump ropes, } 2 \text { double Dutch ropes, } 2 \text { scoop sets, } 2 \text { flying discs, } 2 \text { catchballs, } 1 \text { poco bal, } \\
1 \text { plastic bal, } 2 \text { plastic hoops, } 2 \text { super grips, } 3 \text { juggling scarves, } 6 \text { juggling rings, } 6 \text { juggling beanballs, } 1 \\
\text { diabolo, } 1 \text { angel-stick, } 4 \text { spinning plates, } 2 \text { sets of badminton racquets and } 2 \text { sets of oversized beach } \\
\text { paddles. } \\
\text { Control: not specified }\end{array}$ \\
\hline
\end{tabular}

Outcomes Physical activity rates ( $\%$ of sample physically active)

Notes

\section{Risk of bias}

\begin{tabular}{lll}
\hline Bias & Authors' judgement & Support for judgement \\
\hline $\begin{array}{l}\text { Random sequence genera- } \\
\text { tion (selection bias) }\end{array}$ & Unclear risk & Comment: randomization process not reported \\
\hline $\begin{array}{l}\text { Allocation concealment } \\
\text { (selection bias) }\end{array}$ & Low risk & $\begin{array}{l}\text { Comment: criterion not applicable because all participants were allocated at } \\
1 \text { point in time following recruitment, so at time of recruitment allocation was } \\
\text { not known }\end{array}$ \\
\hline $\begin{array}{l}\text { Blinding (performance } \\
\text { bias and detection bias) }\end{array}$ & Unclear risk & Comment: no information given, likely not done \\
All outcomes & & Comment: incomplete outcome data was not adequately addressed \\
\hline $\begin{array}{l}\text { Incomplete outcome data } \\
\text { (attrition bias) } \\
\text { All outcomes }\end{array}$ & High risk & \\
\hline
\end{tabular}


Verstraete 2006 (Continued)

Selective reporting (re- Low risk Comment: all outcomes identified a priori were reported on porting bias)

\begin{tabular}{lll}
\hline Confounders controlled? & High risk & Comment: not stated therefore likely not done \\
\hline $\begin{array}{l}\text { Data collection methods } \\
\text { valid and reliable? }\end{array}$ & Unclear risk & $\begin{array}{l}\text { Comment: reliability and validity of data collection methods not specifically } \\
\text { stated }\end{array}$ \\
\hline
\end{tabular}

\section{Walter 1988}

Design: cluster randomized controlled trial
Theoretical framework: PRECEDE, Health Belief Model, Social Learning Theory
Number of intervention groups: 2
Number of control groups: 2
Follow-up: immediately post-intervention

$\begin{array}{ll}\text { Participants } & N \text { (intervention in lower income inner city area): } 1590 \text { (14 schools) } \\ N \text { (intervention in middle/upper income suburb): } 485 \text { (8 schools) } \\ \text { N (control in lower income inner city area): } 693 \text { (8 schools) } \\ \text { N (control in middle/upper income suburb): } 620 \text { (7 schools) } \\ \text { Age (mean): } 9 \text { years } \\ \text { Sex: male and female } \\ \text { Ethnicity: White, Hispanic, African-American }\end{array}$

Interventions

Country: US

Setting: school, community, urban

Provider: teachers

Duration: 6 years

Intervention: special curriculum targeting voluntary changes in risk behavior in the area of diet, physical activity, and smoking. Curriculum content was designed to provide the information and motivation necessary for behavioral changes, as well as training in the skills necessary to make such changes. The intervention foci (perceived susceptibility to, and severity of health problems, perceived benefits of and barriers to adopting and maintaining risk-reduction types of behavior) were derived from the Health Belief Model, skills training strategies were derived from Social Learning Theory. Cognitive-development theory provided a framework for the appropriate tailoring of these constructs to the children's changing maturational stages ad the study progressed over a 5-year period. The physical activity component of the intervention fostered the adoption of a regular program of endurance exercise. The special curriculum was taught in classrooms by specially trained regular teachers for approximately 2 hours per week throughout each school year.

Control: not specified

$\begin{array}{ll}\text { Outcomes } & \text { Mean systolic blood pressure }(\mathrm{mmHg}) \\ & \text { Mean diastolic blood pressure }(\mathrm{mmHg}) \\ & \text { Mean blood cholesterol level }(\mathrm{mg} / \mathrm{dL}) \\ & \text { Body mass index }\left(\mathrm{kg} / \mathrm{m}^{2}\right) \\ \text { Pulse rate (beats } / \text { minute) }\end{array}$

\section{Notes}

\section{Risk of bias}

Bias Authors' judgement Support for judgement


Walter 1988 (Continued)

\begin{tabular}{lll}
$\begin{array}{l}\text { Random sequence genera- } \\
\text { tion (selection bias) }\end{array}$ & Unclear risk & Comment randomization process not reported \\
\hline $\begin{array}{l}\text { Allocation concealment } \\
\text { (selection bias) }\end{array}$ & Low risk & $\begin{array}{l}\text { Comment: criterion not applicable because all participants were allocated at } \\
1 \text { point in time following recruitment, so at time of recruitment allocation was } \\
\text { not known }\end{array}$
\end{tabular}

\begin{tabular}{l}
\hline Blinding (performance $\quad$ Unclear risk \\
bias and detection bias) \\
All outcomes
\end{tabular}

\begin{tabular}{ll}
\hline Incomplete outcome data Low risk & Comment: analyses were done to see if bias would be introduced due to attri- \\
(attrition bias) & tion and average values of the risk values were imputed
\end{tabular}

All outcomes

Comment: analyses were done to see if bias would be introduced due to attri-

\begin{tabular}{|c|c|c|}
\hline $\begin{array}{l}\text { Selective reporting (re- } \\
\text { porting bias) }\end{array}$ & Low risk & Comment: all outcomes identified a priori were reported on \\
\hline Confounders controlled? & Low risk & Comment: all relevant confounders controlled for \\
\hline $\begin{array}{l}\text { Data collection methods } \\
\text { valid and reliable? }\end{array}$ & Unclear risk & $\begin{array}{l}\text { Comment: reliability and validity of data collection methods not specifically } \\
\text { stated }\end{array}$ \\
\hline
\end{tabular}

Walther 2009

\begin{tabular}{ll}
\hline Methods & Design: cluster randomized controlled trial \\
Theoretical framework: unstated \\
Number of intervention groups: 1 \\
Number of control groups: 2 \\
Follow-up: immediately post-intervention \\
N (intervention): 109 \\
N (control): 73 \\
Age (mean): 11.1 years \\
Sex: male and female \\
Ethnicity: White \\
Country: Germany \\
Setting: school, unstated if urban or rural \\
Provider: unstated \\
Duration: 1 year \\
Intervention: classes assigned to 1 unit of physical exercise (45 min) with at least 15 min of endurance \\
training per school day. In addition, lessons on healthy lifestyle were included in the regular sched- \\
ule once monthly for all pupils. 2 additional sixth-grade classes from a school focusing on competitive \\
sports and physical education were selected to serve as a reference group. \\
Control: according to German standards, 2 units (each 45 min) of physical education per week are \\
mandatory in all schools. The nonrandomized sport students (reference group) received 12 units (45 \\
min per unit) of high-level endurance exercise training per week and frequently participated in com- \\
petitive sporting events, thus representing a maximum of physical fitness attainable under reasonable \\
conditions in school-age children
\end{tabular}

Outcomes

$$
\begin{aligned}
& \text { Mean systolic blood pressure }(\mathrm{mmHg}) \\
& \text { Mean diastolic blood pressure }(\mathrm{mmHg}) \\
& \text { Mean blood cholesterol level }(\mathrm{mg} / \mathrm{dL})
\end{aligned}
$$


Walther 2009 (Continued)

$$
\mathrm{VO}_{2 \mathrm{~m}} \mathrm{ax}(\mathrm{mL} / \mathrm{kg} / \text { minute) }
$$

Notes

\section{Risk of bias}

\begin{tabular}{lll}
\hline Bias & Authors' judgement & Support for judgement \\
\hline $\begin{array}{l}\text { Random sequence genera- } \\
\text { tion (selection bias) }\end{array}$ & Unclear risk & Comment: randomization process not reported \\
\hline $\begin{array}{l}\text { Allocation concealment } \\
\text { (selection bias) }\end{array}$ & Low risk & $\begin{array}{l}\text { Comment: criterion not applicable because all participants were allocated at } \\
1 \text { point in time following recruitment, so at time of recruitment allocation was } \\
\text { not known }\end{array}$ \\
\hline $\begin{array}{l}\text { Blinding (performance } \\
\text { bias and detection bias) }\end{array}$ & Unclear risk & Comment: no information given, likely not done \\
\hline $\begin{array}{l}\text { All outcomes } \\
\text { (attrition bias) } \\
\text { All outcomes }\end{array}$ & High risk & Comment: incomplete outcome data was not adequately addressed \\
\hline $\begin{array}{l}\text { Selective reporting (re- } \\
\text { porting bias) }\end{array}$ & Low risk & Comment: all outcomes identified a priori were reported on \\
\hline $\begin{array}{l}\text { Confounders controlled? } \\
\begin{array}{l}\text { Data collection methods } \\
\text { valid and reliable? }\end{array}\end{array}$ & Low risk risk & Comment: not all relevant confounders controlled for \\
\hline
\end{tabular}

Wang 2008

\begin{tabular}{ll}
\hline Methods & Design: cluster randomized controlled trial \\
Theoretical framework: unstated \\
Number of intervention groups: 1 \\
Number of control groups: 1 \\
Follow-up: immediately post-intervention \\
\hline N (intervention): 168 \\
Participants $($ control): 148 \\
Age (mean): 8.5 years \\
Sex: Male and female \\
Ethnicity: African-American \\
Country: US \\
Setting: school, urban \\
Provider: physical education (PE) teachers, classroom teachers, paraprofessionals \\
Duration: 3 school years \\
Intervention: 'FitKid' after-school program was offered 5 days a week (not offered during holidays and \\
vacation periods). Certified school teachers and paraprofessionals implemented the program, follow- \\
ing established guidelines that included reinforcement and teaching techniques, safety measures, \\
evaluation procedures, and monthly activity plans that accommodate local weather conditions (i.e. \\
more outdoor-based activities in spring, winter, and late fall and more indoor activities in summer and \\
early fall when it is often too hot and humid to play outside). 2-hour intervention sessions began with a \\
40-min period during which the youths were provided with a healthy snack and academic enrichment
\end{tabular}


Wang 2008 (Continued)

activities. The snacks were provided through the US Department of Agriculture's National School Lunch and Child and Adult Care Food Programs in cooperation with the school nutrition service. The academic enrichment activities were incorporated into the program to ensure that participation in the FitKid intervention during the after-school hours would not damage the academic progress of the children. The 80 min of physical activity included a variety of activities designed to improve sport skills, aerobic fitness, strength, and flexibility; 40 min were devoted to vigorous physical activity Control: not specified

\begin{tabular}{ll}
\hline Outcomes & Mean systolic blood pressure $(\mathrm{mmHg})$ \\
& Mean diastolic blood pressure $(\mathrm{mmHg})$ \\
& Mean cholesterol level $(\mathrm{mg} / \mathrm{dL})$ \\
& Body mass index $\left(\mathrm{kg} / \mathrm{m}^{2}\right)$ \\
$\mathrm{VO}_{2} \max (\mathrm{mL} / \mathrm{kg} /$ minute $)$
\end{tabular}

Notes

\section{Risk of bias}

\begin{tabular}{|c|c|c|}
\hline Bias & Authors' judgement & Support for judgement \\
\hline $\begin{array}{l}\text { Random sequence genera- } \\
\text { tion (selection bias) }\end{array}$ & Unclear risk & Comment: randomization process not reported \\
\hline $\begin{array}{l}\text { Allocation concealment } \\
\text { (selection bias) }\end{array}$ & Low risk & $\begin{array}{l}\text { Comment: criterion not applicable because all participants were allocated at } \\
1 \text { point in time following recruitment, so at time of recruitment allocation was } \\
\text { not known }\end{array}$ \\
\hline $\begin{array}{l}\text { Blinding (performance } \\
\text { bias and detection bias) } \\
\text { All outcomes }\end{array}$ & Unclear risk & Comment: no information given, likely not done \\
\hline $\begin{array}{l}\text { Incomplete outcome data } \\
\text { (attrition bias) } \\
\text { All outcomes }\end{array}$ & High risk & Comment: incomplete outcome data was not adequately addressed \\
\hline $\begin{array}{l}\text { Selective reporting (re- } \\
\text { porting bias) }\end{array}$ & Low risk & Comment: all outcomes identified a priori were reported on \\
\hline Confounders controlled? & Low risk & Comment: all relevant confounders were taken into account \\
\hline $\begin{array}{l}\text { Data collection methods } \\
\text { valid and reliable? }\end{array}$ & High risk & Comment: not all methods were shown to be valid or reliable \\
\hline
\end{tabular}

\section{Webber 2008}

\begin{tabular}{ll}
\hline Methods & $\begin{array}{l}\text { Design: cluster randomized controlled trial } \\
\text { Theoretical framework: Social Cognitive Theory, Diffusion of Innovation, Operant Learning Theory } \\
\text { Number of intervention groups: } 1 \\
\text { Number of control groups: } 1 \\
\text { Follow-up: immediately post-intervention }\end{array}$ \\
\hline Participants & $\mathrm{N}$ (intervention): 18 schools \\
$\mathrm{N}($ control): 18 schools
\end{tabular}


Webber 2008 (Continued)

Age (mean): 12 years

Sex: female

Ethnicity: White

Interventions

Country: US

Setting: community, school, unstated whether urban or rural

Provider: research staff, community groups, teachers

Duration: 2 years

Intervention: TAAG health education included 6 lessons in each of the 7 th and 8 th grades designed to enhance behavioral skills known to influence physical activity participation. Activity challenges associated with the lessons reinforced the contents, encouraged self-monitoring, and set goals for behavior change. To meet the varying formats in which health education was taught at the school, TAAG health education was offered in 2 forms: 1 for a traditional classroom setting and 1 for physical education (PE) class. TAAG PE class promoted moderate to vigorous physical activity (MVPA) for at least $50 \%$ of class time and encouraged teachers to promote physical activity outside of class. Activities targeted to create (1) environmental and organizational changes supportive of physical activity and (2) cues, messages, and incentives to be more physically active. Specifically, the intervention was designed to establish more opportunities, improve social support and norms, and increase self-efficacy, outcome expectations, and behavioral skills to foster greater MVPA. 35 to 40 girls were the focus of the intervention; however, health and PE classes were part of the usual school curriculum and most included boys as well. An innovative feature of the intervention was linking school and community agencies to develop and promote physical activity programs for girls. These programs were delivered both on and off school property, in most cases either before or after school

Control: not specified

$\begin{array}{ll}\text { Outcomes } & \text { Duration of physical activity } \\ \text { Television viewing (minutes spent watching television) } \\ \text { Body mass index }\left(\mathrm{kg} / \mathrm{m}^{2}\right)\end{array}$

Notes

\section{Risk of bias}

\begin{tabular}{lll}
\hline Bias & Authors' judgement & Support for judgement \\
\hline $\begin{array}{l}\text { Random sequence genera- } \\
\text { tion (selection bias) }\end{array}$ & Unclear risk & Comment: randomization process not reported \\
\hline $\begin{array}{l}\text { Allocation concealment } \\
\text { (selection bias) }\end{array}$ & Low risk & $\begin{array}{l}\text { Comment: criterion not applicable because all participants were allocated at } \\
1 \text { point in time following recruitment, so at time of recruitment allocation was } \\
\text { not known }\end{array}$ \\
\hline $\begin{array}{l}\text { Blinding (performance } \\
\text { bias and detection bias) }\end{array}$ & Low risk & $\begin{array}{l}\text { Quote: "TAAG staff was blinded to the study outcomes until the 2006 data col- } \\
\text { lection was complete. Also, separate intervention and measurement staff were } \\
\text { employed" (Webber 2008, p174) }\end{array}$ \\
\hline $\begin{array}{l}\text { Incomplete outcome data } \\
\text { (attrition bias) } \\
\text { All outcomes }\end{array}$ & High risk & $\begin{array}{l}\text { Comment: incomplete outcome data was not addressed adequately. } \\
\text { Quote: "in a study such as TAA, efforts to obtain a complete set of measure- } \\
\text { ments on the girls assigned to each treatment condition would require consid- } \\
\text { erable resources, as it is expensive to track and measure students who have } \\
\text { left a school. Furthermore, despite extraordinary efforts, ascertainment of } \\
\text { measurements in every girl in the cohort is unlikely" (Stevens 2005, p226) }\end{array}$
\end{tabular}

Selective reporting (re- Low risk Comment: all outcomes identified a priori were reported on
porting bias)


Webber 2008 (Continued)

\begin{tabular}{lll} 
Confounders controlled? & High risk & Comment: all relevant confounders were not controlled for \\
\hline $\begin{array}{l}\text { Data collection methods } \\
\text { valid and reliable? }\end{array}$ & Unclear risk & $\begin{array}{l}\text { Comment: data collection methods were not discussed or shown to be valid or } \\
\text { reliable }\end{array}$ \\
\hline
\end{tabular}

Weeks 2008

\begin{tabular}{ll}
\hline Methods & \begin{tabular}{l} 
Design: randomized controlled trial \\
Theoretical framework: unstated \\
Number of intervention groups: 1 \\
Number of control groups: 1 \\
Follow-up: immediately post-intervention \\
\hline N (intervention): 43 \\
N (control): 38 \\
Age (mean): 13.8 years \\
Sex: male and female \\
Ethnicity: unstated \\
Country: Australia \\
Setting: school, unstated whether urban or rural \\
Provider: research staff \\
Duration: 8 months \\
Intervention: 10 min of directed jumping activity at the beginning of every physical education (PE) \\
class (twice per week). Activities designed to apply loads to the skeleton at high strain magnitude, \\
frequency, and rate, and included: jumps, hops, tuck-jumps, jump-squats, stride jumps, star jumps, \\
lunges, side lunges, and skipping. Jumps were occasionally supplemented with upper body strength- \\
ening activities, including push-ups and exercises with resistive latex bands (AusBand; Ausmedic Aus- \\
tralia). \\
Control: regular PE warm-ups and stretching directed by their usual PE teacher at the beginning of \\
every PE class (twice per week). Activities focused on improving flexibility and general preparedness for \\
physical activity without specifically loading the skeleton at higher rates than normal, including: brisk \\
walking, light jogging, and stretching
\end{tabular} \\
\hline
\end{tabular}

\begin{tabular}{ll}
\hline Outcomes & Duration of physical activity \\
Body mass index $\left(\mathrm{kg} / \mathrm{m}^{2}\right)$
\end{tabular}

Notes

\section{Risk of bias}

\begin{tabular}{lll}
\hline Bias & Authors' judgement & Support for judgement \\
\hline $\begin{array}{l}\text { Random sequence genera- } \\
\text { tion (selection bias) }\end{array}$ & Unclear risk & Comment: no description of the randomization process given \\
\hline $\begin{array}{l}\text { Allocation concealment } \\
\text { (selection bias) }\end{array}$ & Low risk & $\begin{array}{l}\text { Comment: criterion not applicable because all participants were allocated at } \\
\text { 1 point in time following recruitment, so at time of recruitment allocation was } \\
\text { not known }\end{array}$ \\
\hline
\end{tabular}

Blinding (performance Unclear risk Comment: no Information given, likely not done

bias and detection bias)

All outcomes 
Weeks 2008 (Continued)

Incomplete outcome data High risk Comment: intention-to-treat analysis was not completed on the outcomes of (attrition bias) interest

All outcomes

Selective reporting (re- Low risk Comment: all outcomes identified a priori were reported on
porting bias)

\begin{tabular}{lll}
\hline Confounders controlled? & Low risk & Comment: all relevant outcomes were accounted for \\
\hline $\begin{array}{l}\text { Data collection methods } \\
\text { valid and reliable? }\end{array}$ & Unclear risk & Comment: reliability and validity were not discussed \\
\hline
\end{tabular}

Williamson 2007

$\begin{array}{ll}\text { Methods } & \text { Design: cluster randomized controlled trial } \\ & \text { Theoretical framework: unstated } \\ & \text { Number of intervention groups: } 2 \\ \text { Number of control groups: } 0 \\ \text { Follow-up: immediately post-intervention }\end{array}$

\begin{tabular}{ll}
\hline Participants & N (intervention): 282 \\
& N (control): 304 \\
& Age (mean): 9.2 years \\
Sex: male and female \\
Ethnicity: White
\end{tabular}

\section{Country: US}

Setting: school, unstated if urban or rural

Provider: classroom teachers

Duration: 2 academic years

The Healthy Eating and Exercise (HEE) and Alcohol/Tobacco/Drug abuse prevention (ADT) programs were developed as environmental approaches for weight gain. The primary components of the programs were to alter the physical and social environment of the schools. Both programs were rationally linked to a "Wise Mind" concept, which was a central feature of both programs, thus allowing the use of Wise Mind as the name for the program (as a whole), as opposed to just one intervention arm of the study. The Wise Mind concept represents the idea that with knowledge and environmental changes, students can make wise decisions about nutrition, physical activity, and substance use/abuse. The environmental changes were designed to alter the ecology of the school environments, including policy, personal, social, cultural, and physical environmental changes.

Intervention: Healthy Eating and Exercise (HEE) program, designed with the goal of preventing inappropriate weight gain by modifying the school environment to improve healthy eating habits, increase physical activity, and decrease sedentary behavior at school and to encourage these same behavioral changes outside the school environment. The goal of the physical activity program was to increase physical activity during the school day and at home. Teachers were provided with containers filled with indoor play supplies (e.g. balloons, bean bags) and outdoor play supplies (e.g. balls, jump ropes) to promote active play during class time and recess. Posters encouraged the use of these physical activity centers (PACs), and brief lesson plans provided academic games that used the supplies contained in the PACs

Control: Alcohol/Tobacco/Drug abuse prevention (ADT) program, designed with the goal of modifying children's beliefs and attitudes regarding the use and abuse of tobacco, alcohol, and illicit drugs so that they reflected "healthier" values

\begin{tabular}{ll}
\hline Outcomes & Duration of physical activity \\
& Television viewing (minutes engaged in inactivity)
\end{tabular}


Williamson 2007 (Continued)

Body mass index $\left(\mathrm{kg} / \mathrm{m}^{2}\right)$

\section{Notes}

\section{Risk of bias}

\begin{tabular}{|c|c|c|}
\hline Bias & Authors' judgement & Support for judgement \\
\hline $\begin{array}{l}\text { Random sequence genera- } \\
\text { tion (selection bias) }\end{array}$ & Unclear risk & Comment: randomization process not reported \\
\hline $\begin{array}{l}\text { Allocation concealment } \\
\text { (selection bias) }\end{array}$ & Low risk & $\begin{array}{l}\text { Comment: criterion not applicable because all participants were allocated at } \\
1 \text { point in time following recruitment, so at time of recruitment allocation was } \\
\text { not known }\end{array}$ \\
\hline $\begin{array}{l}\text { Blinding (performance } \\
\text { bias and detection bias) } \\
\text { All outcomes }\end{array}$ & Unclear risk & Comment: no information given, likely not done \\
\hline $\begin{array}{l}\text { Incomplete outcome data } \\
\text { (attrition bias) } \\
\text { All outcomes }\end{array}$ & Low risk & Comment: missing values were replaced with calculated estimates \\
\hline $\begin{array}{l}\text { Selective reporting (re- } \\
\text { porting bias) }\end{array}$ & Low risk & Comment: all outcomes identified a priori were reported on \\
\hline Confounders controlled? & High risk & Comment: more confounders should have been assessed and controlled for \\
\hline $\begin{array}{l}\text { Data collection methods } \\
\text { valid and reliable? }\end{array}$ & Low risk & Comment: data collection methods were shown to be valid and reliable \\
\hline
\end{tabular}

Wilson 2011

\begin{tabular}{ll}
\hline Methods & Design: cluster randomized controlled trial \\
Theoretical framework: Social Cognitive Theory, Self-Determination Theory \\
Number of intervention groups: 1 \\
Number of control groups: 1 \\
Follow-up: 2 weeks post-intervention \\
\hline N (intervention): 673 \\
N (control): 635 \\
Age (mean): 11.3 years \\
Sex: male and female \\
Ethnicity: African-American (73\%), other \\
Country: US \\
Setting: Grade school, unstated if urban or rural, home \\
Provider: trained team leader
\end{tabular}


Wilson 2011 (Continued)

\section{Duration: 17 weeks}

Intervention: ACT, a 17-week program implemented on Mondays, Tuesdays, and Thursdays for 2 hours after school. On Wednesdays students practiced what they had learned in the after-school program in their home environment. A trained team leader, with expertise in implementing physical activities (PA) in youth, provided the structure for the ACT intervention program implementation. The program had 3 main components: homework/snack (30 min), moderate to vigorous physical activities (MVPA) (60 min) that students selected each week, and a behavioral skills and motivational component (30 min) during which intervention staff worked with participants on developing strategies for increasing their MVPA in their home environment. The ACT intervention specifically targeted development of behavioral skills (communication, reciprocity of social support, group goal setting, and behavioral competence) for increasing PA outside of program days. In addition, the ACT after-school program social environment (autonomy, choice, participation, belongingness, fun, enjoyment, support) was designed to have a positive impact on cognitive mediators (self-confidence, perceived competence) and motivational orientation (intrinsic motivation, commitment, positive self-concept) to promote long-term PA behavior. Control: the General Health Education Program (comparison program) focused on nutrition, stress management, drug prevention, and drop-out prevention (with no PA component). The program consisted of a homework/snack ( $30 \mathrm{~min}$ ) and 3 hands-on activities related to general health (30 min each). The comparison program was held on the same days and times as the ACT intervention program.

Outcomes Duration of PA

\section{Notes}

\section{Risk of bias}

\begin{tabular}{lll}
\hline Bias & Authors' judgement & Support for judgement \\
\hline $\begin{array}{l}\text { Random sequence genera- } \\
\text { tion (selection bias) }\end{array}$ & Unclear risk & Comment: no description of the randomization process given \\
\hline $\begin{array}{l}\text { Allocation concealment } \\
\text { (selection bias) }\end{array}$ & Low risk & $\begin{array}{l}\text { Comment: criterion not applicable because all participants were allocated at } \\
1 \text { point in time following recruitment, so at time of recruitment allocation was } \\
\text { not known }\end{array}$ \\
\hline $\begin{array}{l}\text { Blinding (performance } \\
\text { bias and detection bias) } \\
\text { All outcomes }\end{array}$ & Low risk & Comment: used accelerometers to measure outcome \\
\hline $\begin{array}{l}\text { Incomplete outcome data } \\
\text { (attrition bias) } \\
\text { All outcomes }\end{array}$ & Low risk & Comment: did intention-to-treat analysis, also provided details on drop-outs \\
\hline $\begin{array}{l}\text { Selective reporting (re- } \\
\text { porting bias) }\end{array}$ & Unclear risk & Comment: no Information given, likely not done \\
\hline $\begin{array}{l}\text { Confounders controlled? } \\
\text { Data collection methods }\end{array}$ & Low risk & Low risk \\
\begin{tabular}{l} 
valid and reliable? \\
\hline
\end{tabular} & Comment: adjusted for important confounders before randomization \\
\hline
\end{tabular}

Young 2006

$\begin{array}{ll}\text { Methods } & \text { Design: randomized controlled trial } \\ \text { Theoretical framework: Social Action Theory }\end{array}$


Young 2006 (Continued)

Number of intervention groups: 1

Number of control groups: 1

Follow-up: immediately post-intervention

Participants (intervention): 111
$\mathrm{~N}($ control): 99
Age (mean): 13.8 years
Sex: female
Ethnicity: African-American $(83 \%)$

Interventions

Country: US

Setting: school, urban

Provider: teacher hired by project

Duration: 1 year (school year)

Intervention: the intervention was taught by a teacher hired by the project. Intervention content included information to make an informed decision about the personal benefits of a physically active lifestyle, develop problem-solving skills, and obtain support from others. Specific strategies that were taught and reinforced included goal setting, problem-solving barriers, communication skills, reinforcement of goal achievement through internal and external rewards, and learning from relevant role models. Skills were taught using class lectures and discussions, small-group discussions, and homework activities. Physical activity self-monitoring was given a strong focus. Students were encouraged to keep weekly exercise logs from which the teacher provided feedback on progress toward goal attainment and reward strategies. All students in class received the intervention, irrespective of whether they were trial participants. The intervention was also designed to maximize physical activity during physical education (PE) class. The format was congruent with the school's PE curriculum - 1 semester of individual sports and 1 semester of team sports - taught 5 days per week. Classes were optimized for physical activity by teaching units that were active in nature (e.g. soccer instead of softball (personal fitness unit)), breaking skills training into small-group activities, and playing games in small groups (e.g. 3-on-3 basketball). Skills training was limited to that needed for competency rather than proficiency. Written tests focused on health-related physical activity and fitness concepts and behavioral skills. The family support component consisted of a family workshop, monthly newsletters, and adult-child homework assignments. A 2-hour family workshop, scheduled shortly after randomization, featured tips on how parents could provide support to their daughters. As an in-class activity, students worked on skits illustrating support strategies that were videotaped and viewed at the workshop. Families who did not attend were mailed copies. Families also received a 2-page family support newsletter each month that contained an article on ways families can support physical activity with their daughter Control: standard PE class was a curriculum in which students were taught skills in individual and team sports. For example, during the basketball unit, students were taught how to dribble, shoot, and pass, and were tested on concepts such as game rules and defense strategies. Similar to the intervention structure, 1 semester focused on individual sports and the other on team sports. Classes were taught by certified PE teachers employed by the school. Parents of participants in the standard PE class also received monthly newsletters. Topics were of general health interests and included an article about PE class content that month

Outcomes Mean systolic blood pressure $(\mathrm{mmHg})$

Mean diastolic blood pressure $(\mathrm{mmHg})$

Mean blood cholesterol level $(\mathrm{mg} / \mathrm{dL})$

Body mass index (BMI) $\left(\mathrm{kg} / \mathrm{m}^{2}\right)$ 
Young 2006 (Continued)

Notes

\section{Risk of bias}

\begin{tabular}{|c|c|c|}
\hline Bias & Authors' judgement & Support for judgement \\
\hline $\begin{array}{l}\text { Random sequence genera- } \\
\text { tion (selection bias) }\end{array}$ & Unclear risk & Comment: no description of the randomization process given \\
\hline $\begin{array}{l}\text { Allocation concealment } \\
\text { (selection bias) }\end{array}$ & Low risk & $\begin{array}{l}\text { Comment: criterion not applicable because all participants were allocated at } \\
1 \text { point in time following recruitment, so at time of recruitment allocation was } \\
\text { not known }\end{array}$ \\
\hline $\begin{array}{l}\text { Blinding (performance } \\
\text { bias and detection bias) } \\
\text { All outcomes }\end{array}$ & Unclear risk & Comment: no Information given, likely not done \\
\hline $\begin{array}{l}\text { Incomplete outcome data } \\
\text { (attrition bias) } \\
\text { All outcomes }\end{array}$ & Low risk & $\begin{array}{l}\text { Comment: less than } 10 \% \text { drop-out rate and reasons given (for blood pressure } \\
\text { and BMI outcomes) }\end{array}$ \\
\hline $\begin{array}{l}\text { Selective reporting (re- } \\
\text { porting bias) }\end{array}$ & Unclear risk & Comment: no Information given, likely not done \\
\hline Confounders controlled? & High risk & $\begin{array}{l}\text { Comment: while controlled for baseline outcomes and race, they did not ac- } \\
\text { count for other important confounders }\end{array}$ \\
\hline $\begin{array}{l}\text { Data collection methods } \\
\text { valid and reliable? }\end{array}$ & Unclear risk & Comment: reliability and validity of data collection methods were not stated \\
\hline
\end{tabular}

Characteristics of excluded studies [ordered by study ID]

\begin{tabular}{ll}
\hline Study & Reason for exclusion \\
\hline Abbott 1989 & Weak methodological rating \\
\hline Aburto 2011 & Data on relevant outcomes for children aged 6 to 18 years not reported \\
\hline Adeniran 1988 & Not relevant to public health or health promotion \\
\hline Aganovic 2002 & Not relevant to public health or health promotion \\
\hline Agron 2002 & No control group \\
\hline Al-Nakeeb 2007 & Not a randomized controlled trial \\
\hline Alexandrov 1988 & Not a randomized controlled trial \\
\hline Alexandrov 1992 & Intervention not aimed at promoting physical activity \\
\hline Alhassan 2007 & Data on relevant outcomes for children aged 6 to 18 years not reported \\
\hline Allensworth 1997 & Not relevant to public health or health promotion \\
\hline
\end{tabular}




\begin{tabular}{|c|c|}
\hline Study & Reason for exclusion \\
\hline Allison 1999 & Not relevant to public health or health promotion \\
\hline Allison 2000 & Not a randomized controlled trial \\
\hline Andersen 1998 & No control group \\
\hline Andersen 2003 & Not a randomized controlled trial \\
\hline Andersen 2006 & No control group \\
\hline Anderson 1999 & Not relevant to public health or health promotion \\
\hline Andreacci 2008 & No control group \\
\hline Annesi 2004 & Data on relevant outcomes for children aged 6 to 18 years not reported \\
\hline Ara 2006 & Not a randomized controlled trial \\
\hline Arau jo-Soares 2009 & Not a randomized controlled trial \\
\hline Arborelius 1988 & $\begin{array}{l}\text { Intervention not aimed at promoting physical activity. Data on relevant outcomes for children aged } \\
6 \text { to } 18 \text { years not reported }\end{array}$ \\
\hline Ardoy 2010 & Not a randomized controlled trial \\
\hline Armstrong 2000 & Not a randomized controlled trial \\
\hline Babin 2001 & Data on relevant outcomes for children aged 6 to 18 years not reported \\
\hline Bal 1990 & Intervention not school based. Intervention not aimed at promoting physical activity \\
\hline Baquet 2001 & Weak methodological rating \\
\hline Baquet 2002 & Weak methodological rating \\
\hline Baranowski 2002 & Not a randomized controlled trial \\
\hline Baranowski 2005 & Not a randomized controlled trial \\
\hline Barthold 1993 & Data on relevant outcomes for children aged 6 to 18 years not reported. No control group \\
\hline Baxter 1997 & Intervention not aimed at promoting physical activity \\
\hline Beighle 2006 & No control group \\
\hline Belansky 2006 & Weak methodological rating \\
\hline Benson 2008 & Intervention not school based \\
\hline Berenson 1993 & Not a randomized controlled trial \\
\hline Berenson 1993a & Data on relevant outcomes for children aged 6 to 18 years not reported \\
\hline Berenson 2001 & Data on relevant outcomes for children aged 6 to 18 years not reported. NC \\
\hline
\end{tabular}




\begin{tabular}{|c|c|}
\hline Study & Reason for exclusion \\
\hline Berg-Kelly 1997 & Not relevant to public health or health promotion \\
\hline Bergmann 2010 & Not a randomized controlled trial \\
\hline Biddle 2004 & Not a randomized controlled trial \\
\hline Bindler 2000 & Not relevant to public health or health promotion \\
\hline Bischoff 1987 & No control group \\
\hline Blank Sherman 1992 & No control group \\
\hline Blessing 1994 & No control group \\
\hline Bonhauser 2005 & Weak methodological rating \\
\hline Booth 2001 & Not a randomized controlled trial \\
\hline Boreham 2001 & Not a randomized controlled trial \\
\hline Boyd 1997 & Weak methodological rating \\
\hline Boyle-Holmes 2010 & Not a randomized controlled trial \\
\hline Briancon 2010 & Data on relevant outcomes for children aged 6 to 18 years not reported \\
\hline Brown 2004 & Data on relevant outcomes for children aged 6 to 18 years not reported \\
\hline Brownell 1982 & Intervention not aimed at promoting physical activity \\
\hline Buchan 2011 & Intervention duration less than 3 months \\
\hline Bungum 1997 & Not relevant to public health or health promotion \\
\hline Burgeson 2001 & Not a randomized controlled trial \\
\hline Burgess 2006 & Intervention not school based \\
\hline Bush 2010 & Intervention not school based \\
\hline Butcher 2007 & Data on relevant outcomes for children aged 6 to 18 years not reported \\
\hline Byrd-Williams 2010 & Not a randomized controlled trial \\
\hline Cale 2000 & Not a randomized controlled trial \\
\hline Calfas 1991 & $\begin{array}{l}\text { Intervention not aimed at promoting physical activity. Data on relevant outcomes for children aged } \\
6 \text { to } 18 \text { years not reported. No control group }\end{array}$ \\
\hline Calfas 1994 & Not relevant to public health or health promotion \\
\hline Caravella 1996 & Not relevant to public health or health promotion \\
\hline Cardon 2002 & Not a randomized controlled trial \\
\hline
\end{tabular}




\begin{tabular}{|c|c|}
\hline Study & Reason for exclusion \\
\hline Cardon 2004 & Not a randomized controlled trial \\
\hline Carlson 2008 & Not a randomized controlled trial \\
\hline Carrel 2005b & Weak methodological rating \\
\hline Carrel 2005a & Intervention not aimed at general population (overweight/obese-only sample) \\
\hline Casazza 2007 & Not a randomized controlled trial \\
\hline Cass 2006 & No control group \\
\hline Castelli 2007 & Not a randomized controlled trial \\
\hline Cawley 2007 & No control group \\
\hline Chad 1999 & Data on relevant outcomes for children aged 6 to 18 years not reported. No control group \\
\hline Challener 1990 & Not relevant to public health or health promotion \\
\hline Chatzisarantis 2009 & Intervention duration less than 3 months \\
\hline Chavarro 2005 & $\begin{array}{l}\text { Intervention not aimed at general population (only girls not menstruating were included in the } \\
\text { study) }\end{array}$ \\
\hline Chomitz 2003 & Weak methodological rating \\
\hline Choudhuri 2002 & Not relevant to public health or health promotion \\
\hline Chow 2001 & Data on relevant outcomes for children aged 6 to 18 years not reported \\
\hline Ciccomascolo 2008 & Intervention not school based \\
\hline Cirignano 2010 & Intervention duration less than 3 months \\
\hline Clark 2008 & Data on relevant outcomes for children aged 6 to 18 years not reported \\
\hline Coe 2005 & Not relevant to public health or health promotion \\
\hline Coe 2006 & Data on relevant outcomes for children aged 6 to 18 years not reported \\
\hline Cohen 1991 & No control group \\
\hline Colchico 2000 & No control group \\
\hline Collins 1988 & Not relevant to public health or health promotion \\
\hline Collins 1995 & Not relevant to public health or health promotion \\
\hline Connor 1986 & Weak methodological rating \\
\hline Contento 2010 & Intervention duration less than 3 months \\
\hline Cornelius 1991 & Not relevant to public health or health promotion \\
\hline
\end{tabular}




\begin{tabular}{|c|c|}
\hline Study & Reason for exclusion \\
\hline Cottrell 2005 & Weak methodological rating \\
\hline Cox 2006 & Intervention not school based \\
\hline Crawford 1997 & Not relevant to public health or health promotion \\
\hline Dale 2000 & Weak methodological rating \\
\hline Davis 1995 & Weak methodological rating \\
\hline de Barros 2009 & Data on relevant outcomes for children aged 6 to 18 years not reported \\
\hline De Bourdeaudhuij 2010 & Intervention duration less than 3 months \\
\hline De Meij 2010 & Data on relevant outcomes for children aged 6 to 18 years not reported \\
\hline DeBar 2006 & Data on relevant outcomes for children aged 6 to 18 years not reported \\
\hline Deforche 2004 & Not relevant to public health or health promotion \\
\hline Dehar 1991 & Data on relevant outcomes for children aged 6 to 18 years not reported. No control group \\
\hline Del Ben 1991 & No control group \\
\hline Dellinger 2002 & Data on relevant outcomes for children aged 6 to 18 years not reported. No control group \\
\hline DeMarco 1989 & Not relevant to public health or health promotion \\
\hline Dempsey 1993 & Not relevant to public health or health promotion \\
\hline Dencker 2006 & Not a randomized controlled trial \\
\hline Dennison 2004 & Data on relevant outcomes for children aged 6 to 18 years not reported \\
\hline Derri 2004 & Intervention not school based \\
\hline DeVault 2009 & Data on relevant outcomes for children aged 6 to 18 years not reported \\
\hline Devis 1992 & No control group \\
\hline Diaz 1997 & Data on relevant outcomes for children aged 6 to 18 years not reported \\
\hline Diehl 1998 & $\begin{array}{l}\text { Data on relevant outcomes for children aged } 6 \text { to } 18 \text { years not reported. Intervention not school } \\
\text { based }\end{array}$ \\
\hline Dishman 2005 & Weak methodological rating \\
\hline Dishman 2010 & Data on relevant outcomes for children aged 6 to 18 years not reported \\
\hline Donnelly 1996 & Weak methodological rating \\
\hline Dowda 2001 & Not relevant to public health or health promotion \\
\hline Drews 2009 & Data on relevant outcomes for children aged 6 to 18 years not reported \\
\hline
\end{tabular}




\begin{tabular}{|c|c|}
\hline Study & Reason for exclusion \\
\hline Dudley 2010 & $\begin{array}{l}\text { Intervention not aimed at general population (only girls who expressed low enjoyment of physical } \\
\text { activity were included in the study) }\end{array}$ \\
\hline Dunbar 1998 & $\begin{array}{l}\text { Intervention not school based. Data on relevant outcomes for children aged } 6 \text { to } 18 \text { years not re- } \\
\text { ported. No control group }\end{array}$ \\
\hline Duncan 1983 & Study published prior to inclusion date of 1985 \\
\hline Duncan 2004 & Not a randomized controlled trial \\
\hline Duncan 2009 & Intervention duration less than 3 months \\
\hline Duncan 2010 & Intervention duration less than 3 months \\
\hline Dunn 2006 & No control group \\
\hline DuShaw 1984 & Study published prior to inclusion date of 1985 \\
\hline Dwyer 1979 & Study published prior to inclusion date of 1985 \\
\hline Dwyer 1983 & Study published prior to inclusion date of 1985 \\
\hline Dwyer 1991 & Data on relevant outcomes for children aged 6 to 18 years not reported. No control group \\
\hline Dwyer 2003 & Not a randomized controlled trial \\
\hline Dyson 1998 & Not relevant to public health or health promotion \\
\hline Dzewaltowski 2002 & Data on relevant outcomes for children aged 6 to 18 years not reported \\
\hline Dzewaltowski 2007 & Not a randomized controlled trial \\
\hline Dzewaltowski 2009 & $\begin{array}{l}\text { The type of outcome data collected for physical activity outcomes is this study is too different from } \\
\text { how it was measuered by included studies, therefore cannot be synthesized with the included }\end{array}$ \\
\hline Economos 2007 & Not a randomized controlled trial \\
\hline Edwards 2005 & Data on relevant outcomes for children aged 6 to 18 years not reported \\
\hline Eisenmann 2007 & Not a randomized controlled trial \\
\hline Ekelund 2004 & Not a randomized controlled trial \\
\hline Eliakim 1996 & Intervention duration less than 3 months \\
\hline Eliakim 1997 & Data on relevant outcomes for children aged 6 to 18 years not reported \\
\hline Epstein 2000 & Not relevant to public health or health promotion \\
\hline Ericsson 2011 & Data on relevant outcomes for children aged 6 to 18 years not reported \\
\hline Ernst 1999 & Weak methodological rating \\
\hline Ernst 2003 & Weak methodological rating \\
\hline
\end{tabular}




\begin{tabular}{|c|c|}
\hline Study & Reason for exclusion \\
\hline Errecart 1991 & No control group \\
\hline Erwin 2011 & Not a randomized controlled trial \\
\hline Escobar 2010 & Intervention not school based \\
\hline Everhart 2002 & Weak methodological rating \\
\hline Ewart 1998 & Intervention not aimed at promoting physical activity \\
\hline Ezendam 2007 & Data on relevant outcomes for children aged 6 to 18 years not reported \\
\hline Faigenbaum 1999 & Intervention not school based \\
\hline Faigenbaum 2001 & Data on relevant outcomes for children aged 6 to 18 years not reported \\
\hline Faigenbaum 2003 & Data on relevant outcomes for children aged 6 to 18 years not reported \\
\hline Faigenbaum 2007 & Intervention not school based \\
\hline Faigenbaum 2009 & Data on relevant outcomes for children aged 6 to 18 years not reported \\
\hline Fairclough 2002 & Not relevant to public health or health promotion \\
\hline Fairclough 2005 & Intervention duration less than 3 months \\
\hline Faludi 1999 & Data on relevant outcomes for children aged 6 to 18 years not reported \\
\hline Fardy 1996 & Intervention duration less than 3 months \\
\hline Fisher 2011 & Not a randomized controlled trial \\
\hline Fitzgibbon 2005 & Data on relevant outcomes for children aged 6 to 18 years not reported \\
\hline Fitzgibbon 2011 & Data on relevant outcomes for children aged 6 to 18 years not reported \\
\hline Fleming 2000 & Data on relevant outcomes for children aged 6 to 18 years not reported. No control group \\
\hline Flores 1995 & Weak methodological rating \\
\hline Foster 1985 & Not relevant to public health or health promotion \\
\hline Foster 2008 & Data on relevant outcomes for children aged 6 to 18 years not reported \\
\hline Fox 2004 & Not a randomized controlled trial \\
\hline Francis 2010 & Intervention duration less than 3 months \\
\hline Frauhiger 2002 & Weak methodological rating \\
\hline Frenn 2003 & Not a randomized controlled trial \\
\hline Frenn 2005 & Not a randomized controlled trial \\
\hline
\end{tabular}




\begin{tabular}{|c|c|}
\hline Study & Reason for exclusion \\
\hline Fuchs 2002 & $\begin{array}{l}\text { Intervention not school based. Intervention not aimed at promoting physical activity. Data on rele- } \\
\text { vant outcomes for children aged } 6 \text { to } 18 \text { years not reported }\end{array}$ \\
\hline Fullerton 2007 & Intervention not aimed at general population (overweight/obese-only sample) \\
\hline Gallotta 2009 & Data on relevant outcomes for children aged 6 to 18 years not reported \\
\hline Giralt 2011 & Data on relevant outcomes for children aged 6 to 18 years not reported \\
\hline Goldfine 1993 & Weak methodological rating \\
\hline Goran 1999 & Not relevant to public health or health promotion \\
\hline Goran 2005 & Weak methodological rating \\
\hline Gore 1996 & $\begin{array}{l}\text { Intervention not aimed at promoting physical activity. Data on relevant outcomes for children aged } \\
6 \text { to } 18 \text { years not reported }\end{array}$ \\
\hline Gortmaker 1999a & Weak methodological rating \\
\hline Gortmaker 1999b & Weak methodological rating \\
\hline Graf 2005 & Not a randomized controlled trial \\
\hline Graf 2008 & Not a randomized controlled trial \\
\hline Grafner 1987 & Weak methodological rating \\
\hline Graham 2008 & Not a randomized controlled trial \\
\hline Graham 2008a & Data on relevant outcomes for children aged 6 to 18 years not reported \\
\hline Greene 1995 & Intervention not school based \\
\hline Greening 2011 & Not a randomized controlled trial \\
\hline Grey 2004 & Data on relevant outcomes for children aged 6 to 18 years not reported \\
\hline Grey 2009 & Intervention not aimed at general population (overweight/obese-only sample) \\
\hline Grund 2001 & Not relevant to public health or health promotion \\
\hline Guldbrandsson 2009 & Not a randomized controlled trial \\
\hline Gunter 2008 & Data on relevant outcomes for children aged 6 to 18 years not reported \\
\hline Gutin 1993 & Not relevant to public health or health promotion \\
\hline Gutin 1995 & Not relevant to public health or health promotion \\
\hline Gutin 1999 & Not relevant to public health or health promotion \\
\hline Gutin 2002 & Intervention not school based \\
\hline Gutin 2005 & Not a randomized controlled trial \\
\hline
\end{tabular}




\begin{tabular}{|c|c|}
\hline Study & Reason for exclusion \\
\hline Haerens 2007 & Intervention duration less than 3 months \\
\hline Haines 2006 & Not a randomized controlled trial \\
\hline Halfon 1988 & Intervention not aimed at promoting physical activity \\
\hline Hansen 1991 & Weak methodological rating \\
\hline Hansen 2005 & Not relevant to public health or health promotion \\
\hline Hardman 2011 & $\begin{array}{l}\text { Weak methodological quality (low participation rate; high drop-out rate; less than half of sample } \\
\text { included in the final analysis) }\end{array}$ \\
\hline Hardy 2007 & Not a randomized controlled trial \\
\hline Harrell 1998 & Weak methodological rating \\
\hline Harris 1998 & No control group \\
\hline Hart 2003 & Data on relevant outcomes for children aged 6 to 18 years not reported. No control group \\
\hline Hartmann 2010 & Data on relevant outcomes for children aged 6 to 18 years not reported \\
\hline Hasselstrom 2008 & Data on relevant outcomes for children aged 6 to 18 years not reported \\
\hline Hastie 2007 & Data on relevant outcomes for children aged 6 to 18 years not reported \\
\hline Heale 2008 & Intervention not school based \\
\hline HEALTHY Study Group 2010 & Intervention not aimed at general population (overweight/obese-only sample) \\
\hline Henaghan 2008 & Intervention not school based \\
\hline Hipsky 2002 & Intervention not school based \\
\hline Hoelscher 2010 & Not a randomized controlled trial \\
\hline Holcomb 1998 & Weak methodological rating \\
\hline Hollar 2010 & Not a randomized controlled trial \\
\hline Hopper 1992 & Data on relevant outcomes for children aged 6 to 18 years not reported \\
\hline Hopper 1996 & Weak methodological rating \\
\hline Hopper 2001 & No control group \\
\hline Hopper 2005 & Weak methodological rating \\
\hline Howard 1996 & Weak methodological rating \\
\hline Howe 2003 & Data on relevant outcomes for children aged 6 to 18 years not reported \\
\hline Huang 2007 & Intervention not aimed at general population (overweight/obese-only sample) \\
\hline
\end{tabular}




\begin{tabular}{|c|c|}
\hline Study & Reason for exclusion \\
\hline Huberty 2011 & Not a randomized controlled trial \\
\hline Huguet 1997 & Data on relevant outcomes for children aged 6 to 18 years not reported \\
\hline Ingle 2006 & Intervention not school based \\
\hline Irwin 2010 & Intervention duration less than 3 months \\
\hline Jackson 2001 & Data on relevant outcomes for children aged 6 to 18 years not reported \\
\hline Jago 2009 & Data on relevant outcomes for children aged 6 to 18 years not reported \\
\hline James 2007 & Intervention not aimed at promoting physical activity \\
\hline Jamner 2004 & Weak methodological rating \\
\hline Jansen 2008 & Data on relevant outcomes for children aged 6 to 18 years not reported \\
\hline Janz 2002 & Not relevant to public health or health promotion \\
\hline Jekal 2009 & Intervention not school based \\
\hline Jemmott 2011 & $\begin{array}{l}\text { The type of outcome data collected for physical activity outcomes is this study is too different from } \\
\text { how it was measuered by included studies, therefore cannot be synthesized with the included }\end{array}$ \\
\hline Jiang 2007 & Intervention not aimed at general population (overweight/obese-only sample) \\
\hline Johns 1999 & Not a randomized controlled trial \\
\hline Johnson-Down 1997 & Not relevant to public health or health promotion. \\
\hline Johnston 2007 & Intervention not aimed at general population (overweight/obese-only sample) \\
\hline Jones 1988 & Data on relevant outcomes for children aged 6 to 18 years not reported \\
\hline Jones 2007 & Data on relevant outcomes for children aged 6 to 18 years not reported \\
\hline Jordan 1995 & Weak methodological rating \\
\hline Jurg 2006 & Weak methodological rating \\
\hline Kain 2004 & Not a randomized controlled trial \\
\hline Kain 2008 & Not a randomized controlled trial \\
\hline Kann 2000 & Not a randomized controlled trial \\
\hline Kaplan 1996 & Not relevant to public health or health promotion \\
\hline Karabourniotis 2002 & Data on relevant outcomes for children aged 6 to 18 years not reported \\
\hline Katz 2010 & Not a randomized controlled trial \\
\hline Kawabe 2000 & Not relevant to public health or health promotion \\
\hline
\end{tabular}




\begin{tabular}{|c|c|}
\hline Study & Reason for exclusion \\
\hline Keays 1995 & Not relevant to public health or health promotion \\
\hline Kelder 1995a & Weak methodological rating \\
\hline Kelder 2004 & Not a randomized controlled trial \\
\hline Kijboonchoo 1999 & Not a randomized controlled trial \\
\hline Killen 1989 & Weak methodological rating \\
\hline Kimm 1997 & Not relevant to public health or health promotion \\
\hline Kimm 2005 & Not a randomized controlled trial \\
\hline Kiran 2010 & Data on relevant outcomes for children aged 6 to 18 years not reported \\
\hline Kirkcaldy 2002 & Data on relevant outcomes for children aged 6 to 18 years not reported. No control group \\
\hline Klein-Platat 2005 & Not a randomized controlled trial \\
\hline Klepp 1994 & Not a randomized controlled trial \\
\hline Knox 2009 & Data on relevant outcomes for children aged 6 to 18 years not reported \\
\hline Kolbe 1995 & Data on relevant outcomes for children aged 6 to 18 years not reported. No control group \\
\hline Kong 2009 & No control group \\
\hline Kouli 2009 & Data on relevant outcomes for children aged 6 to 18 years not reported \\
\hline Koutedakis 2003 & Not relevant to public health or health promotion \\
\hline Kovacs 2009 & Data on relevant outcomes for children aged 6 to 18 years not reported \\
\hline Kremers 2005 & Not a randomized controlled trial \\
\hline Kriemler 2011 & Not a randomized controlled trial \\
\hline Kristensen 2010 & Data on relevant outcomes for children aged 6 to 18 years not reported \\
\hline Kwon 2007 & Intervention not aimed at general population (overweight/obese-only sample) \\
\hline La Torre 2006 & Not a randomized controlled trial \\
\hline Lal 1991 & $\begin{array}{l}\text { Intervention not aimed at promoting physical activity. Data on relevant outcomes for children aged } \\
6 \text { to } 18 \text { years not reported. No control group }\end{array}$ \\
\hline Lawman 2011 & Data on relevant outcomes for children aged 6 to 18 years not reported \\
\hline Lazarus 2000 & Not a randomized controlled trial \\
\hline Le Masurier 2005 & Not a randomized controlled trial \\
\hline Lee 2010 & Data on relevant outcomes for children aged 6 to 18 years not reported \\
\hline
\end{tabular}




\begin{tabular}{|c|c|}
\hline Study & Reason for exclusion \\
\hline LeMura 2000 & Not relevant to public health or health promotion \\
\hline Levin 2002 & Data on relevant outcomes for children aged 6 to 18 years not reported \\
\hline Lien 2010 & Data on relevant outcomes for children aged 6 to 18 years not reported \\
\hline Lindstrom 2010 & Not a randomized controlled trial \\
\hline Lionis 1991 & Not a randomized controlled trial \\
\hline Liskova 2002 & Not relevant to public health or health promotion \\
\hline Lubans 2006 & Intervention not school based \\
\hline Lubans 2010a & Intervention duration less than 3 months \\
\hline Lubans 2010b & Data on relevant outcomes for children aged 6 to 18 years not reported (baseline data only) \\
\hline Lubans 2011 & Intervention not aimed at general population (only low active boys were included in the study) \\
\hline Ludwig 2004 & No control group \\
\hline Luepker 1999 & Not relevant to public health or health promotion \\
\hline Lungo 1994 & Weak methodological rating \\
\hline Macaulay 1997 & Data on relevant outcomes for children aged 6 to 18 years not reported \\
\hline MacConnie 1991 & Data on relevant outcomes for children aged 6 to 18 years not reported \\
\hline Macdonald 1999 & Data on relevant outcomes for children aged 6 to 18 yearsnot reported. \\
\hline Macdonald 2007 & Data on relevant outcomes for children aged 6 to 18 yearsnot reported \\
\hline MacKelvie 2001 & Data on relevant outcomes for children aged 6 to 18 yearsnot reported \\
\hline MacKelvie 2002 & Data on relevant outcomes for children aged 6 to 18 yearsnot reported \\
\hline MacKelvie 2004 & Data on relevant outcomes for children aged 6 to 18 yearsnot reported \\
\hline MacLean 2003 & Data on relevant outcomes for children aged 6 to 18 yearsnot reported. \\
\hline Mahar 2006 & Data on relevant outcomes for children aged 6 to 18 yearsnot reported \\
\hline Mahon 1993 & Weak methodological rating \\
\hline Mandigo 2003 & Not relevant to public health or health promotion \\
\hline Manios 1999 & Not a randomized controlled trial \\
\hline Marcus 1987 & Not a randomized controlled trial \\
\hline Marcus 2009 & $\begin{array}{l}\text { The type of outcome data collected for physical activity outcomes is this study is too different from } \\
\text { how it was measuered by included studies, therefore cannot be synthesized with the included }\end{array}$ \\
\hline
\end{tabular}




\begin{tabular}{|c|c|}
\hline Study & Reason for exclusion \\
\hline Marks 2006 & Intervention not school based \\
\hline Martin 2010 & Not a randomized controlled trial \\
\hline Matsudo 1999 & No control group \\
\hline Mauriello 2010 & Intervention not school based \\
\hline McAuley 2010 & Intervention not school based \\
\hline McKay 2003 & Data on relevant outcomes for children aged 6 to 18 yearsnot reported \\
\hline McKenzie 1993 & Data on relevant outcomes for children aged 6 to 18 yearsnot reported \\
\hline McKenzie 2002 & Weak methodological rating \\
\hline McManus 1997 & Intervention not school based \\
\hline McManus 2005 & Not relevant to public health or health promotion \\
\hline McManus 2008a & Intervention not school based \\
\hline McMurray 2002 & Weak methodological rating \\
\hline McMurray 2009 & Data on relevant outcomes for children aged 6 to 18 yearsnot reported \\
\hline McNeil 2009 & Intervention not school based \\
\hline McWhannell 2008 & Intervention not school based \\
\hline Mecredy 1993 & Data on relevant outcomes for children aged 6 to 18 yearsnot reported \\
\hline Meininger 2000 & Not relevant to public health or health promotion \\
\hline Mellin 1987 & Intervention not school based \\
\hline Melnyk 1994 & Not relevant to public health or health promotion \\
\hline Melnyk 2007 & Intervention not aimed at general population (overweight/obese-only sample) \\
\hline Melnyk 2009 & Intervention not aimed at general population (overweight/obese-only sample) \\
\hline Meredith 1991 & Not relevant to public health or health promotion \\
\hline Mettler 2000 & Data on relevant outcomes for children aged 6 to 18 yearsnot reported \\
\hline Metzker 2000 & Weak methodological rating \\
\hline Meunnich Cowell 1989 & No control group \\
\hline Mier 2002 & No control group \\
\hline Missouri 2003 & Not relevant to public health or health promotion \\
\hline Mo-suwan 1998 & Data on relevant outcomes for children aged 6 to 18 yearsnot reported \\
\hline
\end{tabular}




\begin{tabular}{|c|c|}
\hline Study & Reason for exclusion \\
\hline Moberg 1990 & $\begin{array}{l}\text { Intervention not aimed at promoting physical activity. Data on relevant outcomes for children aged } \\
6 \text { to } 18 \text { yearsnot reported }\end{array}$ \\
\hline Monness 2009 & Not a randomized controlled trial \\
\hline Moodie 2011 & Intervention not school based. \\
\hline Moon 1999 & Weak methodological rating \\
\hline Morris 1997 & Intervention not aimed at promoting physical activity \\
\hline Motlagh 2009 & Data on relevant outcomes for children aged 6 to 18 yearsnot reported \\
\hline Mott 1991 & Data on relevant outcomes for children aged 6 to 18 yearsnot reported \\
\hline Moya 2011 & Intervention not school based \\
\hline Muller 2001 & Weak methodological rating \\
\hline Muller 2005 & Not a randomized controlled trial \\
\hline Muth 2008 & Not a randomized controlled trial \\
\hline Nabipour 2004 & Intervention not aimed at promoting physical activity \\
\hline Nader 1992 & Intervention not aimed at promoting physical activity \\
\hline Nahas 2009 & Data on relevant outcomes for children aged 6 to 18 yearsnot reported \\
\hline Naylor 2006 & Data on relevant outcomes for children aged 6 to 18 yearsnot reported \\
\hline NCCDP 1997 & $\begin{array}{l}\text { Intervention not aimed at promoting physical activity. Data on relevant outcomes for children aged } \\
6 \text { to } 18 \text { yearsnot reported. No control group }\end{array}$ \\
\hline Nelson 2011 & Not a randomized controlled trial \\
\hline NeumarkSztainer 2003 & Weak methodological rating \\
\hline Newton 2010 & Not a randomized controlled trial \\
\hline Niederer 2009 & Data on relevant outcomes for children aged 6 to 18 yearsnot reported \\
\hline Nielsen 2010 & Data on relevant outcomes for children aged 6 to 18 yearsnot reported \\
\hline Nyberg 2011 & Data on relevant outcomes for children aged 6 to 18 yearsnot reported \\
\hline O'Loughlin 1999 & $\begin{array}{l}\text { Data on relevant outcomes for children aged } 6 \text { to } 18 \text { yearsnot reported. Intervention not school } \\
\text { based }\end{array}$ \\
\hline Okely 2010 & Intervention not aimed at general population (overweight/obese-only sample) \\
\hline Ostbye 2011 & Data on relevant outcomes for children aged 6 to 18 yearsnot reported \\
\hline Owen 1995 & No control group \\
\hline
\end{tabular}




\begin{tabular}{|c|c|}
\hline Study & Reason for exclusion \\
\hline Oxizoglou 2005 & Weak methodological rating \\
\hline Palmer 2005 & Weak methodological rating \\
\hline Pangrazi 2003 & Not a randomized controlled trial \\
\hline Parcel 1989 & Weak methodological rating \\
\hline Park 2007 & Intervention not school based. \\
\hline Parlee-Hirth 2002 & Data on relevant outcomes for children aged 6 to 18 yearsnot reported. No control group \\
\hline Pate 1987 & Not relevant to public health or health promotion \\
\hline Pate 1994 & Not relevant to public health or health promotion \\
\hline Pate 1995a & Not relevant to public health or health promotion \\
\hline Pate 1995b & Not relevant to public health or health promotion \\
\hline Pate 1996 & Not relevant to public health or health promotion \\
\hline Pate 1999 & Not a randomized controlled trial \\
\hline Pate 2003 & Weak methodological rating \\
\hline Pate 2006 & Not a randomized controlled trial \\
\hline Pena 2004 & Weak methodological rating \\
\hline Peralta 2009a & Intervention not aimed at general population (overweight/obese-only sample) \\
\hline Perry 1987 & No control group \\
\hline Petkevicius 1985 & Weak methodological rating \\
\hline Phillipp 1989 & Weak methodological rating \\
\hline Piper 1993 & No control group. \\
\hline Plachta-Danielzik 2007 & Not a randomized controlled trial. \\
\hline Plotnikoff 1999 & Not a randomized controlled trial. \\
\hline Pollatschek 1989 & Weak methodological rating \\
\hline Prochaska 2002 & Data on relevant outcomes for children aged 6 to 18 yearsnot reported \\
\hline Prusak 2010 & Data on relevant outcomes for children aged 6 to 18 yearsnot reported \\
\hline Racette 2010 & Data on relevant outcomes for children aged 6 to 18 yearsnot reported \\
\hline Raitakari 1994a & Intervention not school based \\
\hline Rakovi 2008 & Not a randomized controlled trial \\
\hline
\end{tabular}




\begin{tabular}{|c|c|}
\hline Study & Reason for exclusion \\
\hline Ramsay 1990 & Intervention not school based \\
\hline Ransdell 2003 & Intervention not school based \\
\hline Reilly 2006 & Data on relevant outcomes for children aged 6 to 18 yearsnot reported \\
\hline Reinhardt 2002 & No control group \\
\hline Renaud 1997 & Data on relevant outcomes for children aged 6 to 18 yearsnot reported. No control group \\
\hline Resaland 2011 & Not a randomized controlled trial \\
\hline Resnick 2009 & Intervention not school based \\
\hline Resnicow 1992 & Weak methodological rating \\
\hline Resnicow 1993 & Not relevant to public health or health promotion \\
\hline Resnicow 1996 & Not relevant to public health or health promotion \\
\hline Resnicow 1997 & Not relevant to public health or health promotion \\
\hline Resnicow 2000 & Not relevant to public health or health promotion \\
\hline Resnicow 2002 & $\begin{array}{l}\text { Data on relevant outcomes for children aged } 6 \text { to } 18 \text { yearsnot reported. Intervention not school } \\
\text { based }\end{array}$ \\
\hline Reybrouck 1990 & Not relevant to public health or health promotion \\
\hline Rezvanian 2010 & Intervention not aimed at general population (overweight/obese-only sample) \\
\hline Ridgers 2010 & $\begin{array}{l}\text { Not a randomized controlled trial (although children from schools were randomly selected to par- } \\
\text { ticipate in the study, the schools were not randomly allocated to intervention or control: } 15 \text { schools } \\
\text { from the low SES area were chosen, and then matched to similar schools) }\end{array}$ \\
\hline Rimmer 1997 & Weak methodological rating \\
\hline Robbins 2006 & Intervention not school based \\
\hline Robinson 1999 & Not relevant to public health or health promotion \\
\hline Robinson 2003 & Intervention not school-based \\
\hline Robinson 2007 & Intervention not school based \\
\hline Robinson 2008 & Intervention not school based \\
\hline Rodgers 2001 & Not a randomized controlled trial \\
\hline Rosenbaum 2007 & Weak methodological rating \\
\hline Rowland 1991 & No control group \\
\hline Ruiz 2006 & Not a randomized controlled trial \\
\hline
\end{tabular}




\begin{tabular}{|c|c|}
\hline Study & Reason for exclusion \\
\hline Saakslahti 2004 & Intervention not school based \\
\hline Sabet-Sarvestani 2008 & Data on relevant outcomes for children aged 6 to 18 yearsnot reported \\
\hline Sacher 2003 & Intervention not school based \\
\hline Sadowsky 1999 & Weak methodological rating \\
\hline Sahota 2001a & Weak methodological rating \\
\hline Sahota $2001 b$ & Data on relevant outcomes for children aged 6 to 18 yearsnot reported \\
\hline Saksvig 2003 & Data on relevant outcomes for children aged 6 to 18 yearsnot reported \\
\hline Sakuragi 2009 & Not a randomized controlled trial \\
\hline Sallis 1993a & Not relevant to public health or health promotion \\
\hline Sallis 1993b & Not relevant to public health or health promotion \\
\hline Sallis 1997 & Not a randomized controlled trial \\
\hline Salmon 2005 & Data on relevant outcomes for children aged 6 to 18 yearsnot reported \\
\hline Salmon 2010 & Data on relevant outcomes for children aged 6 to 18 yearsnot reported \\
\hline Samples 2010 & Data on relevant outcomes for children aged 6 to 18 yearsnot reported \\
\hline Santiago 2007 & Intervention not aimed at promoting physical activity \\
\hline Sasaki 1987 & Intervention not aimed at promoting physical activity \\
\hline Schneider 2007 & Weak methodological rating \\
\hline Schneider 2009 & Data on relevant outcomes for children aged 6 to 18 yearsnot reported \\
\hline Schofield 2005 & Weak methodological rating \\
\hline Schuldheisz 1998 & No control group \\
\hline Schwarzer 2010 & Not a randomized controlled trial \\
\hline Scott 1988 & $\begin{array}{l}\text { Intervention not aimed at promoting physical activity. Data on relevant outcomes for children aged } \\
6 \text { to } 18 \text { yearsnot reported. No control group }\end{array}$ \\
\hline Sharma 2009 & Not a randomized controlled trial \\
\hline Shaw 1989 & $\begin{array}{l}\text { Data on relevant outcomes for children aged } 6 \text { to } 18 \text { yearsnot reported. Intervention not school } \\
\text { based. Intervention not aimed at promoting physical activity. No control group }\end{array}$ \\
\hline Shea 1996 & Data on relevant outcomes for children aged 6 to 18 yearsnot reported \\
\hline Shek 2008 & Intervention not aimed at promoting physical activity \\
\hline Shephard 1992 & Not relevant to public health or health promotion \\
\hline
\end{tabular}




\begin{tabular}{|c|c|}
\hline Study & Reason for exclusion \\
\hline Shephard 1996 & Weak methodological rating \\
\hline Shimon 2009 & Data on relevant outcomes for children aged 6 to 18 yearsnot reported \\
\hline Shingo 2002 & Not relevant to public health or health promotion \\
\hline Siegel 1984 & Intervention not school based \\
\hline Siegrist 2011 & Data on relevant outcomes for children aged 6 to 18 yearsnot reported \\
\hline Simonetti 1986 & Intervention not aimed at promoting physical activity \\
\hline Singh 2007 & Weak methodological rating \\
\hline Skybo 2002 & Weak methodological rating \\
\hline Slawta 2004 & No control group \\
\hline Slootmaker 2010 & $\begin{array}{l}\text { Intervention not aimed at whole school population (only low active children were included in the } \\
\text { study) }\end{array}$ \\
\hline Smith 2009 & Not a randomized controlled trial \\
\hline Smith 2011 & Intervention not school based \\
\hline Sobczyk 1995 & Data on relevant outcomes for children aged 6 to 18 yearsnot reported \\
\hline Sollerhed 2008 & Not a randomized controlled trial \\
\hline Soong 1997 & Not relevant to public health or health promotion \\
\hline Sothern 1993 & Not relevant to public health or health promotion \\
\hline Sothern 1999 & Not relevant to public health or health promotion \\
\hline Sothern 2001 & Not relevant to public health or health promotion \\
\hline Spence 1997 & Not relevant to public health or health promotion \\
\hline Speroni 2007 & Not a randomized controlled trial \\
\hline Spiegel 2006 & Weak methodological rating \\
\hline Standage 2005 & Not a randomized controlled trial \\
\hline Stergioulas 1998 & Not relevant to public health or health promotion \\
\hline Stewart 1997 & Data on relevant outcomes for children aged 6 to 18 yearsnot reported \\
\hline Stewart 2004 & Data on relevant outcomes for children aged 6 to 18 yearsnot reported \\
\hline Stock 2007 & Not a randomized controlled trial \\
\hline Stone 1998 & Not relevant to public health or health promotion \\
\hline
\end{tabular}




\begin{tabular}{|c|c|}
\hline Study & Reason for exclusion \\
\hline Stone 1989 & Not relevant to public health or health promotion \\
\hline Stone 1995 & Not relevant to public health or health promotion \\
\hline Stratton 2000 & Weak methodological rating \\
\hline Stratton 2005 & Not a randomized controlled trial \\
\hline Strazzullo 1988 & Not relevant to public health or health promotion \\
\hline Strong 2005 & Not a randomized controlled trial \\
\hline Tak 2007 & Intervention not aimed at general population (overweight/obese-only sample) \\
\hline Tamir 1990 & Weak methodological rating \\
\hline Tavener 1993 & No control group \\
\hline Taylor 2006 & Not a randomized controlled trial \\
\hline Taylor 2007 & Not a randomized controlled trial \\
\hline Taymoori 2008 & Intervention not school based \\
\hline Taymoori 2008a & Intervention not school based. \\
\hline Teerarungsikul 2009 & Not a randomized controlled trial. \\
\hline Telford 2009 & Not a randomized controlled trial \\
\hline Thakor 2004 & Not relevant to public health or health promotion \\
\hline Theodorakis 2008 & Data on relevant outcomes for children aged 6 to 18 yearsnot reported \\
\hline Thomas 2007 & Not a randomized controlled trial \\
\hline Tolfrey 1998 & Intervention not school based \\
\hline Tolfrey 2004 & Intervention not school based \\
\hline Toruner 2010 & Not a randomized controlled trial \\
\hline Trevino 1998 & Not a randomized controlled trial \\
\hline Trost 1997 & Not relevant to public health or health promotion \\
\hline Trost 1999a & Not relevant to public health or health promotion \\
\hline Trost 1999b & Not relevant to public health or health promotion \\
\hline Trudeau 1999 & Not a randomized controlled trial \\
\hline Trudeau 2008 & Not a randomized controlled trial \\
\hline Tsai 2009 & Not a randomized controlled trial \\
\hline
\end{tabular}




\begin{tabular}{|c|c|}
\hline Study & Reason for exclusion \\
\hline Tsorbatzoudis 2005 & Weak methodological rating \\
\hline Tuckman 1986 & Weak methodological rating \\
\hline Tudor-Locke 2001 & Not relevant to public health or health promotion \\
\hline Tudor-Locke 2006 & Not a randomized controlled trial \\
\hline Turnbull 2004 & Not a randomized controlled trial \\
\hline Uzunovic 2008 & Intervention not school based \\
\hline Vaccaro 1989 & Not relevant to public health or health promotion \\
\hline Valverde 1998 & Not relevant to public health or health promotion \\
\hline van Beurden 2003 & Weak methodological rating. \\
\hline van Mil 1999 & Not relevant to public health or health promotion. \\
\hline Velez 2010 & Outcome data on outcomes relevant to this review not reported \\
\hline Venditti 2009 & Data on relevant outcomes for children aged 6 to 18 yearsnot reported \\
\hline Verderber 2001 & Not relevant to public health or health promotion \\
\hline Verstraete 2007 & Weak methodological rating \\
\hline Verstraete $2007 a$ & $\begin{array}{l}\text { The type of outcome data collected for physical activity outcomes is this study is too different from } \\
\text { how it was measuered by included studies, therefore cannot be synthesized with the included }\end{array}$ \\
\hline Veugelers 2005 & Weak methodological rating. \\
\hline Vissers 2008 & Intervention not aimed at general population (overweight/obese-only sample) \\
\hline Walton 1999 & Not relevant to public health or health promotion \\
\hline Wang 2006 & Data on relevant outcomes for children aged 6 to 18 yearsnot reported \\
\hline Wang 2006a & Data on relevant outcomes for children aged 6 to 18 yearsnot reported \\
\hline Warren 2003 & Data on relevant outcomes for children aged 6 to 18 yearsnot reported \\
\hline Watts 2004 & Data on relevant outcomes for children aged 6 to 18 yearsnot reported \\
\hline Weber 1989 & Data on relevant outcomes for children aged 6 to 18 yearsnot reported \\
\hline Weber Cullen 1999 & Data on relevant outcomes for children aged 6 to 18 yearsnot reported \\
\hline Wechsler 2000 & Not a randomized controlled trial \\
\hline Weintraub 2008 & Intervention not aimed at general population (overweight/obese-only sample) \\
\hline Wen 2008 & Data on relevant outcomes for children aged 6 to 18 yearsnot reported \\
\hline
\end{tabular}




\begin{tabular}{|c|c|}
\hline Study & Reason for exclusion \\
\hline Werch 2005 & Weak methodological rating \\
\hline Werner 1988 & Weak methodological rating \\
\hline Westcott 1995 & Not relevant to public health or health promotion \\
\hline Wharf Higgins 2001 & $\begin{array}{l}\text { Intervention not aimed at promoting physical activity. Data on relevant outcomes for children aged } \\
6 \text { to } 18 \text { yearsnot reported. No control group }\end{array}$ \\
\hline Williden 2006 & Not a randomized controlled trial \\
\hline Wilson 2005 & Weak methodological rating \\
\hline Wilson 2006 & Not a randomized controlled trial \\
\hline Wilson 2008 & Data on relevant outcomes for children aged 6 to 18 yearsnot reported \\
\hline Wing 1998 & $\begin{array}{l}\text { Data on relevant outcomes for children aged } 6 \text { to } 18 \text { yearsnot reported. Intervention not school } \\
\text { based. }\end{array}$ \\
\hline Winters 2003 & No control group \\
\hline Wong 2008 & Intervention not aimed at general population (overweight/obese-only sample) \\
\hline Yin 2005 & Weak methodological rating \\
\hline Yopp Cohen 1989 & Not relevant to public health or health promotion \\
\hline Young 2006a & Weak methodological rating \\
\hline Young 2007 & Not a randomized controlled trial \\
\hline Zahner 2006 & Data on relevant outcomes for children aged 6 to 18 yearsnot reported \\
\hline Zeelie 2010 & Intervention duration less than 3 months \\
\hline Zizzi 2006 & Weak methodological rating \\
\hline Zonderland 1994 & Weak methodological rating \\
\hline Zuckerman 1989 & No control group \\
\hline
\end{tabular}

\section{ADDITIONAL TABLES}

Table 1. Overview of study populations

\begin{tabular}{|c|c|c|c|c|}
\hline $\begin{array}{l}\text { Characteristic } \\
\text { Study ID }\end{array}$ & $\begin{array}{l}\text { Intervention(s) and } \\
\text { control(s) }\end{array}$ & [n] randomized & $\begin{array}{l}\text { [n] finishing } \\
\text { study }\end{array}$ & $\begin{array}{l}\text { [\%] of random- } \\
\text { ized partici- } \\
\text { pants } \\
\text { finishing study }\end{array}$ \\
\hline $\begin{array}{l}\text { Angelopoulos } \\
2009\end{array}$ & $\begin{array}{l}\text { I: } 12 \text {-month program integrated into the existing } \\
\text { curriculum including: student workbook, teacher }\end{array}$ & - & I: 321 & - \\
\hline
\end{tabular}


Table 1. Overview of study populations (Continued)

manual; covering themes: self-esteem, body im-

age, nutrition, PA, fitness, environmental issues.

Implemented for 1 to 2 hours per week with moti-

$\mathrm{T}: 646$ vational methods used for increasing knowledge, skills and self-efficacy and improving self-monitoring and social influence. School teachers trained by the research team delivered the intervention. Parental involvement (reinforcement) was required to complete some (unspecified) home activities

C: not specified

Araujo-Soares
2009

$\begin{array}{lll}\text { I: } 157 & \text { I: } 105 & \text { I: } 67 \\ \text { C: } 134 & \text { C: } 90 & \text { C: } 67 \\ \text { T: } 291 & \text { T: } 195 & \text { T: } 67\end{array}$

\begin{abstract}
I: 2 × 90-min PA sessions with related homework. A trained psychologist delivered the intervention, assisted by a sports education teacher. A research team member supervised preparation for each session, before which each student was asked to keep a diary for a period of 1 week. After the intervention they were asked to keep the diary for an additional 2 weeks. Worksheets and a 3-min film were used, and each student received a leaflet with main topics

\section{C: not specified}

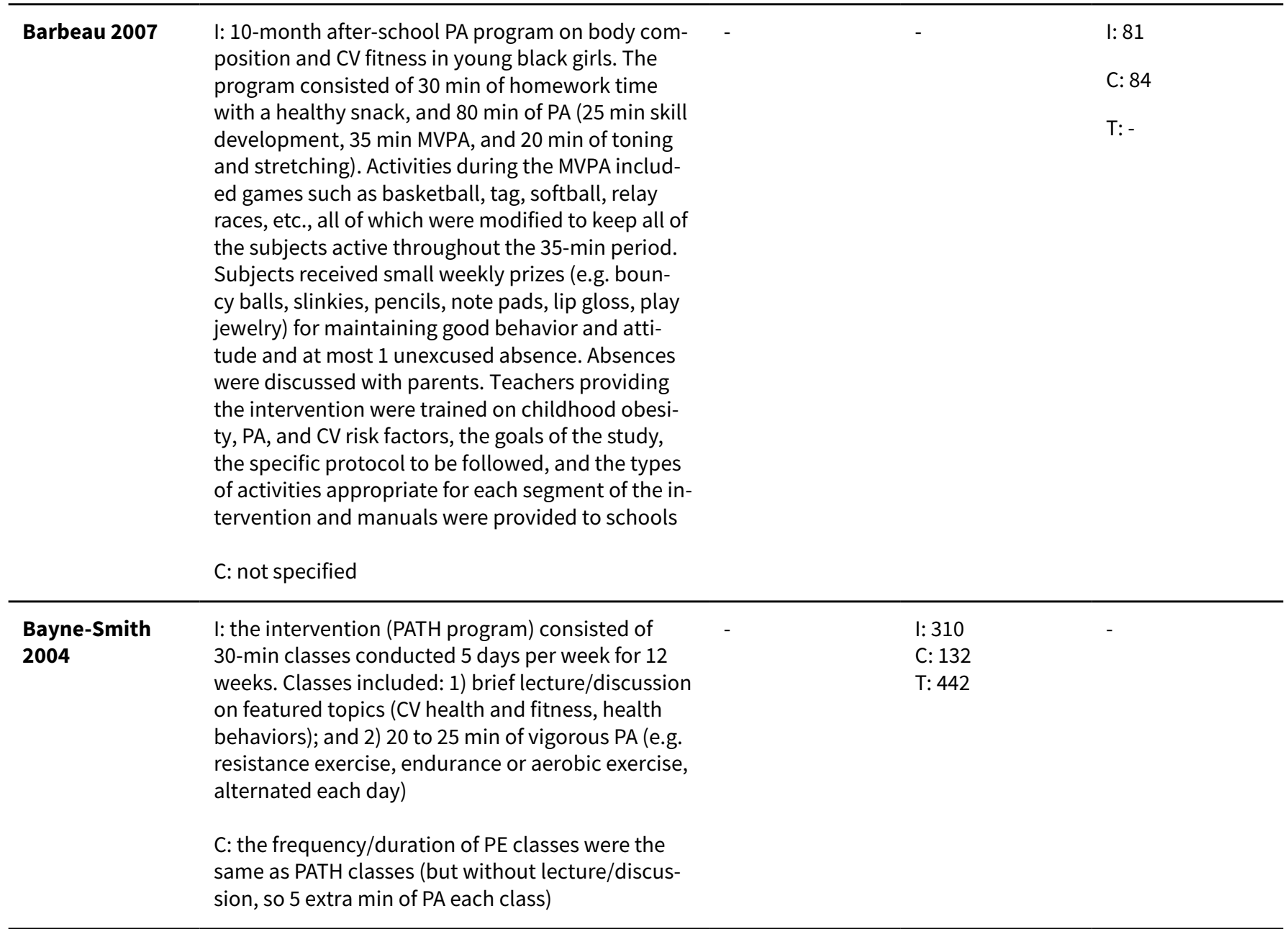


Table 1. Overview of study populations (Continued)

Burke $1998 \quad 11$ : standard PA and nutrition program (WASPAN). Classroom lessons, 20-min fitness sessions daily (minimum 4/week). Nutrition program built around 4 comic books to teach children and parents how to improve diets, plus $1 \mathrm{~h} /$ week nutrition classes

12: standard WASPAN program plus a PA enrichment program for higher-risk children. Incoprorated teacher-parent-student triad, moved PA activities outside of the class and focused on the individual. Children kept weekly diaries

C: no program

$\begin{array}{lll}\text { I: }- & \text { I: }- & \text { I: }- \\ \text { C: }- & \text { C: } & \text { C: }- \\ \text { T: } 800 & \text { T: } 720 & \text { T: } 90\end{array}$

Bush 1989 I1: 'Know Your Body' curriculum focusing on nutri-
tion, fitness, and prevention of smoking. Students
also receive a personalized health screening and
results on a 'health passport'. Parents are mailed
copies of their child's results and kept informed
by a quarterly newsletter and an introductory Par-
ent-Teacher meeting
I2: 'Know Your Body' curriculum and health
screening, but students do not receive the results
of their screening, only their parents receive the re-
sults
C: health screening only, parents only receive re-
sults of screening

Colin-Ramirez
2010

I: RESCATE program, included PA and nutritional components. PA addressed at individual (curriculum), school (PE sessions) and family level (homework and recommendations for parents)

$\begin{array}{lll}\text { I:- } & \text { I: }- & \text { I: }- \\ \text { C: }-892 & \text { C: }- & \text { C: }- \\ \text { T: } 431 & \text { T: } 48\end{array}$

C: no PA/nutrition program

$\begin{array}{lll}\text { I: }- & \text { I: } 245 & \text { I: }- \\ \text { C: }- & \text { C: } 253 & \text { C: }- \\ \text { T: } 619 & \text { T: } 498 & \text { T: } 81\end{array}$

\begin{tabular}{|c|c|c|c|c|}
\hline \multirow[t]{2}{*}{ Dishman 2004} & $\begin{array}{l}\text { I: Lifestyle Education for Activity Program (LEAP). } \\
\text { Aimed to increase girls' self efficacy for PA, via: } \\
\text { PE, school environment, health education, school } \\
\text { health services, faculty or staff health promotion, } \\
\text { and parent and community involvement }\end{array}$ & $\begin{array}{l}\text { I: } 1523 \\
\text { C: } 1221 \\
\text { T: } 2744\end{array}$ & $\begin{array}{l}\text { I: - } \\
\text { C: - } \\
\text { T: } 2111\end{array}$ & $\begin{array}{l}\text { I: - } \\
\text { C: - } \\
\text { T: } 77\end{array}$ \\
\hline & C: standard PE as part of school curriculum & & & \\
\hline
\end{tabular}

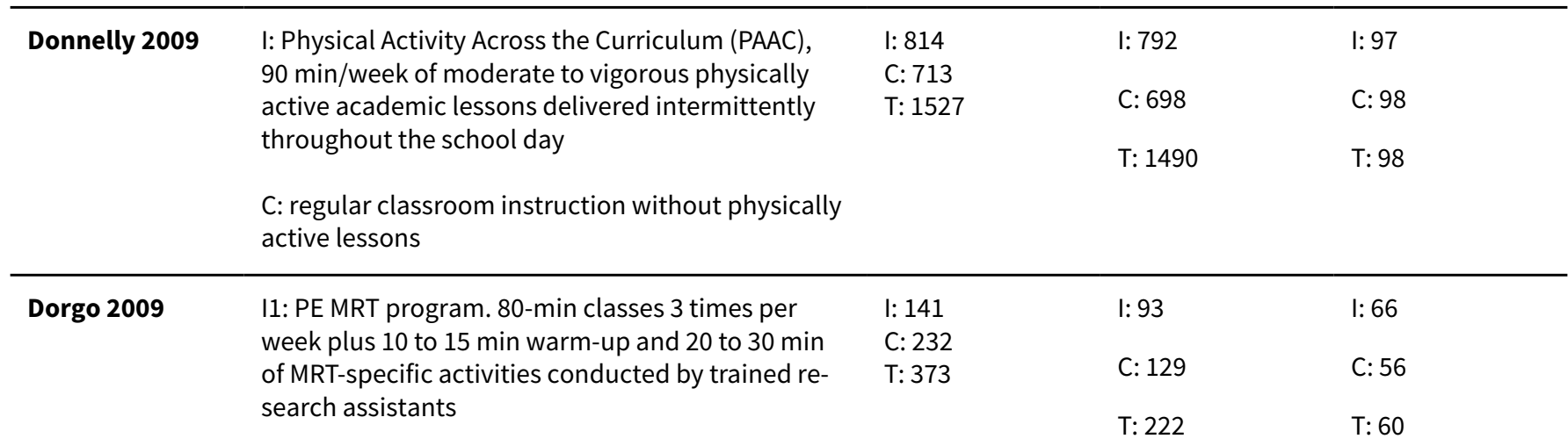


Table 1. Overview of study populations (Continued)

12: PE MRT program plus a CV endurance training segment in every session including: walking, jogging, step aerobics, and aerobic kickboxing

C: a regular PE program that followed the usual school curriculum. 80-min classes 3 times per week

$\begin{array}{ll}\text { Ewart } 1998 & \text { I: 50-min 'Project Heart' aerobic exercise classes in- } \\ \text { cluding didactic instruction. }\end{array}$
cluding didactic instruction.

$\begin{array}{lll}\text { I: } 45 & \text { I: } 44 & \text { I: } 99 \\ \text { C: } 54 & \text { C: } 44 & \text { C: } 82 \\ \text { T: } 99 & \text { T: } 88 & \text { T: } 89\end{array}$

\section{C: 50-min standard PE classes}

$\begin{array}{lll}\text { I: } 670 & \text { I: }- & \text { I: }- \\ \text { C: } 653 & \text { C: }- & \text { C: }- \\ \text { T: } 1323 & \text { T: } 1029 & \text { T: } 78\end{array}$ more per day. Included 3 ecologic levels (family, school, community)
I: 'Switch' program, promoted healthy active lifestyles including: being active for 60 min or more per day, limiting total screen time to 2 hours or fewer per day, and eating 5 fruits/vegetables or
C: no intentional exposure to the Switch program

\section{Haerens 2006}

$\begin{array}{lll}\text { I: } 2105 & \text { I: }- & \text { I: }- \\ \text { C: } 735 & \text { C: }- & \text { C: }- \\ \text { T: } 2840 & \text { T: } 2434 & \text { T: } 86\end{array}$
tion, increase water consumption, and reduce fat. A computer-tailored intervention assessed children's PA activities and provided tailored feedback

12: PA and nutrition intervention (same as I1 group) plus parental involvement, including: an interactive meeting on healthy food and PA, a newsletter 3 times/year, and a CD with an adult computer-tailored intervention (same as the children's computer-tailored intervention) for use at home

C: no PA and nutrition intervention

\begin{tabular}{|c|c|c|c|c|}
\hline Haerens 2009 & $\begin{array}{l}\text { I: computer-tailored PA program consisting of a de- } \\
\text { mographic questionnaire, a PA questionnaire and } \\
\text { a questionnaire on psychosocial determinants fol- } \\
\text { lowed by tailored feedback that related students' } \\
\text { PA levels to the PA guidelines } \\
\text { C: generic information on the benefits of PA, pub- } \\
\text { lic health recommendations, differences between } \\
\text { moderate and vigorous intensity activities and tips } \\
\text { on how to become more active }\end{array}$ & $\begin{array}{l}\text { I: } 563 \\
\text { C: } 608 \\
\text { T: } 1171\end{array}$ & $\begin{array}{l}\text { I: } 433 \\
\text { C: } 448 \\
\text { T: } 881\end{array}$ & $\begin{array}{l}\text { I: } 77 \\
\text { C: } 74 \\
\text { T: } 75\end{array}$ \\
\hline Jones 2008 & $\begin{array}{l}\text { I: included: } 1 \text { ) a health curriculum (classroom } \\
\text { lessons and behavioral journalism - during } 6 \text { th } \\
\text { grade, } 16 \text { sessions during PE classes, } 3 \text { times per } \\
\text { week; during } 7 \text { th grade, science-based lessons dur- } \\
\text { ing science class); } 2 \text { ) a PE program; and } 3 \text { ) a school } \\
\text { food service component, emphasizing calcium-rich } \\
\text { food } \\
\text { C: the control group participated in the usual } \\
\text { health program }\end{array}$ & $\begin{array}{l}\text { I: } 347 \\
\text { C: } 371 \\
\text { T: } 718\end{array}$ & $\begin{array}{l}\text { I: } 291 \\
\text { C: } 315 \\
\text { T: } 606\end{array}$ & $\begin{array}{l}\text { I: } 84 \\
\text { C: } 85 \\
\text { T: } 84\end{array}$ \\
\hline
\end{tabular}


Table 1. Overview of study populations (Continued)

\begin{tabular}{|c|c|c|c|c|}
\hline Kipping 2008 & $\begin{array}{l}\text { I: included: } 16 \text { lessons on healthy eating, increas- } \\
\text { ing PA and reducing television viewing taught over } \\
5 \text { months by } 10 \text { specifically trained teachers. Mate- } \\
\text { rials provided to the schools included: lesson plans } \\
\text { for } 9 \text { PA lessons, } 6 \text { nutrition lessons and } 1 \text { lesson } \\
\text { about screen viewing } \\
\text { C: the control schools were given the materials on- } \\
\text { ly after the completion of the study }\end{array}$ & $\begin{array}{l}\text { I: } 331 \\
\text { C: } 348 \\
\text { T: } 679\end{array}$ & $\begin{array}{l}\text { I: } 304 \\
\text { C: } 300 \\
\text { T: } 604\end{array}$ & $\begin{array}{l}\text { I: } 92 \\
\text { C: } 86 \\
\text { T: } 89\end{array}$ \\
\hline Kriemler 2010 & $\begin{array}{l}\text { I: the intervention was a multicomponent PA pro- } \\
\text { gram that included: } 1 \text { ) } 3 \text { existing } 45-\text {-min PE lessons } \\
\text { per week; 2) } 2 \text { additional 45-min PE lessons per } \\
\text { week; 3) daily short activity breaks; and 4) PA } \\
\text { homework } \\
\text { C: the control group participated in the usual, } \\
\text { mandatory PE lessons (45-min, } 3 \text { times/week) }\end{array}$ & $\begin{array}{l}\text { I: } 305 \\
\text { C: } 235 \\
\text { T: } 540\end{array}$ & $\begin{array}{l}\text { I: } 297 \\
\text { C: } 205 \\
\text { T: } 502\end{array}$ & $\begin{array}{l}\text { I: } 97 \\
\text { C: } 87 \\
\text { T: } 93\end{array}$ \\
\hline Li 2010 & $\begin{array}{l}\text { I: the intervention (TAKE } 10 \text { ! Program) included } 2 \\
\text { daily } 10 \text {-min PA sessions: } 1 \text { ) the teacher or student } \\
\text { selected } 1 \text { to } 3 \text { activity cards; } 2 \text { ) several children } \\
\text { modeled the exercises, the other students followed } \\
\text { along; } 3 \text { ) cool-down period; and 4) the students } \\
\text { were taught a health message } \\
\text { C: no intervention took place }\end{array}$ & $\begin{array}{l}\text { I: } 2371 \\
\text { C: } 2329 \\
\text { T: } 4700\end{array}$ & $\begin{array}{l}\text { I: } 2092 \\
\text { C: } 2028 \\
\text { T:4210 }\end{array}$ & $\begin{array}{l}\text { I: } 88 \\
\text { C: } 87 \\
\text { T: } 88\end{array}$ \\
\hline Lubans 2009 & $\begin{array}{l}\text { I: included: } 1 \text { ) 10-week school sport program and } \\
\text { exercise program booklet; } 2 \text { ) information sessions; } \\
\text { 3) PA and dietary monitoring using pedometers } \\
\text { and diaries; 4) program X weekly messages and } \\
\text { parent information leaflets; and 5) email support } \\
\text { C: the control group attended a 10-week school } \\
\text { sport program and received an exercise program } \\
\text { booklet }\end{array}$ & $\begin{array}{l}\text { I: } 58 \\
\text { C: } 66 \\
\text { T: } 124\end{array}$ & $\begin{array}{l}\text { I: } 53 \\
\text { C: } 53 \\
\text { T: } 106\end{array}$ & $\begin{array}{l}\text { I: } 91 \\
\text { C: } 80 \\
\text { T: } 86\end{array}$ \\
\hline Luepker 1996 & $\begin{array}{l}\text { I1: group received a school-based program consist- } \\
\text { ing of school food service modifications, PE inter- } \\
\text { ventions, and the CATCH curricula } \\
\text { I2: group received the same school-based program } \\
\text { plus a family-based program } \\
\text { C: group received the usual health curricula, PE, } \\
\text { and food service programs, but none of the CATCH } \\
\text { interventions }\end{array}$ & $\begin{array}{l}\text { I: } 3651 \\
\text { C: } 1455 \\
\text { T: } 5106\end{array}$ & $\begin{array}{l}\text { I: } 3297 \\
\text { C: } 722 \\
\text { T: } 4019\end{array}$ & $\begin{array}{l}\text { I: } 90 \\
\text { C: } 50 \\
\text { T: } 79\end{array}$ \\
\hline Martinez 2008 & $\begin{array}{l}\text { I: received: } 1 \text { ) the standard, compulsory PE curricu- } \\
\text { lum ( } 3 \text { hours per week of low-to-moderate intensi- } \\
\text { ty activity); } 2 \text { ) recreational, noncompetitive, after } \\
\text { school PA program ( } 3 \text { x 90-min sessions per week, } \\
\text { for } 24 \text { weeks) } \\
\text { C: received the standard, compulsory PE curricu- } \\
\text { lum: } 3 \text { hours per week of PA at low-to-moderate in- } \\
\text { tensity }\end{array}$ & $\begin{array}{l}\text { I: } 691 \\
\text { C: } 718 \\
\text { T: } 1409\end{array}$ & $\begin{array}{l}\text { I: } 465 \\
\text { C: } 579 \\
\text { T: } 1044\end{array}$ & $\begin{array}{l}\text { I: } 67 \\
\text { C: } 81 \\
\text { T: } 74\end{array}$ \\
\hline
\end{tabular}


Table 1. Overview of study populations (Continued)

\begin{abstract}
McManus $2008 \quad$ I1: Educational Program Group completed a 2week education program, taught using an active game approach, that included: information about heart health, the use of heart rate feedback to attain an activity target, goal-setting and role-play. They then completed 2-weeks with heat rate feedback and 2-weeks without heart rate feedback

12: No-education Program Group completed a 2week control program of standard PE classes without PA or heart health education. They then completed 2-weeks with heart rate feedback and 2weeks without heart rate feedback but were not given any information about the heart rate signal or its meaning

C: no intervention took place
\end{abstract}
I: 128
I: 125
I: 98
C: 69
C: 68
C: 99
T: 193
T: 98

$\begin{array}{ll}\begin{array}{l}\text { Neumark-Sz- } \\ \text { tainer 2009 }\end{array} & \text { I: included: (i) } 14 \times 2 \text {-hour after-school theater } \\ & \text { sessions (which included: check-in, snack, move- } \\ & \text { ment component, theatrical activity - the final ses- } \\ \text { sions focused on rehearsing for a play performance } & \text { (script developed throughout intervention)); (ii) } \\ & 8 \text { weekly after-school booster sessions (activi- } \\ & \text { ties related to healthy eating and PA, rehearsals } \\ & \text { for play); and (iii) family outreach component (to } \\ & \text { enhance home support for behavioral changes } \\ & \text { through positive reinforcement of healthy behav- } \\ & \text { iors, parent-child participation in PAs and avail- } \\ \text { ability of healthy foods) - take home materials, } & \text { family events }\end{array}$

C: a theater-based control condition (i.e. children participated in a play focused on environmental health issues using a prepared script)

\section{Neumark-Sz- tainer 2010

\begin{abstract}
I: participation in the standard all-girls PE class that was supplemented with the New Moves curriculum (nutrition and self-empowerment compoviewing, lunch meetings, and parent outreach)

C: participation in all-girls PE class (during first semester of school year)
\end{abstract} nents, individual sessions using motivational inter-}

$\begin{array}{lll}\text { I: } 56 & \text { I: } 51 & \text { I: } 91 \\ \text { C: } 52 & \text { C: } 45 & \text { C: } 87 \\ \text { T: } 108 & \text { T: } 96 & \text { T: } 89\end{array}$

$\begin{array}{lll}\text { I: } 182 & \text { I: } 177 & \text { I: } 97 \\ \text { C: } 174 & \text { C: } 159 & \text { C: } 91 \\ \text { T: } 356 & \text { T: } 336 & \text { T: } 94\end{array}$

$\begin{array}{lll}\text { I: } 16 & \text { I: } 16 & \text { I: } 100 \\ \text { C: } 17 & \text { C: } 16 & \text { C: } 94 \\ \text { T: } 33 & \text { T: } 32 & \text { T: } 97\end{array}$


Table 1. Overview of study populations (Continued)

tent, motivating them, and suggesting strategies to engage the family in healthy behaviors

C: participated in $16 \times 60$-min PA curriculum at the same time as the intervention group, with a school $\mathrm{PE}$ teacher facilitating the control group

\begin{tabular}{|c|c|}
\hline Petchers 1988 & $\begin{array}{l}\text { I: Chicago Heart Health Curriculum Program called } \\
\text { "Body Power": a 1-year-long curriculum with mod- } \\
\text { ules on } 5 \text { topics: } 1 \text { ) CV system, anatomy, and phys- } \\
\text { iology; } 2 \text { ) smoking; 3) nutrition; 4) exercise; and 5) } \\
\text { risk factors review. The curriculum was implement- } \\
\text { ed by classroom teachers during at least } 3 \times 45-m i n \\
\text { sessions per week for } 4 \text { to } 6 \text { weeks, with training } \\
\text { provided for teachers and supplemented by a com- } \\
\text { prehensive teachers' manual }\end{array}$ \\
\hline & $\begin{array}{l}\text { C: traditional curriculum with approximately the } \\
\text { same amount of teaching time. Control group } \\
\text { teachers were provided an alternative experience } \\
\text { to the training sessions for the intervention group } \\
\text { in the form of a separate in-service }\end{array}$ \\
\hline
\end{tabular}

\section{Reed 2008 I: The Action Schools! BC model was consistent} with the 'active school' framework and emphasized an integrated whole-school approach rather

I: -

C: -

$\mathrm{T}: 452$

I: -

C: -

I: -

T:452

$\mathrm{T}: 325$

C: -

$\mathrm{T}: 72$ than traditional classroom-based health education, targeting 6 Action Zones: i) School Environment, ii) Scheduled Physical Education, iii) Extracurricular, (iv) School Spirit, v) Family and Community, and vi) Classroom Action. Classroom Action included 15 min of moderate to intense PA daily $(75$ min of extra PA per week in addition to $2 x$ 40 min PE classes). Teachers provided opportunities to 'snack on physical activities' such as skipping, dancing, and resistance exercises throughout the day. A school Action Team was convened in each school with a facilitator who helped to design a program with activities across the 6 Action Zones. INT teachers received a 1-day training workshop and a Classroom Action Bin with resources, with the goal for each school to provide students with 150 min of PA/week ( $2 \times 40$ min PE classes +15 x $5 \mathrm{~min}$ /day Classroom Action)

C: teachers in usual practice schools continued the regular program of PE and school-based PA

\begin{tabular}{|c|c|c|c|c|}
\hline Robinson 1999 & $\begin{array}{l}\text { I: limited access to television use and budgeting } \\
\text { television time and involved } 18 \text { lessons of } 30 \text { to } 50 \\
\text { min as part of standard curriculum, taught by reg- } \\
\text { ular classroom teachers trained by research staff. } \\
\text { Most lessons occurred in the first } 2 \text { months of the } \\
\text { year and included self-monitoring and self-report- } \\
\text { ing for television and video game use followed by } \\
\text { a } 10 \text {-day television turnoff challenge after which } \\
\text { students were encouraged to follow a } 7 \text {-h per week } \\
\text { budget. Newsletters designed to help parents mo- } \\
\text { tivate students and regulate time spent on televi- } \\
\text { sion and video games for the entire family were dis- }\end{array}$ & $\begin{array}{l}\text { I: } 106 \\
\text { C: } 121 \\
\text { T: } 227\end{array}$ & $\begin{array}{l}\text { I: } 92 \\
\text { C: } 100 \\
\text { T: } 192\end{array}$ & $\begin{array}{l}\text { I: } 87 \\
\text { C: } 83 \\
\text { T: } 85\end{array}$ \\
\hline
\end{tabular}


Table 1. Overview of study populations (Continued)

tributed. Each household received television time

master(s) to regulate television and video use

C: not specified

\begin{tabular}{|c|c|c|c|c|}
\hline Salmon 2008 & $\begin{array}{l}\text { I: students were assigned to } 1 \text { of } 4 \text { conditions: a be- } \\
\text { havioral modification group }(\mathrm{N}=69) \text {; a fundamen- } \\
\text { tal motor skills group }(\mathrm{N}=73) \text {; a combined behav- } \\
\text { ioral modification and fundamental motor skills } \\
\text { group ( } \mathrm{N}=90) \\
\text { C: usual classroom lessons }\end{array}$ & $\begin{array}{l}\text { I: } 233 \\
\text { C: } 62 \\
\text { T: } 295\end{array}$ & $\begin{array}{l}\text { I: } 213 \\
\text { C: } 55 \\
\text { T: } 268\end{array}$ & $\begin{array}{l}\text { I: } 91 \\
\text { C: } 89 \\
\text { T: } 91\end{array}$ \\
\hline Simon 2004 & $\begin{array}{l}\text { I: the ICAPS program was implemented over } 4 \text { aca- } \\
\text { demic years to promote PA inside and outside. The } \\
\text { intervention includes an educational component } \\
\text { focusing on PA and sedentary behaviors, new op- } \\
\text { portunities for PA during and after school hours. } \\
\text { Activities implemented are either informal or aca- } \\
\text { demic with emphasis on fun, well-being, noncom- } \\
\text { petitiveness. Sporting events, bicycle, and on-foot } \\
\text { transport are organized } \\
\text { C: not specified }\end{array}$ & $\begin{array}{l}\text { I: - } \\
\text { C: - } \\
\text { T: } 1046\end{array}$ & $\begin{array}{l}\text { I: } 475 \\
\text { C: } 479 \\
\text { T: } 954\end{array}$ & $\begin{array}{l}\text { I: - } \\
\text { C: - } \\
\text { T: } 91\end{array}$ \\
\hline Singh 2009 & $\begin{array}{l}\text { I: an interdisciplinary program with adapted cur- } \\
\text { riculum including an individual component ( } 11 \\
\text { lessons in biology and PE) and environmental } \\
\text { change component including encouragement for } \\
\text { schools to increase PE and provision of advice for } \\
\text { schools related to cafeteria changes } \\
\text { C: regular curriculum }\end{array}$ & $\begin{array}{l}\text { I: - } \\
\text { C: - } \\
\text { T: } 1053\end{array}$ & $\begin{array}{l}\text { I: - } \\
\text { C: - } \\
\text { T: } 875\end{array}$ & $\begin{array}{l}\text { I: - } \\
\text { C: - } \\
\text { T: } 83\end{array}$ \\
\hline Singhal 2010 & $\begin{array}{l}\text { I: multicomponent intervention with } 7 \text { compo- } \\
\text { nents related to nutrition and lifestyle education, } \\
\text { including the following activities: dissemination of } \\
\text { health-related information through lectures and fo- } \\
\text { cused group discussions ( } 24 \text { weeks ( } 6 \text { months) of } \\
\text { nutrition education), promotion of PA, other pro- } \\
\text { motion of healthy lifestyle, individual counseling, } \\
\text { policy-level changes in schools, involvement of } \\
\text { teachers and parents, training of student volun- } \\
\text { teers for program sustainability } \\
\text { C: no intervention }\end{array}$ & $\begin{array}{l}\text { I: } 101 \\
\text { C: } 108 \\
\text { T: } 209\end{array}$ & $\begin{array}{l}\text { I: } 99 \\
\text { C:102 } \\
\text { T: } 201\end{array}$ & $\begin{array}{l}\text { I: } 98 \\
\text { C: } 94 \\
\text { T: } 96\end{array}$ \\
\hline Stephens 1998 & $\begin{array}{l}\text { I: } 18 \text { medical students delivered } 3 \text { activity ses- } \\
\text { sions per week, consisting of } 5 \text { min of warm-up and } \\
\text { stretching, plus } 20 \text { min of aerobic activity. Activities } \\
\text { incorporated repetitive movements of large muscle } \\
\text { groups, designed to elevate the pulse rate } 40 \text { to } 60 \\
\text { beats/min over resting level. Sessions ended with } \\
\text { a } 5 \text { to } 10 \text { min cool-down with presentation of edu- } \\
\text { cational material about nutrition, exercise, and dis- } \\
\text { ease prevention } \\
\text { C: students in the control classroom received no } \\
\text { additional PA beyond regular PE classes }\end{array}$ & $\begin{array}{l}\text { I: } 45 \\
\text { C: } 44 \\
\text { T: } 89\end{array}$ & - & - \\
\hline
\end{tabular}


Table 1. Overview of study populations (Continued)

\begin{tabular}{|c|c|c|c|c|}
\hline \multirow[t]{2}{*}{ Stone 2003} & $\begin{array}{l}\text { I: intervention program was implemented during } \\
\text { third through fifth grades, with } 4 \text { components in- } \\
\text { cluding: food service, skills-based classroom curric- } \\
\text { ula, family, and PE }\end{array}$ & $\begin{array}{l}\mathrm{I}: 879 \\
\mathrm{C}: 825 \\
\mathrm{~T}: 1704\end{array}$ & $\begin{array}{l}\text { I: } 644 \\
\text { C: } 653 \\
\text { T: } 1297\end{array}$ & $\begin{array}{l}\text { I: } 73 \\
\text { C: } 79 \\
\text { T: } 76\end{array}$ \\
\hline & C: not specified & & & \\
\hline Trevino 2004 & $\begin{array}{l}\text { I: } 50 \text { sessions of health programming re: } 3 \text { health } \\
\text { behavior messages associated with diabetes mel- } \\
\text { litus control (decreased dietary saturated fat in- } \\
\text { take, increase dietary fiber intake, increase PA). } \\
\text { Children were asked to set goals and keep records } \\
\text { of their accomplishments and were rewarded with } \\
\text { coupons from a store set up in the school }\end{array}$ & $\begin{array}{l}\text { I: } 969 \\
\text { C: } 1024 \\
\text { T: } 1993\end{array}$ & $\begin{array}{l}\text { I: } 619 \\
\text { C: } 602 \\
\text { T: } 1221\end{array}$ & $\begin{array}{l}\text { I: } 64 \\
\text { C: } 59 \\
\text { T: } 61\end{array}$ \\
\hline
\end{tabular}

Verstraete 2006 I: classes were provided game equipment (jump ropes, scoop sets, flying discs, balls, plastic hoops, juggling rings and beanballs, badminton racquets, beach paddles) and 'activity cards' demonstrating use of the equipment for use outdoors during recesses and lunch break

C: not specified
I: 122
C: 113
T: 235

\begin{tabular}{|c|c|c|c|c|}
\hline \multirow[t]{2}{*}{ Walter 1988} & $\begin{array}{l}\text { I: special curriculum targeting voluntary changes in } \\
\text { risk behavior in the area of diet, PA, and smoking, } \\
\text { taught in classrooms by specially trained regular } \\
\text { teachers for } \sim 2 \text { hours per week }\end{array}$ & $\begin{array}{l}\text { I: } 2075 \\
\text { C: } 1313 \\
\text { T: } 3388\end{array}$ & $\begin{array}{l}\text { I: } 961 \\
\text { C: } 871 \\
\text { T: } 1769\end{array}$ & $\begin{array}{l}\text { I: } 46 \\
\text { C: } 66 \\
\text { T: } 53\end{array}$ \\
\hline & C: not specified & & & \\
\hline
\end{tabular}

Walther 2009

I: 1 unit of PE (45 min) with at least 15 min of endurance training per school day, plus lessons on healthy lifestyle 1 per month

$\begin{array}{lll}\text { I: } 112 & \text { I: } 109 & \text { I: } 97 \\ \text { C: } 76 & \text { C: } 73 & \text { C: } 96 \\ \text { T: } 188 & \text { T: } 182 & \text { T: } 97\end{array}$

C: according to German standards, 2 units (each 45 $\mathrm{T}: 188$

$\mathrm{T}: 182$

T: 97 min) of PE per week are mandatory in all schools. 12 units ( 45 min per unit) of high-level endurance exercise training per week plus participation in competitive sporting events

\begin{tabular}{|c|c|}
\hline Wang 2008 & $\begin{array}{l}\text { I: 'FitKid' after-school program, } 2 \text {-h intervention } \\
\text { sessions (40-min academic enrichment activi- } \\
\text { ties and a healthy snack provided; } 80 \text { min of PA } \\
\text { designed to improve sport skills, aerobic fitness, } \\
\text { strength, and flexibility with a minimum of } 40 \text { min } \\
\text { were devoted to vigorous PA), offered } 5 \text { days a } \\
\text { week, instructed by certified school teachers and } \\
\text { paraprofessionals }\end{array}$ \\
\hline & C: not specified \\
\hline
\end{tabular}

Webber 2008

I: six TAAG health education lessons per school year to enhance behavioral skills known to influence PA participation (self-monitoring, setting goals for behavior change). Offered in 2 forms: 1 for a tradition-

$\begin{array}{lll}\text { I: } 603 & \text { I: } 260 & \text { I: } 43 \\ \text { C: } 584 & \text { C: } 265 & \text { C: } 45 \\ \text { T: } 1187 & \text { T: } 525 & \text { T: } 44\end{array}$
al classroom setting and 1 for PE class. Girls were

$\begin{array}{lll}\text { I: }- & \text { I: }- & \text { I: }- \\ \text { C: }- & \text { C: }- & \text { C: }- \\ \text { T: } 3502 & \text { T: } 3378 & \text { T: } 97\end{array}$


Table 1. Overview of study populations (Continued)

the focus of the intervention; however, health and PE classes were part of the usual school curriculum and most included boys as well

C: not specified

\begin{tabular}{ll}
\hline Weeks 2008 & $\begin{array}{l}\text { I: } 10 \text { min of directed jumping activity at the begin- } \\
\text { ning of every PE class (twice per week), designed } \\
\text { to apply loads to the skeleton at high strain magni- } \\
\text { tude, frequency, and rate, including: jumps, hops, } \\
\text { tuck-jumps, jump-squats, stride jumps, star jumps, } \\
\text { lunges, side lunges, and skipping } \\
\text { C: regular PE warm-ups and stretching at the be- } \\
\text { ginning of every PE class (twice per week), includ- } \\
\text { ing: brisk walking, light jogging, and stretching } \\
\text { Williamson 2007 } \\
\text { I: Healthy Eating and Exercise (HEE) program; goal } \\
\text { was to increase PA during the school day and at } \\
\text { home. Teachers were provided with containers } \\
\text { filled with indoor play supplies (e.g. balloons, bean } \\
\text { bags) and outdoor play supplies (e.g. balls, jump } \\
\text { ropes) to promote active play during class time and } \\
\text { recess. Posters encouraged the use of these PACs, } \\
\text { and brief lesson plans provided academic games } \\
\text { that used the supplies contained in the PACs } \\
\text { C: Alcohol/Drug/Tobacco abuse prevention (ADT) } \\
\text { program, designed with the goal of modifying chil- } \\
\text { dren's beliefs and attitudes regarding the use and } \\
\text { abuse of tobacco, alcohol, and illicit drugs so that } \\
\text { they reflected "healthier" values }\end{array}$ \\
\end{tabular}

\section{Wilson 2011}

\section{I: ACT, a 17-week program implemented for 2} hours, 3 days/week by a trained instructor. Three main components: homework/snack (30 min), MVPA activities ( $60 \mathrm{~min}$ ) that students selected each week, and a behavioral skills and motivational component (30 $\mathrm{min})$

C: The General Health Education Program (comparison program) focused on nutrition, stress management, drug prevention, and drop-out prevention (with no PA component), and consisted of a homework/snack ( $30 \mathrm{~min}$ ) and 3 hands-on activities related to general health (30 min each). The comparison program was held on the same days and times as the ACT intervention program

$\begin{array}{lll}\text { I: } 52 & \text { I: } 43 & \text { I: } 83 \\ \text { C: } 47 & \text { C: } 38 & \text { C: } 81 \\ \text { T: } 99 & \text { T: } 81 & \text { T: } 82\end{array}$

$\begin{array}{lll}\text { I: } 313 & \text { I: } 282 & \text { I: } 90 \\ \text { C: } 348 & \text { C: } 304 & \text { C: } 87 \\ \text { T: } 661 & \text { T: } 586 & \text { T: } 89\end{array}$

$\begin{array}{lll}\text { I: } 729 & \text { I: } 673 & \text { I: } 92 \\ \text { C: } 693 & \text { C: } 635 & \text { C: } 94 \\ \text { T: } 1422 & \text { T: } 1308 & \text { T: } 92\end{array}$

$\begin{array}{lll}\text { I: } 116 & \text { I: } 111 & \text { I: } 96 \\ \text { C: } 105 & \text { C: } 99 & \text { C: } 94 \\ \text { T: } 221 & \text { T: } 210 & \text { T: } 95\end{array}$

I: included information to make an informed decision about the personal benefits of a physically active lifestyle, develop problem-solving skills, and obtain support from others. Specific strategies taught by a trained teacher included: goal setting, problem-solving barriers, communication skills, reinforcement of goal achievement through internal and external rewards, and learning from relevant role models. The PA portion of the intervention was congruent with the school's PE curriculum - 1 semester of individual sports and 1 semester of team 
Table 1. Overview of study populations (Continued)

sports - taught 5 days per week. The family support component consisted of a family workshop, monthly newsletters, and adult-child homework assignments

C: standard PE class in which students were taught skills in individual and team sports. Similar to the intervention structure, 1 semester focused on individual sports and the other on team sports. Classes were taught by certified PE teachers employed by the school. Parents of participants in the standard $P E$ class also received monthly newsletters

\begin{tabular}{lll}
\hline Total & $I: 20,930$ & $I: 13,358$ \\
& $C: 15,897$ & $C: 10,163$ \\
& $T^{\star}: 45,191$ & $T^{\star}: 36,593$ \\
\hline
\end{tabular}

C: control; CV: cardiovascular; I: intervention; MRT: manual resistance training; MVPA: moderate to vigorous physical activity; PA: physical activity; PAC: physical activity center; PE: physical education; T: total.

"-" denotes not reported.

${ }^{*} T$ does not equal the sum of I and $\mathrm{C}$ as some studies did not report the breakdown of participants in each group.

\section{AP P E N D I CES}

\section{Appendix 1. Search strategies}

\section{Search terms and databases}

Unless otherwise stated, search terms are free text terms.

Abbreviations:

'\$': stands for any character; '?': substitutes one or no character; adj: adjacent (i.e. number of words within range of search term); exp: exploded MeSH; MeSH: medical subject heading (MEDLINE medical index term); pt: publication type; sh: MeSH; tw: text word.

\section{The Cochrane Library}

Update search, via Wiley InterScience: January 12007 to October 212011 (search conducted 21 October 2011)

Original search: Issue 3, 2007 (search conducted 16 May 2007)

Random* control ${ }^{\star}$ trial ${ }^{\star}$ OR double blind OR single blind OR clinical trial* OR placebo* OR random* allocat* OR intervention AND

Exercise OR physical education OR physical training OR physical activity OR physical inactivity OR physical fitness OR fitness OR sedentary OR lifestyle OR sport* OR walk* OR danc*

AND
child* OR adolescen*

AND

school 


\section{MEDLINE}

Update search, via Ovid: May Week 12007 to October Week 22011 (search conducted 21 October 2011)

Original search via Ovid: 1950 to June Week 32007 (search conducted 27 June 2007)

1. Randomized controlled trials/

2. Randomized controlled trial.pt

3. Random allocation/

4. Double blind method/

5. Single blind method/

6. Clinical trial.pt. or clinical trial.sh. or clinical trials.jn. or clinical trials.kw.

7. or/1-6

8. (clinic\$ adj trial\$1).tw.

9. ((singl\$ or doubl\$ or treb\$ or tripl\$) adj (blind\$3 or mask\$3)).tw.

10. Placebos/

11. Placebo\$.tw.

12. Randomly allocated.tw.

13. (allocated adj2 random).tw.

14. or/8-13

15. 7 or 14

16. Case report.tw.

17. Letter.pt.

18. Historical article.pt.

19. or/16-18

20. 15 not 19

21. exp exercise/

22. physical inactivity.mp.

23. physical activity.mp.

24. exp motor activity/

25. (physical education and training).mp.

26. exp "Physical Education and Training"/

27. exp physical fitness/

28. sedentary.ab. or sedentary.ti.

29. exp life style/

30. exp leisure activities/

31. exp walking/

32. exp sports/

33. exp dancing/

34. dancing.mp.

35. exp exercise therapy/

36. (exercise\$ adj aerobic\$).tw.

37. (physical\$ adj5 (fit\$ or train\$ or activ\$ or endur\$)).tw.

38. (exercis\$ adj5 (train\$ or physical\$ or activ\$)).tw.

39. sport\$.tw.

40. walk\$.tw.

41. cycle\$.tw.

42. (("lifestyle" or life-style) adj5 activ\$).tw.

43. (("lifestyle" or life-style) adj5 physical\$).tw.

44. or/21-43

45. limit 44 to ("child (6 to 12 years)" or "adolescent (13 to 18 years)")

46. 20 and 45

47. school.tw.

48.46 and 47

49. limit 48 to ed $=20070501-20111021$ 
EMBASE

Update search, via Ovid Week 182007 to Week 412011 (search conducted 21 October 2011)

Original search, via Ovid: 1985 to June 2007, week 26 (search conducted 27 June 2007)

1. Randomized controlled trials/

2. Random allocation/

3. Double blind method/

4. Single blind method/

5. clinical trial/

6. (clinic\$ adj trial\$1).tw.

7. ((singl\$ or doubl\$ or treb\$ or tripl\$) adj (blind\$3 or mask\$3)).tw.

8. Placebos/

9. Placebo\$.tw.

10. Randomly allocated.tw.

11. (allocated adj2 random).tw.

12. or/1-11

13. Case report.tw.

14. Letter.pt.

15. 13 or 14

16. 12 not 15

17. exp physical activity/

18. physical inactivity.mp.

19. exp exercise/

20. exp fitness/

21. exp physical education/

22. exp sport/

23. exp exertion/

24. exp leisure/

25. exp lifestyle/

26. exercis\$.tw.

27. (physical\$ adj5 activ\$).tw.

28. (physical\$ adj5 fit\$).tw.

29. (physical\$ adj5 lifestyle\$).tw.

30. (physical\$ adj5 train\$).tw.

31. exp dancing/

School-based physical activity programs for promoting physical activity and fitness in children and adolescents aged 6 to 18 (Review) 
(Continued)

32. walk.tw.

33. exp kinesiotherapy/

34. exp Exercise Therapy/

35. exercis\$.af.

36. (aerobics or physical therapy or physical activity or physical inactivity).af.

37. (fitness adj (class\$ or regime\$ or program\$)).af.

38. (aerobics or physical therapy or physical training or physical education).af.

39. dance therapy.af.

40. sedentary behavio?r.af.

41. or $/ 17-40$

42. limit 41 to (school child $<7$ to 12 years $>$ or adolescent $<13$ to 17 years $>$ )

43. 16 and 42

44. school.tw.

45. 43 and 44

46. limit 45 to em=200718-201141

\section{BIOSIS}

Update search, via Web of Science: January 2007 to October 2011 (search conducted October 21, 2011)

Original search, via Web of Science: 1995 to June 2007 (search conducted June 27, 2007)

1. $\mathrm{TS}=($ physical activity OR exercise)

2. $\mathrm{TS}=$ (obesity $\mathrm{OR}$ overweight)

3. TS=(physical fitness OR fitness)

4. $\mathrm{TS}=\left(\right.$ school OR school-based intervention OR physical education OR student ${ }^{\star}$ )

5. $\mathrm{TS}=\left(\right.$ child $^{\star}$ OR adolescent $\left.{ }^{\star}\right)$

6. $\mathrm{TS}=($ randomized controlled trial OR random trial OR control trial)

7. 1 OR 2 OR 3

8. 4 AND 5 AND 6 AND 7

\section{CINAHL}

Update search, via EBSCO Host Research Databases: January 2007 to October 2011 (search conducted 21 October 2011)

Original search, via Ovid: 1982 to June Week 42007 (search conducted 28 June 2007)

S1. (MH "Clinical Trials+")

S2. (MH "Clinical Effectiveness")

S3. (MH "Single-Blind Studies") or (MH "Double-Blind Studies")

S4. (MH "Random Assignment") 
(Continued)

S5. (MH "Placebos")

S6. (MH "Quantitative Studies")

$\mathrm{S} 7 . \mathrm{S} 1$ or $\mathrm{S} 2$ or $\mathrm{S} 3$ or $\mathrm{S} 4$ or $\mathrm{S} 5$ or $\mathrm{S} 6$

S8. (MH "Exercise+") or (MH "Aerobic Exercises+")

S9. "physical inactivity"

S10. (MH "Life Style, Sedentary")

S11. ("physical education") or (MH "Physical Education and Training+")

S12. ("physical activity") or (MH "Physical Activity")

S13. ("physical fitness") or (MH "Physical Fitness+") or ("fitness")

S14. ("walk") or (MH "Walking") or (MH "Sports")

S15. "sport*"

$\mathrm{S} 16 . \mathrm{S} 8$ or $\mathrm{S} 9$ or $\mathrm{S} 10$ or $\mathrm{S} 11$ or $\mathrm{S} 12$ or $\mathrm{S} 13$ or $\mathrm{S} 14$ or $\mathrm{S} 15$

S17. ((MH "Schools+") or (MH "Schools, Elementary") or (MH "Schools, Middle") or ("school*"))

S18. S7 and S16 and S17 ? Limiters - Publication Year from: 2007-2011; Age Groups: Child, 6-12 years, Adolescence, 13-18 years

\section{SPORTDiscus}

Updata search, via EBSCO Host Research Databases: January 12007 to October 2011 (search conducted 21 October 2011 )

Original search, via EBSCO Host Research Databases: 1985 to June 2007 (search conducted 13 July 2007)

Control group OR randomi ${ }^{\star}$ control $^{\star}$ trial OR effect* ${ }^{\star}$ R random sample* OR control subject*

AND

Physical activity OR physical inactivity OR exercise OR physical fitness OR fitness OR sport* OR danc* OR walk* OR physical education OR obesity OR body weight

AND

Child OR adolescent

AND

School

\section{PsycINFO}

Update search, via Ovid: May Week 12007 to October Week 32011 (search conducted 21 October 2011)

Original search, via Ovid: 1985 to June 2007 (search conducted 13 July 2007)

1. Randomized controlled trial.mp.

2. Random allocation.mp.

3. Double blind method.mp.

4. Single blind method.mp.

5. clinical trial.mp.

6. (clinic\$ adj trial\$1).tw. 
(Continued)

7. ((singl\$ or doubl\$ or treb\$ or tripl\$) adj (blind\$3 or mask\$3)).tw.

8. Placebo\$.tw.

9. Randomly allocated.tw.

10. (allocated adj2 random).tw.

11. Case report.tw.

12. Letter.mp.

13. Historical article.mp.

14. or/1-10

15. or/11-13

16. 14 not 15

17. exp exercise/

18. physical inactivity.mp.

19. physical activity.mp.

20. (physical education and training).mp.

21. exp physical fitness/

22. sedentary.ab. or sedentary.ti.

23. exp walking/

24. exp sports/

25. dancing.mp.

26. (exercise\$ adj aerobic\$).tw.

27. (physical\$ adj5 (fit\$ or train\$ or activ\$ or endur\$)).tw.

28. (exercis\$ adj5 (train\$ or physical\$ or activ\$)).tw.

29. sport\$.tw.

30. walk\$.tw.

31. cycle\$.tw.

32. (("lifestyle" or life-style) adj5 activ\$).tw.

33. (("lifestyle" or life-style) adj5 physical\$).tw.

34. lifestyle.mp.

35. leisure.mp.

36. or/17-35

37.16 and 36

38. school.tw.

39. 37 and 38

40. limit 39 to ( 180 school age <age 6 to $12 \mathrm{yrs}>$ or 200 adolescence <age 13 to $17 \mathrm{yrs}>$ ) 
(Continued)

41. limit 40 to $u p=20070501-20111021$

\section{Sociological Abstracts}

Update search, via Scholars Portal: January 12007 to October 212011 (search conducted 21 October 2011)

Original search, via Scholars Portal: 1985 to June 2007 (search conducted 27 June 2007)

Control group OR randomi ${ }^{\star}$ control $^{\star}$ trial OR effect* OR random sample* OR control subject $^{\star}$

AND

Physical activity OR physical inactivity OR exercise OR physical fitness OR fitness OR sport* OR danc* OR walk* OR physical education OR obesity OR body weight

AND

Child OR adolescent

AND

School

\section{Appendix 2. Description of interventions}

\begin{tabular}{|c|c|c|c|}
\hline $\begin{array}{l}\text { Characteristic } \\
\text { Study ID }\end{array}$ & Design & Intervention(s) and control(s) & $\begin{array}{l}\text { Theoretical frame- } \\
\text { work }\end{array}$ \\
\hline
\end{tabular}

$\begin{array}{ll}\text { Angelopoulos } 2009 \text { Cluster RCT } & \text { I: 12-month program integrated into the existing curriculum in- } \\ \text { cluding: student workbook, teacher manual; covering themes: } & \text { Behavior } \\ \text { self-esteem, body image, nutrition, PA, fitness, environmen- } & \text { tal issues. Implemented for } 1 \text { to } 2 \text { hours per week with motiva- } \\ \text { tional methods used for increasing knowledge, skills, and self- } & \text { efficacy and improving self-monitoring and social influence. } \\ & \text { School teachers trained by the research team delivered the in- } \\ \text { tervention. Parental involvement (reinforcement) was required } & \text { to complete some (unspecified) home activities } \\ & \\ \text { C: not specified }\end{array}$

Araujo-Soares $\quad$ Cluster RCT
2009

I: 2 × 90-min PA sessions with related homework. A trained psychologist delivered the intervention, assisted by a sports education teacher. A research team member supervised preparation for each session, before which each student was asked to keep a diary for a period of 1 week. After the intervention they were asked to keep the diary for an additional 2 weeks. Worksheets and a 3-min film were used, and each student received a leaflet with main topics

C: not specified
Social Cognitive Theory

\begin{tabular}{ll}
\hline Barbeau 2007 & RCT \\
& I: 10-month after-school PA program on body composition and \\
& CV fitness in young black girls. The program consisted of 30 min \\
of homework time with a healthy snack, and 80 min of PA ( 25 \\
min skill development, 35 min MVPA, and 20 min of toning and \\
stretching). Activities during the MVPA included games such \\
as basketball, tag, softball, relay races, etc., all of which were
\end{tabular}


modified to keep all of the subjects active throughout the 35min period. Subjects received small weekly prizes (e.g. bouncy balls, slinkies, pencils, note pads, lip gloss, play jewelry) for maintaining good behavior and attitude and at most 1 unexcused absence. Absences were discussed with parents. Teachers providing the intervention were trained on childhood obesity, PA, and CV risk factors, the goals of the study, the specific protocol to be followed, and the types of activities appropriate for each segment of the intervention and manuals were provided to schools

\section{C: not specified}

Bayne-Smith 2004 RCT
I: the intervention (PATH program) consisted of 30-min classes conducted 5 days per week for 12 weeks. Classes included: 1 ) brief lecture/discussion on featured topics (CV health and fitness, health behaviors); and 2) 20 to 25 min of vigorous PA (e.g. resistance exercise, endurance or aerobic exercise, alternated each day)

C: the frequency/duration of PE classes were the same as PATH classes (but without lecture/discussion, so 5 extra min of PA each class)

\begin{tabular}{ll}
\hline Burke $1998 \quad$ Cluster RCT & $\begin{array}{l}\text { I1: standard PA and nutrition program (WASPAN). Classroom } \\
\text { lessons, 20-min fitness sessions daily (min 4/week). Nutrition } \\
\text { program built around } 4 \text { comic books to teach children and par- } \\
\text { ents how to improve diets, plus } 1 \text { h/week nutrition classes }\end{array}$ \\
& $\begin{array}{l}\text { 12: standard WASPAN program plus a PA enrichment program } \\
\text { for higher-risk children. Incorporated teacher-parent-student } \\
\text { triad, moved PA activities outside of the class and focused on } \\
\text { the individual. Children kept weekly diaries }\end{array}$ \\
C: no program
\end{tabular}

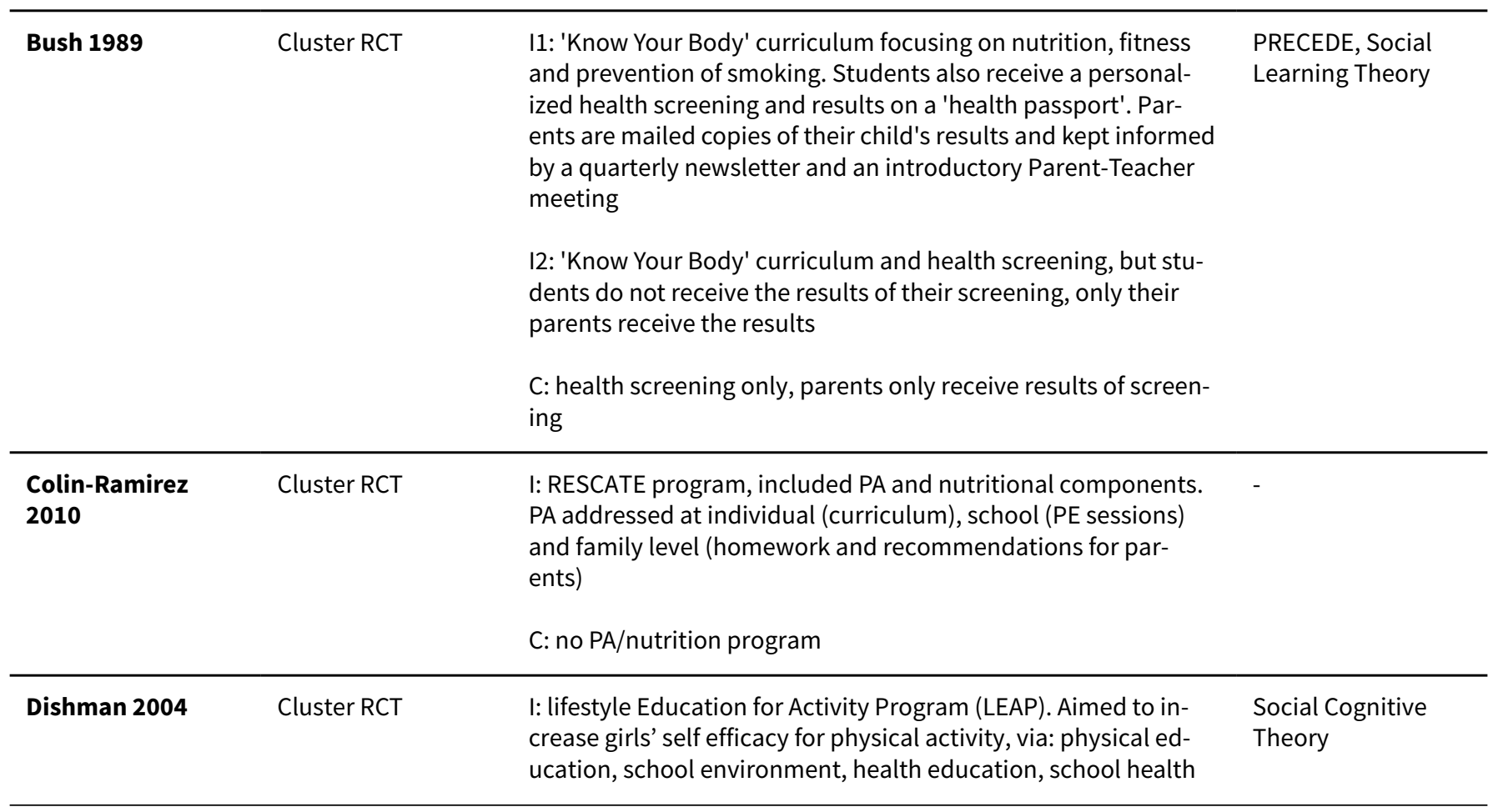


services, faculty or staff health promotion, and parent and com-

munity involvement

C: standard physical education as part of school curriculum

Donnelly 2009 Cluster RCT I: physical Activity Across the Curriculum (PAAC), 90 min/wk of
moderate to vigorous physically active academic lessons delivered intermittently throughout the school day

C: regular classroom instruction without physically active lessons

Dorgo $2009 \quad$ Cluster RCT

I1: PE manual resistance training (MRT) program. 80-min classes 3 times per week plus 10 to 15 min warm-up and 20 to $30 \mathrm{~min}$ of MRT-specific activities conducted by trained research assistants

Intervention 2: PE MRT program plus a cardiovascular endurance training segment in every session including: walking, jogging, step aerobics, and aerobic kickboxing

Control: a regular PE program that followed the usual school curriculum. 80-min classes 3 times per week

\begin{tabular}{lll}
\hline Ewart 1998 & RCT & $\begin{array}{l}\text { I: } 50 \text {-min 'Project Heart' aerobic exercise classes including di- } \\
\text { dactic instruction }\end{array}$ \\
& C: 50 -min standard physical education classes \\
\hline Gentile 2009 & Cluster RCT & $\begin{array}{l}\text { I: 'Switch' program, promoted healthy active lifestyles includ- } \\
\text { ing: being active for } 60 \text { min or more per day, limiting total } \\
\text { screen time to } 2 \text { hours or fewer per day, and eating } 5 \text { fruits/veg- } \\
\text { etables or more per day. Included } 3 \text { ecological levels (family, } \\
\text { school, community) }\end{array}$ \\
C: No intentional exposure to the Switch program
\end{tabular}

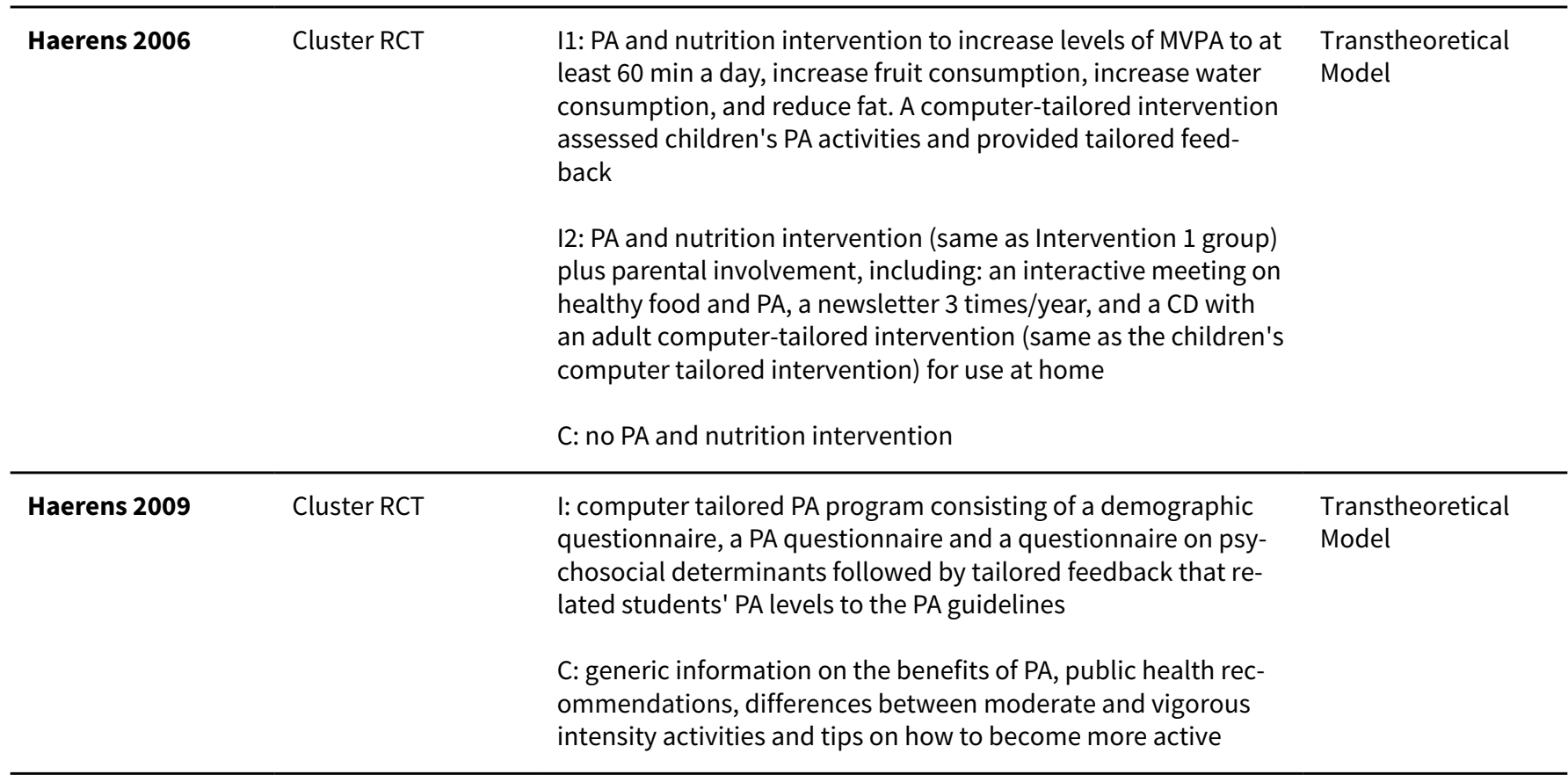


(Continued)

Cluster RCT
I: the intervention included: 1 ) a health curriculum (classroom lessons and behavioral journalism - during 6th grade, 16 sessions during physical education classes, 3 times per week; during 7th grade, science-based lessons during science class); 2) a physical education program; and 3) a school food service component, emphasizing calcium-rich food

C: the control group participated in the usual health program
Transtheoretical, Social Cognitive Theory

Kipping $2008 \quad$ Cluster RCT

I: the intervention included: 16 lessons on healthy eating, increasing physical activity, and reducing television viewing taught over 5 months by 10 specifically trained teachers. Materials provided to the schools included: lesson plans for 9 physical activity lessons, 6 nutrition lessons and 1 lesson about screen viewing

$\mathrm{C}$ : the control schools were given the materials only after the completion of the study

Kriemler $2010 \quad$ Cluster RCT

I: the intervention was a multicomponent PA program that included: 1) 3 existing 45-min physical education lessons per week; 2) 2 additional 45-min physical education lessons per week; 3) daily short activity breaks; and 4) physical activity homework

C: the control group participated in the usual, mandatory physical education lessons (45-min, 3 times/week)
Socio-Ecological Conceptual Model
I: the intervention (TAKE 10! Program) included 2 daily 10-min physical activity sessions: 1 ) the teacher or student selected 1 to 3 activity cards; 2) several children modelled the exercises, the other students followed along; 3) cool-down period; and 4) the students were taught a health message

C: no intervention took place

\begin{tabular}{lll}
\hline Lubans 2009 & Cluster RCT & $\begin{array}{l}\text { I: the intervention included: } 1 \text { 1) 10-week school sport program } \\
\text { and exercise program booklet; } 2 \text { ) information sessions; } 3 \text { ) phys- } \\
\text { ical activity and dietary monitoring using pedometers and di- } \\
\text { aries; } 4 \text { ) Program X weekly messages and parent information } \\
\text { leaflets; and 5) email support }\end{array}$ \\
& $\begin{array}{l}\text { C: the control group attended a 10-week school sport program } \\
\text { and received an exercise program booklet }\end{array}$
\end{tabular}

I1: One group received a school-based program consisting of school food service modifications, physical education interventions, and the CATCH curricula

12: One group received the same school-based program plus a family-based program

C: The control group received the usual health curricula, PE, and food service programs, but none of the $\mathrm{CATCH}$ interventions

\begin{tabular}{ll}
\hline Martinez 2008 & Cluster RCT \\
& I: the intervention group received: 1 ) the standard, compulsory \\
PE curriculum (3 hours per week of low-to-moderate intensity
\end{tabular}


activity); 2) recreational, noncompetitive, after school PA program ( 3 × 90-min sessions per week, for 24 weeks)

C: the control group received the standard, compulsory physical education curriculum: 3 hours per week of physical activity at low-to-moderate intensity

McManus $2008 \quad$ Cluster RCT

I1: the Educational Program Group completed a 2-week education program, taught using an active game approach, that included: information about heart health, the use of heart rate feedback to attain an activity target, goal-setting, and role-play. They then completed 2-weeks with heart rate feedback and 2weeks without heart rate feedback

12: the No-education Program Group completed a 2-week control program of standard PE classes without PA or heart health education. They then completed 2-weeks with heart rate feedback and 2-weeks without heart rate feedback but were not given any information about the heart rate signal or its meaning

C: no intervention took place

Neumark-Sztainer Cluster RCT
2009

\begin{abstract}
I: the intervention included: (i) $14 \times 2$-hour after-school theatre sessions (which included: check-in, snack, movement component, theatrical activity - the final sessions focused on rehearsing for a play performance (script developed throughout intervention)); (ii) 8 weekly after-school booster sessions (activities related to healthy eating and physical activity, rehearsals for play); and (iii) family outreach component (to enhance home support for behavioral changes through positive reinforcement of healthy behaviors, parent-child participation in physical activities and availability of healthy foods) - take home materials, family events
\end{abstract}

C: there was a theatre-based control condition (i.e. children participated in a play focused on environmental health issues using a prepared script)

Neumark-Sztainer Cluster RCT
2010

I: the intervention group participated in the standard all-girls PE class that was supplemented with the New Moves curriculum (nutrition and self-empowerment components, individual sessions using motivational interviewing, lunch meetings, and parent outreach)

C: participation in all-girls PE class (during first semester of school year)
Health Belief Model, Social Cognitive Theory, Diffusion of Innovation
Social Cognitive Theory
Social Cognitive Theory, Transtheoretical Model
Social Cognitive

Theory

\begin{abstract}
I: the intervention ran over 16 weeks, with each week including $1 \times 60$-min curriculum session and $2 \times 20$-min lunchtime PA sessions. Each 60 -min curriculum session included practical or theoretical (or both) components focused on promoting physical activity and increasing fruit consumption and the acquisition and practice of self-regulatory behaviors. Behavior modification techniques were used. The practical component included modified games and activities. The researcher primarily facilitated the intervention with staff and parents' involvement. Eleventh grade students peer facilitated lunchtime sessions. Parents were emailed 6 newsletters throughout, informing them of the program content, motivating them, and suggesting strategies to engage the family in healthy behaviors
\end{abstract}


C: participated in $16 \times 60$-min physical activity curriculum at the same time as the intervention group, with a school PE teacher facilitating the control group

Petchers $1988 \quad$ RCT

I: Chicago Heart Health Curriculum Program called "Body Power": a year-long curriculum with modules on 5 topics: 1 ) CV system, anatomy, and physiology; 2) smoking; 3) nutrition; 4) exercise; and 5) risk factors review. The curriculum was implemented by classroom teachers during at least $3 \times 45$-min sessions per week for 4 to 6 weeks, with training provided for teachers and supplemented by a comprehensive teachers' manual

C: traditional curriculum with approximately the same amount of teaching time. Control group teachers were provided an alternative experience to the training sessions for the intervention group in the form of a separate in-service

\section{Reed 2008} Cluster RCT

\begin{abstract}
I: the Action Schools! BC model was consistent with the 'active school' framework and emphasized an integrated whole-school approach rather than traditional classroom-based health education, targeting 6 Action Zones: i) School Environment, ii) Scheduled Physical Education, iii) Extra-curricular, (iv) School Spirit, v) Family and Community and vi) Classroom Action. Classroom Action included 15 min of moderate to intense physical activity daily ( $75 \mathrm{~min}$ of extra PA per week in addition to $2 \mathrm{x}$ 40 min PE classes). Teachers provided opportunities to 'snack on physical activities' such as skipping, dancing, and resistance exercises throughout the day. A school Action Team was convened in each school with a facilitator who helped to design a program with activities across the 6 Action Zones. INT teachers received a 1-day training workshop and a Classroom Action Bin with resources, with the goal for each school to provide students with 150 min of PA/week ( $2 \times 40$ min PE classes $+15 \times 5$ $\mathrm{min}$ /day Classroom Action)
\end{abstract}

C: teachers in UP schools continued the regular program of physical education and school-based PA

\begin{abstract}
I: limited access to television use and budgeting television time and involved 18 lessons of 30 to $50 \mathrm{~min}$ as part of standard curriculum, taught by regular classroom teachers trained by research staff. Most lessons occurred in the first 2 months of the year and included self-monitoring and self-reporting for television and video game use followed by a 10-day television turnoff challenge after which students were encouraged to follow a 7$\mathrm{h}$ per week budget. Newsletters designed to help parents motivate students and regulate time spent on television and video games for the entire family were distributed. Each household received television time master(s) to regulate television and video use
\end{abstract}

\section{C: not specified}

\begin{tabular}{|c|c|c|c|}
\hline Salmon 2008 & Cluster RCT & $\begin{array}{l}\text { I: students were assigned to } 1 \text { of } 4 \text { conditions: a behavioral } \\
\text { modification group }(N=69) \text {; a fundamental motor skills group } \\
(N=73) \text {; a combined behavioral modification and fundamental } \\
\text { motor skills group }(N=90)\end{array}$ & $\begin{array}{l}\text { Social Marketing } \\
\text { Theory, Behavioral } \\
\text { Choice Theory }\end{array}$ \\
\hline & & C: usual classroom lessons & \\
\hline
\end{tabular}

Social Cognitive Theory
Health Behavior Model 
Cluster RCT
I: the ICAPS program was implemented over 4 academic years to promote PA inside and outside. The intervention includes an educational component focusing on PA and sedentary behaviors, new opportunities for PA during and after school hours. Activities implemented are either informal or academic with emphasis on fun, well-being, non-competitiveness. Sporting events, bicycle, and on-foot transport are organized

C: not specified

$\begin{array}{ll}\text { Singh } 2009 & \text { Cluster RCT } \\ & \begin{array}{l}\text { I: an interdisciplinary program with adapted curriculum includ- } \\ \text { ing an individual component (11 lessons in biology and physi- } \\ \text { cal education) and environmental change component including } \\ \text { encouragement for schools to increase physical education and } \\ \text { provision of advice for schools related to cafeteria changes }\end{array} \\ & \text { C: regular curriculum }\end{array}$

Singhal $2010 \quad$ Cluster RCT

I: multicomponent intervention with 7 components related to nutrition and lifestyle education, including the following activities: dissemination of health-related information through lectures and focused group discussions ( 24 weeks ( 6 months) of nutrition education), promotion of physical activity, other promotion of healthy lifestyle, individual counseling, policy-level changes in schools, involvement of teachers and parents, training of student volunteers for program sustainability

C: no intervention

Stephens $1998 \quad$ Cluster RCT

I: 18 medical students delivered 3 activity sessions per week, consisting of 5 min of warm-up and stretching, plus 20 min of aerobic activity. Activities incorporated repetitive movements of large muscle groups, designed to elevate the pulse rate $40-$ 60 beats over resting level. Sessions ended with a 5-10 $\mathrm{min}$ cool-down with presentation of educational material about nutrition, exercise, and disease prevention

C: students in the control classroom received no additional PA beyond regular PE classes

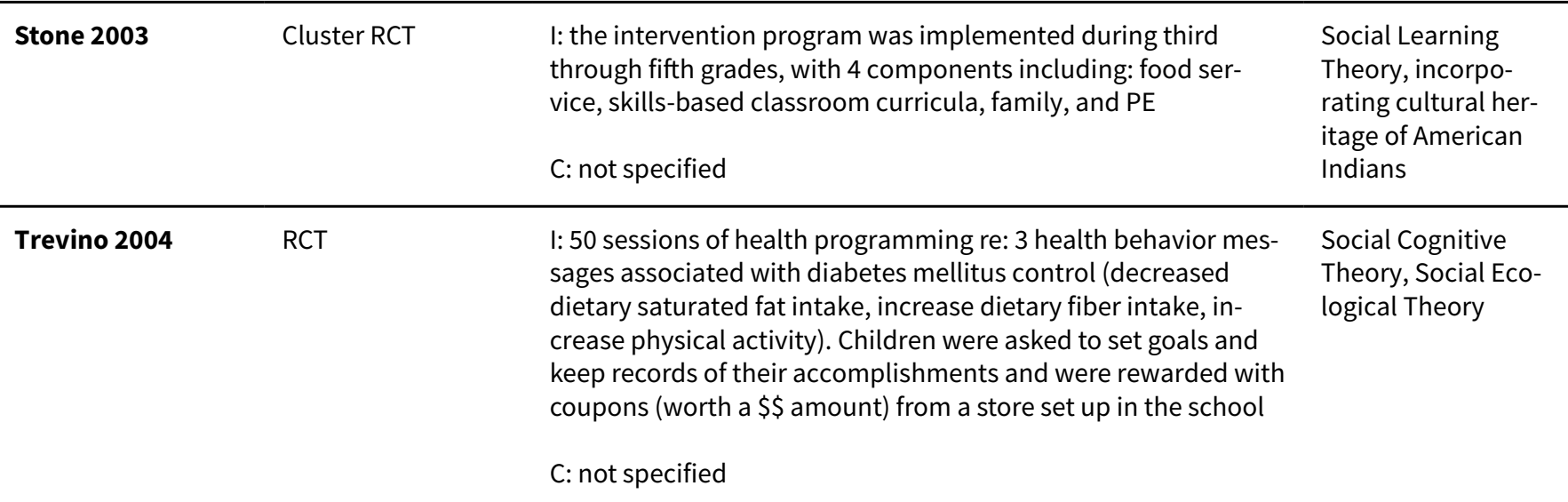

$\begin{array}{ll}\text { Verstraete } 2006 \quad \text { Cluster RCT } & \text { I: classes were provided game equipment (jump ropes, scoop } \\ & \text { sets, flying discs, balls, plastic hoops, juggling rings and bean- } \\ & \text { balls, badminton racquets, beach paddles) and 'activity cards' }\end{array}$


demonstrating use of the equipment for use outdoors during recesses and lunch break

C: not specified

\begin{tabular}{lll}
\hline Walter 1988 & Cluster RCT & $\begin{array}{l}\text { I: special curriculum targeting voluntary changes in risk behav- } \\
\text { ior in the area of diet, physical activity and smoking, taught in } \\
\text { classrooms by specially trained regular teachers for } 2 \text { hours } \\
\text { per week }\end{array}$ \\
& $\begin{array}{l}\text { PRECEDE, Health } \\
\text { Belief Model, Social } \\
\text { Learning Theory }\end{array}$ \\
\hline Walther 2009 & Cluster RCT & $\begin{array}{l}\text { I: } 1 \text { unit of physical exercise (45 min) with at least } 15 \text { min of } \\
\text { endurance training per school day, plus lessons on healthy } \\
\text { lifestyle } 1 \text { per month }\end{array}$ \\
& $\begin{array}{l}\text { C: according to German standards, } 2 \text { units (each } 45 \text { min) of } \\
\text { PE per week are mandatory in all schools. } 12 \text { units (45 min per } \\
\text { unit) of high-level endurance exercise training per week plus } \\
\text { participation in competitive sporting events }\end{array}$
\end{tabular}

I: 'FitKid' after-school program, 2-hour intervention sessions (40 min academic enrichment activities and a healthy snack provided; $80 \mathrm{~min}$ of PA designed to improve sport skills, aerobic fitness, strength, and flexibility with a minimum of 40 min were devoted to vigorous PA), offered 5 days a week, instructed by certified school teachers and paraprofessionals

\section{C: not specified}

\begin{tabular}{|c|c|c|c|}
\hline Webber 2008 & Cluster RCT & $\begin{array}{l}\text { I: } 6 \text { TAAG health education lessons per school year to enhance } \\
\text { behavioral skills known to influence PA participation (self-mon- } \\
\text { itoring, setting goals for behavior change). Offered in } 2 \text { forms: } 1 \\
\text { for a traditional classroom setting and } 1 \text { for PE class. Girls were } \\
\text { the focus of the intervention; however, health and PE classes } \\
\text { were part of the usual school curriculum and most included } \\
\text { boys as well }\end{array}$ & $\begin{array}{l}\text { Social Cognitive } \\
\text { Theory, Diffusion of } \\
\text { Innovation, Oper- } \\
\text { ant Learning Theo- } \\
\text { ry }\end{array}$ \\
\hline & & C: not specified & \\
\hline
\end{tabular}

$\begin{array}{ll}\text { Weeks } 2008 & \text { RCT } \\ & \text { I: } 10 \text { min of directed jumping activity at the beginning of every } \\ \text { PE class (twice per week), designed to apply loads to the skele- } \\ \text { ton at high-strain magnitude, frequency, and rate, includ- } \\ \text { ing: jumps; hops; tuck-jumps; jump-squats; stride jumps; star } \\ \text { jumps; lunges; side lunges; and skipping } \\ \text { C: regular PE warm-ups and stretching at the beginning of } \\ \text { every PE class (twice per week), including: brisk walking, light } \\ \text { jogging, and stretching }\end{array}$

Williamson $2007 \quad$ Cluster RCT

\begin{abstract}
I: Healthy Eating and Exercise (HEE) program; goal was to increase PA during the school day and at home. Teachers were provided with containers filled with indoor play supplies (e.g. balloons, bean bags) and outdoor play supplies (e.g. balls, jump ropes) to promote active play during class time and recess. Posters encouraged the use of these physical activity centers (PACs), and brief lesson plans provided academic games that used the supplies contained in the PACs
\end{abstract}


C: Alcohol/Tobacco/Drug abuse prevention (ADT) program, designed with the goal of modifying children's beliefs and attitudes regarding the use and abuse of tobacco, alcohol, and illicit drugs so that they reflected "healthier" values

Wilson $2011 \quad$ Cluster RCT I: ACT, a 17-week program implemented for 2 hours, 3 days/
week by a trained instructor. Three main components: homework/snack (30 min), MVPA activities (60 min) that students selected each week, and a behavioral skills and motivational component (30 $\mathrm{min})$

C: the General Health Education Program (comparison program) focused on nutrition, stress management, drug prevention, and drop-out prevention (with no PA component), and consisted of a homework/snack ( $30 \mathrm{~min}$ ) and 3 hands-on activities related to general health ( $30 \mathrm{~min}$ each). The comparison program was held on the same days and times as the ACT intervention program

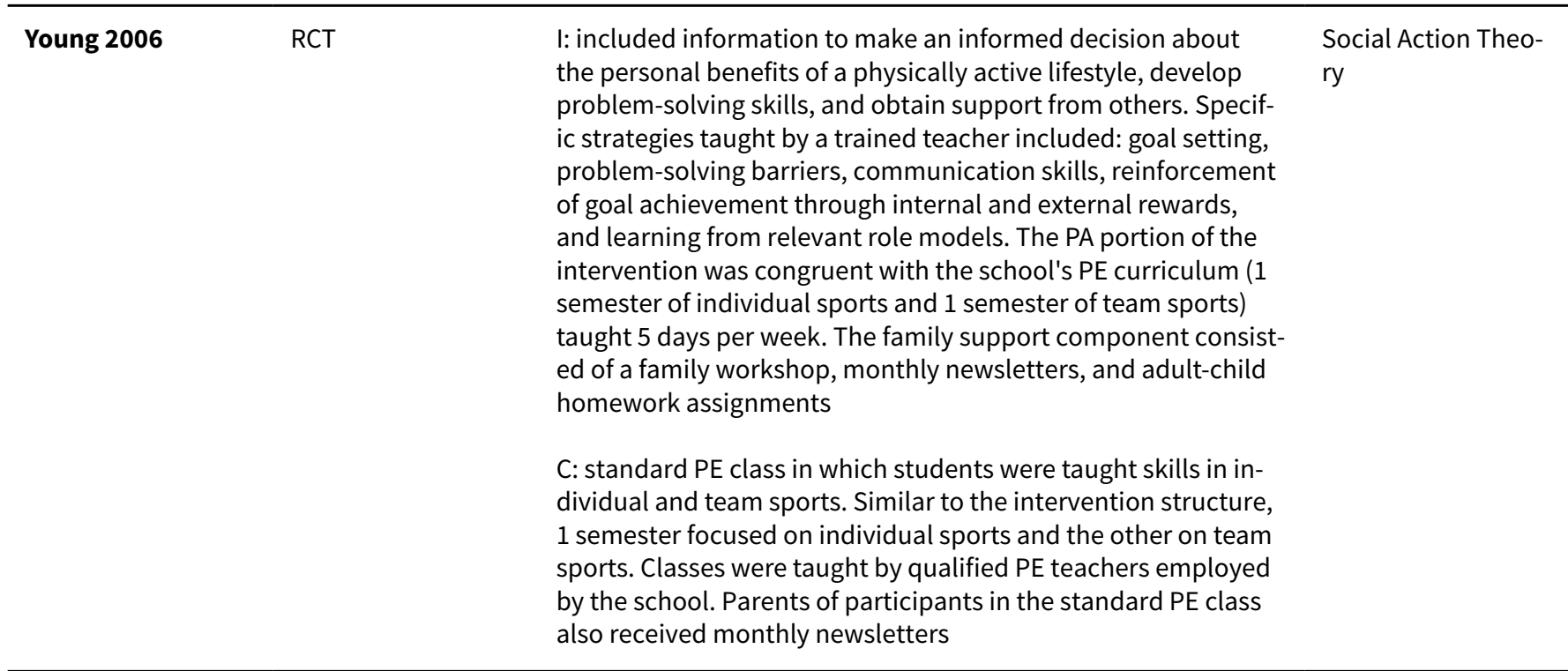

\footnotetext{
"-" denotes not reported.
}

C: control; CV: cardiovascular; I: intervention; MVPA: moderate to vigorous physical activity; PA: physical activity; PE: physical education; RCT: randomized controlled trial. 


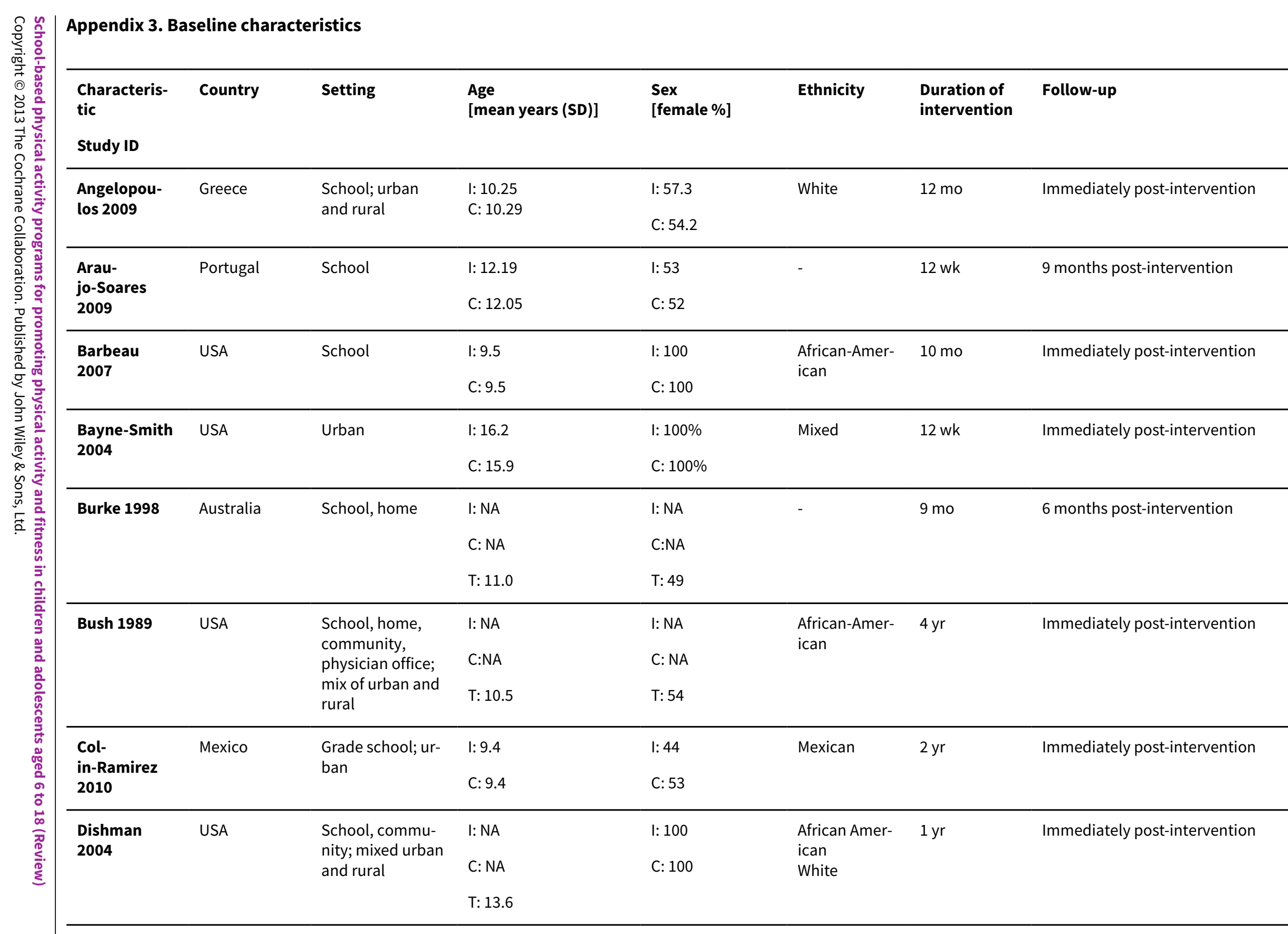




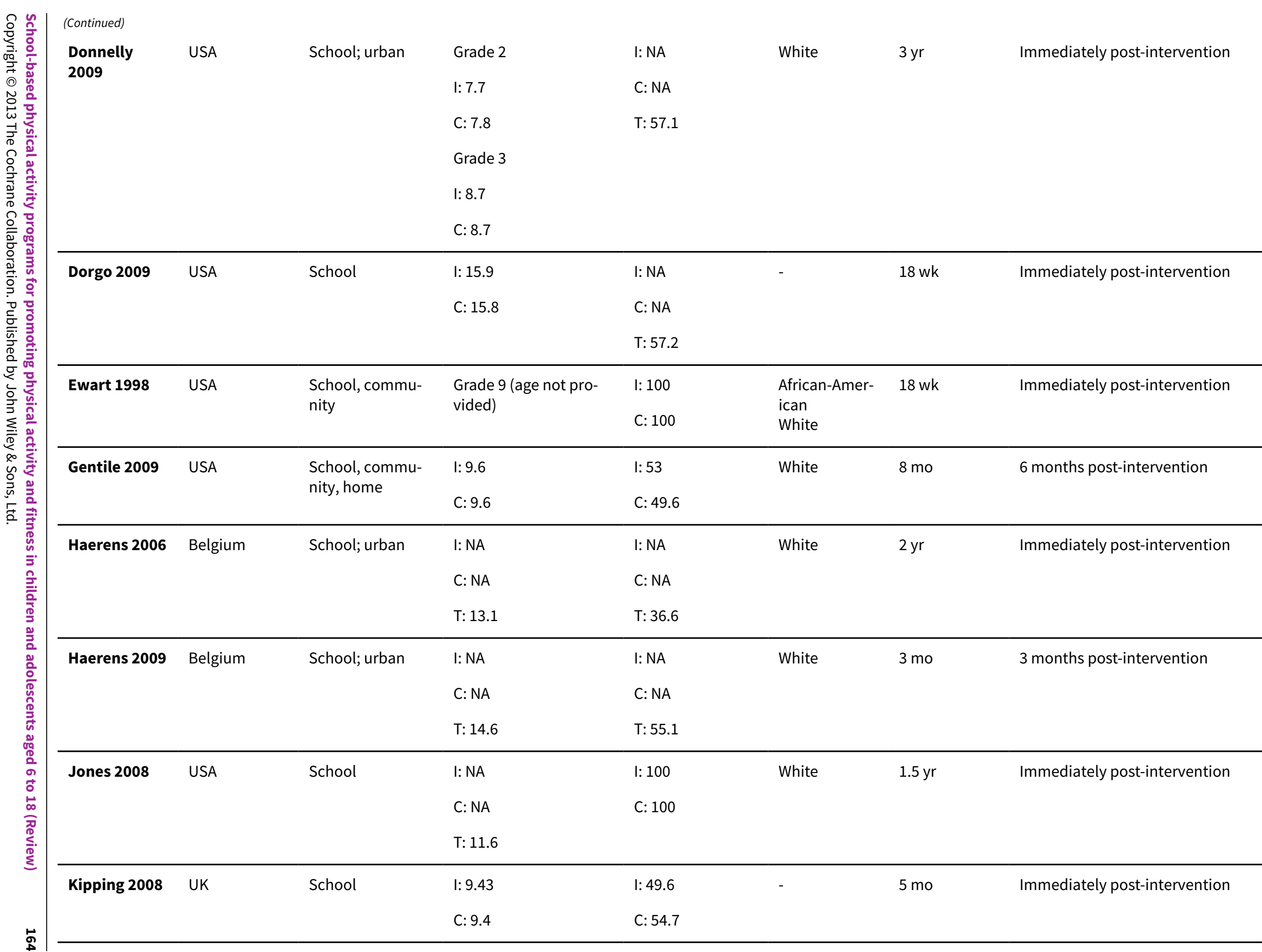




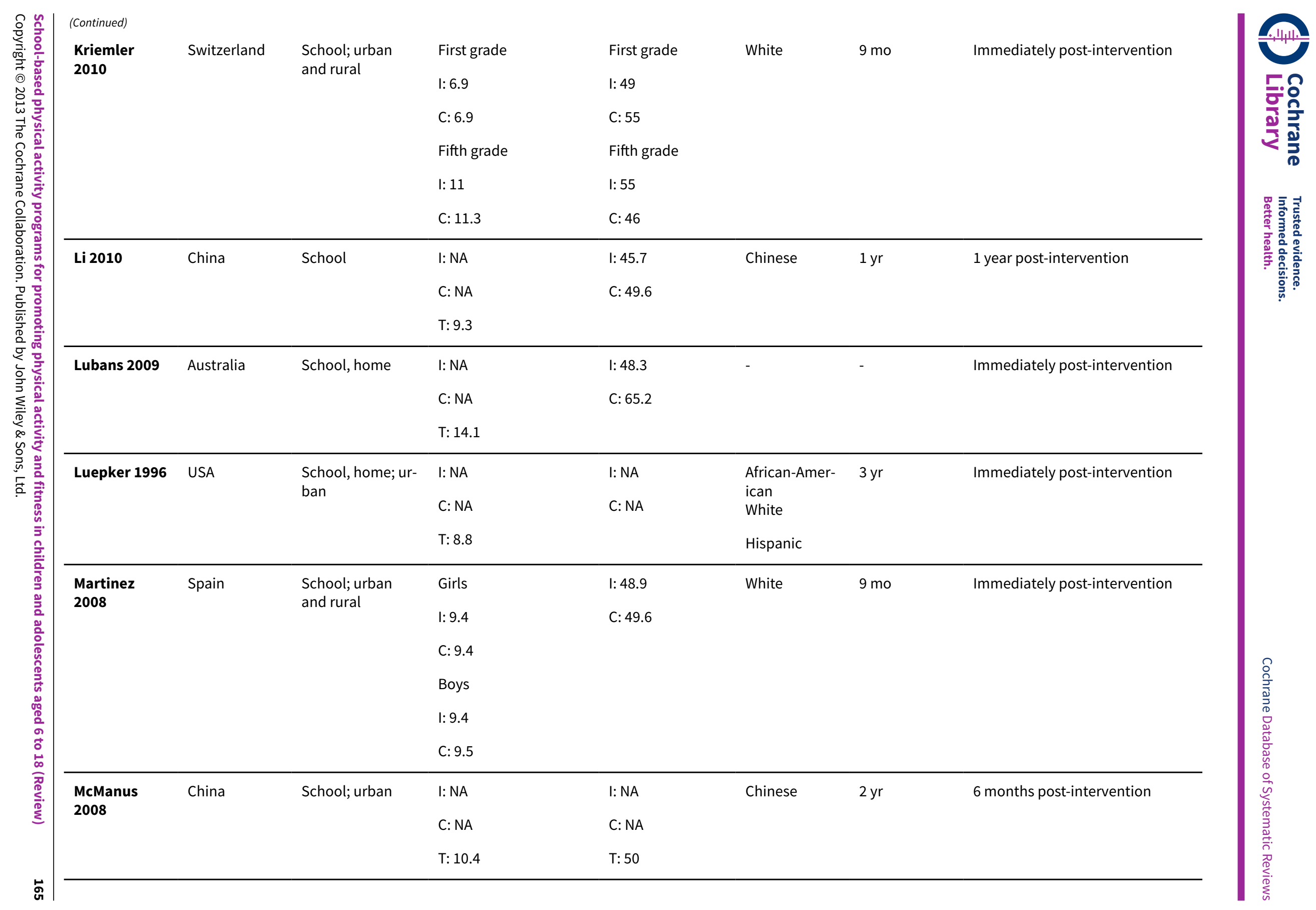




\begin{tabular}{|c|c|c|c|c|c|c|c|c|}
\hline 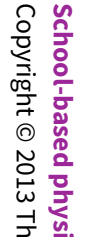 & $\begin{array}{l}\text { (Continued) } \\
\text { Neumark-Sz- } \\
\text { tainer } 2009\end{array}$ & USA & $\begin{array}{l}\text { School, commu- } \\
\text { nity, theater; ur- } \\
\text { ban }\end{array}$ & $\begin{array}{l}\text { I: NA } \\
\text { C: NA } \\
\text { T: } 10.3\end{array}$ & $\begin{array}{l}\text { I: NA } \\
\text { C: NA } \\
\text { T: NA }\end{array}$ & $\begin{array}{l}\text { African-Amer- } \\
\text { ican }\end{array}$ & $16 w k$ & Immediately post-intervention \\
\hline 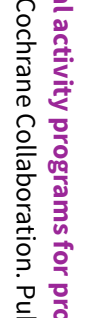 & $\begin{array}{l}\text { Neumark-Sz- } \\
\text { tainer } 2010\end{array}$ & USA & School; urban & $\begin{array}{l}\text { I: } 15.7 \\
\text { C: } 15.8\end{array}$ & $\begin{array}{l}\text { I: } 100 \\
\text { C: } 100\end{array}$ & $\begin{array}{l}\text { African-Amer- } \\
\text { ican } \\
\text { American-In- } \\
\text { dian } \\
\text { Asian } \\
\text { White } \\
\text { Hispanic } \\
\text { Mixed/other }\end{array}$ & $16 w k$ & Immediately post-intervention \\
\hline 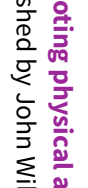 & Peralta 2009 & Australia & School & $\begin{array}{l}\text { I: NA } \\
\text { C: NA } \\
\text { T: } 12.5\end{array}$ & $\begin{array}{l}\mathrm{I}: 0 \\
\mathrm{C}: 0\end{array}$ & - & 16 wk & Immediately post-intervention \\
\hline 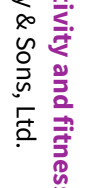 & $\begin{array}{l}\text { Petchers } \\
1988\end{array}$ & USA & $\begin{array}{l}\text { School; mixed } \\
\text { (urban, suburban } \\
\text { and residential) }\end{array}$ & $\begin{array}{l}\text { I: NA } \\
\text { C: NA } \\
\text { T: } 11.1\end{array}$ & $\begin{array}{l}\text { I: NA } \\
\text { C: NA } \\
\text { T: } 52.6\end{array}$ & - & $40 w k$ & 1 year post-intervention \\
\hline 흘 & Reed 2008 & Canada & $\begin{array}{l}\text { School, commu- } \\
\text { nity, home; urban }\end{array}$ & $\begin{array}{l}\text { Liaison (int 1) } \\
\text { I1: } 10.2 \\
\text { I2: } 10.1 \\
\text { C: } 10.3\end{array}$ & $\begin{array}{l}\text { I1: } 44.8 \\
\text { I2: } 50 \\
\text { C: } 50.3\end{array}$ & $\begin{array}{l}\text { Predominate- } \\
\text { ly White and } \\
\text { Asian }\end{array}$ & $11 \mathrm{mo}$ & Immediately post-intervention \\
\hline 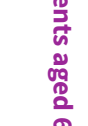 & $\begin{array}{l}\text { Robinson } \\
1999\end{array}$ & USA & School & $\begin{array}{l}\text { I: } 8.95 \\
\text { C: } 8.92\end{array}$ & $\begin{array}{l}\text { I: } 44.6 \\
\text { C: } 48.6\end{array}$ & - & $6 \mathrm{mo}$ & Immediately post-intervention \\
\hline 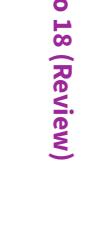 & Salmon 2008 & Australia & School; urban & $\begin{array}{l}\text { 11: NA } \\
\text { 12: NA } \\
\text { I3: NA } \\
\text { C: NA }\end{array}$ & $\begin{array}{l}\text { I1: } 50.7 \\
\text { I2: } 52.6 \\
\text { I3: } 51.1 \\
\text { C: } 50.8\end{array}$ & - & $1 \mathrm{yr}$ & 1 year post-intervention \\
\hline
\end{tabular}




\begin{tabular}{|c|c|c|c|c|c|c|c|c|}
\hline \multicolumn{9}{|c|}{ (Continued) } \\
\hline 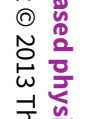 & Simon 2004 & France & $\begin{array}{l}\text { School, commu- } \\
\text { nity; urban }\end{array}$ & $\begin{array}{l}\text { I: } 11.6 \\
\text { C: } 11.7\end{array}$ & $\begin{array}{l}\text { I: } 53.7 \\
\text { C: } 48.2\end{array}$ & White & $4 \mathrm{yr}$ & Immediately post-intervention \\
\hline$\overbrace{0}^{\circ}$ & \multirow[t]{6}{*}{ Singh 2009} & \multirow[t]{6}{*}{ Netherlands } & \multirow[t]{6}{*}{ School } & Girls & I: 53.3 & \multirow[t]{6}{*}{ White } & \multirow[t]{6}{*}{$8 \mathrm{mo}$} & \multirow[t]{6}{*}{1 year post-intervention } \\
\hline 突 & & & & I: 12.8 & C: 53.3 & & & \\
\hline 产寄 & & & & C: 12.9 & & & & \\
\hline 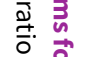 & & & & Boys & & & & \\
\hline 훙 & & & & I: 12.6 & & & & \\
\hline$\stackrel{\bar{n}}{\overrightarrow{0}} \stackrel{0}{0}$ & & & & C: 12.7 & & & & \\
\hline$\sum$ & \multirow[t]{2}{*}{ Singhal 2010} & \multirow[t]{2}{*}{ India } & \multirow[t]{2}{*}{ School; urban } & I: 16 & I: 39.4 & \multirow[t]{2}{*}{ Indian } & \multirow[t]{2}{*}{$42 \mathrm{wk}$} & \multirow[t]{2}{*}{ Immediately post-intervention } \\
\hline$\sum_{\underline{2}}^{5} \frac{\hat{a}}{2}$ & & & & C: 16 & C: 40.2 & & & \\
\hline 帛 & \multirow{2}{*}{$\begin{array}{l}\text { Stephens } \\
1998\end{array}$} & \multirow[t]{2}{*}{ USA } & \multirow[t]{2}{*}{ School; urban } & I: 8.4 & I: 44 & \multirow{2}{*}{$\begin{array}{l}\text { African-Amer- } \\
\text { ican }\end{array}$} & \multirow[t]{2}{*}{$15 \mathrm{wk}$} & \multirow[t]{2}{*}{ Immediately post-intervention } \\
\hline$\frac{0}{2}$ & & & & C: 8.4 & C: 57 & & & \\
\hline Ф & \multirow[t]{3}{*}{ Stone 2003} & \multirow[t]{3}{*}{ USA } & \multirow[t]{3}{*}{ School } & I: NA & I: NA & \multirow{3}{*}{$\begin{array}{l}\text { American-In- } \\
\text { dian }\end{array}$} & \multirow{3}{*}{$\begin{array}{l}3 \mathrm{yr}(12 \mathrm{wks} \\
\text { per yr) }\end{array}$} & \multirow[t]{3}{*}{ Immediately post-intervention } \\
\hline 今. & & & & $\mathrm{C}: \mathrm{NA}$ & $\mathrm{C}: \mathrm{NA}$ & & & \\
\hline$\frac{2}{3}$ & & & & $\mathrm{~T}: 7.6$ & $\mathrm{~T}: \mathrm{NA}$ & & & \\
\hline$\frac{2}{2}$ & \multirow[t]{2}{*}{ Trevino 2004} & \multirow[t]{2}{*}{ USA } & School; urban & I: 9.8 & I: 50 & Hispanic & $7 \mathrm{mo}$ & Immediately post-intervention \\
\hline$\frac{0}{5}$ & & & & C: 9.8 & C: 49 & & & \\
\hline $\begin{array}{l}\overrightarrow{\tilde{n}} \\
\tilde{n}\end{array}$ & Verstraete & Belgium & School; urban & I: 10.8 & I: 38.5 & White & $3 \mathrm{mo}$ & Immediately post-intervention \\
\hline$\frac{1}{a}$ & & & & C: 10.9 & C: 59.3 & & & \\
\hline$\stackrel{\infty}{\pi}$ & Walter 1988 & USA & School, commu- & Bronx & Bronx & African-Amer- & $6 \mathrm{yr}$ & Immediately post-intervention \\
\hline कें & & & & I: 9 & I: 48.9 & White & & \\
\hline & & & & C: 9 & C: 46.2 & Hispanic & & \\
\hline & & & & Westchester & Westchester & & & \\
\hline
\end{tabular}




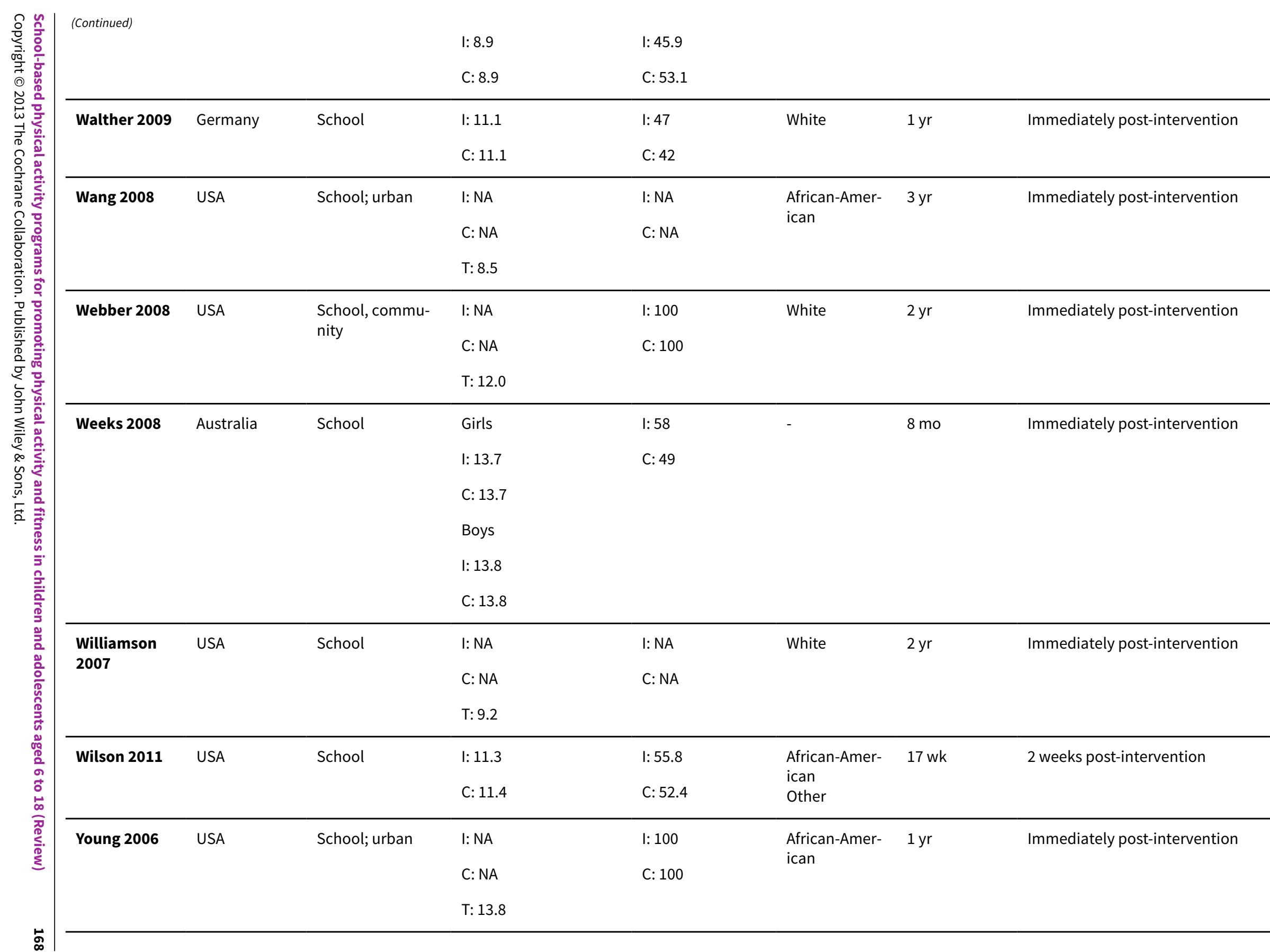




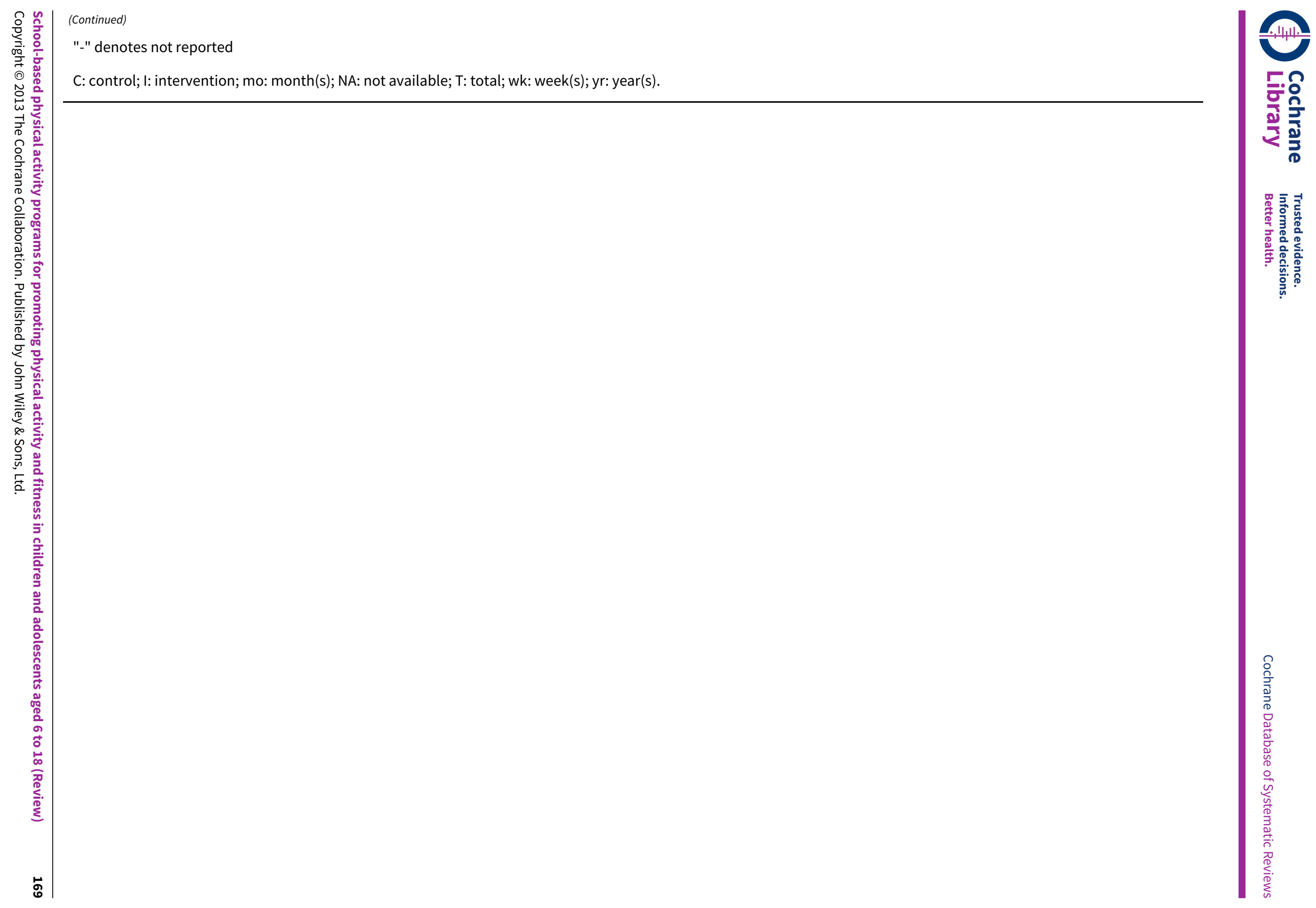




\section{Appendix 4. Matrix of study endpoints}

\begin{tabular}{|c|c|c|}
\hline $\begin{array}{l}\text { Characteristic } \\
\text { Study ID }\end{array}$ & Endpoint(s) & Author statements of primary and secondary endpoint(s) \\
\hline Angelopoulos 2009 & $\begin{array}{l}\text { Blood pressure, diastolic and } \\
\text { systolic }(\mathrm{mm} \mathrm{Hg}) \\
\text { BMI }\left(\mathrm{kg} / \mathrm{m}^{2}\right)\end{array}$ & $\begin{array}{l}\text { Primary and secondary endpoints not specified, outcomes included: cer- } \\
\text { tain physiological and behavioural indices, such as anthropometric, di- } \\
\text { etary, and PA indices }\end{array}$ \\
\hline Araujo-Soares 2009 & PA duration & $\begin{array}{l}\text { Primary outcome was "moderate to vigorous physical activity" (Interna- } \\
\text { tional Physical Activity Questionnaire).... [social cognitive theory], [self- } \\
\text { regulation theory] and planning variables were secondary outcomes...." }\end{array}$ \\
\hline Barbeau 2007 & $\begin{array}{l}\mathrm{BMI}\left(\mathrm{kg} / \mathrm{m}^{2}\right) \\
\text { Duration of PA } \\
\mathrm{VO}_{2} \max (\mathrm{mL} / \mathrm{kg} / \text { minute })\end{array}$ & $\begin{array}{l}\text { Primary and secondary endpoints not specified, outcomes included: PA; } \\
\text { fat mass; fat-free soft tissue; percentage body fat; bone mineral content; } \\
\text { bone mineral density; visceral adipose tissue; subcutaneous abdominal } \\
\text { adipose tissue; cardiovascular; moderate to vigorous PA }\end{array}$ \\
\hline Bayne-Smith 2004 & $\begin{array}{l}\text { Blood cholesterol level (mg/ } \\
\mathrm{dL} \text { ) } \\
\text { Blood pressure, diastolic and } \\
\text { systolic }(\mathrm{mm} \mathrm{Hg}) \\
\mathrm{BMI}\left(\mathrm{kg} / \mathrm{m}^{2}\right) \\
\mathrm{PA} \text { duration } \\
\mathrm{VO}_{2} \max (\mathrm{mL} / \mathrm{kg} / \text { minute) }\end{array}$ & $\begin{array}{l}\text { Primary and secondary endpoints not specified; outcomes included: age, } \\
\text { height, weight, } \mathrm{BMI} \text {, percentage body fat, resting systolic and diastolic } \\
\text { blood pressure, total serum cholesterol, and estimated } \mathrm{VO}_{2} \mathrm{max}\end{array}$ \\
\hline
\end{tabular}

\begin{tabular}{|c|c|c|}
\hline Burke 1998 & $\begin{array}{l}\text { Blood pressure, diastolic and } \\
\text { systolic }(\mathrm{mm} \mathrm{Hg}) \\
\text { BMI }\left(\mathrm{kg} / \mathrm{m}^{2}\right) \\
\text { TV viewing (minutes spent } \\
\text { watching TV) }\end{array}$ & $\begin{array}{l}\text { Primary and secondary endpoints not specified, outcomes included: BMI, } \\
\text { systolic blood pressure, diastolic blood pressure, heart rate, cholesterol }\end{array}$ \\
\hline Bush 1989 & $\begin{array}{l}\text { Blood cholesterol level (mg/ } \\
\mathrm{dL} \text { ) } \\
\text { Blood pressure, diastolic and } \\
\text { systolic }(\mathrm{mm} \mathrm{Hg}) \\
\text { BMI }\left(\mathrm{kg} / \mathrm{m}^{2}\right) \\
\text { Pulse rate (beats/minute) }\end{array}$ & $\begin{array}{l}\text { Primary and secondary endpoints not specified, outcomes included: sys- } \\
\text { tolic blood pressure, diastolic blood pressure, postexercise pulse recov- } \\
\text { ery rate, serum total and high-density lipoprotein cholesterol }\end{array}$ \\
\hline Colin-Ramirez 2010 & $\begin{array}{l}\text { PA rates (\% of sample physi- } \\
\text { cally active) } \\
\text { TV viewing (minutes spent } \\
\text { watching TV) }\end{array}$ & $\begin{array}{l}\text { Primary and secondary endpoints not specified, outcomes included: } \\
\text { moderate to vigorous PA rates, tTV viewing }\end{array}$ \\
\hline Dishman 2004 & $\begin{array}{l}\text { PA rates (\% of sample physi- } \\
\text { cally active) }\end{array}$ & $\begin{array}{l}\text { Primary outcomes were "self-efficacy, outcome-expectancy value, goal } \\
\text { setting, satisfaction, and physical activity" }\end{array}$ \\
\hline Donnelly 2009 & $\begin{array}{l}\text { BMI }\left(\mathrm{kg} / \mathrm{m}^{2}\right) \\
\text { Duration of PA }\end{array}$ & $\begin{array}{l}\text { BMI was the primary outcome, daily PA (duration) and academic achieve- } \\
\text { ment were secondary outcomes" }\end{array}$ \\
\hline Dorgo 2009 & $\mathrm{BMI}\left(\mathrm{kg} / \mathrm{m}^{2}\right)$ & Primary and secondary endpoints not specified, outcomes included: BMI \\
\hline Ewart 1998 & $\begin{array}{l}\text { Blood pressure, diastolic and } \\
\text { systolic }(\mathrm{mm} \mathrm{Hg}) \\
\text { BMI }\left(\mathrm{kg} / \mathrm{m}^{2}\right) \\
\text { PA duration }\end{array}$ & $\begin{array}{l}\text { Primary and secondary endpoints not specified, outcomes included: } \\
\text { blood pressure, cardiorespiratory fitness, and BMI }\end{array}$ \\
\hline
\end{tabular}




\begin{tabular}{|c|c|c|}
\hline Gentile 2009 & $\begin{array}{l}\text { BMI }\left(\mathrm{kg} / \mathrm{m}^{2}\right) \\
\text { TV viewing (minutes spent } \\
\text { watching TV) }\end{array}$ & $\begin{array}{l}\text { Primary and secondary endpoints not specified, outcomes included: PA } \\
\text { duration, TV viewing, BMI }\end{array}$ \\
\hline Haerens 2006 & $\begin{array}{l}\text { BMI }\left(\mathrm{kg} / \mathrm{m}^{2}\right) \\
\text { PA duration } \\
\text { TV viewing (minutes spent } \\
\text { watching TV) }\end{array}$ & $\begin{array}{l}\text { Primary and secondary endpoints not specified, outcomes included: du- } \\
\text { ration of moderate to vigorous PA, TV viewing, BMI }\end{array}$ \\
\hline Haerens 2009 & PA duration & Primary endpoint: PA levels \\
\hline Jones 2008 & $\begin{array}{l}\text { PA duration } \\
\text { TV viewing (minutes spent } \\
\text { watching TV) }\end{array}$ & $\begin{array}{l}\text { Primary and secondary endpoints not specified, but: outcomes includ- } \\
\text { ed weight bearing physical activity; moderate to vigorous PA; vigorous } \\
\text { PA; metabolic equivalent; sedentary activity; before/after-school PA; and } \\
\text { weekend PA }\end{array}$ \\
\hline Kipping 2008 & $\begin{array}{l}\text { BMI }\left(\mathrm{kg} / \mathrm{m}^{2}\right) \\
\text { TV viewing (minutes spent } \\
\text { watching TV) }\end{array}$ & $\begin{array}{l}\text { The primary outcome was reduction in time spent doing screen-based } \\
\text { activities (watching TV, videos, computer games). Other outcomes men- } \\
\text { tioned (but not necessarily classified as secondary): were hours of screen } \\
\text { activities, BMI, mode of transport to school and teachers' views of the in- } \\
\text { tervention. }\end{array}$ \\
\hline
\end{tabular}

\section{Kriemler 2010}

Blood pressure, diastolic and systolic (mm Hg)

BMI $\left(\mathrm{kg} / \mathrm{m}^{2}\right)$

PA duration
Primary outcome measures included body fat (sum of 4 skinfolds), aerobic fitness (shuttle run test), PA (accelerometry), and quality of life. Secondary outcome measures included BMI and cardiovascular risk score (average $Z$ score of waist circumference, mean blood pressure, blood glucose, inverted high density lipoprotein cholesterol, and triglycerides)

Li $2010 \quad$ BMI $\left(\mathrm{kg} / \mathrm{m}^{2}\right)$

Primary and secondary endpoints not specified; outcomes included: height, fasting body weight, BMI, body composition, body impedance, fat free mass, fat mass, percent body fat

\begin{tabular}{ll}
\hline Lubans 2009 & PA duration \\
& TV viewing (minutes spent \\
& watching TV)
\end{tabular}

The primary outcome measured was mean steps/day as determined by 4 days of pedometer monitoring. Time spent in non-organized PA and sedentary behavior were also measured

\begin{tabular}{|c|c|c|}
\hline Luepker 1996 & $\begin{array}{l}\text { Blood cholesterol level }(\mathrm{mg} / \\
\mathrm{dL}) \\
\text { Blood pressure, diastolic and } \\
\text { systolic }(\mathrm{mm} \mathrm{Hg}) \\
\text { BMI }\left(\mathrm{kg} / \mathrm{m}^{2}\right) \\
\text { PA duration } \\
\text { Pulse rate (beats/minute) }\end{array}$ & $\begin{array}{l}\text { At the school level, the } 2 \text { primary end points were changes in the fat con- } \\
\text { tent of food service lunch offerings and the amount of moderate too } \\
\text { vigorous PA in the physical education programs. At the individual stu- } \\
\text { dent level, serum cholesterol change was the primary end point and was } \\
\text { used for power calculations for the study. Individual level secondary end } \\
\text { points included psychosocial factors, recall measures of eating and PA } \\
\text { patterns, and other physiologic measures }\end{array}$ \\
\hline
\end{tabular}

\begin{tabular}{lll}
\hline Martinez 2008 & Blood cholesterol level (mg/ & $\begin{array}{l}\text { Main outcome measures: BMI, triceps skin-fold thickness and percentage } \\
\text { body fat. Secondary measures were blood lipids and blood pressure }\end{array}$ \\
& $\begin{array}{l}\text { Blood pressure, diastolic and } \\
\text { systolic }(\mathrm{mm} \mathrm{Hg})\end{array}$ \\
& BMI $\left(\mathrm{kg} / \mathrm{m}^{2}\right)$ &
\end{tabular}

$\begin{array}{ll}\text { McManus } 2008 & \text { Blood pressure, diastolic and Main outcome measures: PA and changes in attraction to PA } \\ \text { systolic }(\mathrm{mm} \mathrm{Hg}) \\ \text { BMI }\left(\mathrm{kg} / \mathrm{m}^{2}\right) \\ \text { PA duration } \\ \text { Pulse rate (beats/minute) }\end{array}$




\section{Neumark-Sztainer} 2009
BMI $\left(\mathrm{kg} / \mathrm{m}^{2}\right)$

Physical activity duration TV viewing (minutes spent watching TV)
Primary and secondary endpoints were not specified; but outcomes measured included: assessment of program participation (sign-in sheets, attendance records, surveys), satisfaction and perceived impact among children and parents in the intervention condition (process surveys)

$\begin{array}{ll}\text { Neumark-Sztainer } & \text { BMI }\left(\mathrm{kg} / \mathrm{m}^{2}\right) \\ \mathbf{2 0 1 0} & \text { PA duration } \\ & \text { TV viewing (minutes spent } \\ & \text { watching TV) }\end{array}$

Main outcome measures: percentage body fat, BMI, PA, sedentary activity, dietary intake, eating patterns, unhealthy weight control behaviors, and body/ self-image. Other outcomes included perceived changes in the social environments of the participating girls, given the importance placed on providing a supportive environment within New Moves. Finally, program satisfaction among participating girls and their parents were examined

\begin{tabular}{lll}
\hline Peralta 2009 & $\begin{array}{l}\text { BMI }\left(\mathrm{kg} / \mathrm{m}^{2}\right) \\
\text { PA duration } \\
\text { TV viewing (minutes spent } \\
\text { watching TV) }\end{array}$ & $\begin{array}{l}\text { Primary outcome: BMI; secondary outcomes: waist circumference, per- } \\
\text { centage body fat, cardiorespiratory fitness, PA and small screen recre- } \\
\text { ation time }\end{array}$ \\
\hline Petchers 1988 & $\begin{array}{l}\text { PA rates (\% of sample physi- } \\
\text { cally active) }\end{array}$ & $\begin{array}{l}\text { Primary and secondary endpoints not specified; outcomes included: } \\
\text { knowledge, attitudes and behaviors reported on the knowledge scale }\end{array}$ \\
\hline Reed 2008 & $\begin{array}{l}\text { Blood cholesterol level (mg/ } \\
\text { dL) } \\
\text { Blood pressure, diastolic and } \\
\text { systolic (mm Hg) } \\
\text { BMI (kg/m²) }\end{array}$ & $\begin{array}{l}\text { Primary and secondary endpoints not specified; outcomes included: } \\
\text { cardiovascular fitness (20-m shuttle run), blood pressure, BMI, total } \\
\text { cholesterol, total to high-density cholesterol, low-density lipoprotein, } \\
\text { apolipoprotein B, C-reactive protein and fibrinogen, academic perfor- } \\
\text { mance, amounts of physical activity (questionnaire) and PA counts (pe- } \\
\text { dometer). (Power calculation was based on cardiovascular outcome, but } \\
\text { data were not extracted for this outcome) }\end{array}$ \\
\end{tabular}

\begin{tabular}{lll}
\hline Robinson 1999 & BMI $\left(\mathrm{kg} / \mathrm{m}^{2}\right)$ & The primary outcome was BMI; other end points were triceps skinfolds, \\
PA duration & waist and hip circumference, PA, dietary behaviors, parental and child \\
TV viewing (minutes spent & behaviors \\
watching TV) &
\end{tabular}

\begin{tabular}{lll}
\hline Salmon 2008 & BMI $\left(\mathrm{kg} / \mathrm{m}^{2}\right)$ & Primary outcome: BMI; secondary outcomes: sedentary behaviors, PA, \\
& PA duration & and enjoyment of PA \\
TV viewing (minutes spent & \\
watching TV) &
\end{tabular}

\begin{tabular}{|c|c|c|}
\hline Simon 2004 & $\begin{array}{l}\text { Blood cholesterol level (mg/ } \\
\text { dL) } \\
\text { Blood pressure, diastolic and } \\
\text { systolic }(\mathrm{mm} \mathrm{Hg}) \\
\text { BMI }\left(\mathrm{kg} / \mathrm{m}^{2}\right) \\
\text { PA duration } \\
\text { PA rates (\% of sample PA) } \\
\text { TV viewing (minutes spent } \\
\text { watching TV) }\end{array}$ & $\begin{array}{l}\text { Primary and secondary endpoints not specified; outcomes included: par- } \\
\text { ticipation in leisure organized PA, high sedentary behavior ( } 43 \mathrm{~h} / \text { day), } \\
\text { self-efficacy, and intention toward PA }\end{array}$ \\
\hline
\end{tabular}

Singh 2009 BMI $\left(\mathrm{kg} / \mathrm{m}^{2}\right) \quad$ Primary outcome measures: body composition (i.e., waist circumference,
TV viewing (minutes spent skinfold thickness, and BMI). engaged in inactivity)

Secondary outcome measures: dietary and PA behavior (i.e., energy balance related behaviors)

\begin{tabular}{|c|c|c|}
\hline Singhal 2010 & BMI (kg/m²) & $\begin{array}{l}\text { Primary outcomes: waist circumference, hip circumference, triceps and } \\
\text { biceps skinfolds, mid-thigh circumference, mid-upper arm circumfer- }\end{array}$ \\
\hline
\end{tabular}


ence, sagittal abdominal diameter, BMI, waist-to-hip ratio, waist-to thigh ratio and waist-to-height ratio

Secondary outcomes: body composition, knowledge, attitude and practices, body image satisfaction, biochemical measures related to diagnosing metabolic syndrome

\begin{tabular}{lll}
\hline Stephens 1998 & $\begin{array}{l}\text { Blood pressure, diastolic and } \\
\text { systolic }(\mathrm{mm} \mathrm{Hg}) \\
\text { Pulse rate (beats/minute) }\end{array}$ & $\begin{array}{l}\text { Primary and secondary endpoints not specified; outcomes included: } \\
\text { skinfold thickness, heart rate response to submaximal exercise, and sit } \\
\text { and reach flexibility }\end{array}$ \\
\hline Stone $\mathbf{2 0 0 3}$ & $\mathrm{BMI}(\mathrm{kg} / \mathrm{m} 2)$ & $\begin{array}{l}\text { Primary and secondary endpoints not specified; outcomes included: per- } \\
\text { centage body fat, physical activity levels, knowledge of healthy behaviors }\end{array}$ \\
\hline Trevino $\mathbf{2 0 0 4}$ & $\mathrm{VO}_{2} \mathrm{max}(\mathrm{mL} / \mathrm{kg} /$ minute) & $\begin{array}{l}\text { The primary end point was fasting capillary glucose, however this out- } \\
\text { come was not included in this review therefore data was not extracted on } \\
\text { this outcome. A secondary outcome was fitness level }\end{array}$
\end{tabular}

\begin{tabular}{|c|c|c|}
\hline Verstraete 2006 & $\begin{array}{l}\text { PA rates (\% of sample physi- } \\
\text { cally active) }\end{array}$ & Primary end point was PA level \\
\hline Walter 1988 & $\begin{array}{l}\text { Blood cholesterol level (mg/ } \\
\mathrm{dL} \text { ) } \\
\text { Blood pressure, diastolic and } \\
\text { systolic }(\mathrm{mm} \mathrm{Hg}) \\
\text { BMI }\left(\mathrm{kg} / \mathrm{m}^{2}\right) \\
\text { Pulse rate (beats/minute) }\end{array}$ & $\begin{array}{l}\text { Primary and secondary endpoints not specified; outcomes included: } \\
\text { levels of risk factors and health knowledge, systolic and diastolic blood } \\
\text { pressures, nonfasting plasma levels of total cholesterol, height and } \\
\text { weight }\end{array}$ \\
\hline
\end{tabular}

\begin{tabular}{lll}
\hline Walther 2009 & Blood cholesterol level $(\mathrm{mg} /$ & Primary endpoint was $\mathrm{VO}_{2} \mathrm{max}$ \\
& $\mathrm{dL})$ & \\
& Blood pressure, diastolic and & Secondary outcomes included: blood pressure, heart rate, total choles- \\
& systolic $(\mathrm{mm} \mathrm{Hg})$ & terol \\
& $\mathrm{VO}_{2} \max (\mathrm{mL} / \mathrm{kg} /$ minute $)$ &
\end{tabular}

\begin{tabular}{|c|c|c|}
\hline Wang 2008 & $\begin{array}{l}\text { Blood cholesterol level (mg/ } \\
\mathrm{dL}) \\
\text { Blood pressure, diastolic and } \\
\text { systolic }(\mathrm{mm} \mathrm{Hg}) \\
\mathrm{BMI}\left(\mathrm{kg} / \mathrm{m}^{2}\right) \\
\mathrm{VO}_{2} \max (\mathrm{mL} / \mathrm{kg} / \text { minute })\end{array}$ & $\begin{array}{l}\text { Primary end point was percentage body fat; however, this outcome was } \\
\text { not included in this review, therefore data on this outcome was not ex- } \\
\text { tracted } \\
\text { Secondary outcome was fitness level }\end{array}$ \\
\hline Webber 2008 & $\begin{array}{l}\text { BMI }\left(\mathrm{kg} / \mathrm{m}^{2}\right) \\
\text { PA duration } \\
\text { TV viewing (minutes spent } \\
\text { watching TV) }\end{array}$ & Primary outcome: moderate to vigorous PA \\
\hline Weeks 2008 & $\begin{array}{l}\text { BMI }\left(\mathrm{kg} / \mathrm{m}^{2}\right) \\
\text { PA duration }\end{array}$ & $\begin{array}{l}\text { Primary and secondary outcomes were not specified; outcomes includ- } \\
\text { ed: BMI }\end{array}$ \\
\hline Williamson 2007 & $\begin{array}{l}\mathrm{BMI}\left(\mathrm{kg} / \mathrm{m}^{2}\right) \\
\text { PA duration } \\
\text { TV viewing (minutes spent } \\
\text { engaged in inactivity) }\end{array}$ & $\begin{array}{l}\text { Primary end point was change in BMI Z-scores, however this outcome } \\
\text { was not included, therefore data on this outcome was not extracted } \\
\text { Secondary outcomes were: time spent engaged in PA and time spent en- } \\
\text { gaged in sedentary behaviors }\end{array}$ \\
\hline Wilson 2011 & PA duration & Primary outcome was PA duration \\
\hline Young 2006 & $\begin{array}{l}\text { Blood cholesterol level (mg/ } \\
\mathrm{dL} \text { ) }\end{array}$ & $\begin{array}{l}\text { Daily energy expenditure, measured as time spent engaged in PA was the } \\
\text { primary outcome. }\end{array}$ \\
\hline
\end{tabular}


Blood pressure, diastolic and Secondary outcomes included: fitness level, time engaged in sedentary systolic $(\mathrm{mm} \mathrm{Hg})$ behavior, BMI, blood pressure, and total plasma cholesterol BMI (kg/m2)

BMI: body mass index; PA: physical activity; TV: television; $\mathrm{VO}_{2}$ max: maximal oxygen uptake.

\section{Appendix 5. Physical activity rates (\% of sample physically active)}

\begin{tabular}{|c|c|c|c|c|c|c|}
\hline $\begin{array}{l}\text { Character- } \\
\text { istic } \\
\text { Study ID }\end{array}$ & $\begin{array}{l}\text { Measurement } \\
\text { period }\end{array}$ & $\begin{array}{l}\text { Study pop- } \\
\text { ulation }\end{array}$ & $\begin{array}{l}\text { Interven- } \\
\text { tion group }\end{array}$ & $\begin{array}{l}\text { Control } \\
\text { group }\end{array}$ & $\begin{array}{l}\text { Overall ef- } \\
\text { fect }\end{array}$ & Comments \\
\hline \multirow{2}{*}{$\begin{array}{l}\text { Col- } \\
\text { in-Ramirez } \\
2010\end{array}$} & Baseline & \multirow{2}{*}{$\begin{array}{l}498 \text { boys } \\
\text { and girls }\end{array}$} & 87 & 85 & - & \multirow{2}{*}{$\begin{array}{l}\text { Data on TV viewing reported here. Simi- } \\
\text { lar results reported for video game play- } \\
\text { ing and computer use. }\end{array}$} \\
\hline & $\begin{array}{l}\text { Follow-up (12 } \\
\text { months post- } \\
\text { intervention) }\end{array}$ & & 92 & 91 & NS & \\
\hline \multirow[t]{2}{*}{$\begin{array}{l}\text { Dishman } \\
2004\end{array}$} & Baseline & \multirow[t]{2}{*}{2111 girls } & 71 & 74 & NS & \multirow{2}{*}{$\begin{array}{l}\text { Physical activity was assessed using the } \\
\text { 3-Day Physical Activity Recall } \\
\text { MVPA } \geq 2 \text { blocks of moderate to vigor- } \\
\text { ous physical activity/day }\end{array}$} \\
\hline & $\begin{array}{l}\text { End of inter- } \\
\text { vention }\end{array}$ & & 69 & 72 & NS & \\
\hline \multirow{2}{*}{$\begin{array}{l}\text { Petchers } \\
1988\end{array}$} & Baseline & \multirow{2}{*}{$\begin{array}{l}325 \text { boys } \\
\text { and girls }\end{array}$} & NA & NA & NS & \multirow{2}{*}{$\begin{array}{l}\text { Self-reported physical activity level as } \\
\text { number of times physically active per } \\
\text { week }\end{array}$} \\
\hline & $\begin{array}{l}\text { Follow-up } \\
\text { (year 1) }\end{array}$ & & NA & NA & NS & \\
\hline \multirow{2}{*}{$\begin{array}{l}\text { Simon } \\
2004\end{array}$} & Baseline & \multirow{2}{*}{$\begin{array}{l}954 \text { ado- } \\
\text { lescent } \\
\text { males and } \\
\text { females }\end{array}$} & 64 & 58 & NS & \multirow{2}{*}{$\begin{array}{l}\text { Self-reported physical activity assessed } \\
\text { in the last year on a weekly basis in } \\
\text { terms of frequency }\end{array}$} \\
\hline & $\begin{array}{l}\text { During inter- } \\
\text { vention ( } 6 \\
\text { months) }\end{array}$ & & 83 & 58 & $\begin{array}{l}\mathrm{P}<0.0001 \\
\mathrm{OR} 2.74 \\
(95 \% \mathrm{Cl} \\
2.01 \text { to } \\
3.75)\end{array}$ & \\
\hline \multirow{2}{*}{$\begin{array}{l}\text { Verstraete } \\
2006\end{array}$} & Baseline & 235 boys & 57 baseline & 56 baseline & & \multirow{2}{*}{$\begin{array}{l}\text { Accelerometers were used to measure } \\
\text { physical activity levels. The } 1 \text { min move- } \\
\text { ment counts were used to determine } \\
\text { light, moderate, and vigorous intensity } \\
\text { activity }\end{array}$} \\
\hline & $\begin{array}{l}\text { End of inter- } \\
\text { vention }\end{array}$ & & $\begin{array}{l}53 \text { fol- } \\
\text { low-up }\end{array}$ & $\begin{array}{l}44 \text { fol- } \\
\text { low-up }\end{array}$ & $P<0.01$ & \\
\hline
\end{tabular}

$\mathrm{Cl}$ : confidence interval; NA: not acknowledged; NS: not significant; OR: odds ratio; TV: television; MVPA: moderate to vigorous physical activity 


\begin{tabular}{|c|c|c|c|c|c|c|c|c|}
\hline \multirow{4}{*}{\multicolumn{2}{|c|}{ 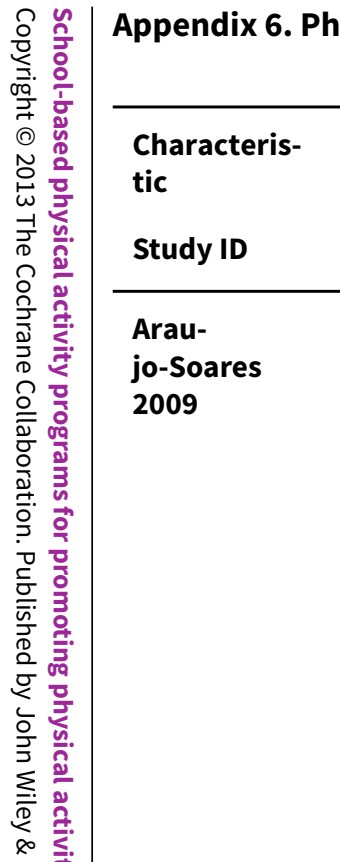 }} & \multirow[b]{2}{*}{ Measurement period } & \multirow[b]{2}{*}{$\begin{array}{l}\text { Study popu- } \\
\text { lation }\end{array}$} & \multirow[b]{2}{*}{$\begin{array}{l}\text { Intervention } \\
\text { group }\end{array}$} & \multirow[b]{2}{*}{$\begin{array}{l}\text { Control } \\
\text { group }\end{array}$} & \multirow[b]{2}{*}{ Overall effect } & \multirow[b]{2}{*}{ Comments } & \multirow{4}{*}{ 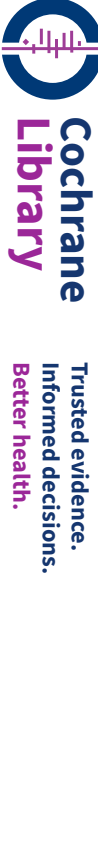 } \\
\hline & & & & & & & & \\
\hline & & Baseline & 195 boys and & 122 & 115 & NS & \multirow[b]{2}{*}{$\begin{array}{l}\text { PA was assessed with the International Physi- } \\
\text { cal Activity Questionnaire for adolescents using } \\
\text { the 7-day recall method. Children indicated how } \\
\text { many sessions of activities they had engaged in } \\
\text { and how long each lasted. From this question- } \\
\text { naire a measure of general MVPA and exercise } \\
\text { was derived consisting of a composite score that } \\
\text { multiplied the frequency of sessions per week } \\
\text { with minutes per session. }\end{array}$} & \\
\hline & & End of intervention (9 months) & & 158 & 113 & $\begin{array}{l}\mathrm{P}=0.016 \\
45(95 \% \mathrm{Cl} 9 \\
\text { to } 82)\end{array}$ & & \\
\hline 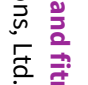 & \multirow[t]{2}{*}{$\begin{array}{l}\text { Barbeau } \\
2007\end{array}$} & Baseline & 201 girls & 27.6 & 27.6 & NA & \multirow{2}{*}{$\begin{array}{l}\text { Free-living PA was measured using a 7-day recall } \\
\text { tool }\end{array}$} & \\
\hline 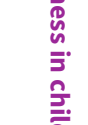 & & End of intervention & & 60 & 40.2 & $\begin{array}{l}P=0.0006 \\
22.2(95 \% \mathrm{Cl} \\
9.6 \text { to } 34.2)\end{array}$ & & \\
\hline J & \multirow{2}{*}{$\begin{array}{l}\text { Bayne-Smith } \\
2004\end{array}$} & Baseline & 442 girls & 67.5 & 82.5 & NS & \multirow{2}{*}{$\begin{array}{l}\text { Self-reported activity measured as the number } \\
\text { of } 15 \text { min sessions engaged in outside of school } \\
\text { time }\end{array}$} & \\
\hline$\frac{0}{0}$ & & End of intervention & & 79.5 & 82.5 & NS & & \\
\hline$\stackrel{\Phi}{3}$ & \multirow{2}{*}{$\begin{array}{l}\text { Donnelly } \\
2009\end{array}$} & Baseline & 1490 boys and & NA & NA & NS & \multirow{2}{*}{$\begin{array}{l}\text { PA assessment was conducted using direct ob- } \\
\text { servations via the System for Observing Fitness } \\
\text { Instruction Time (SOFIT) method. Values are } \\
\text { means taken from 4-day averages of minutes of } \\
\text { MVPA ( } \geq 4 \text { METs) }\end{array}$} & 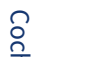 \\
\hline $\begin{array}{l}\text { 吅 } \\
\text { on } \\
\vdots \\
\vdots \\
0\end{array}$ & & End of intervention (year 3) & & 98 & 72 & $P=0.001$ & & 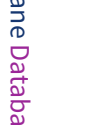 \\
\hline 內్ & \multirow[t]{2}{*}{ Ewart 1998} & Baseline & 88 adolescent & 8.6 & 8.1 & - & \multirow{2}{*}{$\begin{array}{l}\text { Observed step test exercise duration measured in } \\
\text { seconds }\end{array}$} & $\stackrel{0}{\infty}$ \\
\hline$=$ & & End of intervention & & 9.55 & 7.03 & $P<0.0003$ & & $\stackrel{0}{3}$ \\
\hline$r$ & Haerens 2006 & Baseline & $\begin{array}{l}2434 \text { boys and } \\
\text { girls }\end{array}$ & 18 & 23 & - & $\begin{array}{l}\text { Self-reported leisure time PA measured in num- } \\
\text { ber of minutes. }\end{array}$ & 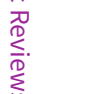 \\
\hline
\end{tabular}




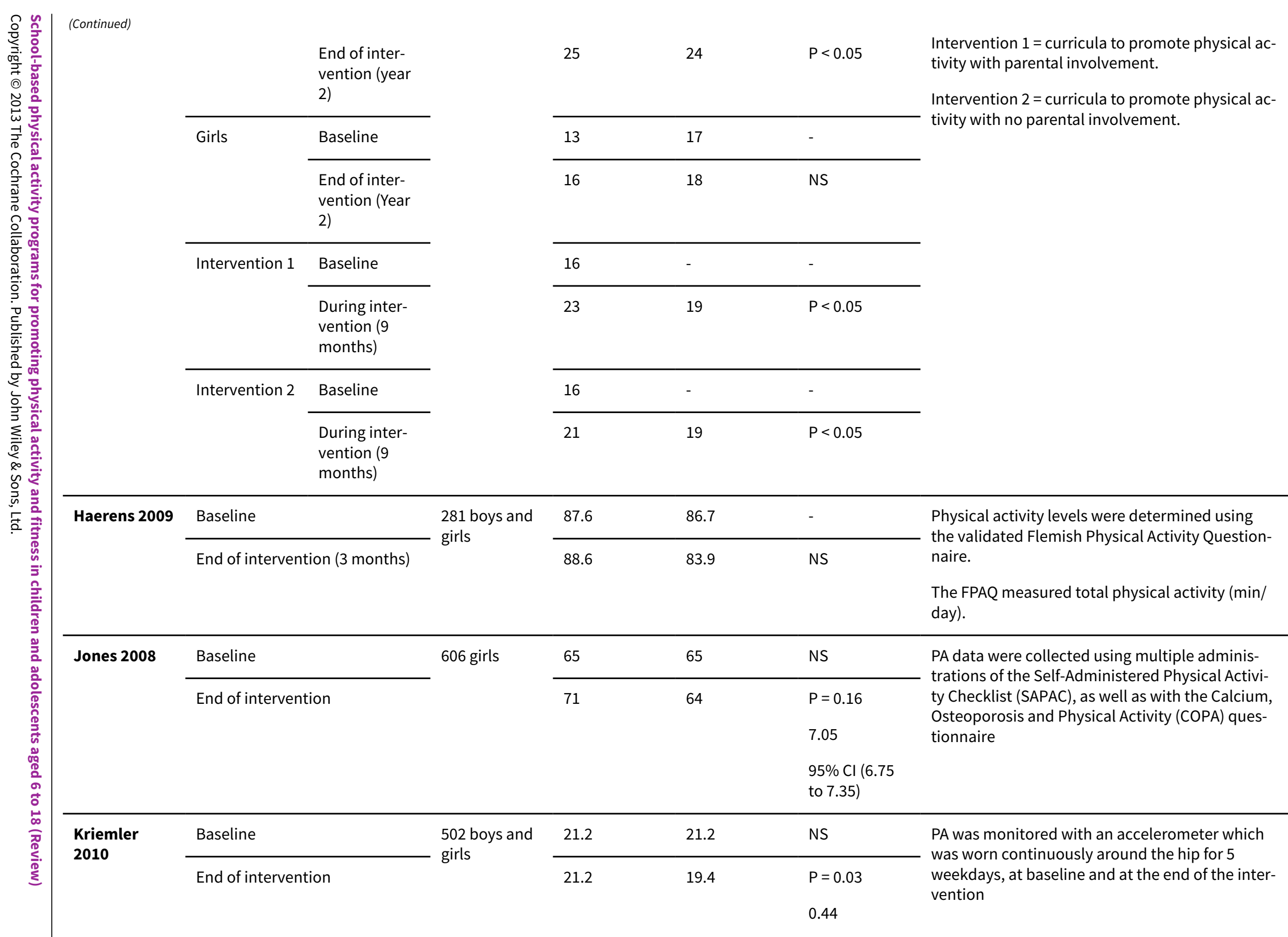




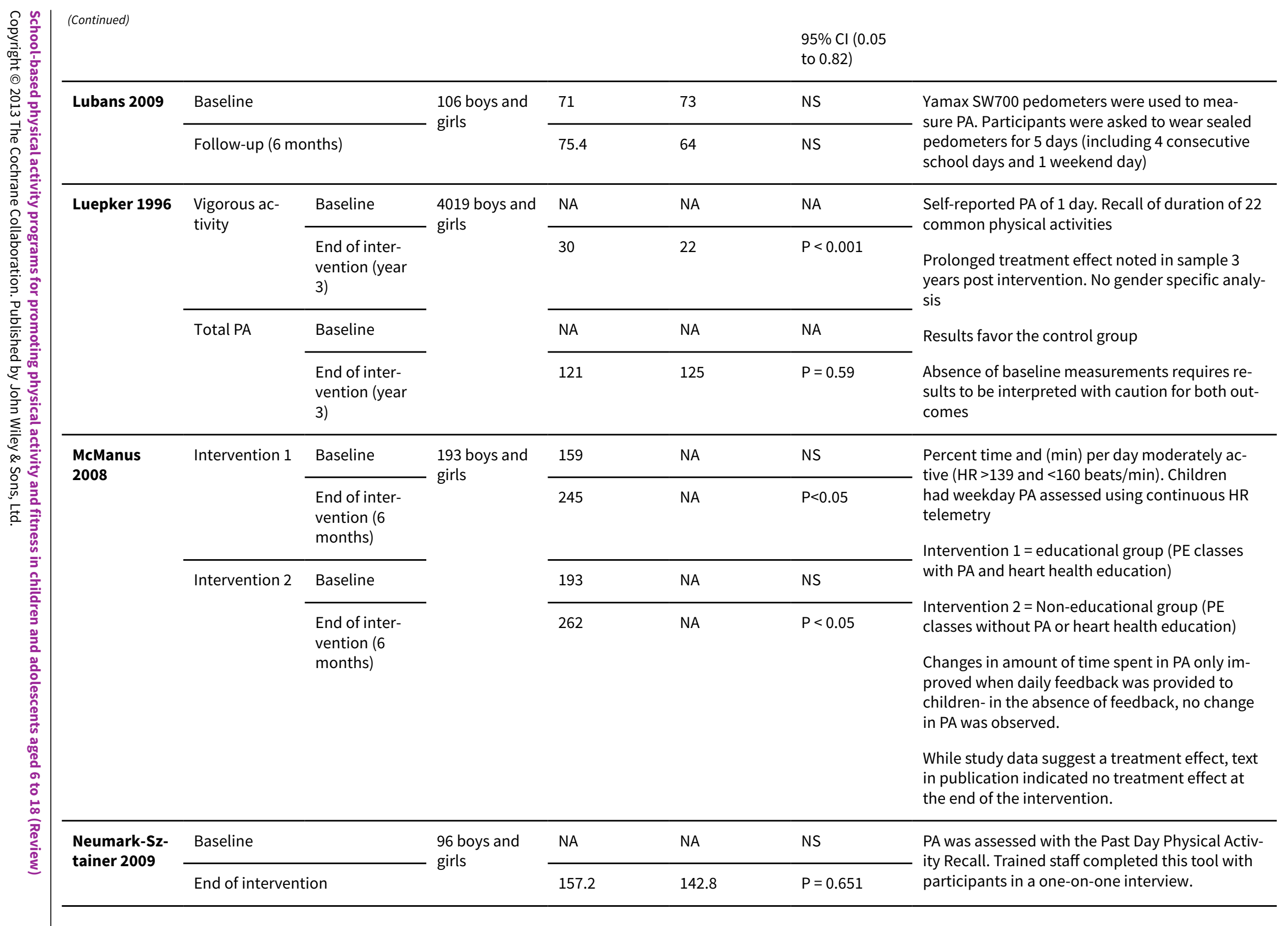




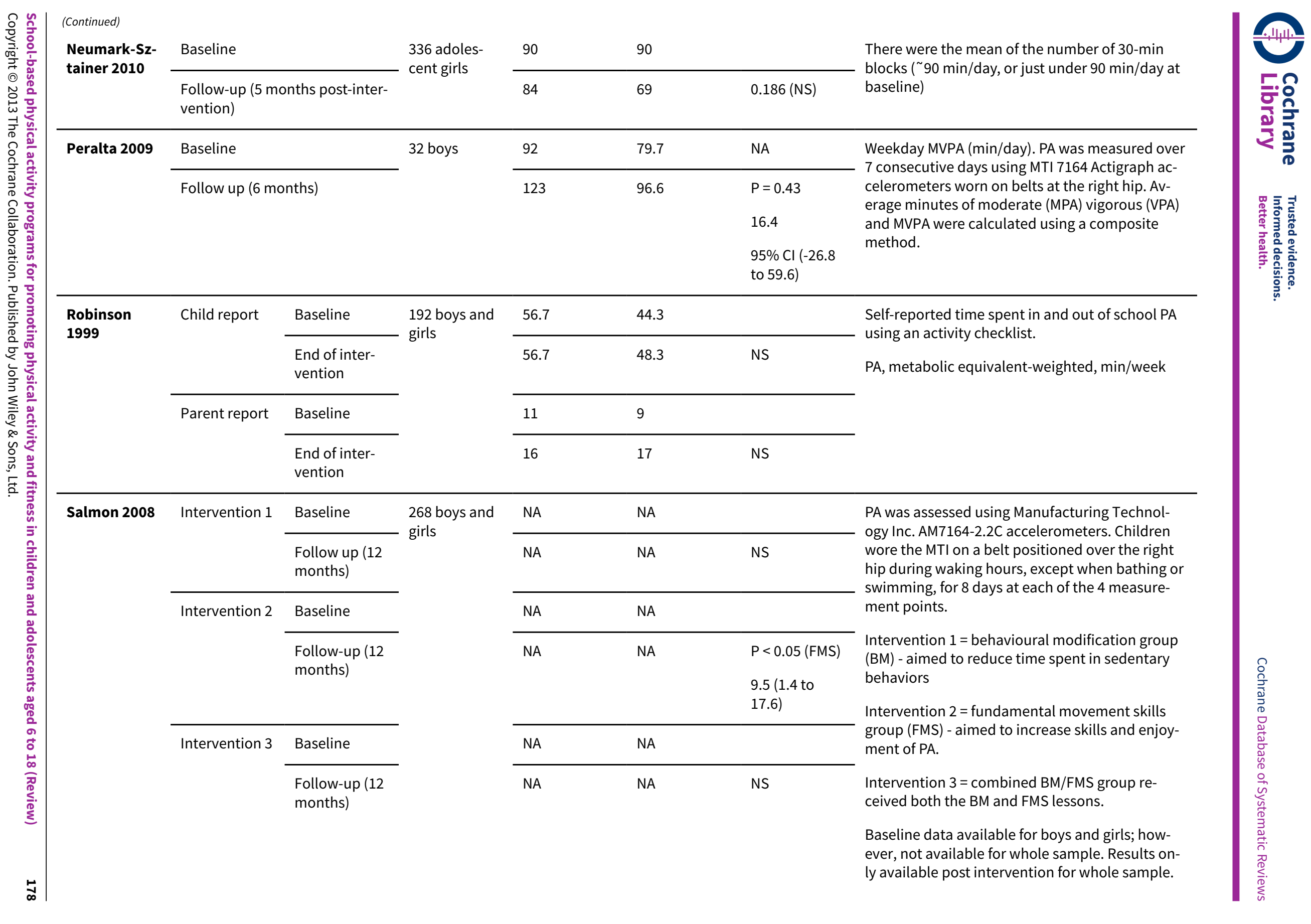




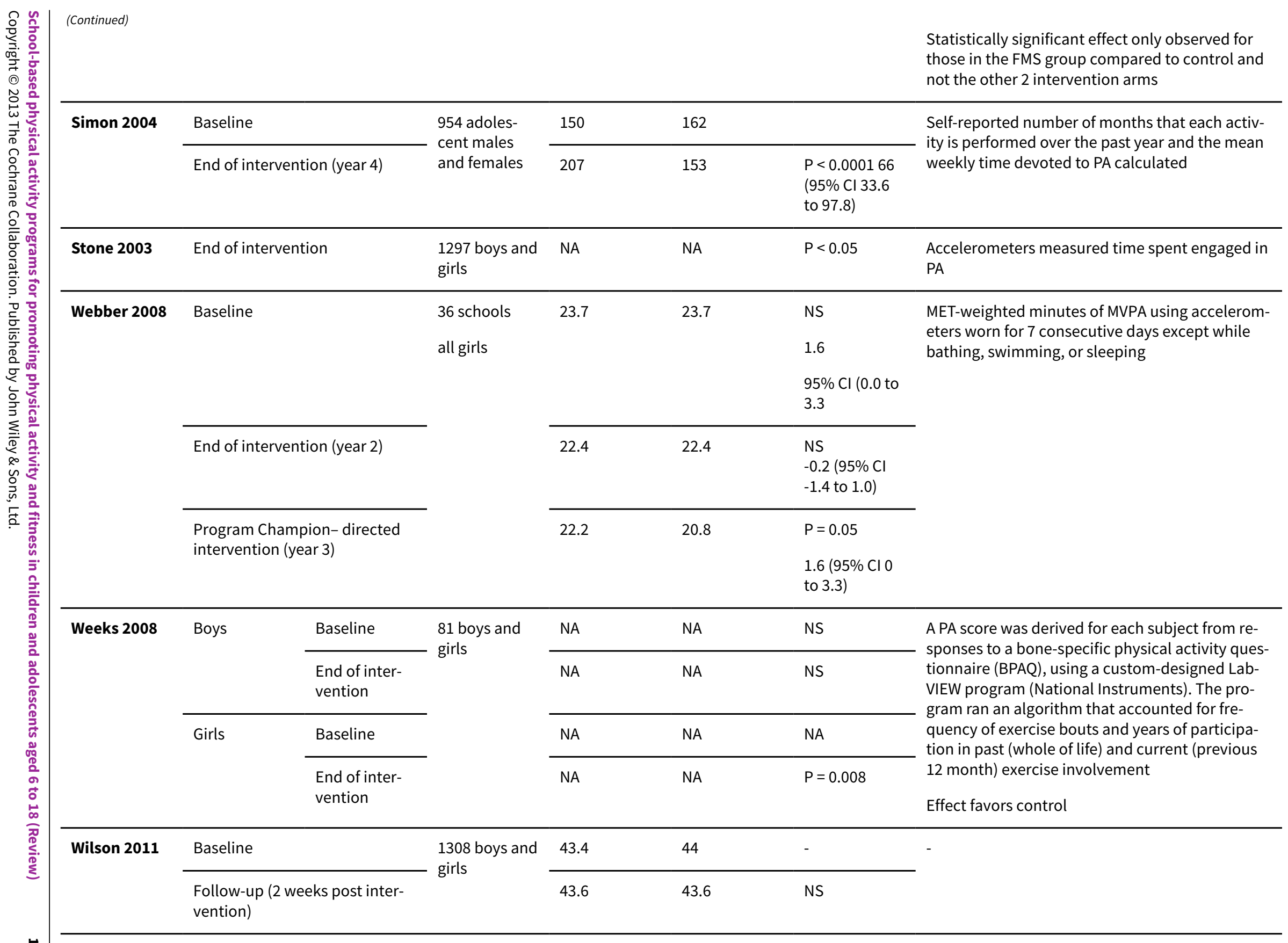


586 boys and

HEE

girls

End of intervention (18 months)
NA

22
ADT

NA

$-3$

A

NS

$P=0.06$

The Self-Administered Physical Activity Checklist (SAPAC) is a 29-item self-report, 1-day recall of physical and selected sedentary activities using a checklist format. Self-reported data from the SAPAC were summarized to measure minutes of MVPA

Intervention 1 = healthy eating and exercise group (HEE). Provided with increased opportunity for PA during the day and education

Intervention 2 = Alcohol/Drug/Tobacco use/

abuse prevention (ADT). Program to modify children's beliefs about the use of tobacco, alcohol, and illicit drugs

Cl: confidence interval; NA: not acknowledged; NS: not significant; MVPA: moderate to vigorous physical activity; MET: metabolic equivalent; FPAQ: Flemish Physical Activity Questionnaire; HR: heart rate; PE: physical education; PA: physical activity. 


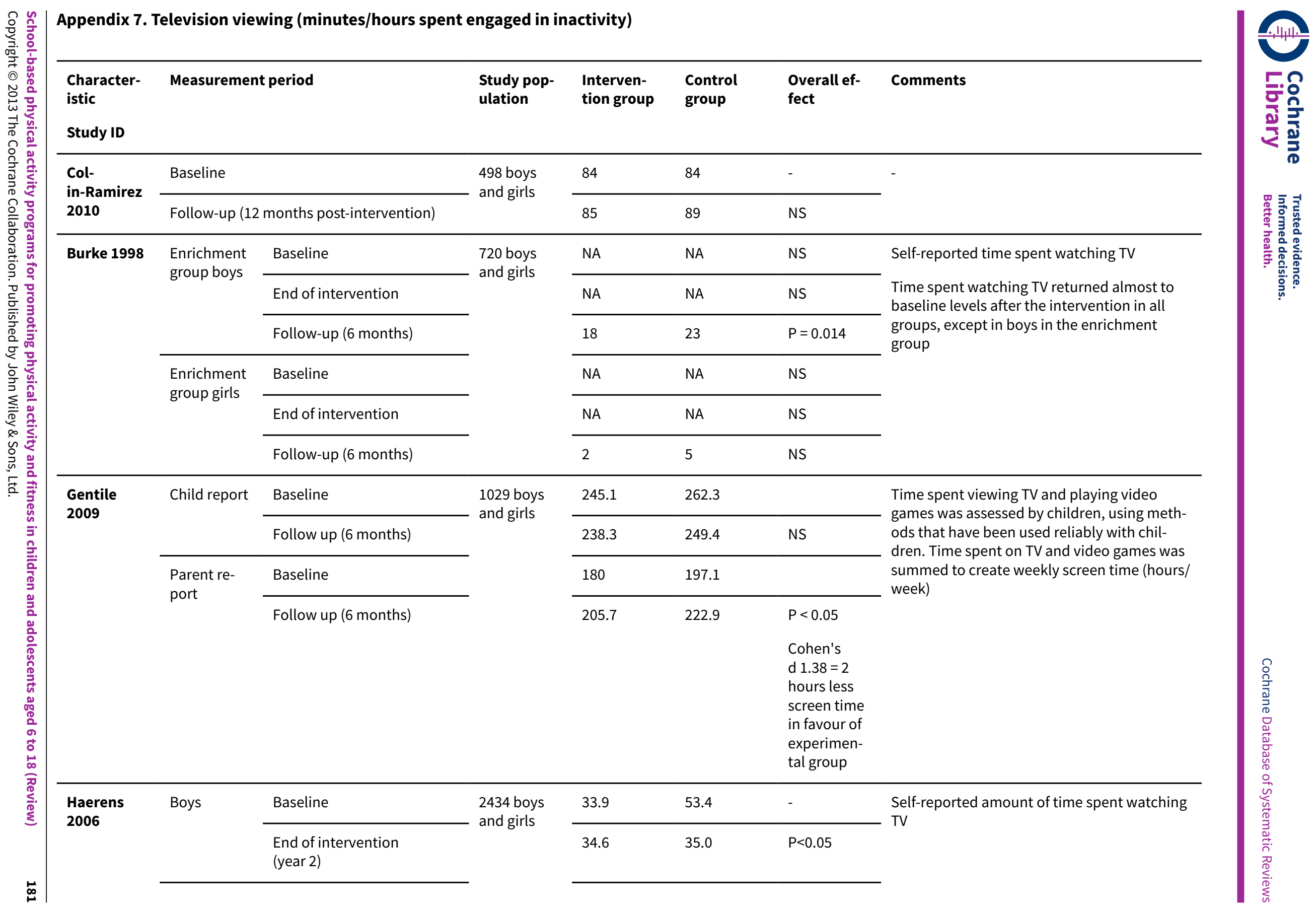




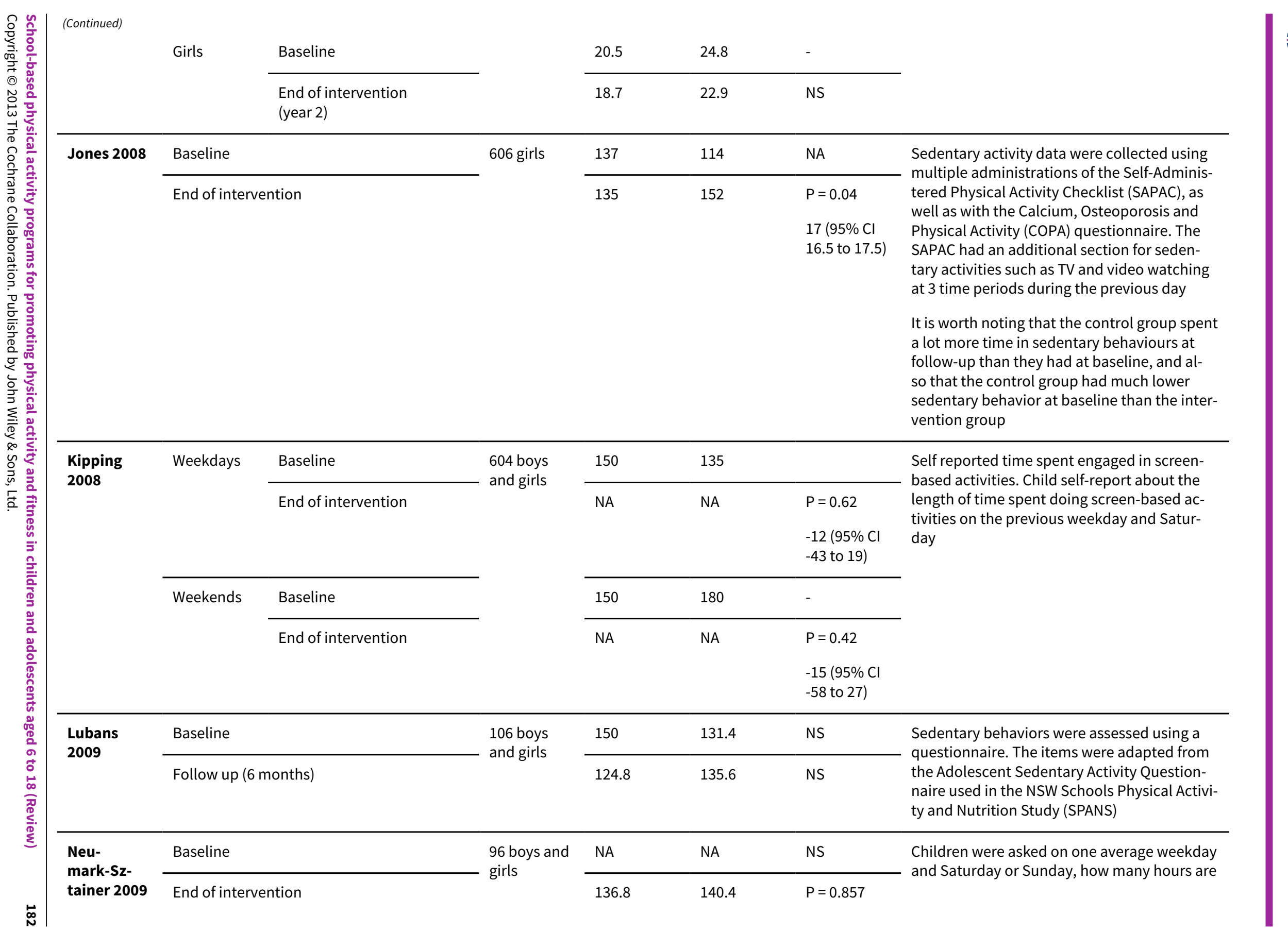




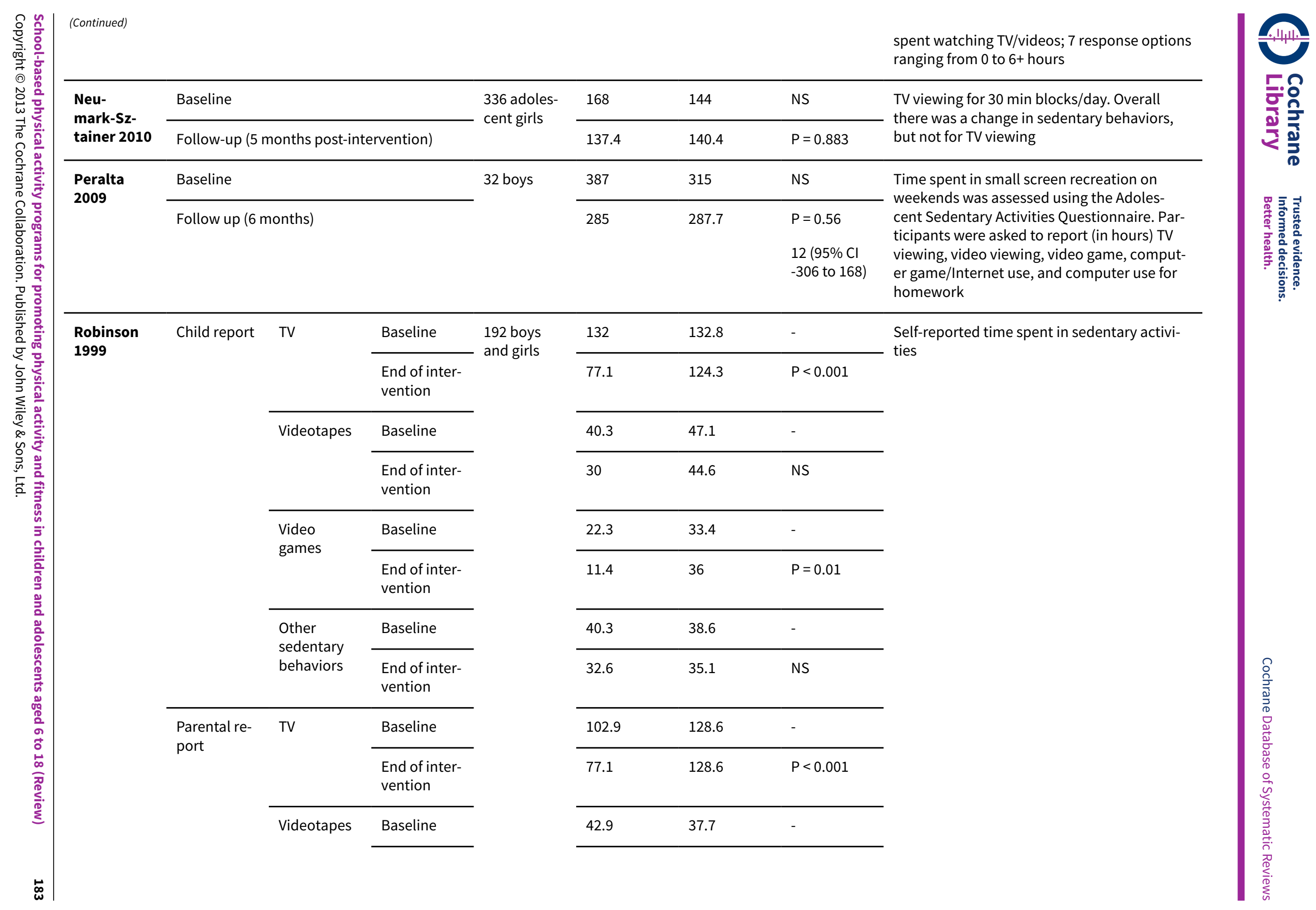




\begin{tabular}{ll} 
& $\begin{array}{l}\text { End of inter- } \\
\text { vention }\end{array}$ \\
\hline $\begin{array}{l}\text { Video } \\
\text { games }\end{array}$ & Baseline \\
\cline { 2 - 2 } & $\begin{array}{l}\text { End of inter- } \\
\text { vention }\end{array}$ \\
\hline $\begin{array}{l}\text { Other } \\
\text { sedentary } \\
\text { behaviors }\end{array}$ & Baseline \\
\cline { 2 - 2 } & $\begin{array}{l}\text { End of inter- } \\
\text { vention }\end{array}$
\end{tabular}

\begin{tabular}{lll}
\hline 15.4 & 23.1 & - \\
\hline 12 & 22.3 & NS \\
\hline 385.7 & 342.9 & - \\
\hline 351.4 & 368.6 & NS
\end{tabular}

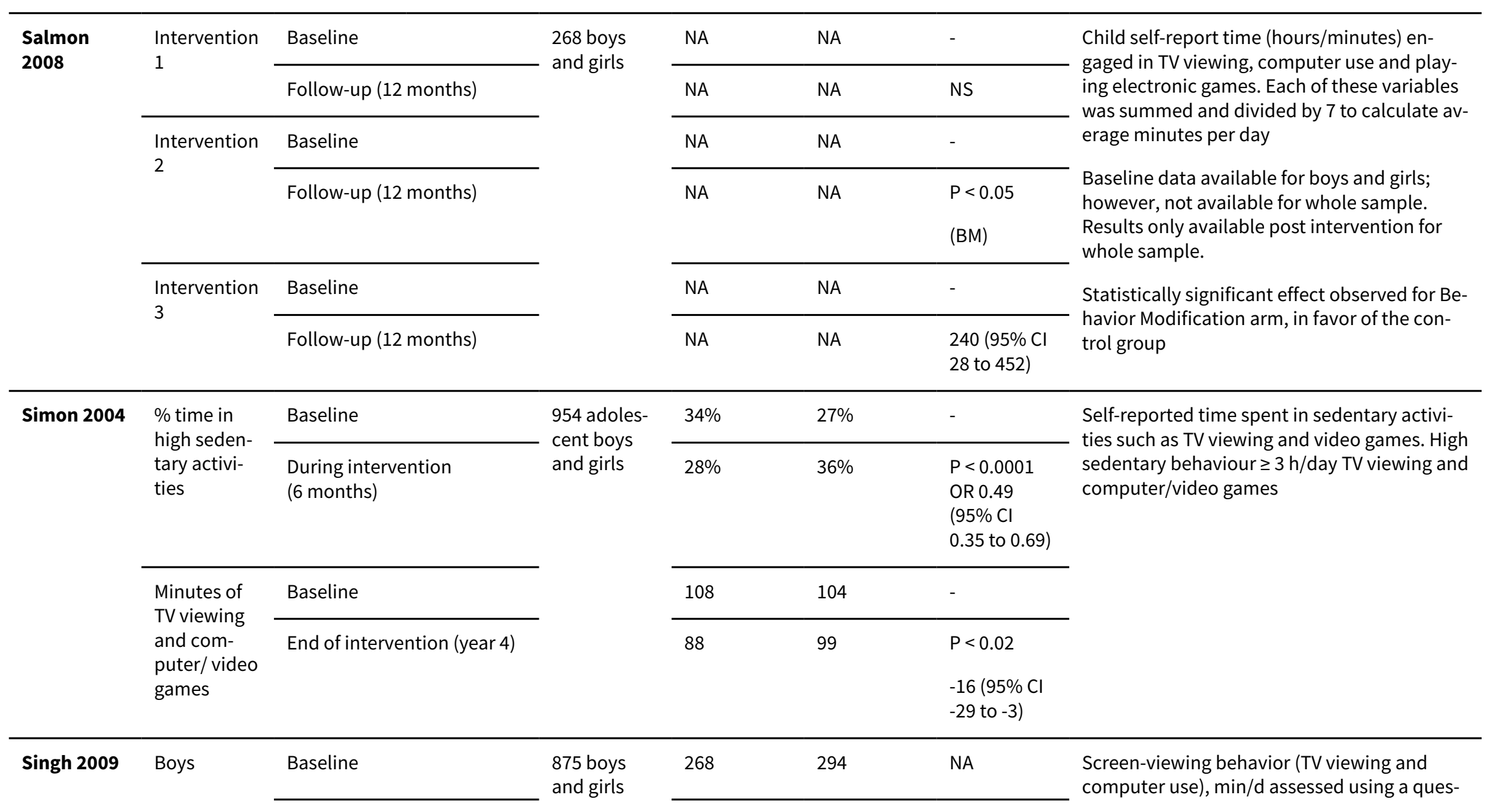




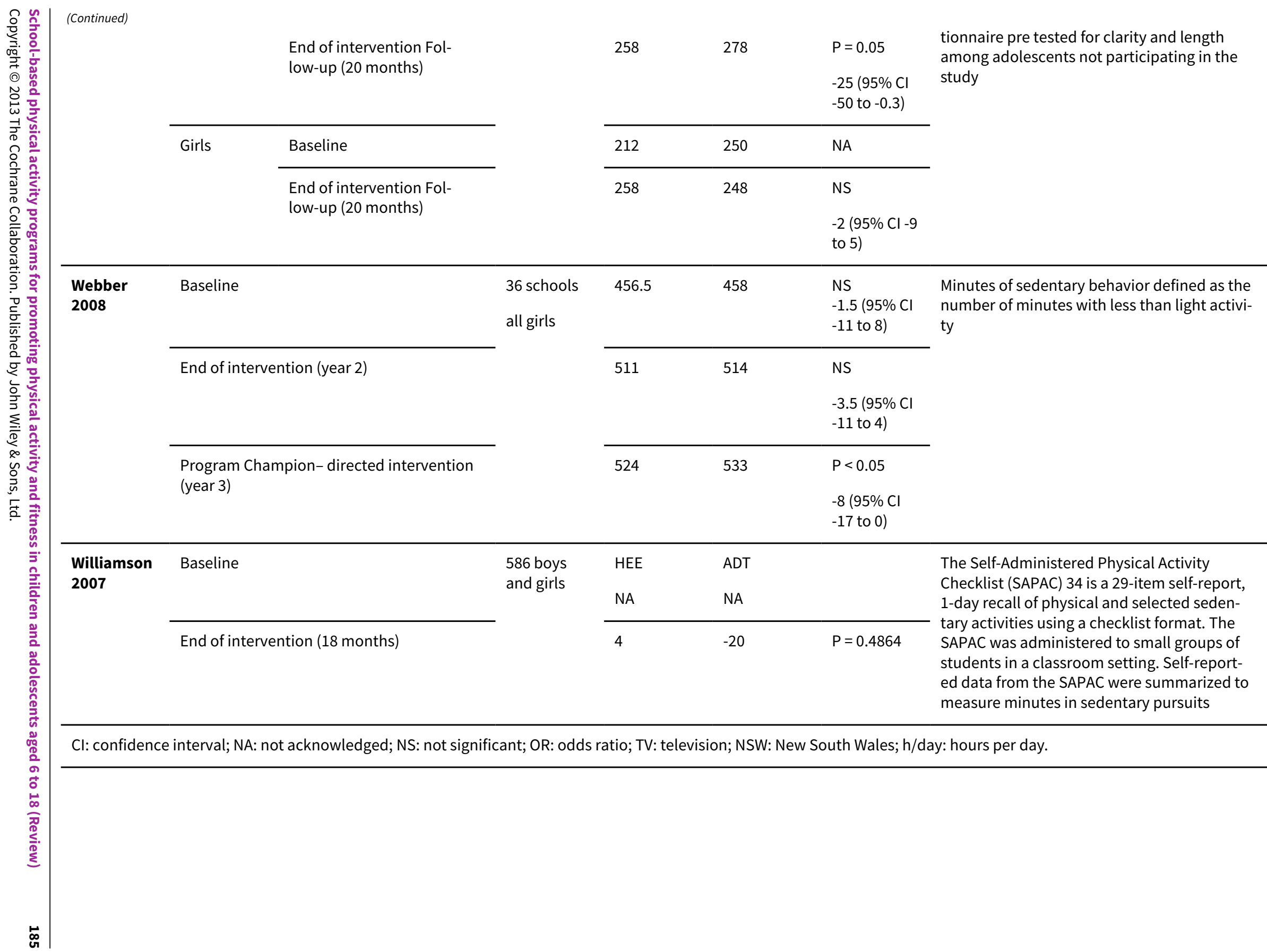




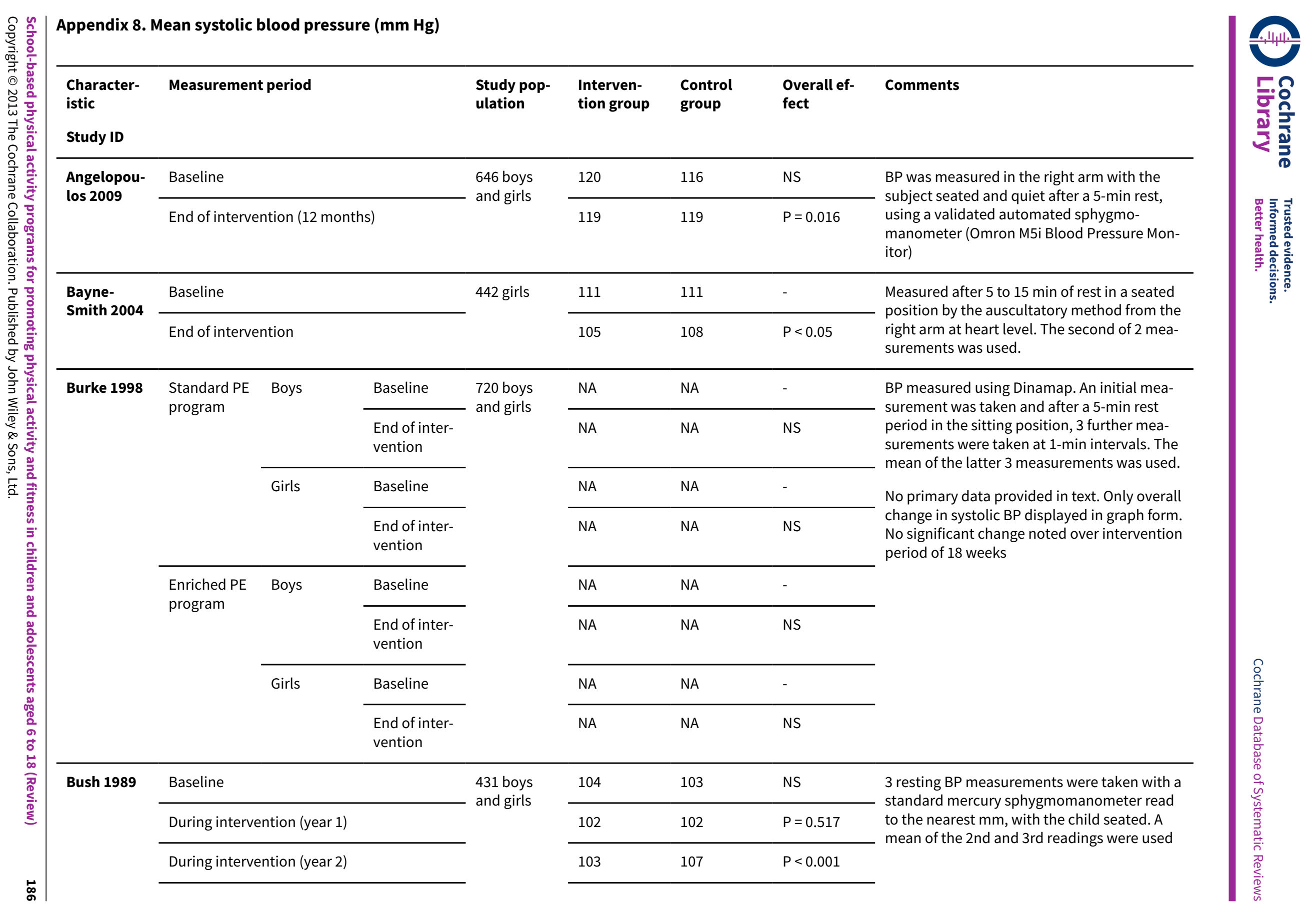




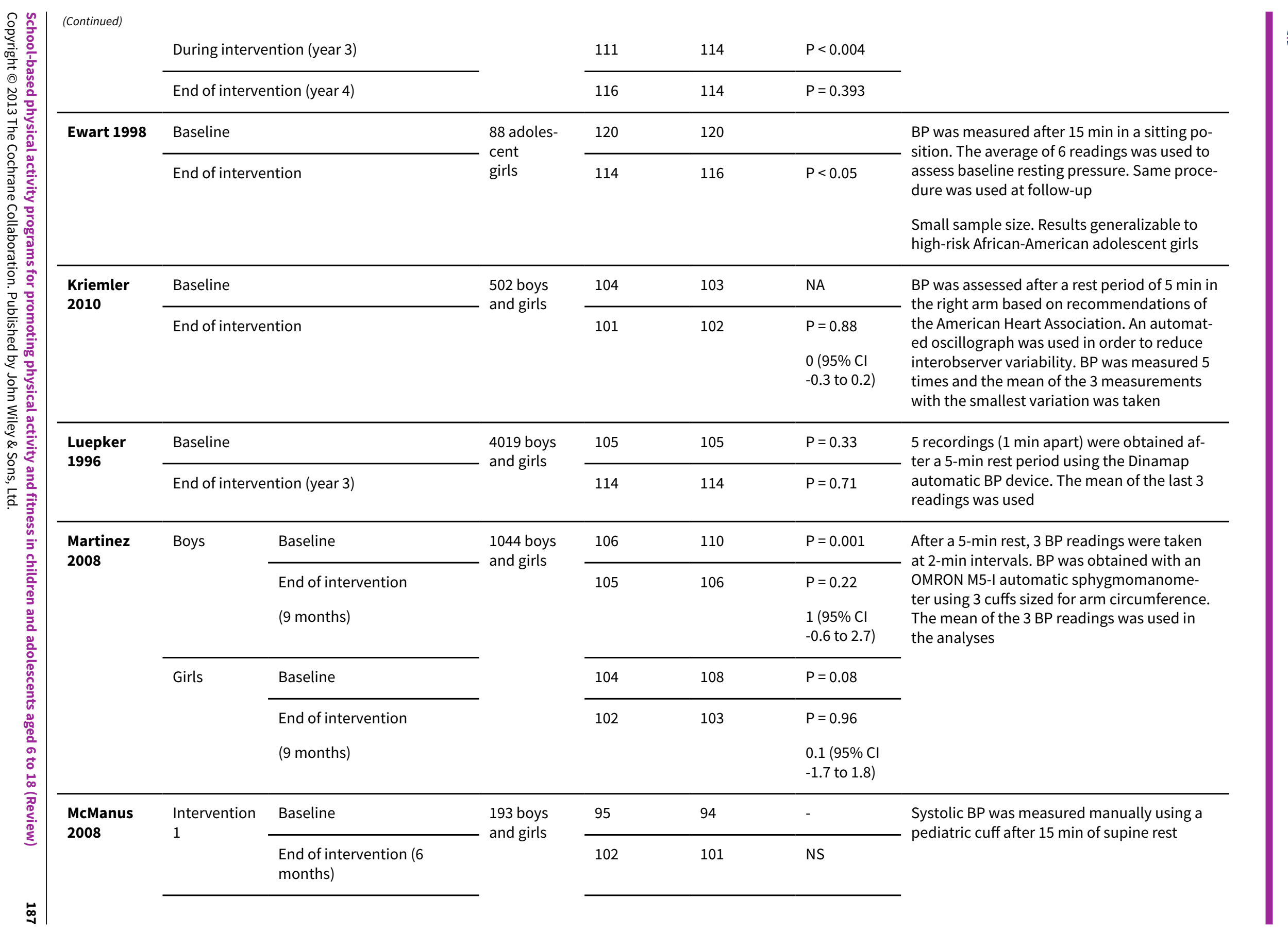


Intervention Baseline

2

End of intervention (6

months)

\begin{tabular}{|c|c|c|c|c|c|}
\hline \multirow[t]{2}{*}{ Reed 2008} & Baseline & \multirow{2}{*}{$\begin{array}{l}514 \text { boys } \\
\text { and girls }\end{array}$} & 105 & 104 & NS \\
\hline & End of intervention & & 102 & 108 & $P=0.05$ \\
\hline
\end{tabular}

101

$105 \quad$ NS

Duplicate measurements were taken on the left arm using an automatedsphygmomanometer and an appropriately sized cuff after 5 to 10 min rest in a supine position

The lowest systolic and diastolic BPs $(\mathrm{mm} \mathrm{Hg})$ were recorded

\begin{tabular}{|c|c|c|c|c|c|c|}
\hline \multirow[t]{3}{*}{ Simon 2004} & Baseline & \multirow{3}{*}{$\begin{array}{l}954 \text { adoles- } \\
\text { cent males } \\
\text { and females }\end{array}$} & 109 & 107 & - & \multirow{3}{*}{$\begin{array}{l}\text { Systolic BP was measured on seated children, } \\
\text { after a 5-min rest, using a fully automatic BP } \\
\text { monitor and an adapted cuff size }\end{array}$} \\
\hline & End of intervention (year 4) & & 115 & 114 & $P=0.66$ & \\
\hline & & & & & $\begin{array}{l}-0.4(95 \% \mathrm{Cl} \\
-2.3 \text { to } 1.4)\end{array}$ & \\
\hline
\end{tabular}

\begin{tabular}{|c|c|c|c|c|c|c|c|}
\hline \multirow{2}{*}{$\begin{array}{l}\text { Stephens } \\
1998\end{array}$} & \multicolumn{2}{|l|}{ Baseline } & \multirow{2}{*}{$\begin{array}{l}90 \text { boys and } \\
\text { girls }\end{array}$} & 98 & 100 & - & \\
\hline & \multicolumn{2}{|c|}{ End of intervention } & & 96 & 97 & NS & \\
\hline \multirow[t]{4}{*}{ Walter 1988} & \multirow{2}{*}{$\begin{array}{l}\text { Westchester } \\
\text { (whole sam- } \\
\text { ple) }\end{array}$} & Baseline & \multirow{4}{*}{$\begin{array}{l}3388 \text { boys } \\
\text { and girls }\end{array}$} & 102 & 106 & NA & \multirow{4}{*}{$\begin{array}{l}\text { BP was measured in the seated position using } \\
\text { the right arm using a Baum mercury sphyg- } \\
\text { momanometer three times. The mean of the } \\
3 \text { measurements was used. }\end{array}$} \\
\hline & & End of intervention & & 103 & 107 & NS & \\
\hline & \multirow[t]{2}{*}{ Bronx } & Baseline & & 105 & 104 & NA & \\
\hline & & End of intervention & & 106 & 105 & NS & \\
\hline \multirow{3}{*}{$\begin{array}{l}\text { Walther } \\
2009\end{array}$} & \multicolumn{2}{|l|}{ Baseline } & \multirow{3}{*}{$\begin{array}{l}182 \text { boys } \\
\text { and girls }\end{array}$} & 129 & 128 & NS & \multirow[t]{3}{*}{-} \\
\hline & \multirow{2}{*}{\multicolumn{2}{|c|}{ End of intervention (year 1) }} & & 138 & 139 & $P=0.232$ & \\
\hline & & & & & & $\begin{array}{l}-2(95 \% \mathrm{Cl}-5 \\
\text { to } 1)\end{array}$ & \\
\hline \multirow[t]{2}{*}{ Wang 2008} & \multicolumn{2}{|l|}{ Baseline } & 316 boys & 110 & 110 & NS & \multirow{2}{*}{$\begin{array}{l}\text { The biological measurements were made in } \\
\text { a mobile laboratory that was brought to the } \\
\text { school sites. Systolic BP was measured with } \\
\text { a Dinamap. Subjects sat quietly for } 5 \text { min, } 5 \\
\text { measures were taken at 1-min intervals, and }\end{array}$} \\
\hline & \multicolumn{2}{|c|}{ End of intervention } & & 106 & 108 & $P=0.15$ & \\
\hline
\end{tabular}




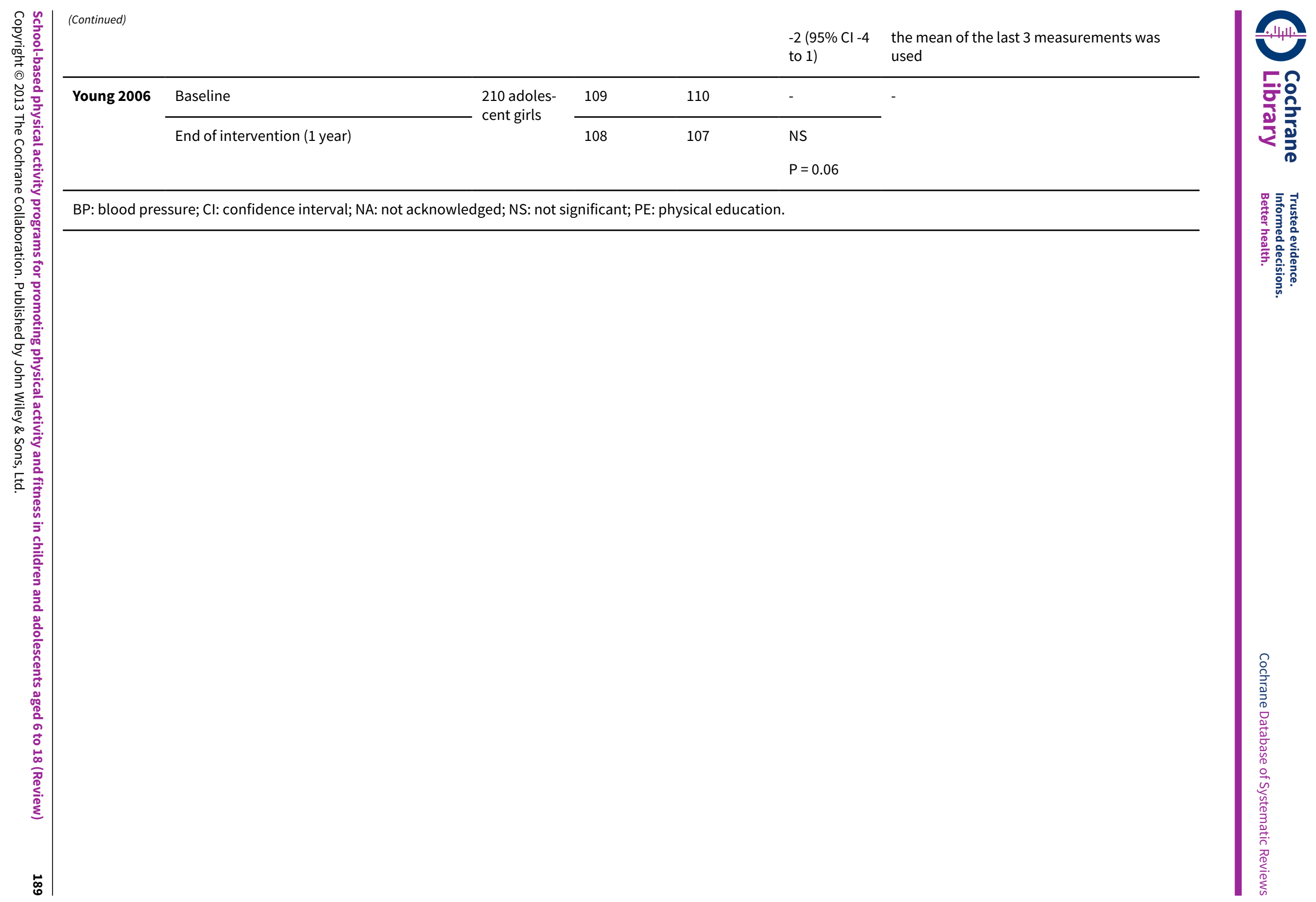




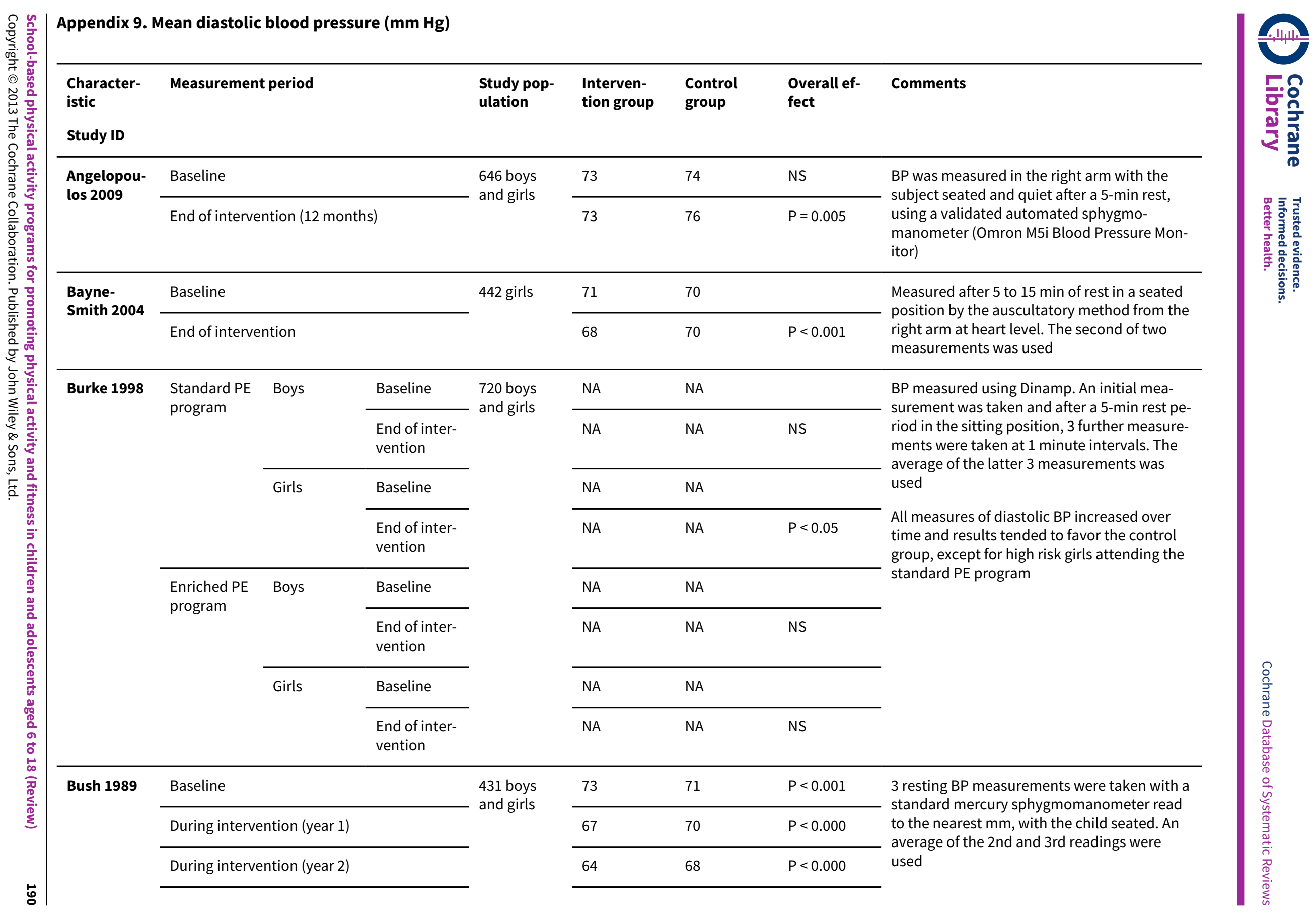




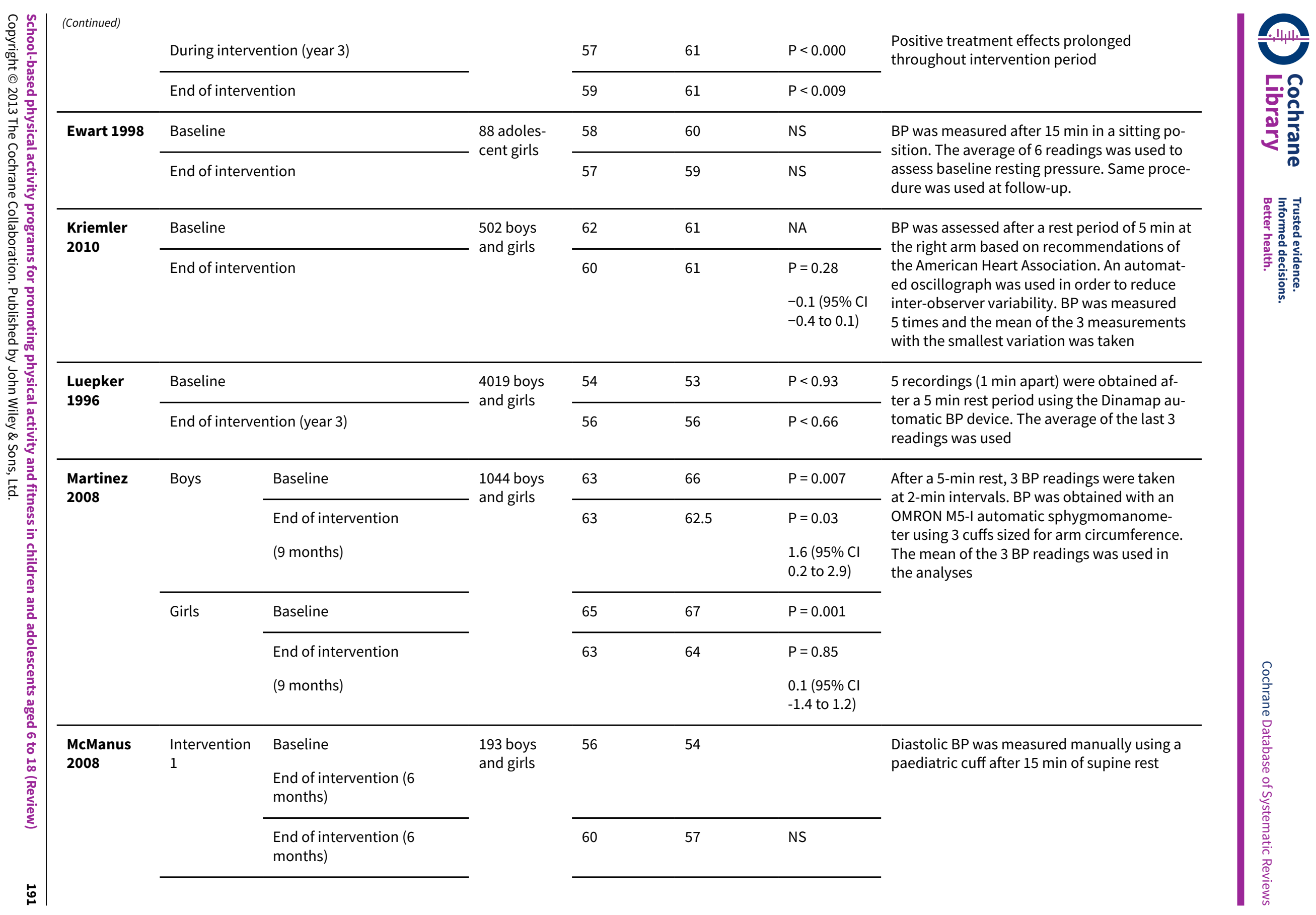


Intervention Baseline

2

End of intervention (6

months)

\begin{tabular}{|c|c|c|c|c|c|}
\hline \multirow[t]{2}{*}{ Reed 2008} & Baseline & 514 boys & 63 & 60 & NA \\
\hline & End of intervention & & 63 & 65 & NS \\
\hline
\end{tabular}

simon 2004 Baseline

Simon 2004 Baseline

954 adoles-

cent males

and females

$\frac{65}{67}$

64

End of intervention (year 4)

66

$\begin{array}{ll} & \text { Diast } \\ \mathrm{P}=0.60 & \text { ic B } \\ & \\ -0.5(95 \% \mathrm{Cl} & \\ -2 \text { to } 1) & \end{array}$

Duplicate measurements were taken on the left arm using an automated sphygmomanometer and an appropriately sized cuff after 5 to $10 \mathrm{~min}$ rest in a supine position

The lowest systolic and diastolic BP ( $\mathrm{mm} \mathrm{Hg}$ ) were recorded

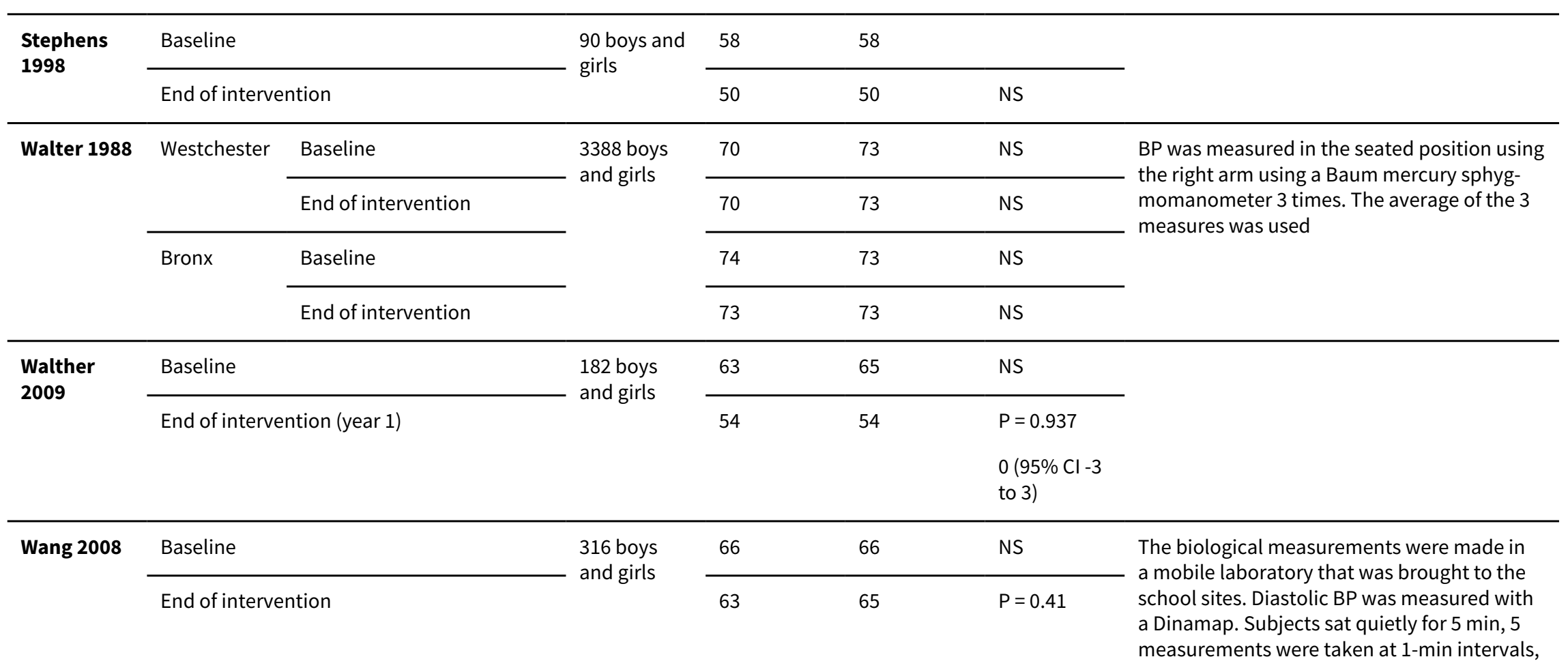



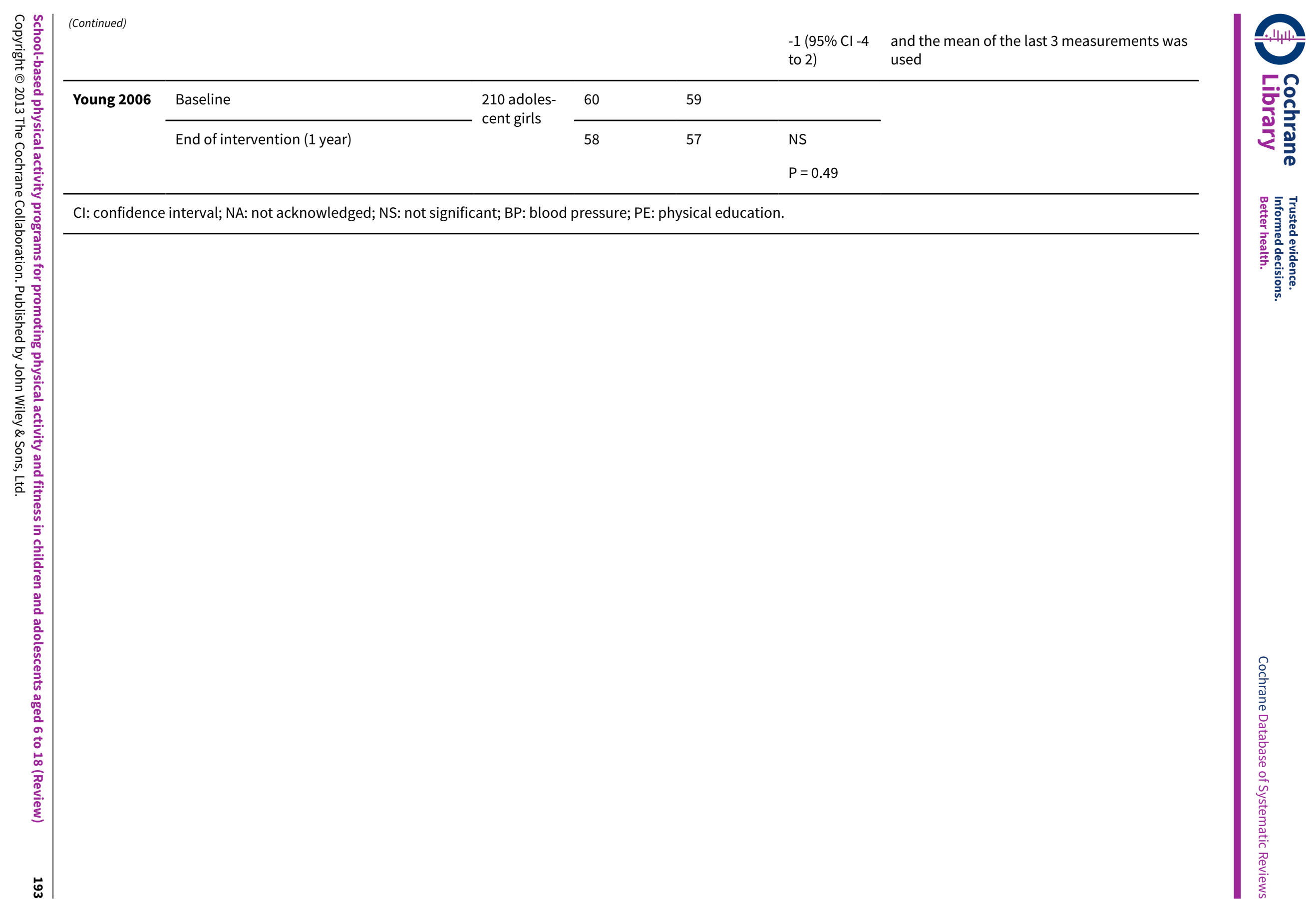


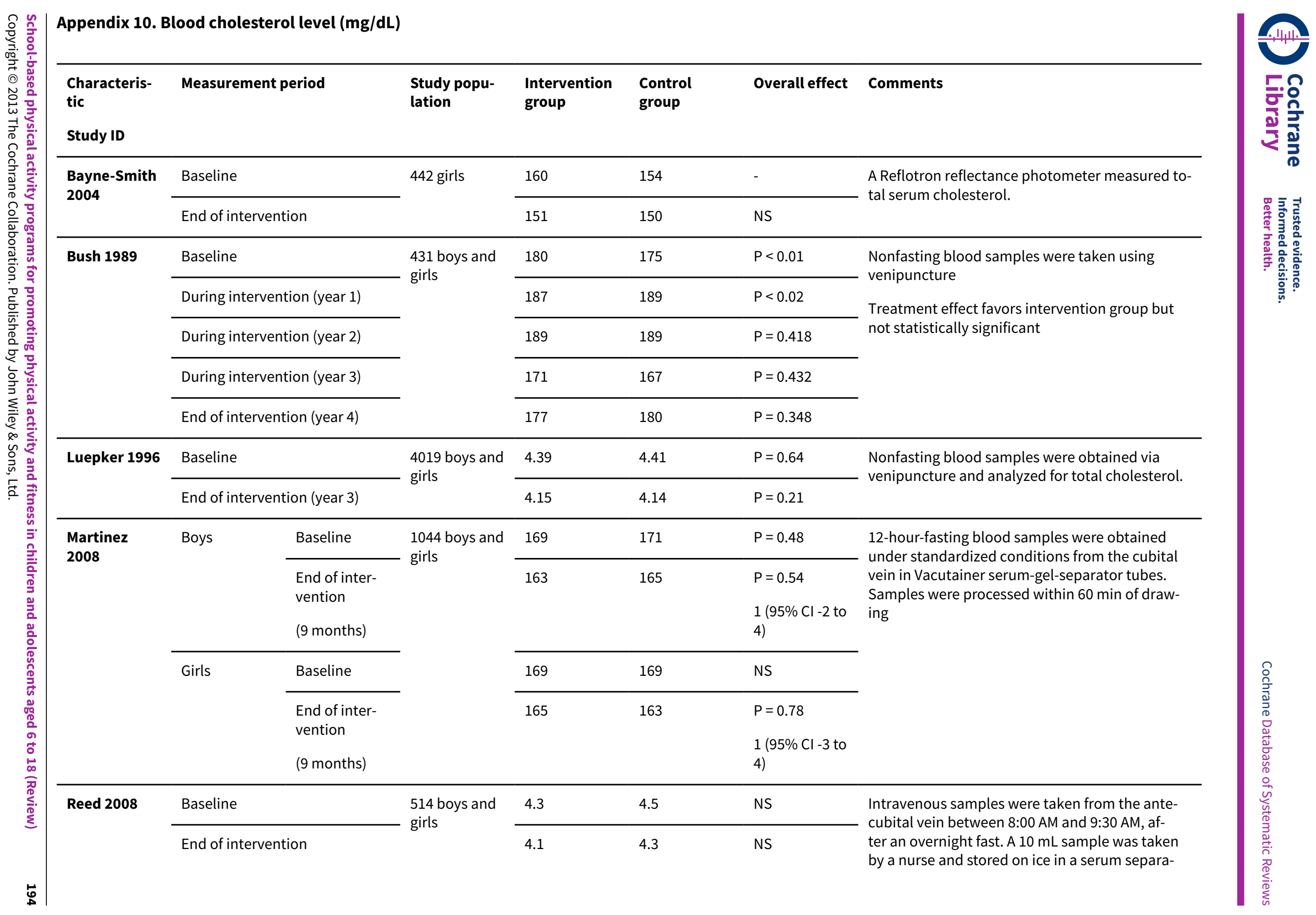




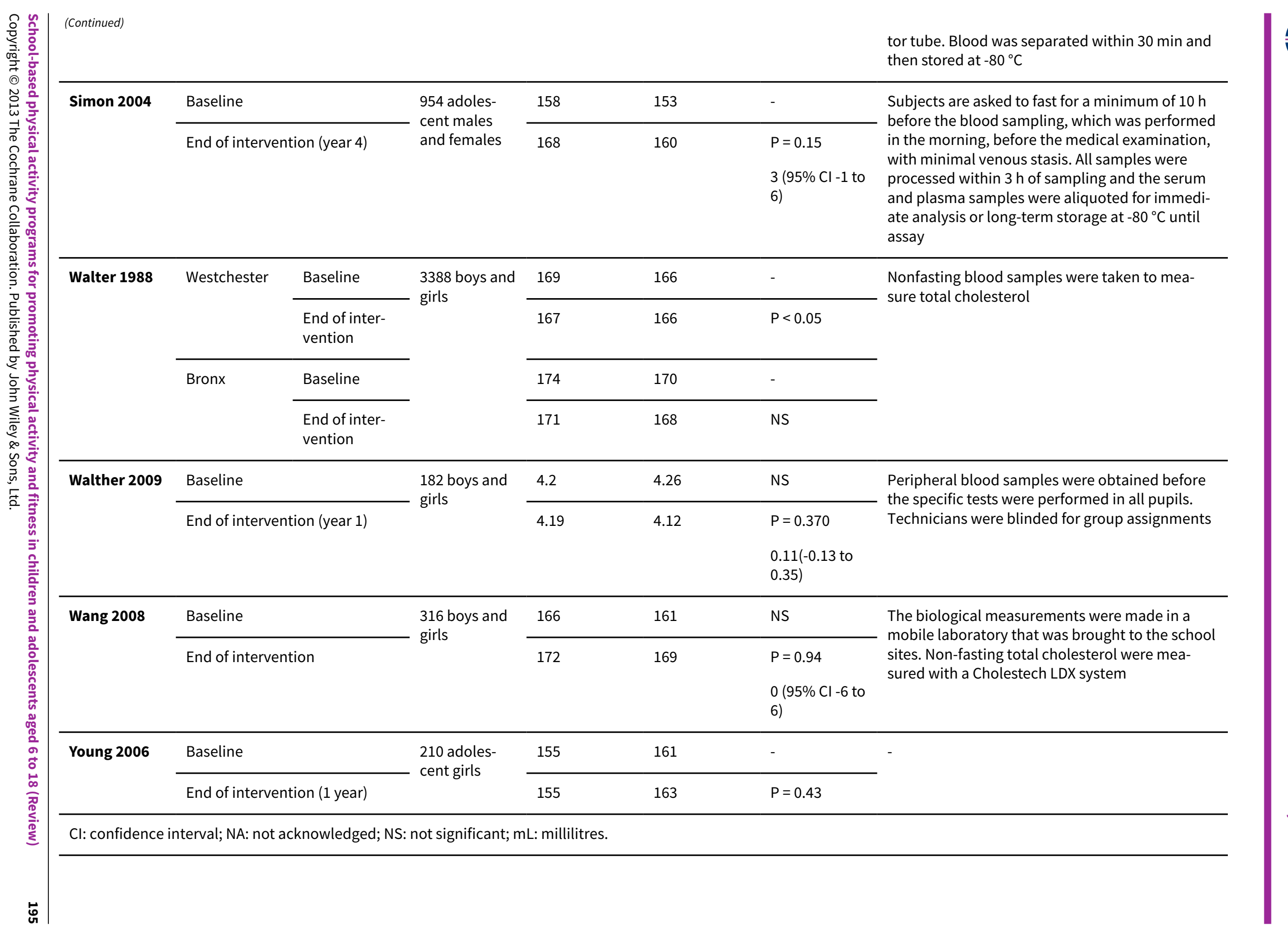




\begin{tabular}{|c|c|c|c|c|c|c|c|c|c|c|}
\hline \multirow{4}{*}{\multicolumn{2}{|c|}{ 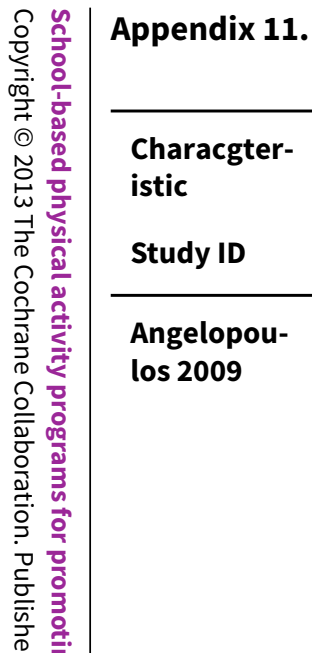 }} & Body mass in & $\operatorname{lex}(B N$ & $\left.n^{2}\right)$ & & & & & & \\
\hline & & \multicolumn{3}{|c|}{ Measurement period } & $\begin{array}{l}\text { Study pop- } \\
\text { ulation }\end{array}$ & $\begin{array}{l}\text { Interven- } \\
\text { tion group }\end{array}$ & $\begin{array}{l}\text { Control } \\
\text { group }\end{array}$ & $\begin{array}{l}\text { Overall ef- } \\
\text { fect }\end{array}$ & Comments & 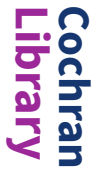 \\
\hline & & \multicolumn{3}{|l|}{ Baseline } & 646 boys & 20.3 & 20.1 & NS & \multirow{2}{*}{$\begin{array}{l}\text { Body weight was measured using a digital } \\
\text { scale (Seca Personal Floor Scale } 861 \text { ) with } \\
\text { an accuracy of } 100 \text { g. Subjects were weighed } \\
\text { without shoes, in the minimum clothing pos- } \\
\text { sible (i.e. underwear). Standing height was al- } \\
\text { so measured without shoes to the nearest } 0.1 \\
\mathrm{~cm} \text { with the use of a portable commercial sta- } \\
\text { diometer (Leicester Height Measure). Stan- } \\
\text { dard BMI formula was used }\end{array}$} & \\
\hline & & \multicolumn{3}{|c|}{ End of intervention } & & 19.2 & 20.2 & $P=0.047$ & & 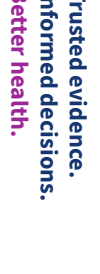 \\
\hline 远豆 & Barbeau & \multicolumn{3}{|l|}{ Baseline } & 201 girls & 20.9 & 20.9 & NS & \multirow{2}{*}{$\begin{array}{l}\text { Height and weight were measured by stan- } \\
\text { dard methods using a wall-mounted sta- } \\
\text { diometer and a scale, respectively }\end{array}$} & \\
\hline 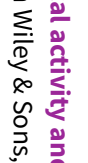 & & \multicolumn{3}{|c|}{ End of Intervention } & & 21.6 & 22.2 & $\begin{array}{l}P=0.008 \\
-0.5(95 \% \mathrm{Cl} \\
-0.8 \text { to }-0.1)\end{array}$ & & \\
\hline 8 & Bayne- & \multicolumn{3}{|l|}{ Baseline } & 442 girls & 22.8 & 23.6 & NS & \multirow{2}{*}{$\begin{array}{l}\text { Height and weight were measured on a stan- } \\
\text { dard physicians scale wearing lightweight } \\
\text { clothing }\end{array}$} & \\
\hline $\begin{array}{ll}\bar{E}^{\prime} \\
\end{array}$ & & \multicolumn{3}{|c|}{ End of intervention } & & 22.8 & 23.7 & NS & & \\
\hline$\frac{0}{3}$ & \multirow[t]{7}{*}{ Burke 1998} & \multirow{4}{*}{$\begin{array}{l}\text { Standard PE } \\
\text { program }\end{array}$} & Boys & Baseline & \multirow{7}{*}{$\begin{array}{l}720 \text { boys } \\
\text { and girls }\end{array}$} & NA & NA & \multirow[t]{2}{*}{$P=0.016$} & \multirow{7}{*}{$\begin{array}{l}\text { Standard formula for height and weight used } \\
\text { Positive effect only seen in boys in the stan- } \\
\text { dard treatment program }\end{array}$} & \\
\hline $\begin{array}{l}\text { 흠 } \\
\frac{2}{0} \\
\frac{0}{0}\end{array}$ & & & & $\begin{array}{l}\text { End of inter- } \\
\text { vention }\end{array}$ & & NA & NA & & & \\
\hline$\stackrel{0}{9}$ & & & Girls & Baseline & & NA & NA & NA & & לे \\
\hline 然 & & & & $\begin{array}{l}\text { End of inter- } \\
\text { vention }\end{array}$ & & NA & NA & & & 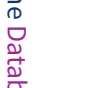 \\
\hline$\stackrel{\infty}{\prod_{0}}$ & & \multirow{3}{*}{$\begin{array}{l}\text { Enriched PE } \\
\text { program }\end{array}$} & Boys & Baseline & & NA & NA & \multirow[t]{2}{*}{ NA } & & $\begin{array}{l}0 \\
\stackrel{D}{0} \\
\text { in }\end{array}$ \\
\hline$=$ & & & & $\begin{array}{l}\text { End of inter- } \\
\text { vention }\end{array}$ & & NA & NA & & & . \\
\hline 点 & & & Girls & Baseline & & NA & NA & NA & & 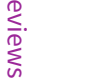 \\
\hline
\end{tabular}




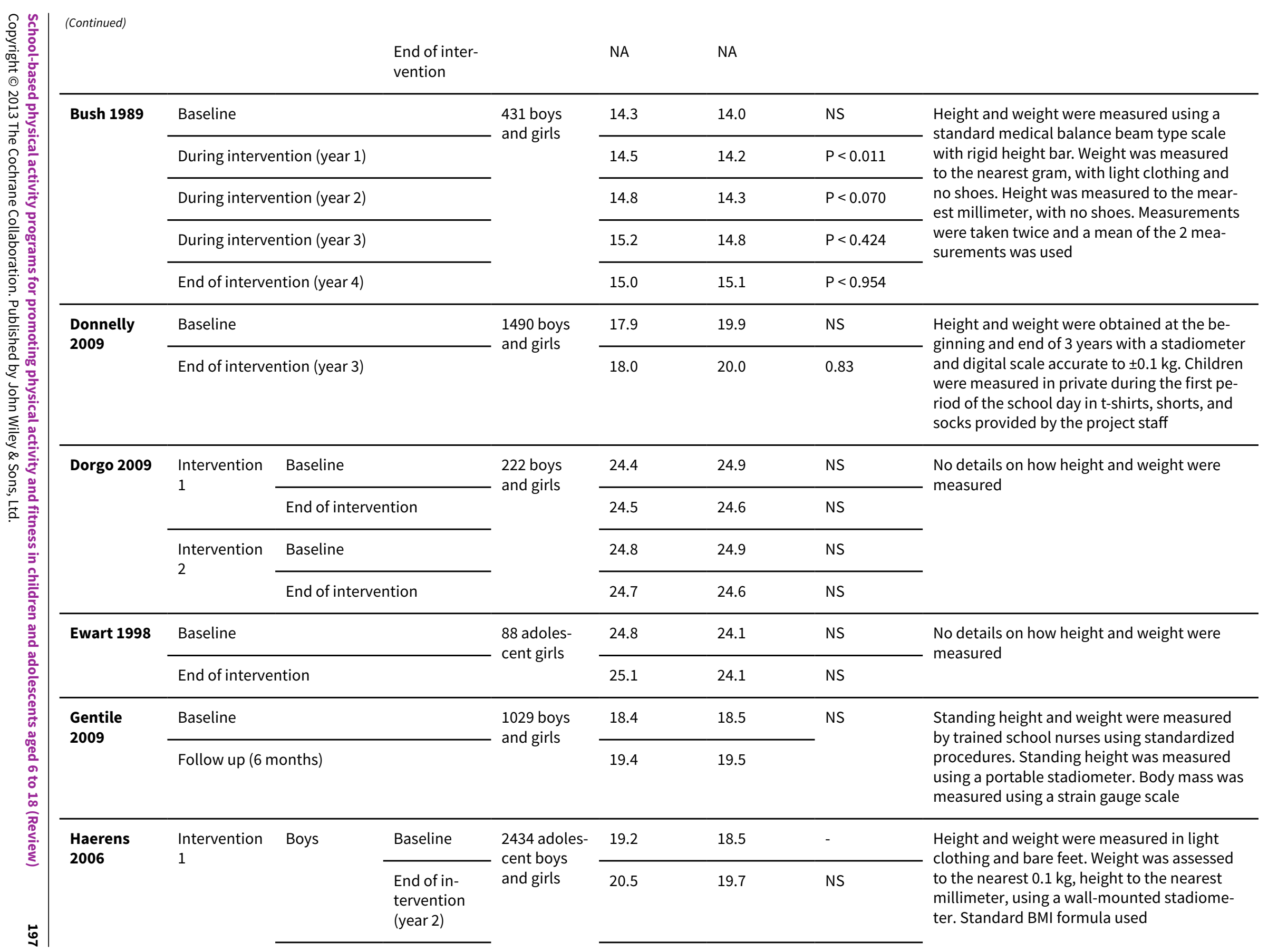




\begin{tabular}{|c|c|c|c|c|c|c|c|c|c|}
\hline \multirow{6}{*}{\multicolumn{2}{|c|}{ 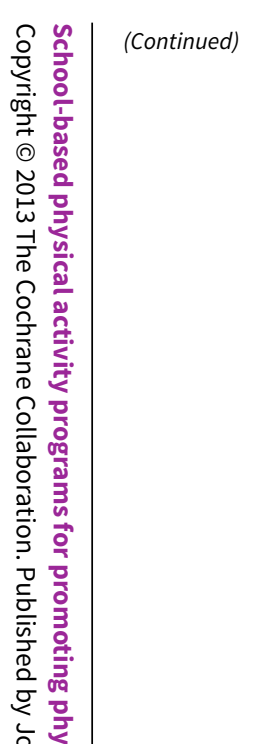 }} & \multicolumn{7}{|c|}{ 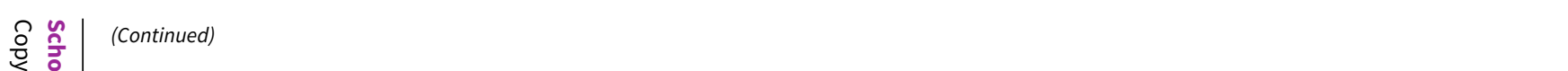 } & \multirow{6}{*}{$\begin{array}{l}\text { Intervention } 1 \text { = curricula to promote physical } \\
\text { activity with parental involvement } \\
\text { Intervention } 2 \text { = curricula to promote physi- } \\
\text { cal activity with no parental involvement }\end{array}$} \\
\hline & & & & $\begin{array}{l}\text { End of in- } \\
\text { tervention } \\
\text { (year 2) }\end{array}$ & & 21.3 & 20.8 & $P<0.05$ & \\
\hline & & \multirow{4}{*}{$\begin{array}{l}\text { Intervention } \\
2\end{array}$} & \multirow[t]{2}{*}{ Boys } & Baseline & & 19.3 & 18.5 & - & \\
\hline & & & & $\begin{array}{l}\text { End of in- } \\
\text { tervention } \\
\text { (year 2) }\end{array}$ & & 20.9 & 19.7 & NS & \\
\hline & & & \multirow[t]{2}{*}{ Girls } & Baseline & & 20.2 & 19.1 & - & \\
\hline & & & & $\begin{array}{l}\text { End of in- } \\
\text { tervention } \\
\text { (year 2) }\end{array}$ & & 21.7 & 20.8 & $P<0.05$ & \\
\hline$\sum_{i}^{\infty} \frac{3}{2}$ & \multirow{2}{*}{$\begin{array}{l}\text { Kipping } \\
2008\end{array}$} & \multicolumn{3}{|l|}{ Baseline } & 604 boys & 17.9 & 17.7 & NA & \multirow{2}{*}{$\begin{array}{l}\text { Height (without shoes) was measured to the } \\
\text { nearest } 0.1 \mathrm{~cm} \text { with minimeter height scales. } \\
\text { Weight (without heavy clothing) was mea- } \\
\text { sured to the nearest } 0.1 \mathrm{~kg} \text { on portable bath- } \\
\text { room scales }\end{array}$} \\
\hline 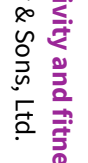 & & \multicolumn{3}{|c|}{ End of intervention } & & NA & NA & $\begin{array}{l}P=0.58 \\
0.10(95 \% \mathrm{Cl} \\
-0.3 \text { to } 0.5)\end{array}$ & \\
\hline$\vec{n}^{\prime}$ & \multirow{2}{*}{$\begin{array}{l}\text { Kriemler } \\
2010\end{array}$} & \multicolumn{3}{|l|}{ Baseline } & 502 boys & 17.1 & 17.0 & NA & \multirow{2}{*}{$\begin{array}{l}\text { Standing and sitting height were measured } \\
\text { by a wall mounted stadiometer and body } \\
\text { weight was determined using an electronic } \\
\text { scale }\end{array}$} \\
\hline $\begin{array}{l}\frac{1}{2} \\
\frac{1}{3} \\
\frac{2}{2} \\
\frac{2}{2} \\
\frac{2}{2}\end{array}$ & & \multicolumn{3}{|c|}{ End of intervention } & & 17.4 & 17.4 & $\begin{array}{l}P=0.003 \\
-0.1(95 \% \mathrm{Cl} \\
-0.2 \text { to }-.04)\end{array}$ & \\
\hline గ్ర & \multirow[t]{2}{*}{ Li 2010} & \multicolumn{3}{|l|}{ Baseline } & 4120 adoles- & 17.8 & 17.7 & - & \multirow{2}{*}{$\begin{array}{l}\text { In subgroup analysis a statistically significant } \\
\text { difference was observed for girls }(-0.19,95 \% \\
\mathrm{Cl}-0.34 \text { to }-0.03 ; \mathrm{P}=0.02) \text {, but not for boys } \\
(-0.08,95 \% \mathrm{Cl}-0.25 \text {-to } 0.09 ; \mathrm{P}<0.37)\end{array}$} \\
\hline 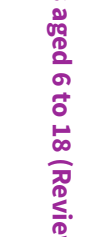 & & \multicolumn{3}{|c|}{ Follow-up 1 year post intervention } & and girls & +1.6 & +1.7 & $\begin{array}{l}\text { Mean dif- } \\
\text { ference }-0.1 \\
(95 \% \mathrm{Cl}-0.3 \\
\text { to }-0.01) \\
\mathrm{P}<0.04\end{array}$ & \\
\hline & \multirow{2}{*}{$\begin{array}{l}\text { Luepker } \\
1996\end{array}$} & \multicolumn{3}{|l|}{ Baseline } & 4019 boys & 17.6 & 17.6 & $P=0.72$ & \multirow{2}{*}{$\begin{array}{l}\text { Height was measured to the nearest } 0.1 \mathrm{~cm} \\
\text { and weight to the nearest } 0.1 \mathrm{~kg}\end{array}$} \\
\hline & & \multicolumn{3}{|c|}{ End of intervention (year 3) } & & 22.0 & 22.1 & $P=0.88$ & \\
\hline
\end{tabular}




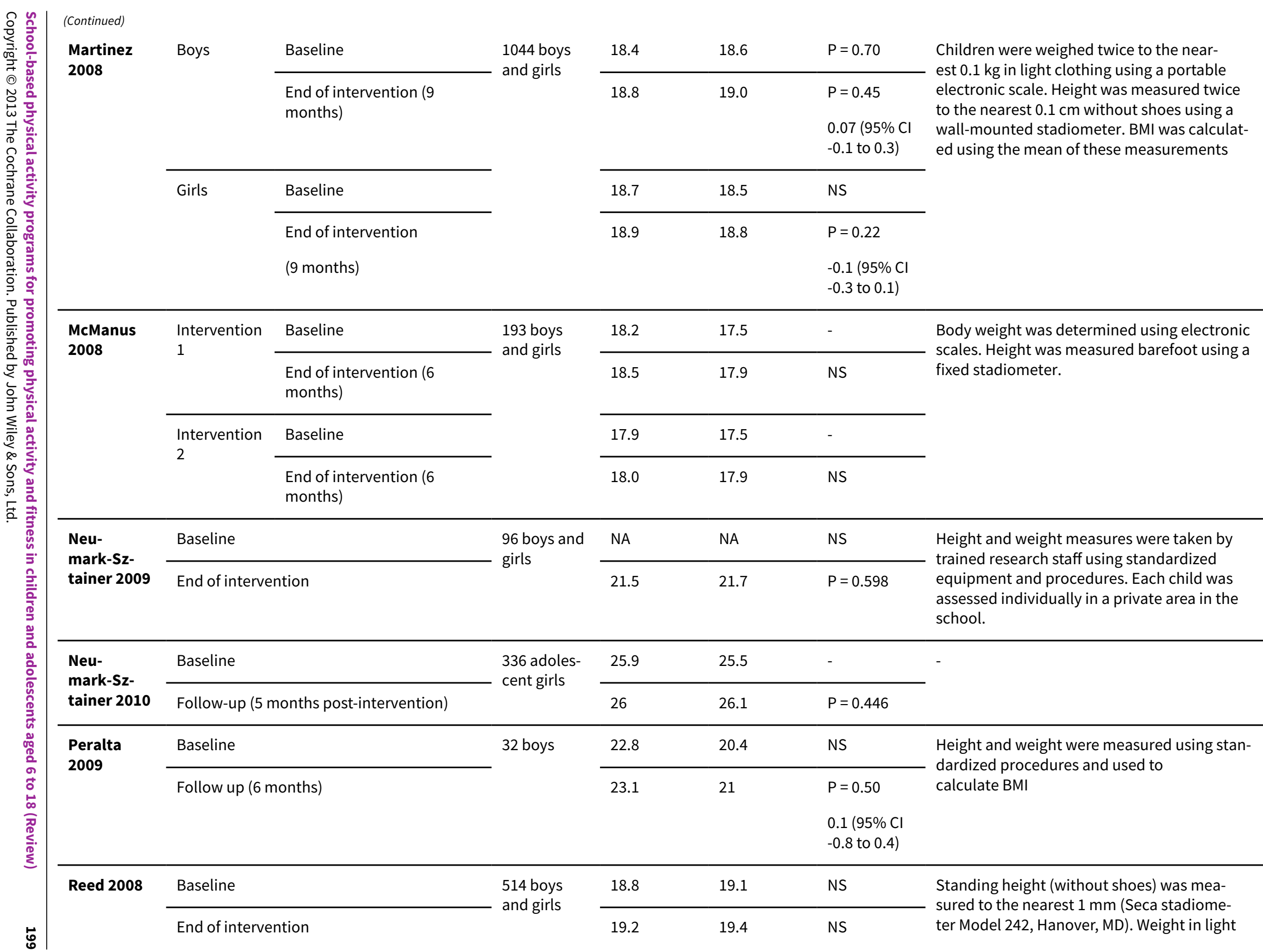




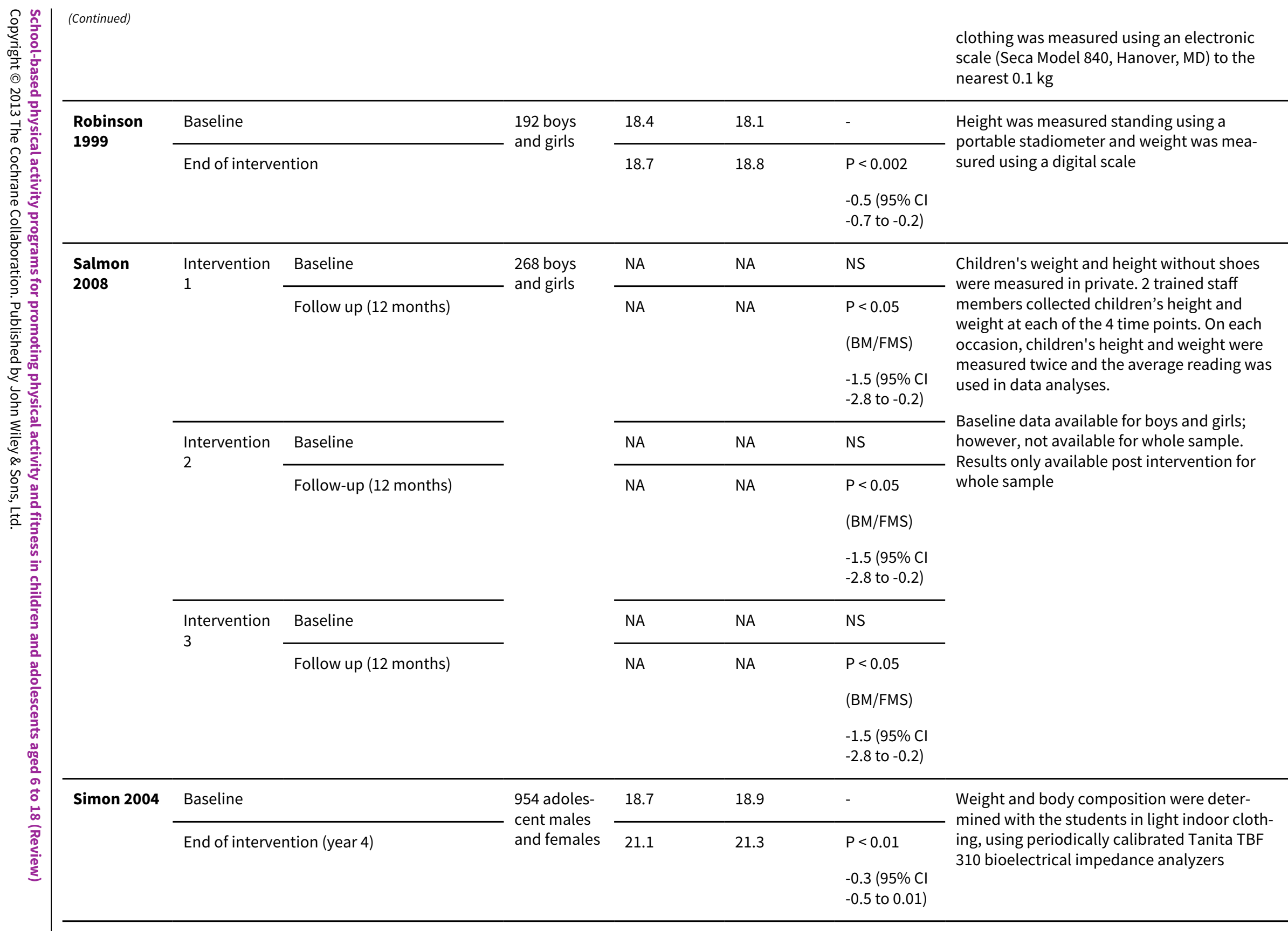




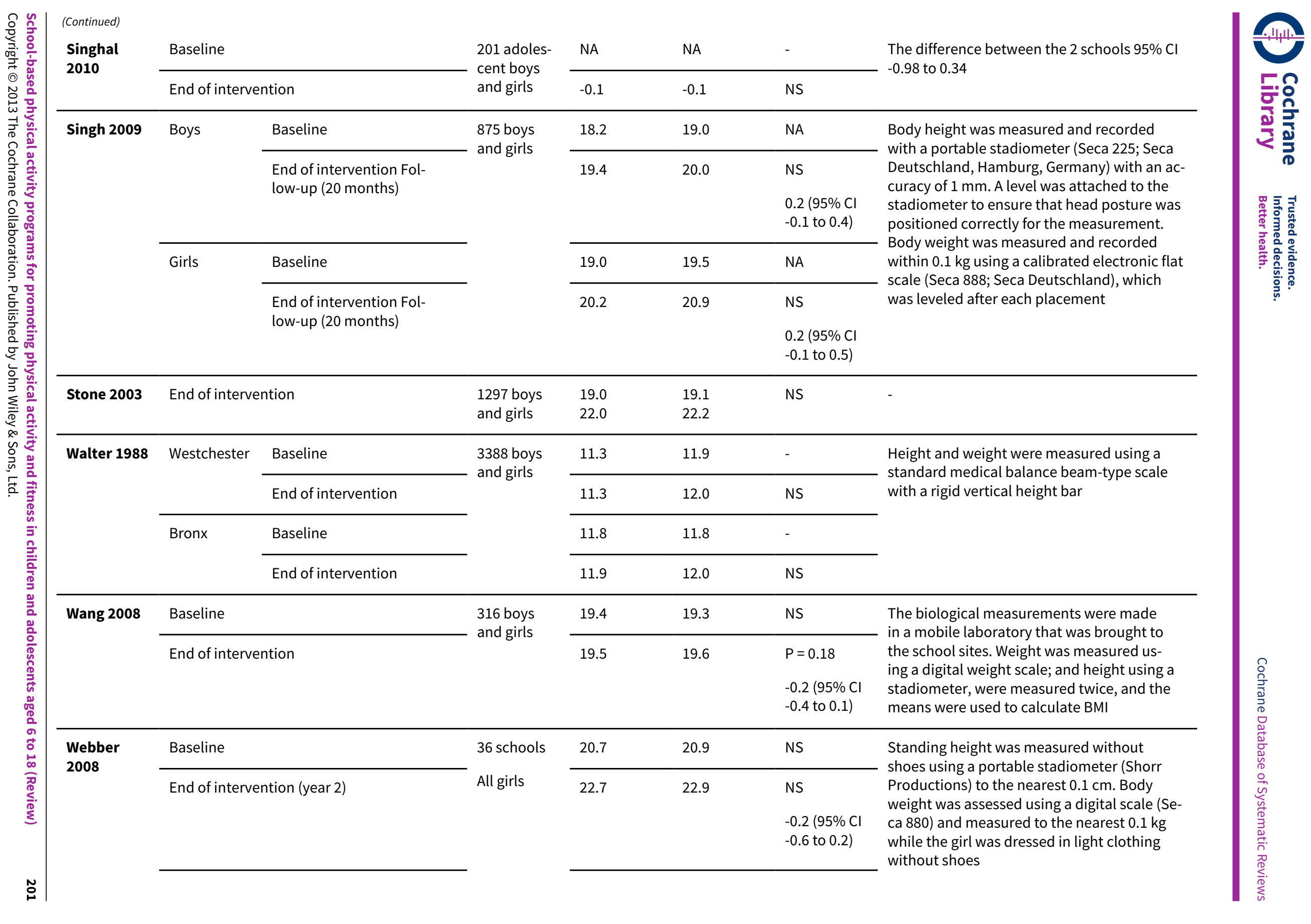




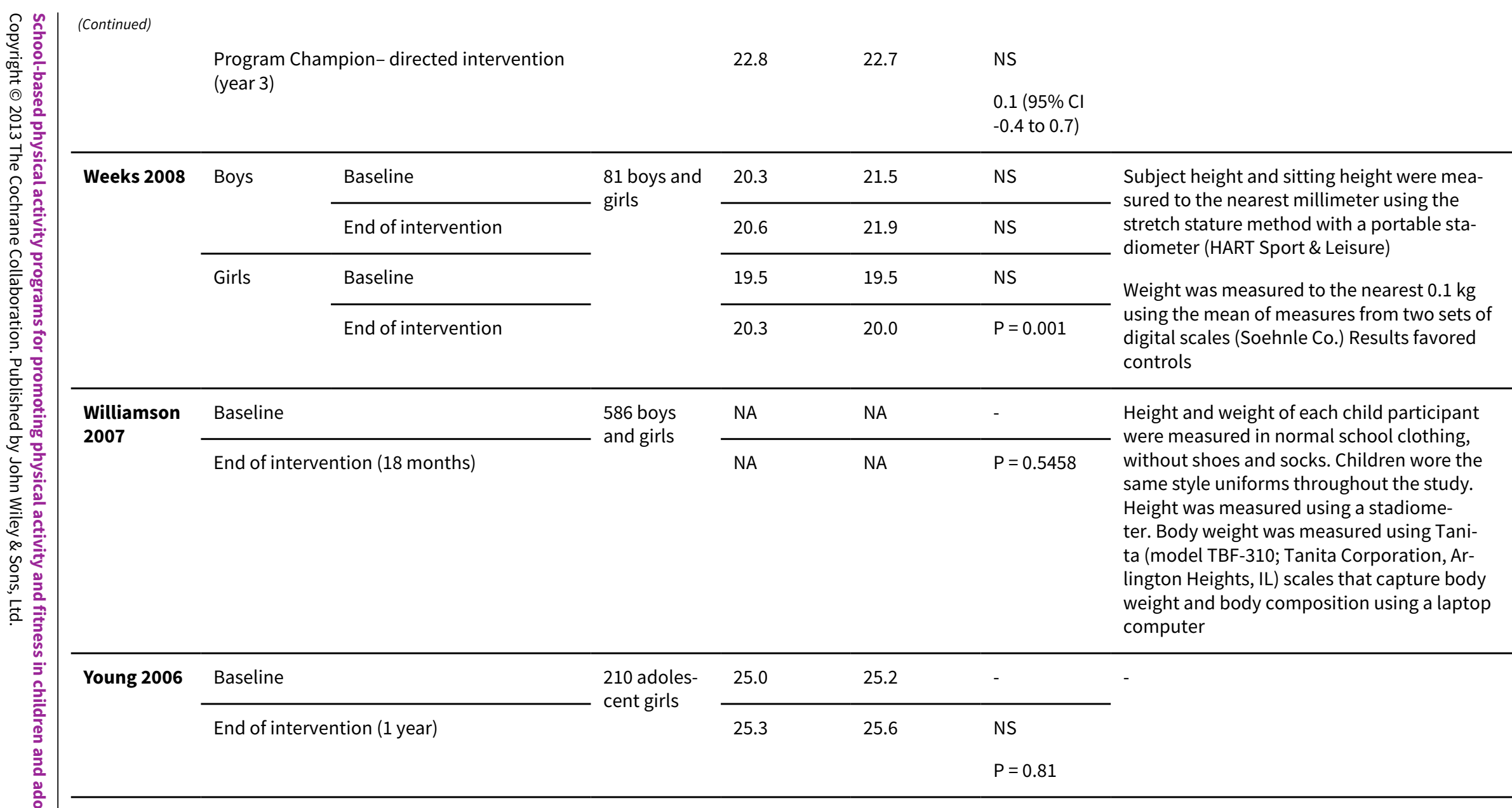

BM: behavioral modification; BMI: body mass index; Cl: confidence interval; FMS: fundamental motor skills; g: gram; Kg: kilogram; NA: not acknowledged; NS: not PE: physical education. 


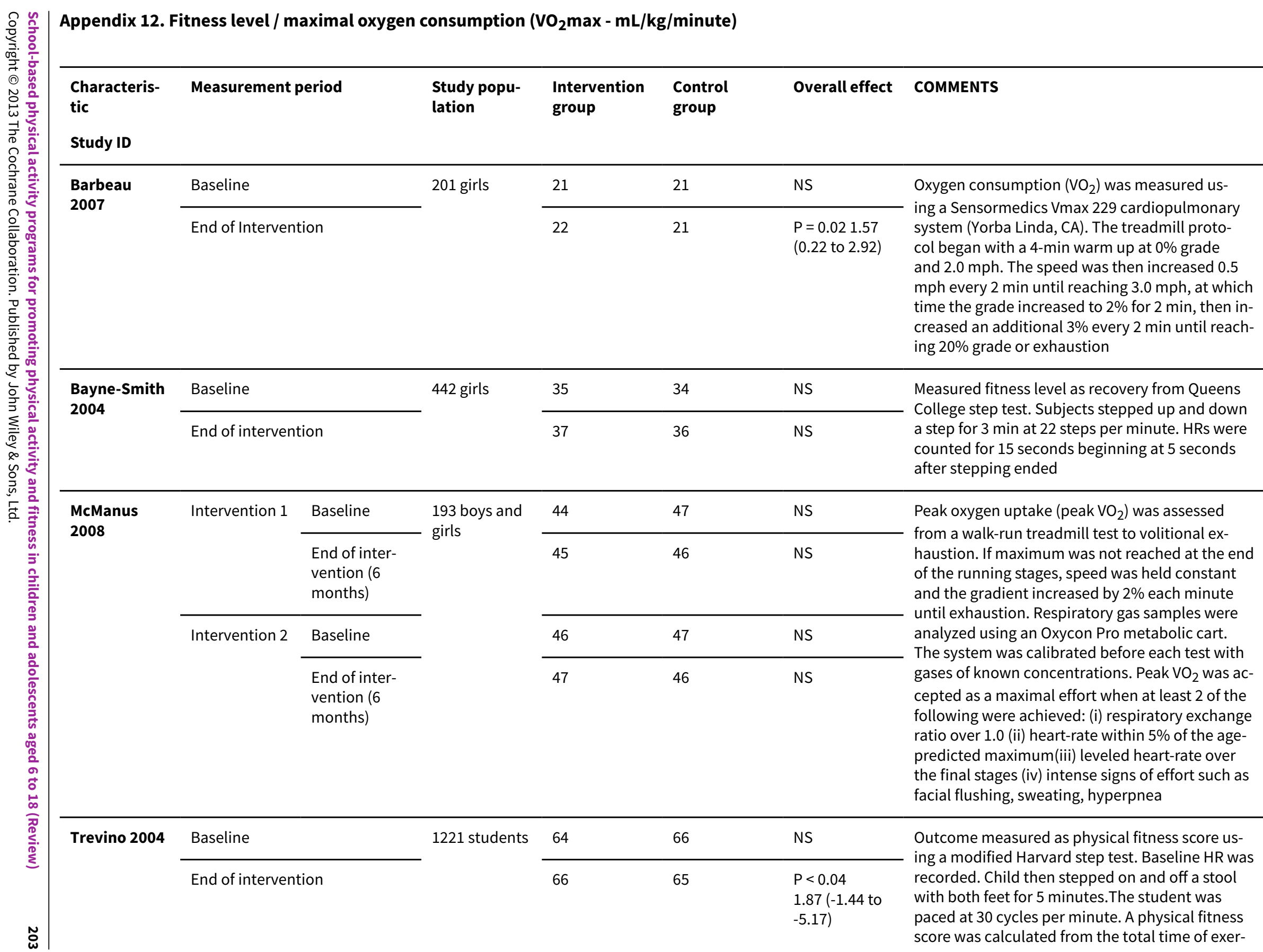




\begin{tabular}{|c|c|c|c|c|c|c|}
\hline \multirow{5}{*}{ 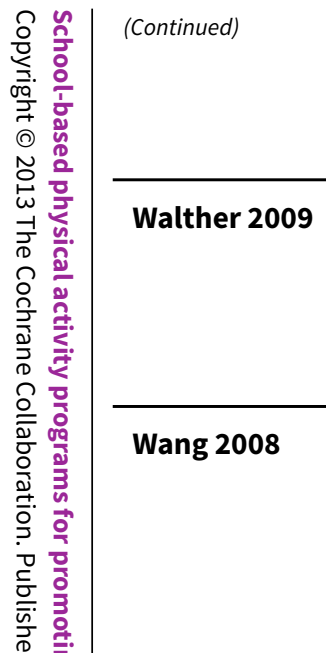 } & \multicolumn{5}{|c|}{ 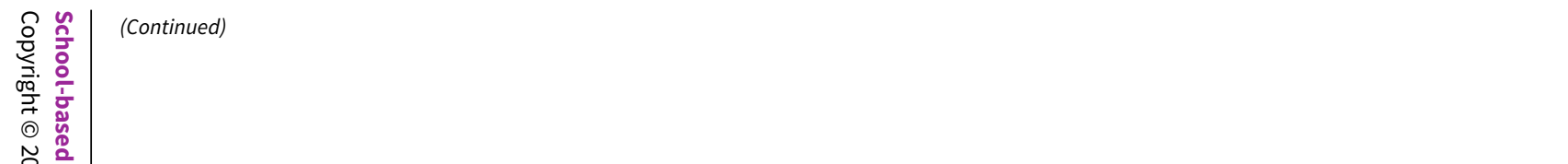 } & $\begin{array}{l}\text { cise (in seconds) multiplied by } 100 \text { and divided } \\
\text { by the sum of } 3 \mathrm{HR} \text { values measured at } 0,1 \text {, and } 2 \\
\text { min after exercise }\end{array}$ \\
\hline & Baseline & \multirow{2}{*}{$\begin{array}{l}182 \text { boys and } \\
\text { girls }\end{array}$} & 38 & 39 & NS & \multirow{2}{*}{$\begin{array}{l}\text { All participants underwent a graded treadmill } \\
\text { test with spirometry until exhaustion, according } \\
\text { to a modified Bruce protocol for children starting } \\
\text { at } 1.7 \mathrm{mph} \text { and } 0 \text { degrees }\end{array}$} \\
\hline & End of intervention (year 1) & & 49 & 46 & $\begin{array}{l}P=0.032 \\
3.7(0.3 \text { to } 7.2)\end{array}$ & \\
\hline & Baseline & \multirow{2}{*}{$\begin{array}{l}316 \text { boys and } \\
\text { girls }\end{array}$} & 159 & 163 & NS & \multirow{2}{*}{$\begin{array}{l}\text { The biological measurements were made in a } \\
\text { mobile laboratory that was brought to the school } \\
\text { sites. Fitness level was assessed by HR at the } \\
\text { completion of the bench-stepping test. Low HR } \\
\text { at the end of 3-min stepping indicates better CVF }\end{array}$} \\
\hline & End of intervention & & 155 & 161 & $\begin{array}{l}P=0.025 \\
-4.4(-8.2 \text { to } \\
-0.6)\end{array}$ & \\
\hline
\end{tabular}

Cl: confidence interval; HR: heart rate; NA: not acknowledged; NS: not significant; mph: miles per hour. 


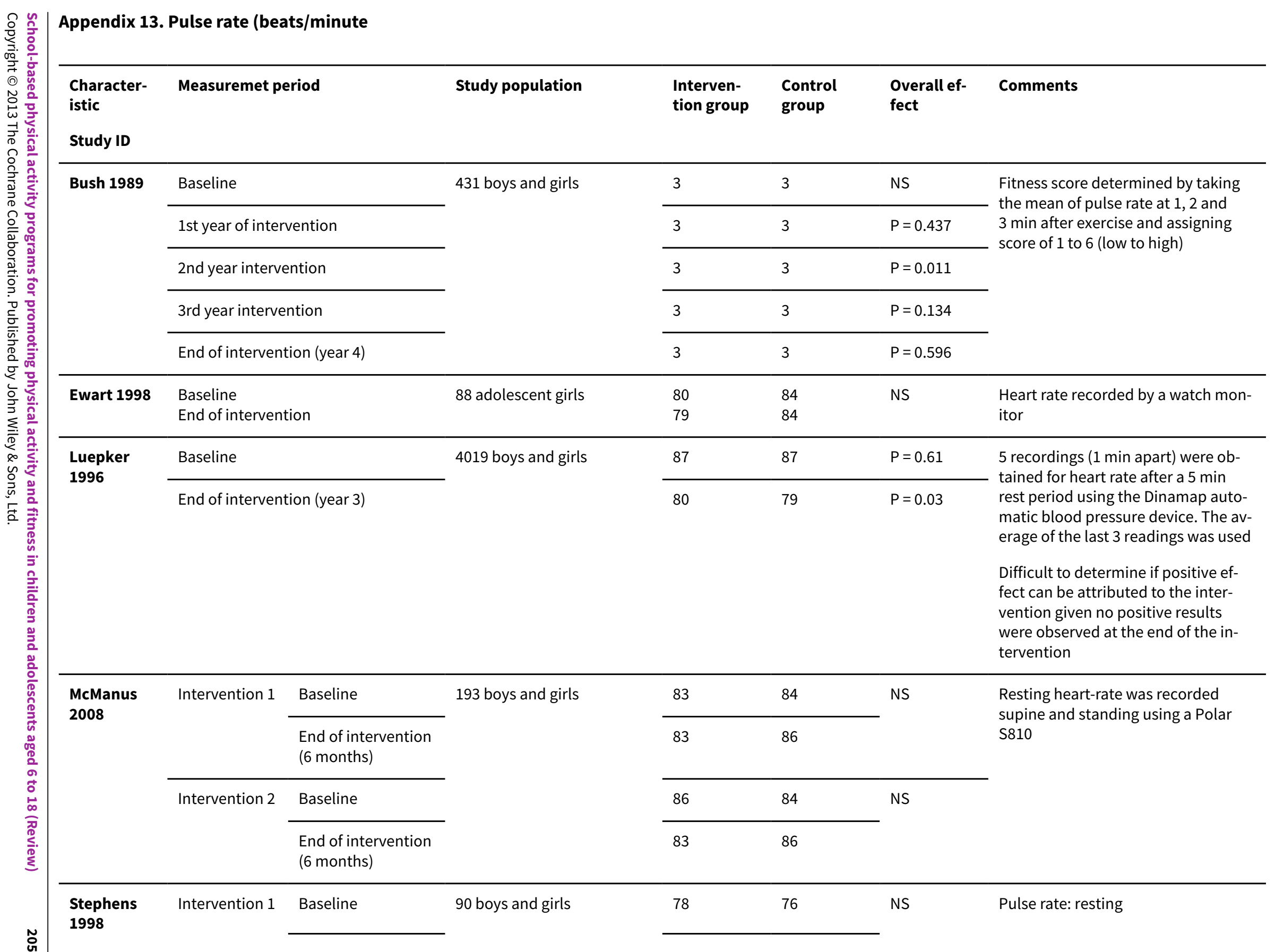




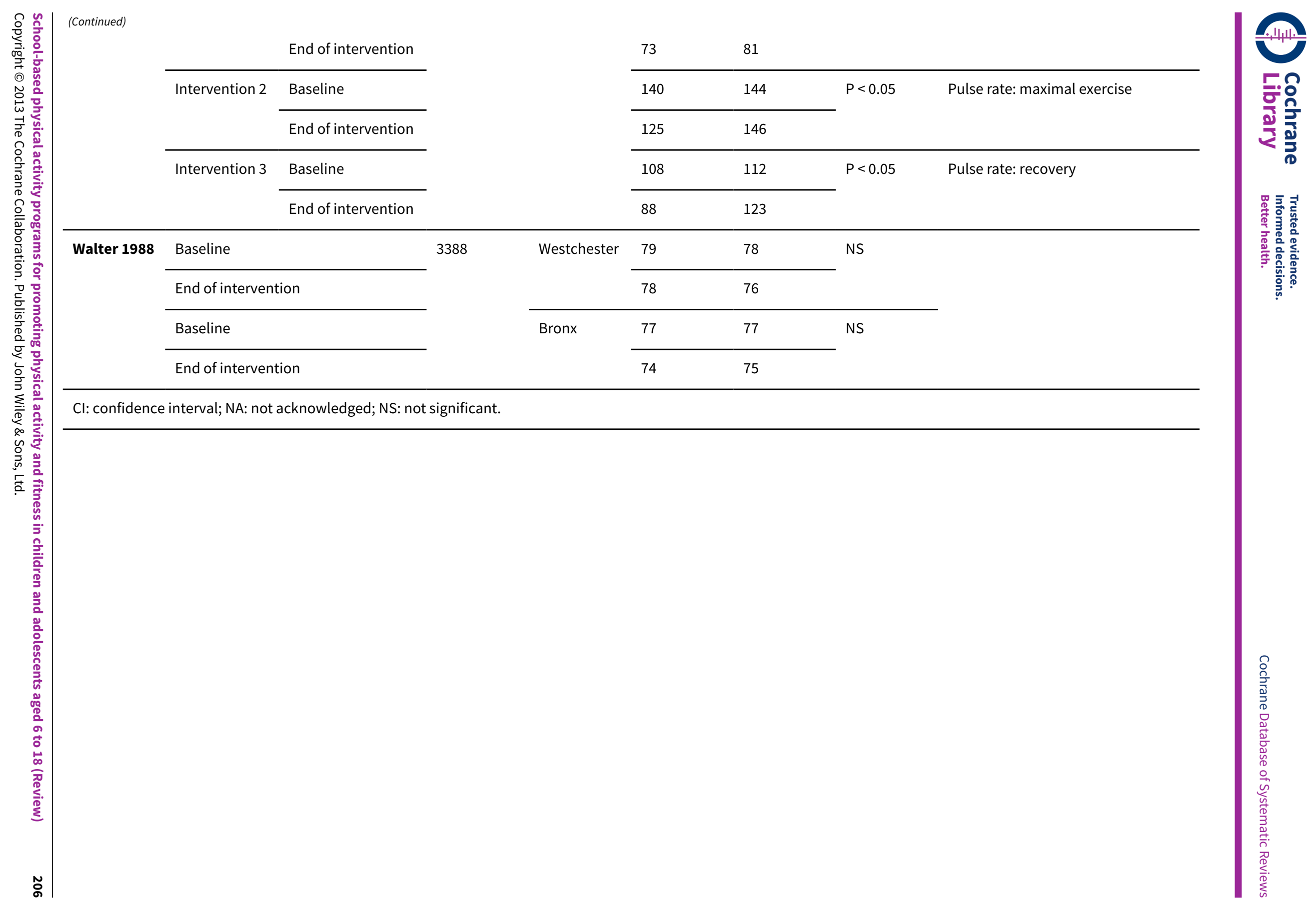


WHAT'S NEW

\begin{tabular}{lll}
\hline Date & Event & Description \\
\hline 21 October 2011 & $\begin{array}{l}\text { New citation required but conclusions } \\
\text { have not changed }\end{array}$ & $\begin{array}{l}\text { This update has not impacted the conclusions and recommen- } \\
\text { dations from the original review. One change to note is that the } \\
\text { physical health status outcome blood cholesterol level (mg/dL) } \\
\text { is no longer statistically significant. }\end{array}$ \\
\hline 21 October 2011 & New search has been performed & $\begin{array}{l}\text { Searches run for update period (July 2007 - October 2011); 30 } \\
\text { new project accounts identified and included in updated review }\end{array}$ \\
\hline
\end{tabular}

\section{HIST O R Y}

Review first published: Issue 1, 2009

\begin{tabular}{|c|c|c|}
\hline Date & Event & Description \\
\hline 29 April 2010 & Amended & $\begin{array}{l}\text { Change in Scope: Three new relevance criteria added and ap- } \\
\text { plied to all included studies: 1) Randomized controlled trial; } 2 \text { ) } \\
\text { Intervention implemented for a minimum of } 12 \text { weeks; 3) Inter- } \\
\text { vention aimed at general population. This resulted in } 12 \text { studies } \\
\text { from the original review being excluded from the update: } 9 \text { be- } \\
\text { cause they were not RCTs (Alexandrov 1988; Berenson 1993; Graf } \\
\text { 2005; Klepp 1994; Lionis 1991; Manios 1999; Marcus 1987; Plot- } \\
\text { nikoff 1999; Sallis 1997); } 2 \text { because the intervention was shorter } \\
\text { than twelve weeks (Eliakim 1996; Fardy 1996); and } 1 \text { because the } \\
\text { study sample included overweight or obese children only (Carrel } \\
\text { 2005a) }\end{array}$ \\
\hline 19 January 2010 & Amended & Additon of author: RL LaRocca \\
\hline 21 May 2008 & Amended & Converted to new review format \\
\hline
\end{tabular}

\section{CONTRIBUTIONS OF AUTHORS}

Maureen Dobbins (MD): as lead author, I oversaw all aspects of the review process. In particular I was responsible for conceiving and designing the review, assisting with the development of the search strategies, screening search results, screening retrieved papers against inclusion criteria, appraising quality of papers, extracting data from papers, analysis of data, interpretation of data, providing a methodological perspective, writing the review.

Heather Husson $(\mathrm{HH})$ : undertaking update searches, organizing retrieval of papers, data management, entering data into RevMan, and editing and coordination of the final draft of the update.

Kara Decorby KD): overall coordination of the original review, and data extraction and review of drafts of this update.

Rebecca Larocca $(\mathrm{RL})$ : coordinating the review, screening search results, organizing retrieval of papers, screening retrieved papers against inclusion criteria, appraising quality of papers, extracting data from papers, updating original review new inclusion/exclusion criteria, wrote update section on risk of bias, contributed findings from the searches to the results section.

\section{DECLARATIONS OF INTEREST}

None known. 


\section{SOURCES OF SUPPORT}

\section{Internal sources}

- No sources of support supplied

\section{External sources}

- Cochrane Health Promotion and Public Health Field, Australia.

- City of Hamilton Public Health Services, Canada.

\section{DIFFERENCES BETWEEN PROTOCOL AND REVIEW}

Significant differences between the protocol and review exist including the addition of risk of bias and overview of study population tables. Changes were made to the inclusion criteria after consulting with the Metabolic and Endocrine Disorders Group because of the large number of studies published since 2008. On 11 March 2010, review authors decided to exclude studies that did not provide the intervention to the general population of elementary students. This decision was made because in a number of developed countries more than half of school attending children are overweight. The purpose of this review is to determine if school-based intervention, directed at otherwise healthy children. On 29 April 2010, review authors decided to limit their scope by including only RCTs and studies where the intervention was implemented for a minimum of 12 weeks. Similar criteria have been implemented in recent Cochrane reviews. This resulted in 12 of the 26 studies included in the original review being excluded in this update. In the original review, studies of very poor methodological quality were excluded from the review. In this update, all studies identified for the update meeting the relevance criteria, were included regardless of the level of bias.

\section{N DEX TERMS}

\section{Medical Subject Headings (MeSH)}

${ }^{\star}$ Health Promotion; ${ }^{\star}$ Schools; Exercise [ ${ }^{\star}$ physiology]; Motor Activity; Physical Fitness [ ${ }^{\star}$ physiology]; Program Evaluation; Randomized Controlled Trials as Topic

\section{MeSH check words}

Adolescent; Child; Humans 